\title{
Physical and Numerical Modeling of Joule-Heated Melters
}
L. L. Eyler
R. J. Skarda
R. S. Crowder III
D. S. Trent
C. R. Reid
D. L. Lessor

October 1985

Prepared for the U.S. Department of Energy under Contract DE-AC06-76RLO 1830

Pacific Northwest Laboratory

Operated for the U.S. Department of Energy by Battelle Memorial Institute 


\title{
DISCLAIMER
}

This report was prepared as an account of work sponsored by an agency of the United States Government. Neither the United States Government nor any agency thereof, nor any of their employees, makes any warranty, express or implied, or assumes any legal liability or responsibility for the accuracy, completeness, or usefulness of any information, apparatus, product, or process disclosed, or represents that its use would not infringe privately owned rights. Reference herein to any specific commercial product, process, or service by trade name, trademark, manufacturer, or otherwise, does not necessarily constitute or imply its endorsement, recommendation, or favoring by the United States Government or any agency thereof. The views and opinions of authors expressed herein do not necessarily state or reflect those of the United States Government or any agency thereof.

\author{
PACIFIC NORTHWEST LABORATORY \\ operated by \\ BATTELLE \\ for the \\ UNITED STATES DEPARTMENT OF ENERGY \\ under Contract DE-AC06-76RLO 1830
}

\begin{tabular}{|c|c|}
\hline \multicolumn{2}{|c|}{ Printed in the United States of America } \\
\hline \multirow{2}{*}{\multicolumn{2}{|c|}{$\begin{array}{l}\text { Available from } \\
\text { National Technical Information Service }\end{array}$}} \\
\hline & \\
\hline \multicolumn{2}{|c|}{ United States Department of Commierce } \\
\hline \multirow{2}{*}{\multicolumn{2}{|c|}{$\begin{array}{l}5285 \text { Port Royal Road } \\
\text { Springfield, Virginia } 22161\end{array}$}} \\
\hline & \\
\hline \multicolumn{2}{|c|}{ NTIS Price Codes } \\
\hline \multicolumn{2}{|c|}{ Microfiche A01 } \\
\hline \multicolumn{2}{|c|}{ Printed Copy } \\
\hline & Price \\
\hline Pages & Codes \\
\hline $001-025$ & $\mathrm{~A} 02$ \\
\hline $026-050$ & $\mathrm{~A} 03$ \\
\hline $051-075$ & A04 \\
\hline $076-100$ & A05 \\
\hline $101-125$ & $\mathrm{~A} 06$ \\
\hline $126-150$ & A07 \\
\hline $151-175$ & $\mathrm{~A} 08$ \\
\hline $176-200$ & A 09 \\
\hline $201-225$ & A.010 \\
\hline $226-250$ & A011 \\
\hline $251-275$ & $A 012$ \\
\hline $276-300$ & A013 \\
\hline
\end{tabular}


PHYSICAL AND NUMERICAL MODELING OF JOULE-HEATED MELTERS

L. L. Eyler

R. J. Skarda

R. S. Crowder III

D. S. Trent

C. R. Reid

D. L. Lessor

October 1985

Prepared for the U.S. Department of Energy under contract DE-ACO6-76RLO 1830

Pacific Northwest Laboratory

Richland, Washington 99352 


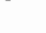

. 
SUMMARY

The Joule-heated ceramic-lined melter is an integral part of the high level waste immobilization process under development by the U.S. Department of Energy. Scaleup and design of this waste glass melting furnace requires an understanding of the relationships between melting cavity design parameters and the furnace performance characteristics such as mixing, heat transfer, and electrical requirements. Developing empirical models of these relationships through actual melter testing with numerous designs would be a very costly and time consuming task.

Additionally, the Pacific Northwest Laboratory (PNL) has been developing numerical models that simulate a Joule-heated melter for analyzing melter performance. This report documents the method used and results of this modeling effort. Numerical modeling results are compared with the more conventional, physical modeling results to validate the approach. Also included are the results of numerically simulating an operating research melter at PNL.

Several programs supported by the U.S. Department of Energy led to the development of numerical models to simulate coupled fluid, heat, and electrically conducting materials. These models were included in a special version of the TEMPEST computer code, which was modified to implement the models necessary for simulating Joule-heated melters. Modeled solutions included current- or power-controlled electrodes in either single or dual pairs.

Physical Joule-heated melters modeling results used for qualifying the simulation capabilities of the melter code included: 1) a melter with a single pair of electrodes and 2) a melter with a dual pair (two pairs) of electrodes. The physical model of the meiter having two electrode pairs utilized a configuration with primary and secondary electrodes. The principal melter parameters (the ratio of power applied to each electrode pair, modeling fluid depth, electrode spacing) were varied in nine tests of the physical model during Fy85. Code predictions were made for five of these tests. Voltage 
drops, temperature field data, and electric field data varied in their agreement with the physical modeling results, but in general were judged acceptable.

Detailed conclusions regarding all the physical modeling and numerical simulation results can be found in the Conclusions and Recommendations section of this report. The recommendations concern future experimental work, the melter version of TEMPEST, physical melter simulation, and simulation of operating melters and melter designs. 


\section{ACKNOWLEDGEMENTS}

This report results from melter modeling studies over several years involving two U.S. Department of Energy sponsored programs; the Nuclear Waste Treatment Program (NWTP) and the Hanford Waste Vitrification Program (HWVP). R.A. Brouns and S. M. Barnes (formerly of PNL) provided programatic guidance and technical coordination of the work. Prinicipal investigators and their major reponsibilities included: Ray Skarda and Carl Reid, physical melter modeling; Del Lessor, theoretical aspects of power-split electric field model; and Don Trent, Scott Crowder, and Loren Eyler, code modification, numerical approximation, and simulation analysis. 


\section{CONTENTS}

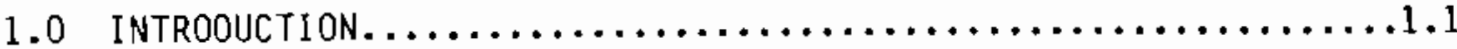

2.0 CONCLUSIONS AND RECOMMENOATIONS $\ldots \ldots \ldots \ldots \ldots \ldots \ldots \ldots \ldots \ldots .1$

2.1 CONCLUSIONS $. \ldots \ldots \ldots \ldots \ldots \ldots \ldots \ldots \ldots \ldots \ldots \ldots \ldots, 1$

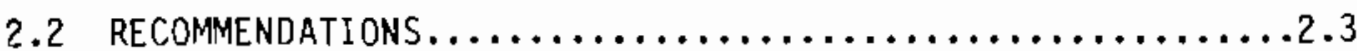

3.0 BIPP PHYSICAL MELTER MOOEL AND EXPERIMENTAL RESULTS $\ldots \ldots \ldots \ldots . .1$

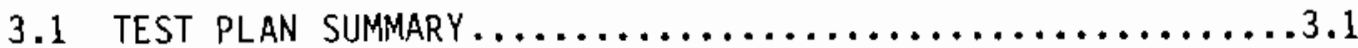

3.2 PHYSICAL MELTER MODEL DESCRIPTION AND EXPERIMENTAL

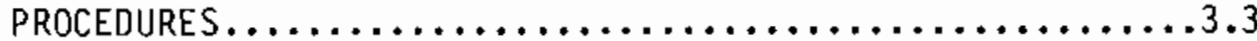

3.2.2 Data Acquisition and Instrumentation..............5

3.2.2 Experimental Measurement Procedure.............. 3.7

3.2.3 Flow Field Data and Digitization Procedures......3.12

3.3 EXPERIMENTAL RESULTS AND DISCUSSION..................1?

3.1.1 Temperature Results.......................14

3.3.1 Temperature Results (Near Electrode Region)......3.23

3.3.2 Electrical Potential Results..................25

3.4 ELECTRODE POWER SUPPLY SIGNAL ANALYSIS..............3.34

3.5 COMMON GROUNDED ELECTRODE EXPERIMENTAL RESULTS..........3.42

4.0 THEORETICAL BASIS FOR NUMERICAL MODELING OF JOULE-HEATED

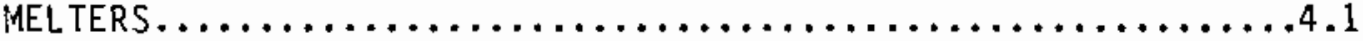

4.1 GOVERnING EQUATIONS..............................

4.2 SOLUTION APPROACH..................................

4.3 CONSIDERATIONS AND BASIS FOR DUAL-ELECTRIC-FIELD CASES ..4.10

4.3.1 Theoretical Basis...........................10

4.3.2 TEMPEST Solution Procedure $. . \ldots \ldots \ldots \ldots \ldots \ldots \ldots . .20$ 
5.0 ELECTRIC FIELD SOLUTION AND NUMERICAL MELTER MODELING........5.1

5.1 ElECTRIC Field SOLUTION VERIFICATION..................

5.2 PHYSICAL MELTER MODEL SIMLUATION-SINGLE ELECTRODE

pair............................................5.5

5.3 PHYSICAL MELTER MODEL SIMULATION - DUAL ELECTRODE

PAIR........................................... 5.8

5.3.1 Numerical Model Description...................10

5.3 .2 Analysis Approach........................ 5.12

5.3.3 Numerical Melter Model Results

(Two-Dimensional) .........................5.34

5.3.4 Numerical Melter Model Results

(Three-Dimensional) .......................5.30

6.0 Simulations OF THE PILOT SCALE CERAMIC MELTER $\ldots \ldots \ldots \ldots \ldots \ldots .1$

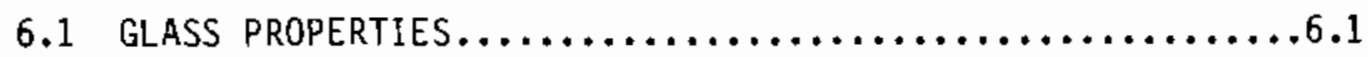

6.2 Pilot Scale ceramic Melter $\ldots \ldots \ldots \ldots \ldots \ldots \ldots \ldots \ldots \ldots .5$

6.2 .1 Idling Mode Operation.......................6.5

6.2 .2 Feeding Mode Operation...................... 6.9

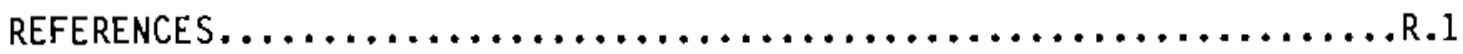

APPENDIX A - Tabulation of Measured Temperature Data................

APPENDIX B - Tabulation of Measured Electric Field Data............. 1

APPENDIX C - Modeling Fluid MF-D Properties..................... 


\section{FIGIIRES}

3.1 B-Plant Immobilization Pilot Plant Morel Configuration.......3.4

3.2 Argon Laser Configuration for Flow Field Visualization...... 3,6

3.3 Instrumentation and Data Acquisition for BIPP Mode1..........

3.4 Temperature Profile Locations: Tests BRUN-1 to BRINN-3,

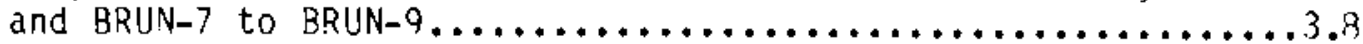

3.5 Temperature Profile Locations: Tests BRUN-4 to BRUN-6....... 3,9

3.6 Potential Profile Locations: Tests BRUN-1 to BRUN-3, and BRUN-7 to BRUN-9..............,

3.7 Potential Profile Locations: Tests BRUN-4 to BRUN-6.........11

3.8 Horizontal Temperature Profile for Test Run RRUN-1...........16

3.9 Horizontal Temperature Profile for Test Run BRIIN-?...........16

3.10 Horizontal Temperature Profile for Test Run BRIJN-3...... 3,17

3.11 Horizontal Temperature Profile Test for Run RRINN-4,.........17

3.12 Horizontal Temperature Profile Test for Run RRUJN-5,..........18

3.13 Horizontal Temperature Profile Test for Run BRUN-6..........18

3.14 Horizontal Temperature Profile Test for Run BRUN-9...... 3,19

3.15 Vertical Temperature Profile at Model Center...............20

3.16 Vertical Temperature Profile Near Left Electrode....... 3.2.4

3.17 Vertical Temperature Profile Near Right Electrode..........3.?4

3.18 Fluid Temperature Time Series for BRUN-1....... 3,25

3.19 Fluid Temperature Time Series for BRUN-2.................26

3.20 Fluid Temperature Time Series for BRUN-3....... 3,27

3.21 Fluid Temperature Time Series for BRIJN-5................27

3.22 Fluid Temperature Time Series 1 for BRI3N-9.............?.

3.23 Fluid Temperature Time Series 2 for RRIJN-9..............28 
3.24 Horizontal Potential Profile Test for Run BRUN-3..........3.29

3.25 Vertical Potential Profile Test for Run BRUN-1............29

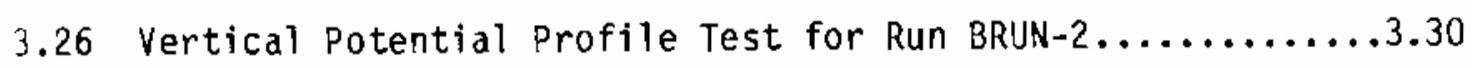

3.27 Vertical Potential Profile Test for Run BRUN-3...........3.30

3.28 Vertical Potential Profile Test for Run BRUN-4 ............3.31

3.29 Vertical Potential Profile Test for Run BRUN $-5 \ldots \ldots \ldots \ldots \ldots 3.31$

3.30 Vertical Potential Profile Test for Run BRUN $-6 \ldots \ldots \ldots \ldots \ldots 3.32$

3.31 Vertical Potential Profile Test for Run BRUN-9...........3.32

3.32 Schematic of SCR Power Supply voltage Configuration........3.34

3.33 SCR Power Supply Voltage Signal (Phase-Angle Fired)........3.36

3.34 Applied and Induced Voltage Signals From Dual

Electrode System...................................37

3.34 Wave Form $U / L$ EPR $=1.0: 0.0$ ETEST $\ldots \ldots \ldots \ldots \ldots \ldots \ldots \ldots .38$

3.35 Wave Form $U / L$ EPR $=0.5: 0.5$ ETEST2 $\ldots \ldots \ldots \ldots \ldots \ldots \ldots .3 . \ldots \ldots$

3.36 Wave Form $U / L$ EPR $=0.5: 0.5$ ETEST3 $\ldots \ldots \ldots \ldots \ldots \ldots \ldots \ldots .38$

3.37 Wave Form $U / L$ EPR $=0.75: 0.25$ ETEST4 $\ldots \ldots \ldots \ldots \ldots \ldots \ldots .38$

3.38 Vertical Temperature Profile Test for Run BRUN-7A ...........43

3.39 Vertical Temperature Profile Test for Run BRUN-7B..........43

3.40 Vertical Temperature Profile Test for Run BRUN-8...........44

3.41 Flow Field Stroboscopic Photograph for BRUN-7A

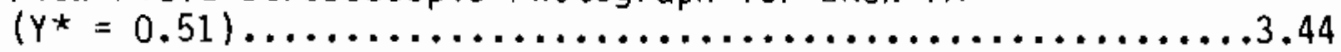

3.42 Flow Field Stroboscopic Photograph for BRUN-7A

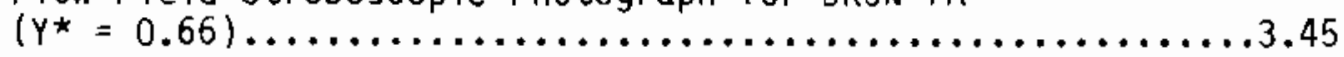

3.43 Flow Field Stroboscopic Photograph for BRUN-8

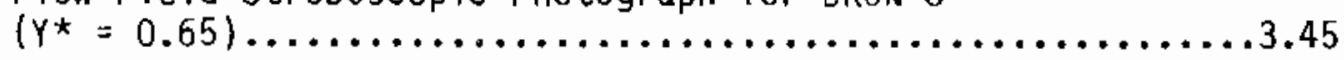

3.45 Power Supply Schematic Showing a) Scoped Connected and

b) Common Grounded Equivalent Circuit.....................4.47

3.46 ETectric Potential Distribution for Test BRUN-7B..........48 
3.47 Electric Potential Distribution for Test BRUN-8...........48

3.48 Fluid Temperature Time Series for Test BRUN-7B.............49

3.49 Fluid Temperature Time Series for Test BRUN-7B.............49

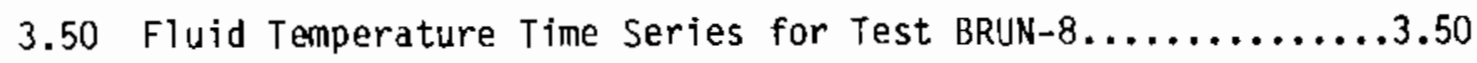

4.1 Two of the Four On-0ff Conditions for Voltage Sources $E_{A}(t)$ and $E_{B}(t) \ldots \ldots \ldots \ldots \ldots \ldots \ldots \ldots \ldots \ldots \ldots \ldots \ldots \ldots \ldots \ldots \ldots \ldots \ldots \ldots \ldots \ldots \ldots \ldots \ldots, 12$

4.2 Oual Electrode Pair Time-Dependent Voltage Shape..............17

5.1 Schematic Representation of One-Armed Body in an Electric Field................................................ 5

5.2 Calculated Equipotential Surfaces at 1000-Volt Increments for the One-armed Body Model............................

5.3 Calculated Conduction Current Inside the Structure and Displacement Current Outside One-armed Model................5.4

5.4 Schematic of Quigley and Kreid (1979) Physical Melter Model...5.6

5.5 Single-Electrode Physical Melter Flow Field and Temperature Contours............................................

5.6 Numerical Model Vertical Cross Section.....................11

5.7 Transient Temperatures - Test Run BRUN-? ...............

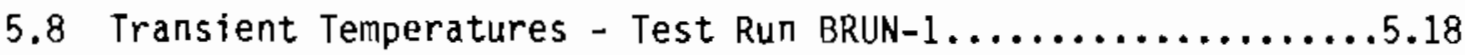

5.9 Transient Temperatures - Test Run BRUN-3..................18

5.10 Transient Temperatures - Test Run BRUN-4..................19

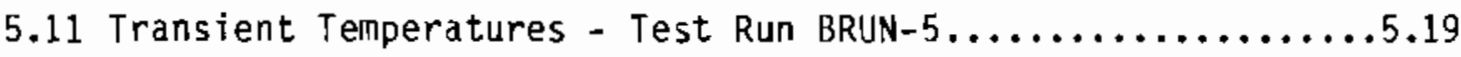

5.12 Temperature Distributions in Modeling Fluid, Test Run

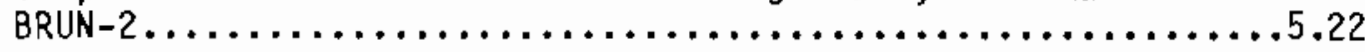

5.13 Temperature Distributions in Modeling Fluid, Test Run

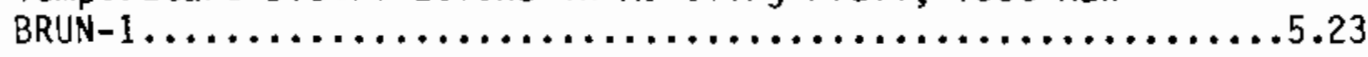

5.14 Temperature Distributions in Modeling Fluid, Test Run

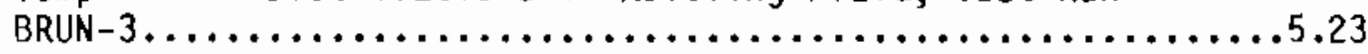

5.15 Temperature Distributions in Modeling Fluid, Test Run

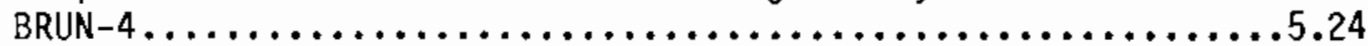


5.16 Temperature Distributions in Modeling Fluid, Test Run

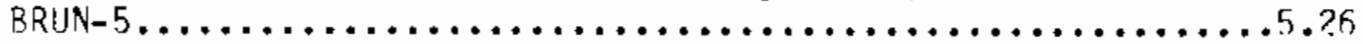

5.17 Normalized Flectric Potential, Test Run RRIN-1...... ..5.?5

5.18 Normalized Electric Potential, Test Run BRUN-? ...........5.?7

5.19 Normalized Flectric Potential, Test, Run BRIIN-4 ...... 5.27

5.20 Normalized Electric Potential, Test Run BRUN-5..............

5.21 Transient Temperatures at $y^{*}=0.4$ ? , Test Run RRUN-3....... 5.28

5.22 Temperature Distribution in Modeling Fluid at $\gamma^{\star}=0.44$

Test Run BRUN-3...... ..... .....

6.1 Simplified Thermal Boundary Representation ..............

6.2 PSCM Two-Dimensional Model Cross-Section Schematic....... 6,6

6.3 Three-Dimensional PSCM Idling Model Schematic..............

6.4 PSCM Idling Model Power Density....................... 10

6.5 PSCM Feeding Time-Dependent Temperatures $\ldots \ldots \ldots .6 .13$ 


\section{$\underline{\text { TABLES }}$}

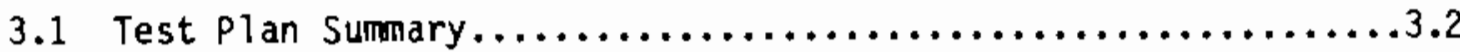

3.2 BIPP Model Nominal Boundary Temperatures..................14

3.3 Summary of BRUN Test Series Operating Conditions.............15

3.4 Y-Plane-Averaged Bulk Fluid Temperature Characterization.....3.22

3.5 Summary of Upper and Lower Electrode Pair Voltage Signal

Measurements....................................... 40

4.1 Computational Time Comparison for Code Operational Modes.....4.23

5.1 TEMPEST Representation of Quigley and Kreid Run \#15,.........

5.2 Grid Refinement Study Results........................

5.3 Sequential Simulation Summary and Interrelationship of Numerical Model Runs.................................5.13

5.4 Two-Dimensional Numerical Model Voltage Drop Results After $1-\mathrm{Hr}$ at Simulated Operating Conditions....................15

5.5 Time-Dependent Voltage Drop Across Lower Electrode for Test Run BRUN $-2 . \ldots \ldots \ldots \ldots \ldots \ldots \ldots \ldots \ldots \ldots \ldots \ldots \ldots \ldots \ldots .17$

5.6 Time-Dependent Voltage Drop Results................... 5.20

5.7 Three-Dimensional Numerical Model Voltage Drop Results Test Run BRUN-3...................................5.31

5.8 Three-Dimensional Numerical Model Time-Dependent Vol tage Drop Results (Test Run BRUN-3) ..........................32

6.1 Glass Property Sensitivity Results.....................

6.2 Idling PSCM Voltage Orop..................................

6.3 Preliminary PSCM Feeding Mode Results Comparison...........6.12 
PHYSICAL AND NUMERICAL MODELING OF JOULE-HEATED MELTERS

\subsection{INTRODUCTION}

Commercial and military appications of nuclear technology in the U.S. and the rest of the world have produced large amounts of high-level nuclear waste $(H L W)$. This waste is currently being stored in temporary storage systems to isolate it from the environment. However, a more permanent and environmentally acceptable method of final storage of $H L W$ is required.

The vitrification process is the process chosen within the U.S. and much of the world to best satisfy the above criteria. In the U.S. vitrification process, HLW is blended with glass-forming constituents and fed to a Joule (electrically) heated melter as a slurry. The solids react to form a durable borosilicate glass product. The molten glass is then transferred into metal canisters, allowed to solidify, and ultimately stored in stable geological formations. The final product of this process is a stable, solid form which has excellent resistance to leaching, dissipates waste heat effectively, and resists radioactive damage.

The Pacific Northwest Laboratory (PNL) has conducted research in $\mathrm{HL} W$ vitrification for the U.S. Department of Energy (and its predecessors) since the mid 1960s. Because of the expense and time required to test different prototype designs, physical and numerical modeling techniques are used to study various options to help optimize the melter configuration and estimated generalized design correlations. A computer model (TEMPEST) capable of accurately predicting performance of waste vitrification melters was developed. Qualification and validation of the computer model for Joule-heated melters is important to provide future vitrification plant designers with the necessary melter analysis tools. For that reason, physical melter model experiments have been conducted to provide a data base for evaluation of numerical solution procedures and prediction results. To put the present work in perspective, the following is a brief historical overview of physical melter modeling at PNL. 
Physical melter modeling has been employed at PNL as a method to investigate design alternatives and operational processes of various Jouleheated, ceramic glass melter concepts since 1978. The goal of this earlier modeling program was to develop suitable fluids, modeling facilities, and measurement techniques to study the fundamental physical phenomena in the giass melting process. In addition, results from those experiments were to serve as a data base for numerical code comparison and evaluation.

Two PNL test melters, the Calcine Fed Ceramic Melter (CFCM) and the Liquid Fed Ceramic Melter (LFCM), were physically modeled. Operating configurations of the LFCM included various feed coverage (cold cap) orientations and upperto-lower electrode power ratios (11/L F.PR). In addition, LFCM operating performance was compared with the performance of the CFCM single-pair, plateelectrode configuration. Measurement techniques and modeling criteria established during this study were heavily relied upon in subsequent PNL physical modeling efforts. Results of this effort are summarized by Quigley and Kreid (1979).

A 1983 glass melter physical modeling task was initiated to provide direct support to the Hanford Waste Vitrification Plant (HWVP) (Gurley and Minor 1985). The two systems that were modeled in this investigation were the B-Plant Immobilization Pilot Plant (BIPP) Melter and the Pilot Scale Ceramic Melter (PSCM). The PSCM is an operating, pilot-scale research melter having a melt surface area of $0.73 \mathrm{~m}^{\text {? }}$. Its operation supports various Department of Energy (DOE) Waste Management programs. The BIPP melter was part of a proposed conceptual design used for early design studies associated with the HWVP.

Objectives of the BIPP modeling were to measure the effects of electrode positioning and electrode power skewing. PSCM modeling objectives were to measure the effects of using nitrogen bubblers as flow stabiiizers and measure the effect of cold cap (top surface) size and location. During this investigation, modeling fluids were developed using established similarity criteria. Results obtained from both PSCM and BIPP model testing were also to serve in the verification of numerical models. Several successful tests were performed using the PSCM model; however, only preliminary testing of the BIPP 
model was performed. Results of this effort are summarized by Skarda, Hauser, and Fort (1985).

The current physical modeling effort is a continuation of the 1983 work. The emphasis of this study is to provide a data base for numerical computer code verification using the BIPP model. A modeling fluid, designated as MF-0, was used for BIPP model testing. While MF-0 was originally scaled for use in the PSCM model based on a prototypic glass (Skarda, Hauser, and Fort 1985), MF-0 was used in this investigation because of its availability and emphasis of the present work on numerical code evaluation. In addition, initial scaling of MF-0 to Savannah River Laboratory (SRL) waste glasses SRL 131 and SRL 165 indicated that use of MF-O in the BIPP model will adequately model the hydrodynamic and thermal phenomena of current waste glasses.

Various BIPP electrode operating configurations were investigated in this study. Specifically, tests were performed at two different electrode spacings and three U/L EPRs. Experimental test results are contained in Section 3.0 of this report. These tests model a melter design in which a dual pair of electrodes is present. Each electrode pair may be operated at a controlled power level. Test results are obtained for several power splits between electrode pairs in two modeled melter aspect ratios (model fluid depth-to-width ratios of 0.47 and 0.38 ).

In Section 4.0, the theoretical and numerical basis for the melter version of the TEMPEST computer code is described, including the theoretical basis and modifications for the solution of electric fields in melter designs using single and dual electrode pairs. The code uses finite-difference approximations of time-dependent equations governing conservation of mass, momentum, energy, and electric potentials in three-dimensional geometries. Code predictions are compared to test data in Section 5.0 of this report. For qualification, comparisons are made to data in several configurations. Included are: a model of a one-armed, electrically conducting body; physical melter mode? results utilizing a single electrode pair (Quigley and Kreid 1979); and data acquired in this work utilizing a physical melter model with two individually controlled electrode pairs. 
Additionally, simulation results computed in FY84 before the present numerical model qualification work with dual pairs of electrodes are included in Section 6.0. These include simulation results computed for a numerical model of the Pilot Scale Ceramic Melter (PSCM). Certain limited data are available from the operating PSCM for comparison to predictions. 


\subsection{CONCLUSIONS AND RECOMMENDATIONS}

The objective of this work is to document recent meiter modeling results at PNL. Included here are experimental results of physical melter modeling, the theoretical basis for modeling Joule-heated (electric field) melters with single and dual electrode-pair and simulation results of numerical models of physical melter model experiments and the operating pilot Scale Ceramic Melter. Data presented lead to the following conclusions and recommendations.

\subsection{CONCLUSIONS}

Physical melter modeling using a dual-electrode-pair configuration provides a means of testing electrode spacing and ratio of power to each pair. It also provides a data base for testing numerical models. Experimental results obtained in the present work led to the following observations and conclusions:

- The dual-electrode-pair system provides additional control of mixing in the molten glass not available in a single-electrode-pair system.

- An upper-to-lower electrode power ratio (U/L EPR) of 1.0:0.0 is a poor operating configuration because temperature stratification occurs between upper and lower fluid regions, which inhibits mixing.

- Results of using an U/L EPR of 0.0:1.0 indicated very high local temperatures directiy in front of the powered electrode pair. This may indicate excessive crossfiring between pairs, which could shorten electrode life.

- Onty moderate crossfiring and themal stratification occurred for cases in which the U/L EPR was 0.5:0.5.

- The largest temperature variations with time occur in central regions of the fluid. This results because of the enhanced cooling of the modeled (top surface) cold cap. 
- (Inadvertent) common grounding of one side of both electrode pairs resulted in grossly asymmetric temperature and electric field measurements in two tests.

- Flow visuatization results are inconclusive. Conclusions drawn from numerical simulation results presented are broken into categories. For theory and numerical basis, conclusions are:

- Operational modes and solution procedures used in the melter version of TFMPEST are working correctiy for the test applications evaluated.

- In a test of the electric field solution, the predicted current in a onearm body model is 3.32 $\mu \mathrm{A}$. Measured data was $3.33 \pm 0.1 \mu \mathrm{A}$. Surface enhancement is predicted to be 2.56 compared to a measured value of $2.6 \pm$ 0.1 .

From simulation of physical melter model experiments with a single electrode pair, conclusions include:

- Voltage drop agreements varying from 3 to $20 \%$ underprediction are found with bulk temperatures agreeing within $\pm 1^{\circ} \mathrm{C}$.

- Accurate results are obtainabie when two-dimensional simulation of physical melter model experiments is used with sufficient noding resolution. Three-dimensional models of three-dimensional tests, however, are found to be generally more consistent.

- Flow-field predictions qualitatively follow observations, as indicated by viewing a computer-generated video movie.

From simulation of physical melter model (e.g., RIPP) experiments with a dual electrode pair, conclusions include:

- Predicted voltage drop results for tests with an 11/L EPR of $0.0: 1.0$, 1.0:0.0, and 0.5:0.5 vary in agreement from an underprediction of $30 \%$ to "exact" agreement for two-dimensional models.

- Particular attention to thermal boundary condition is required because of strong dependence of electrical conductivity on temperature. 
- Temperature field data in the modeling fluid is typically at $\pm 10^{\circ} \mathrm{C}$ variance with data for two-dimensional models.

- Agreement of overall voltage drop and temperature field data is significantly improved in a three-dimensional model of a 0.5:0.5 powersplit test. This results because of more correct accounting of heat transfer through front and back walls.

- Electric field data and predictions are in good qualitative agreement when normalized to corresponding overall voltage drops. Local deviations are directly attributable to differences in local temperature because of temperature-dependent electric conductivity.

- Comparison of local electric field data in power-split ratios other than 0.0:1.0 or 1.0:0.0 cannot currently he made with TEMPF.ST.

From simulation of the idling and feeding operation modes of the pilot Scale Ceramic Melter, conclusions include:

- Attaining thermal equilibrium or quasi-steady conditions is a prerequisite for correct predictions. This requires that special attention be given to thermal boundary conditions.

- Accurate thermal properties of melter glass are required to improve confidence in predictions.

- Additional investigation of prescribed thermal boundary conditions, timestep dependence, and noding resolution are required to improve confidence in predicting meiter operation.

\subsection{RECOMMENDATIONS}

Several recommendations can be made hased on present experimental work. These include:

- Flow visualization should be an integral part of the physical melter model experiments. Visual observations can not only be used for obtaining velocity data, but can also aid in interpretation of other data obtained during experiments. Additional work is required to determine the best tracer particles in modeling fluids. 
- Accurate overall heat balance data should be obtained. This could be done by sufficiently instrumenting cooling channels and would assist in the evaluation and specification of thermal houndary conditions for numerical models.

- Prolonged operation at an $1 \mathrm{~J} / \mathrm{L}$ FPR of $1, n: \cap . \cap$ should be avoided, as extensive stratification can result from this powered configuration and inhibit mixing.

- Power controller configuration should be set up to eliminate the possibility of crossfiring between electrode pairs.

Concerning the melter version of TEMPEST, recommendations include:

- Operational modes and use of the melter version of the TEMPEST computer code should be documented in the form of a users' manual.

- Dual-electrode-pair (combined) electric field output should be made avaflable to the user. This requires a modification to the code.

- Difficulties are encountered in electric field solution convergence at start up. An automated (numerically considered) methodology should be developed to adjust power levels, etc., in response to ill-defined initial conditions.

- Bulk fluid temperature determination should be included as part of the computation.

- The electric field solution procedure and operational modes should he upgraded to be compatible with nost current TEMPEST developments in other programs.

- A standard set of inputs for electric field and melter test problems should be developed and a quality assurance program commenced for maintaining and qualifying future code evaluation and madel development.

Concerning physical melter simulation, recommendations include:

- Further investigation and development of a methodology for qualifying the attainment of equilibrium or quasi-steady conditions should be addressed. 
- Two-dimensional modeling advantages and limitations need to be better defined, as this approach represents a means of significantly improved computational efficiency for parameter testing of melter design and analysis.

- Flow visualization experimental data should be obtained in the dualelectrode-pair physical melter model to allow qualification of predictions of basic fluid flow characteristics (flow direction, magnitude, etc.).

For simulation of operating melters and melter designs, recommendations include:

- The pilot Scale Ceramic Melter model and simulation results need to be reevaluated in more detail; in particular, specification of themal boundary conditions and detemination of fluid properties need to be better addressed.

- Thermal radiation modeling in TEMPEST needs to be improved to provide better physical definition of heat transfer within the glass melt and at the cold cap surface. 
. 


\subsection{BIPP PHYSICAL MELTER MODEL AND EXPERIMENTAL RESULTS}

Experimentaliy measured temperatures and electric potential are reported for nine tests run in the BIPP physical melter model. The objective in obtaining this data is to provide a data base to which numerical simulation predictions can be compared, thus providing a means of qualifying the prediction tool. In this section, the experimental apparatus, measurement procedures, data acquisition, and measured results are presented. Present experimental results are compared to numerical predictions in Section 5.0 of this report.

\subsection{TEST PLAN SUMMARY}

The test plan for this work included running experiments in the BIPP physical melter model to satisfy specific test objectives. These included studying the effects of electrode spacing and electrode power skew in a dualelectrode-pair melter configuration with each electrode pair being independently powered. Modeling fluid and melter model parameters were determined by physical scaling laws to simulate proposed operating conditions in the BIPP melter. Specific details of determination of the scaled parameters are presented by Skarda, Hauser, and Fort (1985).

Six tests were originally planned using two electrode spacings and three power skews as listed in Table 3.1. Planned data to be acquired included:

- fluid temperatures

- electric potentiar

- flow velocity

- wall heat flux,

thus providing a rather complete set of data for evaluating numerical predictions. Temperatures were to be measured at selected locations in the modeling fluid, as well as in the cooling jackets, to provide thermal boundary conditions. Electric potentials were also to be measured at selected points in the modeling fluid and across each electrode pair. Flow velocities were to be obtained from digitized flow visualization data. Wall heat fluxes were to be 


\section{IABLE 3.1. Test Plan Summary}

\begin{tabular}{|c|c|c|c|c|}
\hline Run №. & $\begin{array}{l}\text { Electrode } \\
\text { Power Skew }\end{array}$ & $\begin{array}{l}\text { Model Electrode* } \\
\text { Spacing } \\
\end{array}$ & $\begin{array}{l}\text { Model ing } \\
\text { Fluid Level }\end{array}$ & $\begin{array}{l}\text { Electrode } \\
\text { Potential Reference }\end{array}$ \\
\hline BRUN-1 & $\begin{array}{l}100 \% \text { Top } \\
0 \% \text { Bottom }\end{array}$ & $6.35 \mathrm{~cm}$ & $17.94 \mathrm{~cm}$ & Floating ground \\
\hline BRUN-2 & $\begin{array}{l}0 \% \text { Top } \\
100 \% \text { Rottom }\end{array}$ & $6.35 \mathrm{~cm}$ & $17.94 \mathrm{~cm}$ & Floating ground \\
\hline BRIJN-3 & $\begin{array}{l}50 \% \text { Top } \\
50 \% \text { Rottom }\end{array}$ & $6.35 \mathrm{~cm}$ & $17.94 \mathrm{~cm}$ & Floating ground \\
\hline$B R I M N-4$ & $\begin{array}{l}100 \% \text { Top } \\
0 \% \text { Rottom }\end{array}$ & $2.54 \mathrm{~cm}$ & $14.61 \mathrm{~cm}$ & Floating ground \\
\hline BRUN -5 & $\begin{array}{l}0 \% \text { Top } \\
100 \% \text { Bottom }\end{array}$ & $2.54 \mathrm{~cm}$ & $14.61 \mathrm{~cm}$ & Floating ground \\
\hline BRUN -6 & $\begin{array}{l}50 \% \text { Top } \\
50 \% \text { Botton }\end{array}$ & $2.54 \mathrm{~cm}$ & $14.61 \mathrm{~cm}$ & Floating ground \\
\hline$\star \star B R \cup N-7$ & $\begin{array}{l}50 \% \text { Top } \\
50 \% \text { Bottom }\end{array}$ & $6.35 \mathrm{~cm}$ & $17.94 \mathrm{~cm}$ & Absolute ground \\
\hline$\star \star B R U N-8$ & $\begin{array}{l}75 \% \text { Top } \\
25 \% \text { Bottom }\end{array}$ & $6.35 \mathrm{~cm}$ & $17.94 \mathrm{~cm}$ & Absolute ground \\
\hline$\star \star B R U N-9$ & $\begin{array}{l}50 \% \text { Top } \\
50 \% \text { Bottom }\end{array}$ & $6.35 \mathrm{crm}$ & $17.94 \mathrm{~cm}$ & Floating ground \\
\hline
\end{tabular}

$\star B I P P$ spacing is $4 x$ model spacing.

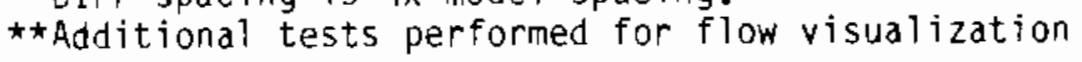

determined from cooling jacket temperature rise and selectively placed thermocouples incated in walls.

Planned tests are identified herein as test runs BRINN-1 through RRUN$5^{(a)}$. nuring these tests, only temperature and electric potential data were

(a) Test run identification is as follows. RRUN identifies a test run for the RIPP melter. Appended numbers refer to run number, e.g. ${ }^{-3}$. In data tabulation in appendices, individual data sets are further indicated by $-T$ for temperature and -E for electric potential. 
acquired. Subsequently, test run BRUN-7 was performed at the same conditions as BRUN-3 with the objective of acquiring requisite flow visualization data. BRUN-8 was also performed with a similar objective but at a different power skew than used in previous tests. As discussed subsequently, difficulties were encountered which precluded the use of this latter data for numerical simulation evaluation of predicted flow characteristics.

The following sections give a brief description of the experimental apparatus used and the method of operation. Additional discussion concerning apparatus and procedure, as well as modeling fluid characterization, can be found in Quigley and Kreid (1979) and Skarda, Hauser, and Fort (1985). A summary of the data acquisition procedure and the locations at which data were taken is also included.

\subsection{PHYSICAL MELTER MODEL DESCRIPTION AND EXPERIMENTAL PROCEDURES}

The melter model is depicted in Figure 3.1. The model consists primarily of an inner vessel into which the modeling fluid was placed and an outer vessel through which coolant (water) was pumped to maintain required boundary temperatures. Electrodes were placed in the modeling fluid at either end of the inner vessel. A water-cooled top simulated the molten crust of the cold cap which forms at the molten glass surface in the melter. The centrally located area which was cooled represents $66 \%$ of the top fluid surface area. cooling water temperatures and flow rates of the cooling jackets (front, back, electrode, and top) were independently controlled.

The physical dimensions of the internal melter model cavity were $38.10 \mathrm{~cm}$ between electrodes and $27.94 \mathrm{~cm}$ from front to back. Fluid depth was varied, depending upon the spacing used between electrodes (see Table 3.1). The origin for the reference coordinate axis was taken to be the back, lower left junction between the electrode face and the melter bottom as shown in Figure 3.1. The melter bottom sloped $5^{\circ}$ downward from each electrode into a 2.54- $\mathrm{cm}$ trough located at the center. A glycerine-1ithium chloride mixture denoted as MF- 0 was used as the modeling fluid during this investigation. MF-0 modeling fluid properties are provided in Appendix C. 


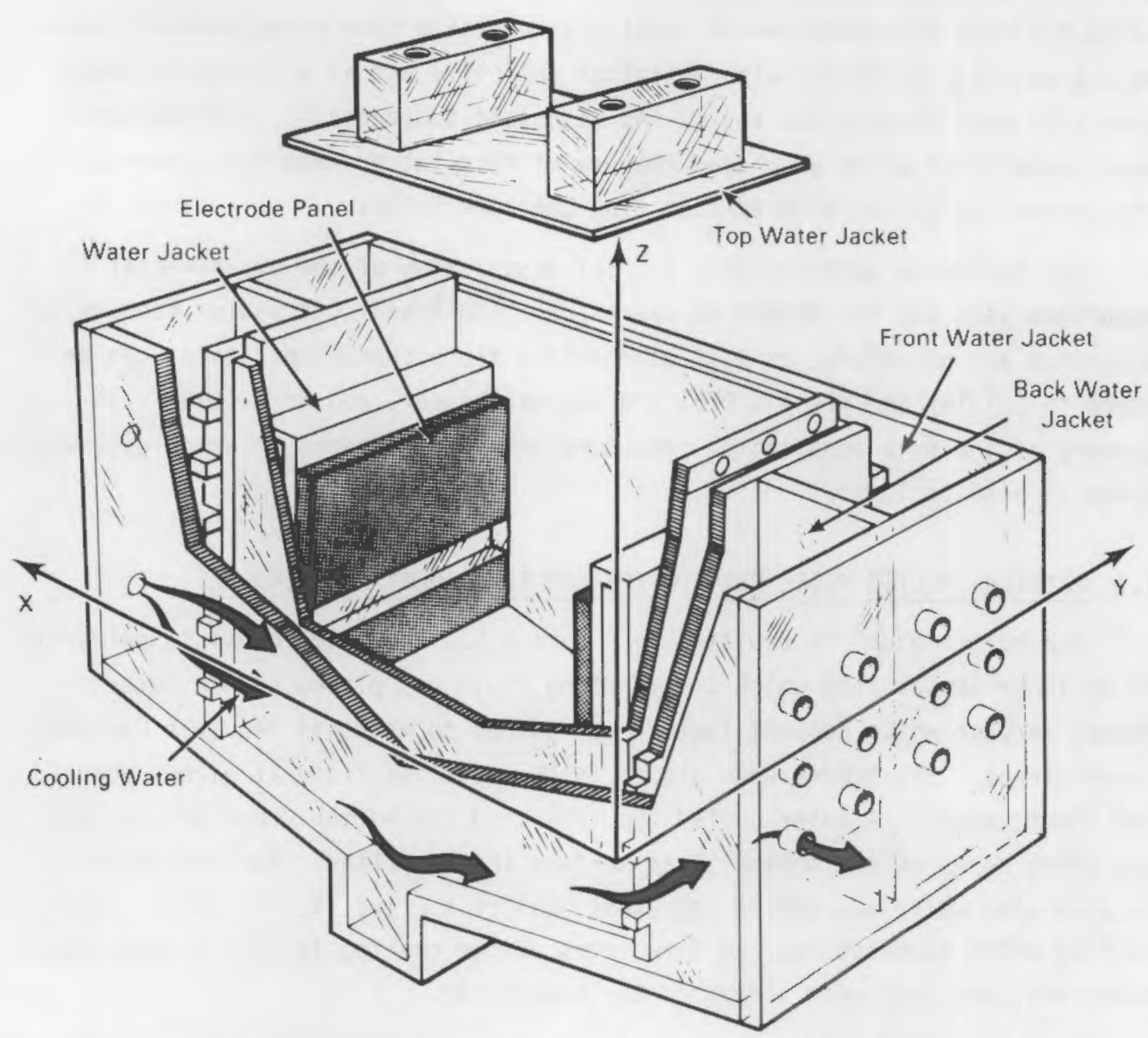

FIGURE 3.1. B-Plant Immobilization Pilot Plant Model Configuration

Power was supplied to each electrode pair using two independently controlled Silicon Controlled Rectifiers (SCRS). These power controllers were phase angle fired.

Thermocouple and electric potential probes were inserted through isolated holes (drywells) in the top cooling jacket to measure local values throughout 
the modeling fluid region. Neutrally bouyant glassy carbon particles were used as flow tracers during stroboscopic photography. An Argon ion laser provided the light source for flow photography. The light from the laser was spread into a sheet so that the two-dimensional flow at a given $y$-plane could be analyzed from the photographic record as discussed in Quigley and Kreid (1979) and Skarda et al. (1985). Figure 3.2 shows the laser 111 umination configuration.

\subsubsection{Data Acquisition and Instrumentation}

The data acquisition system recorded 50 readings per scan during the testing; a scan was commenced at 30-second intervals. Thermocouple measurements performed during a single scan were: three readings at the front wall, seven readings at the back wall, nine readings on the model bottom, six modeling fluid readings, three readings per electrode, and one ambient reading. Eight resistance temperature devices (RTDs) were used to take temperature readings at the inlet and outlet of each cooling jacket. Cooling jacket flow readings from four flow turbine meters were taken during each scan. Current, voltage, and power from the electrode power supply were monitored and recorded. Operating conditions were typically monitored and recorded every 5 minutes during testing.

The experimental setup is depicted in Figure 3.3. Several components of the setup are evident. The thermocouple extension wires are above and to the left of the model. The thermocouple extension wires connect to a data logger which is located to the left of the model. The electrode power supply is shown between the desk and tables and against the wall. Power supply signals, as well as temperature and flow signals, were directed to the Integrated System for Automated Acquisition and Control (ISAAC) module. This system converted the 0 - to 5 -volt analog signals to digital signals. The digitized signals were then assigned 12-bit binary values which were read by the data acquisition computer (Apple 1I). Further processing of the signal was then user directed. The ISAAC $31 \mathrm{~A}$ is shown on the desk and to the right of the Apple personal computer. The electrode power supply is located to the right of ISAAC module. Run conditions were displayed on a terminal, stored on disk, and simultaneously printed during model operation. 


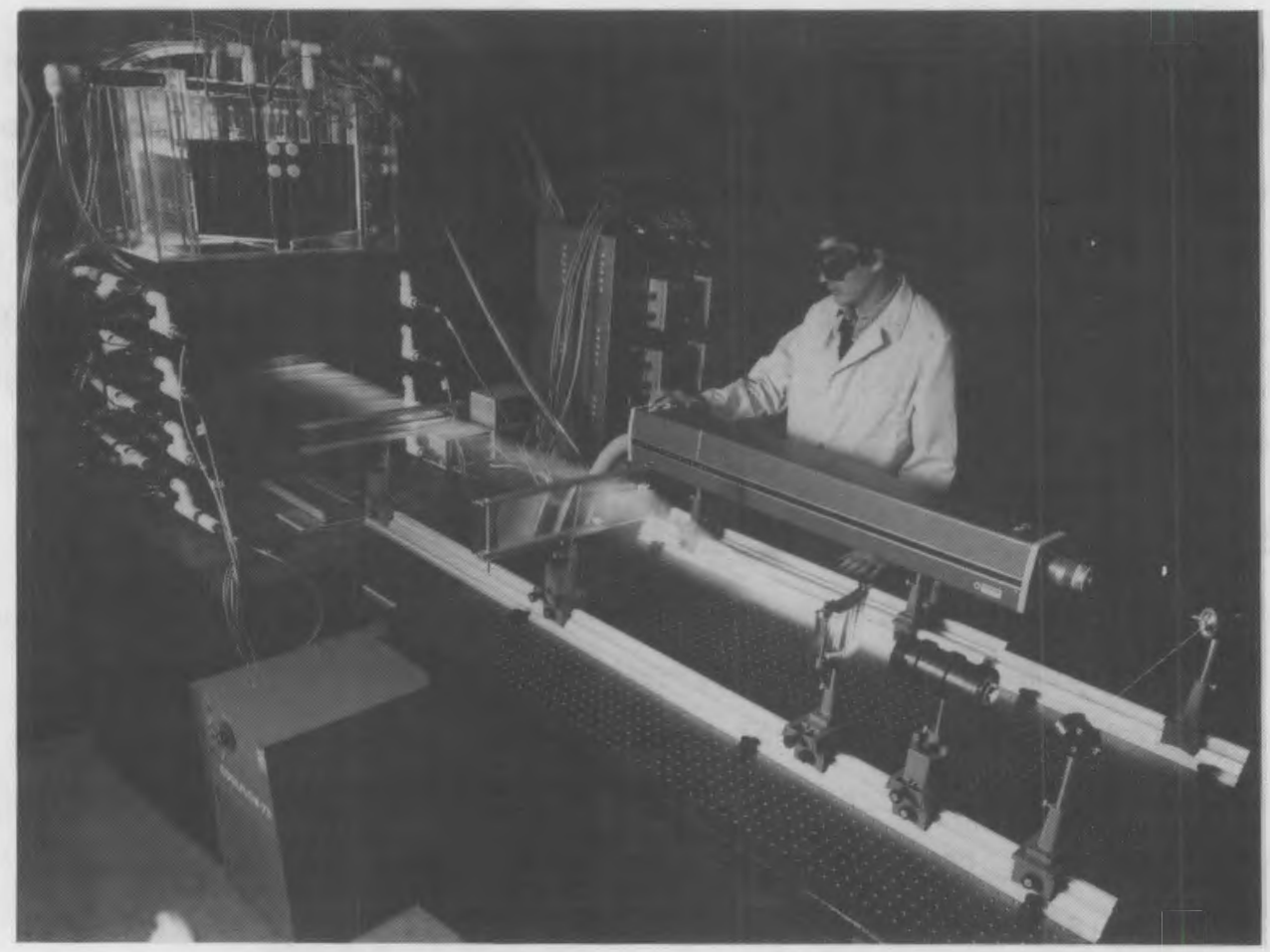

FIGURE 3.2. Argon Laser Configuration for Flow Field Visualization

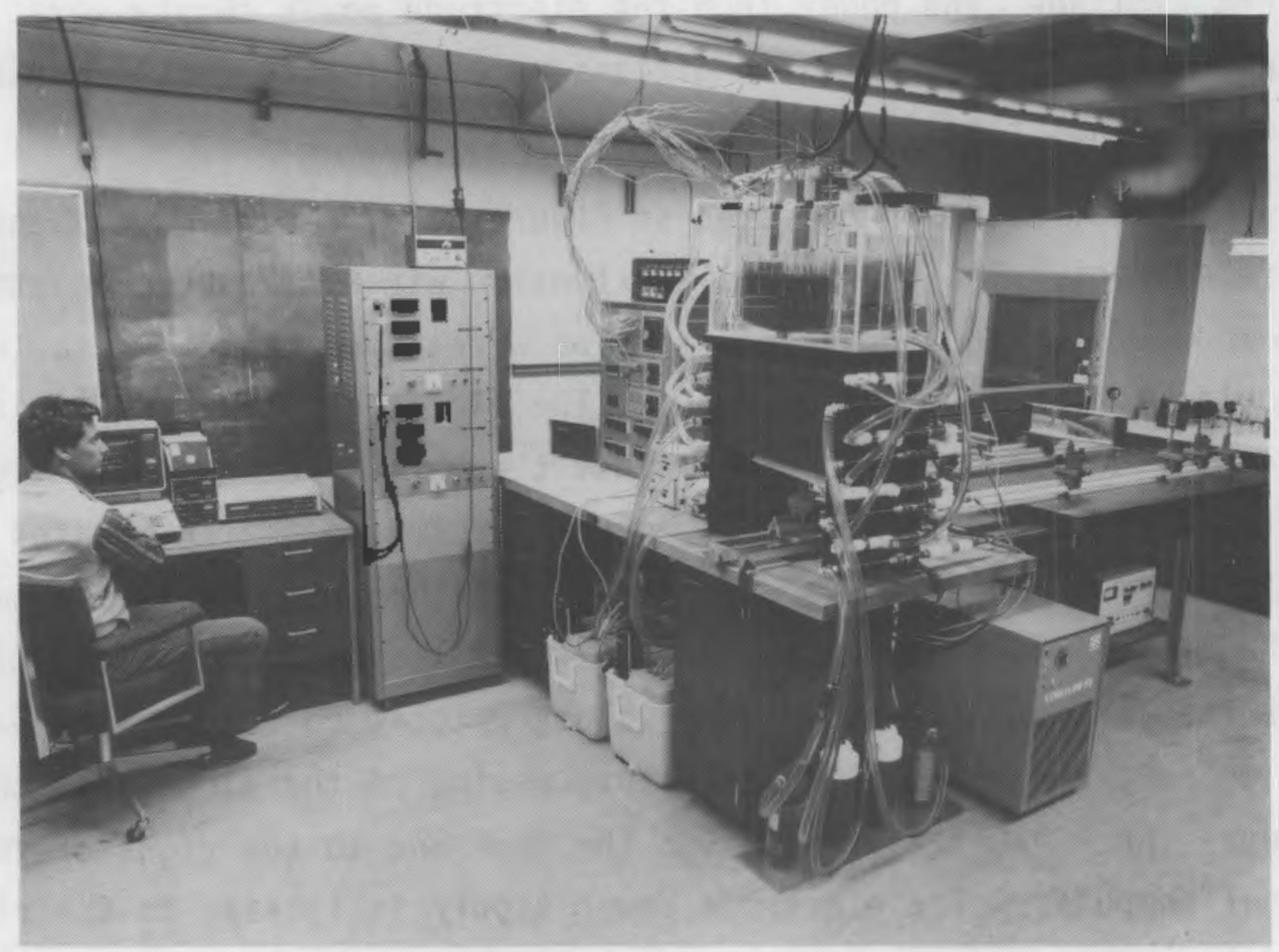

FIGURE 3.3. Instrumentation and Data Acquisition for BIPP Model 


\subsubsection{Experimental Measurement Procedure}

Modeling fluid temperature measurements were performed using six 1/16-in.-diameter, sheathed, ungrounded Type $T$ thermocouples. The thermocouples were inserted into the modeling fluid through the drywells of the simulated cold cap (model top). The six thermocouples were simultaneously placed at the same depth and at the same distance between front and back walls during a measurement scan. Readings were recorded at 30 -second intervals for approximately 5 minutes. This procedure was then repeated at the next depth in the measuring plane. Longer recordings of about 15 minutes were sometimes made at a given level to record the transient nature of the temperatures. Temperature measurement locations are given in Figures 3.4 and 3.5 for the various test runs. Temperature data acquired during testing is tabulated in Appendix A. Tabulated temperatures are averages of the data taken over the 5minute data acquisition intervals. Boundary conditions given are taken from the data acquisition output at an arbitrary point in time during which the temperature traverse measurements were being taken. Wall temperatures are averages of the various thermocouples placed in the given wall.

Electric potential measurements were accomplished using a probe cut from 1/16-in.-diameter aluminum stock. The probe was electrically insulated with the exception of a small area at the probe tip. Measurements were recorded from a true RMS voltmeter. One lead was attached to the probe, while the other was grounded to an electrode. The locations at which the potentials were measured are shown in Figures 3.6 and 3.7 for the various test runs. Tabulations of the measured potentials are included in Appendix B. As in the case of the temperature traverses, the boundary conditions are obtained at an arbitrary point in time during the measurement of the potential traverse, and the values for the wall temperatures are averages for the various thermocouples in the indicated wall. 


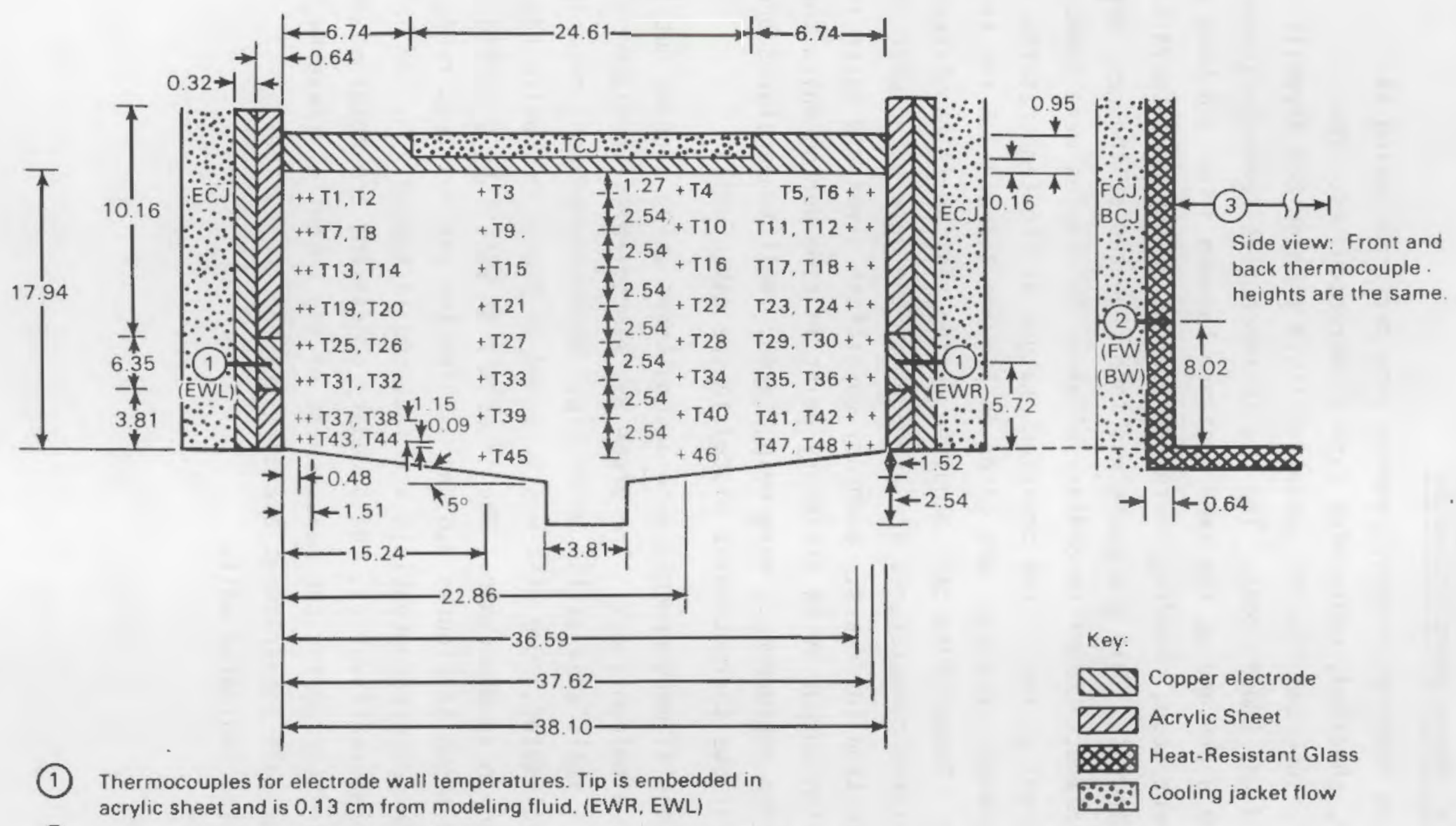

(2) Thermocouples for front and back wall temperatures. Tip is embedded in glass and is $0.13 \mathrm{~cm}$ from modeling fluid. (FW, BW)

(3) Front-to-back distance is $27.94 \mathrm{~cm}$.

Note: Drawing not to scale. All dimensions are in centimeters.

FIGURE 3.4. Temperature Profile Locations: Tests BRUN-1 to BRUN-3 and BRUN-7 to BRUN-9 


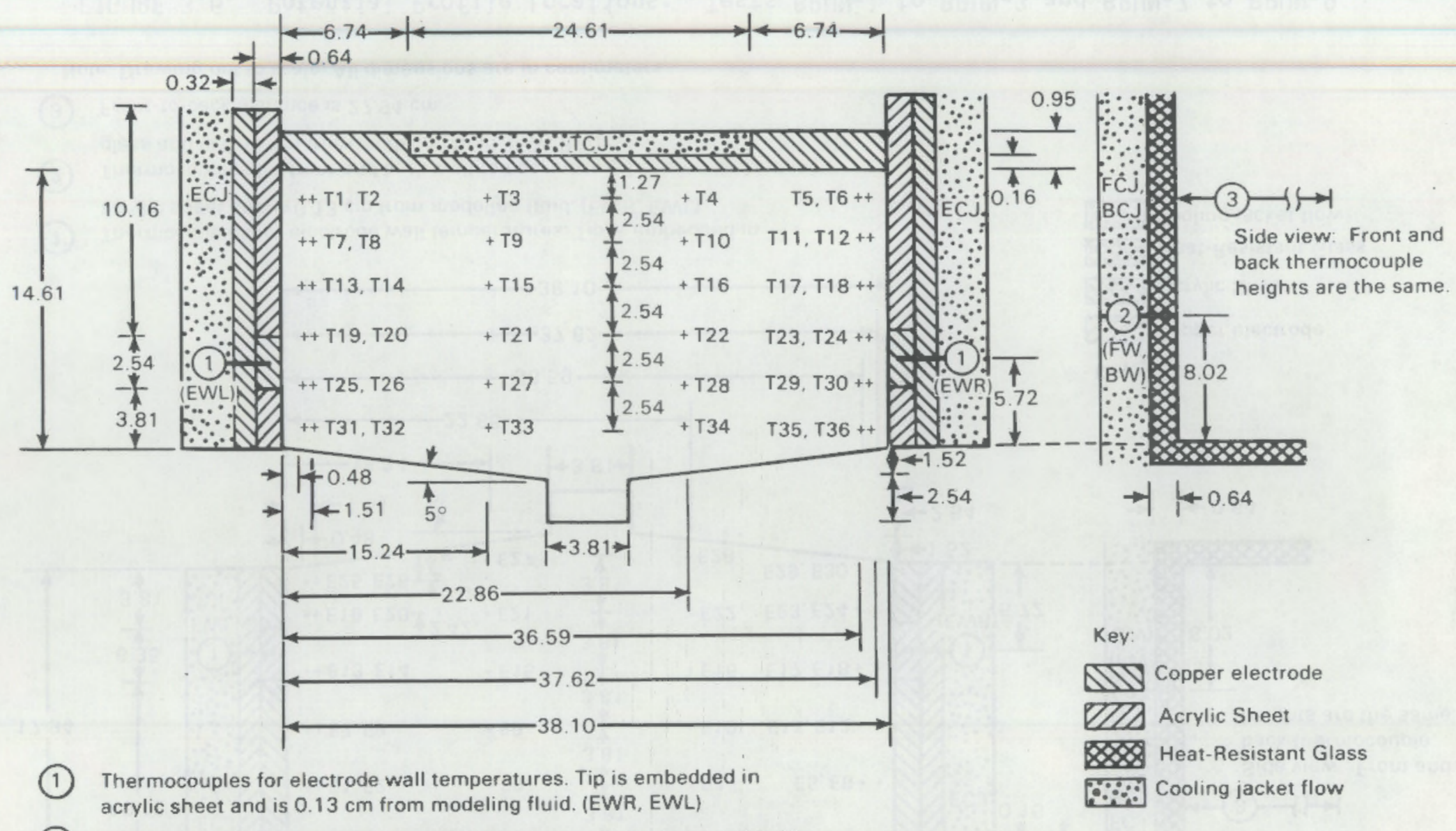

(2) Thermocouples for front and back wall temperatures. Tip is embedded in glass and is $0.13 \mathrm{~cm}$ from modeling fluid. (FW, BW)

(3) Front-to-back distance is $27.94 \mathrm{~cm}$.

Note: Drawing not to scale. All dimensions are in centimeters.

FIGURE 3.5. Temperature Profile Locations: Tests BRUN-4 to BRUN- 6 


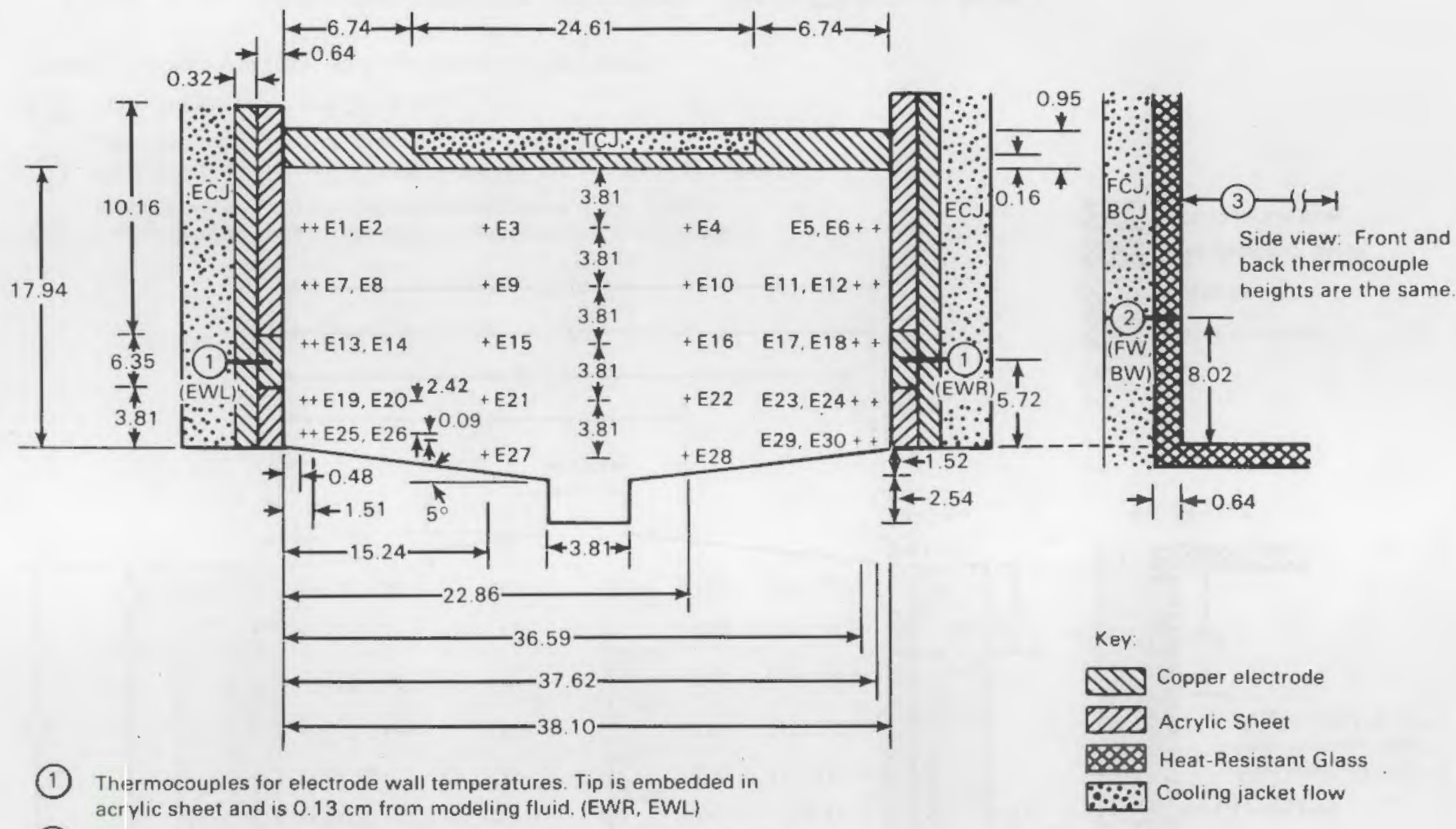

(2) Thermocouples for front and back wall temperatures. Tip is embedded in glass and is $0.13 \mathrm{~cm}$ from modeling fluid. (FW, BW)

(3) Front-to-back distance is $27.94 \mathrm{~cm}$.

Note: Drawing not to scale. All dimensions are in centimeters.

FIGURE 3.6. Botential Profile Locations: Tests BRUN-1 to BRUN-3 and BRUN-7 to BRUN-9 


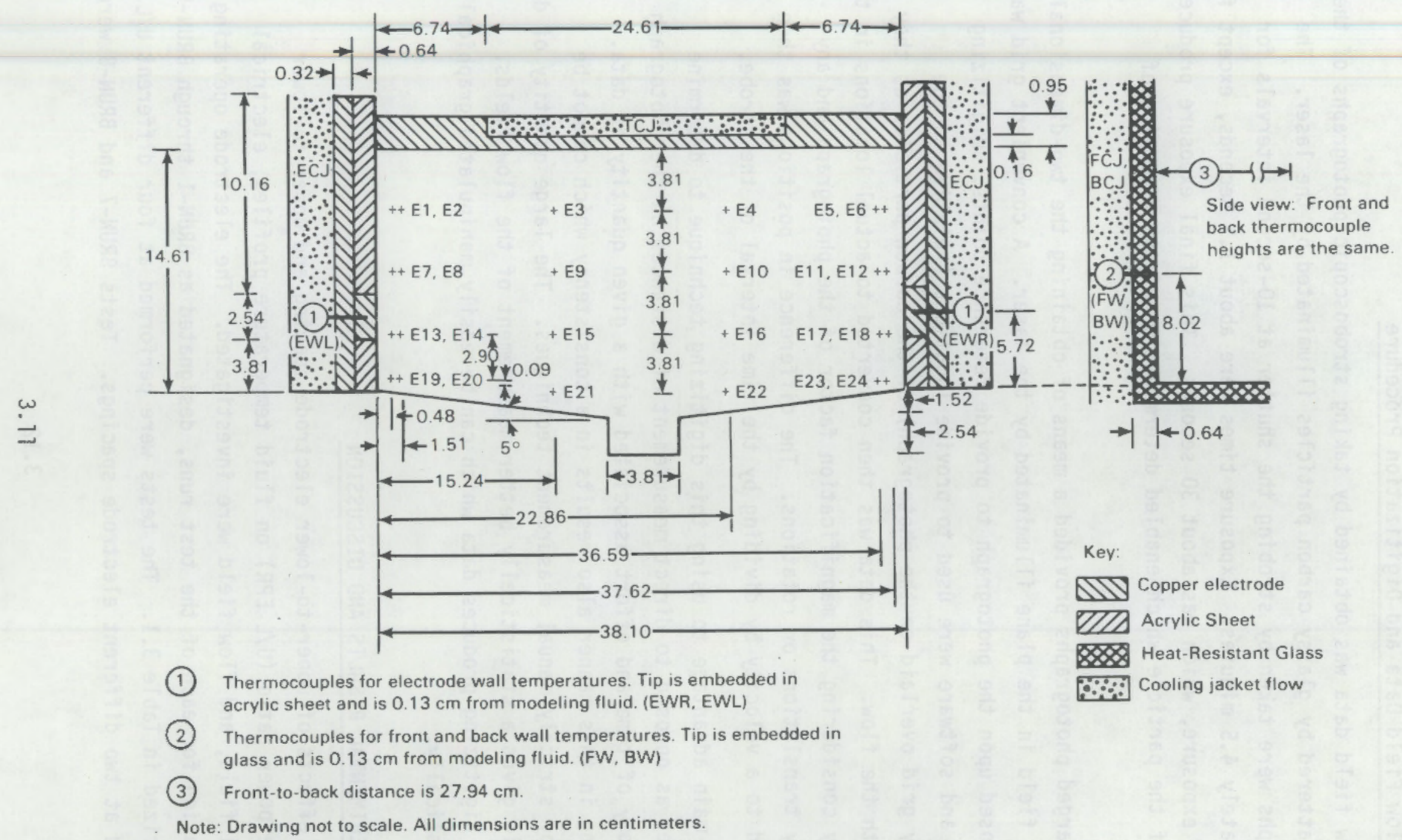

FIGURE 3.7. Potential Profile Locations: Tests BRUN-4 to BRUN-6 


\subsubsection{Flow Field Data and Digitization Procedure}

Flow field data was obtained by taking stroboscopic photographs of the light scattered by glassy carbon particles 111 uminated by the laser. The photographs were taken by strobing the shutter at 10-second intervals for approximately 4.5 minutes. Exposure times were about 1.1 seconds, except for the last exposure, which was about 30 seconds. This final exposure produced a streak of the particle which enabled determination of the direction of motion.

Enlarged photographs provided a means of obtaining the two-dimensional velocity field in the plane illuminated by the laser. A convenient grid was superimposed upon the photograph to provide reference points. Digitizing hardware and software were used to provide locations (relative to the arbitrary grid overlaid on the photograph) of the carbon particles as they moved with the flow. This data was then converted to actual locations in the melter by considering the magnification factor of the photograph and any necessary translations or rotations. The difference in positions was then converted to a velocity by dividing by the time interval of the strobe.

The main advantage to using this digitizing technique to determine velocities as opposed to direct measurement of distances on the photograph is the economy of time and effort associated with a given quantity of data. Digitizing in this manner also results in a consistency which cannot be matched by strictly manual measurement techniques. The large quantity of data obtainable gives a statistically better measurement of the flow fields. Finally, digitizing produces data which can be easily manipulated graphically or statistically.

\subsection{EXPERIMENTAL RESULTS AND DISCUSSION}

The effects of upper-to-10wer electrode spacing and upper-to-lower electrode power ratio (U/L EPR) on fluid temperature profiles, electrical potential field, and flow field were investigated. The electrode operating configuration for each of the test runs, designated as BRUN-1 through BRUN-9, is summarized in Table 3.1. The tests were performed at four different $U / L$ EPR's and at two different electrode spacings. Tests BRUN-7 and BRUN-8 were 
made to provide flow visualization results, to model at a more realistic $\mathrm{U} / \mathrm{L}$ EPR, and to obtain power supply firing characteristics. Temperature and flow results from these two test runs were inconsistent with tests BRUN-1 through BRUN-6. Discrepancies encountered in test runs BRUN-7 and BRUN-8 are discussed subsequently apart from the other test results. An additional test run, BRUN-9, was performed to confirm the repeatability of the earlier test results (specifically BRUN-3) after correcting for the cause of the inconsistency.

Fluid temperature measurements, electrical potential measurements, and streaked/strobed photography were performed at selected locations in the model to investigate the influences of the various model operating configurations on the fluid temperature profile, electric field, and flow field. Temperature measurement locations are shown in Figures 3.4 and 3.5 , while potential measurement locations are shown in Figures 3.6 and 3.7. Tabulated temperature and potential results are presented in Appendices $A$ and $B$, respectively.

Photographs of the time-dependent voltage signal for the SCR power supply were taken to examine the interaction of the electrode pairs. Graphical representation of results are given with respect to the dimensionless coordinates, $X^{*}, Y^{*}$, and $Z^{*}$, defined as $X / X_{C}, Y / Y_{C}$, and $Z / Z_{C}$, respectively. The characteristic lengths, $X_{C}, Y_{C}$, and $Z_{C}$ are the dimensions of the interior of the test apparatus. The characteristic length, $Z_{C}$, was measured with its origin at the model bottom adjacent to a side wall (or electrode). Because the BIPP model has a bottom which is sloped downward from the electrodes, $Z$ (and $Z^{*}$ ) coordinates along the model bottom may be negative.

A centered cold cap spanning $66 \%$ of the top surface area, as depicted in Figure 3.1, was used during the BIPP test series. The cooled portion of the cold cap in contact with the upper fluid surface occupied the area defined by:

$$
\begin{aligned}
& 0.17 \leqslant X^{\star} \leqslant 0.83 \\
& 0.00<Y^{\star}<1.00
\end{aligned}
$$

Boundary temperatures, which were to be maintained during all test runs according to appropriate BIPP-to-model scaling, are given in Table 3.?. A 
variation of approximately $\pm 2^{\circ} \mathrm{C}$ in boundary conditions occurred among test runs. However, boundary temperatures varied less than $\pm 1 / 2^{\circ} \mathrm{C}$ during a test. run. Nominal power input during testing was $325 \mathrm{~W}$. While some variation in total average power existed hetween test runs, power variation during all test runs, except BRUN-2, remained invariant. Boundary temperatures and power supply voltage, current, and power values for each test are summarized in Table 3.3.

\section{TABLE 3.2. BIPP Model Nominal Boundary Temperatures}

$\begin{array}{ll}\text { Modeling Fluid Temperature } & 70^{\circ} \mathrm{C} \\ \text { Wall Temperature } & 60^{\circ} \mathrm{C} \\ \text { Top Temperature } & 9.5^{\circ} \mathrm{C} \\ \text { Electrode Temperature } & 50^{\circ} \mathrm{C}\end{array}$

\subsubsection{Temperature Results}

Temperature results presented graphically in Figure 3.8 through 3.14 are time-averaged values as tabulated in Appendix A. Results presented are temperature profiles with respect to horizontal direction which is perpendicular to the electrode faces. Temperature profiles shown in each figure are from the same test run hut at different depths (or $Z^{*}$ ) positions.

Temperature stratification is observed in the vertical direction. However, a large cooling effect for temperature profiles at $Z^{*}=0.93$ is also apparent in these figures. Little temperature variation in the horizonta? fluid layers is observed, with exception of regions near the electrodes. The near electrode temperature field, at $x^{*} \leq 0.04$ and $x^{\star} \geq 0.96$, exhibited large fluid temperature gradients. In general, fluid temperatures increased upon approaching electrodes. 


\section{TABLE 3.3. Summary of BRUN Test Series Operating Conditions}

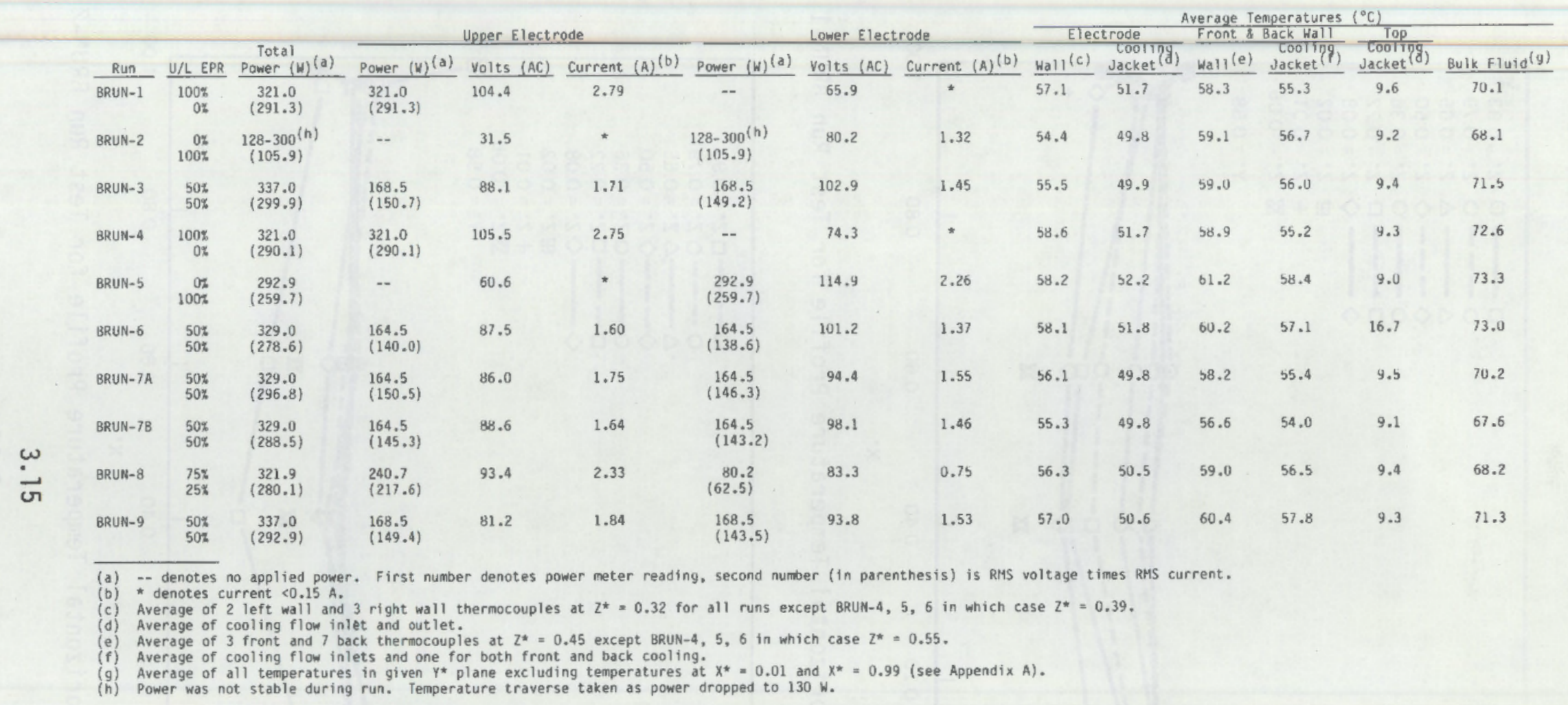




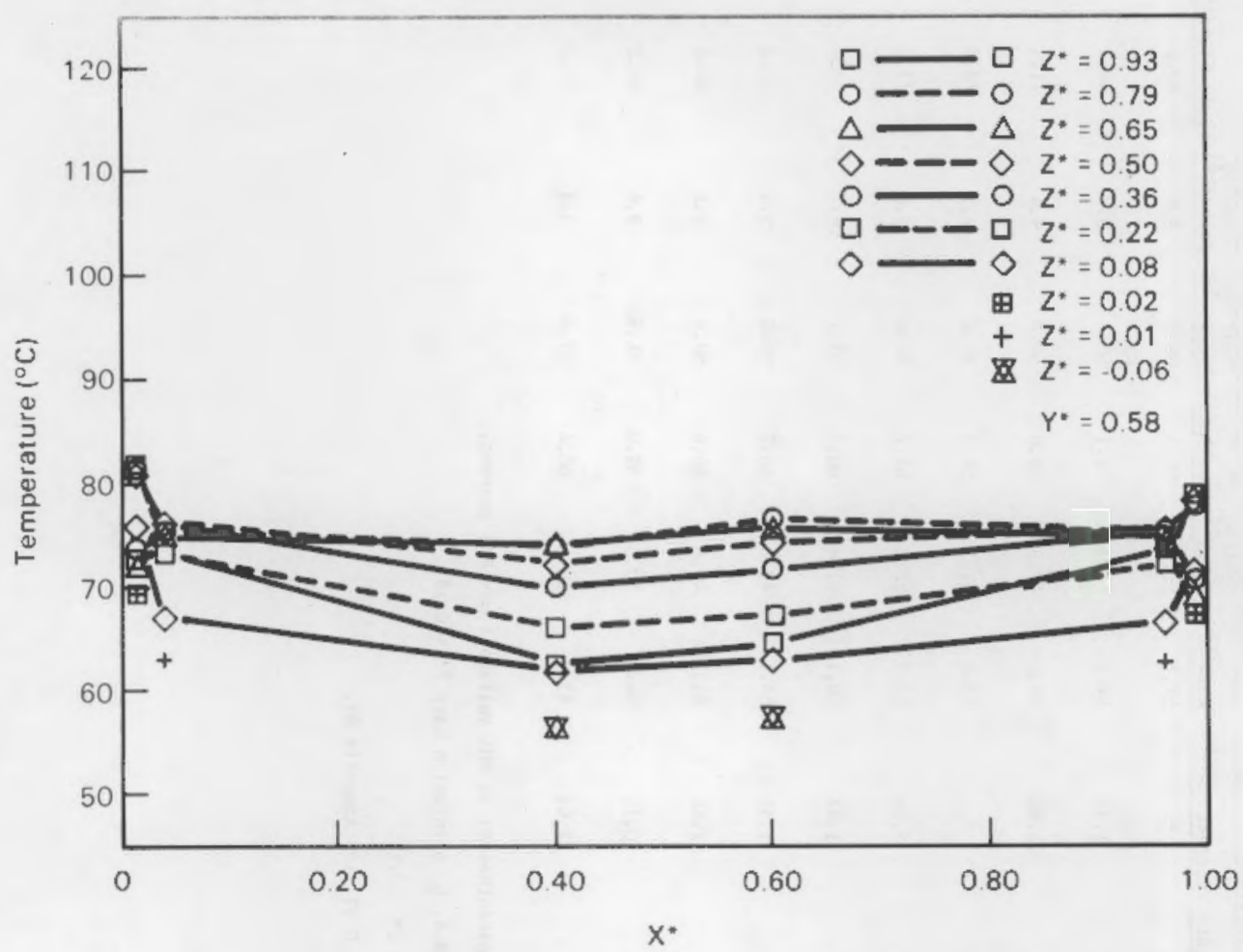

FIGIJRE 3.8. Horizontal Temperature Profile for Test Run RRIIN-1

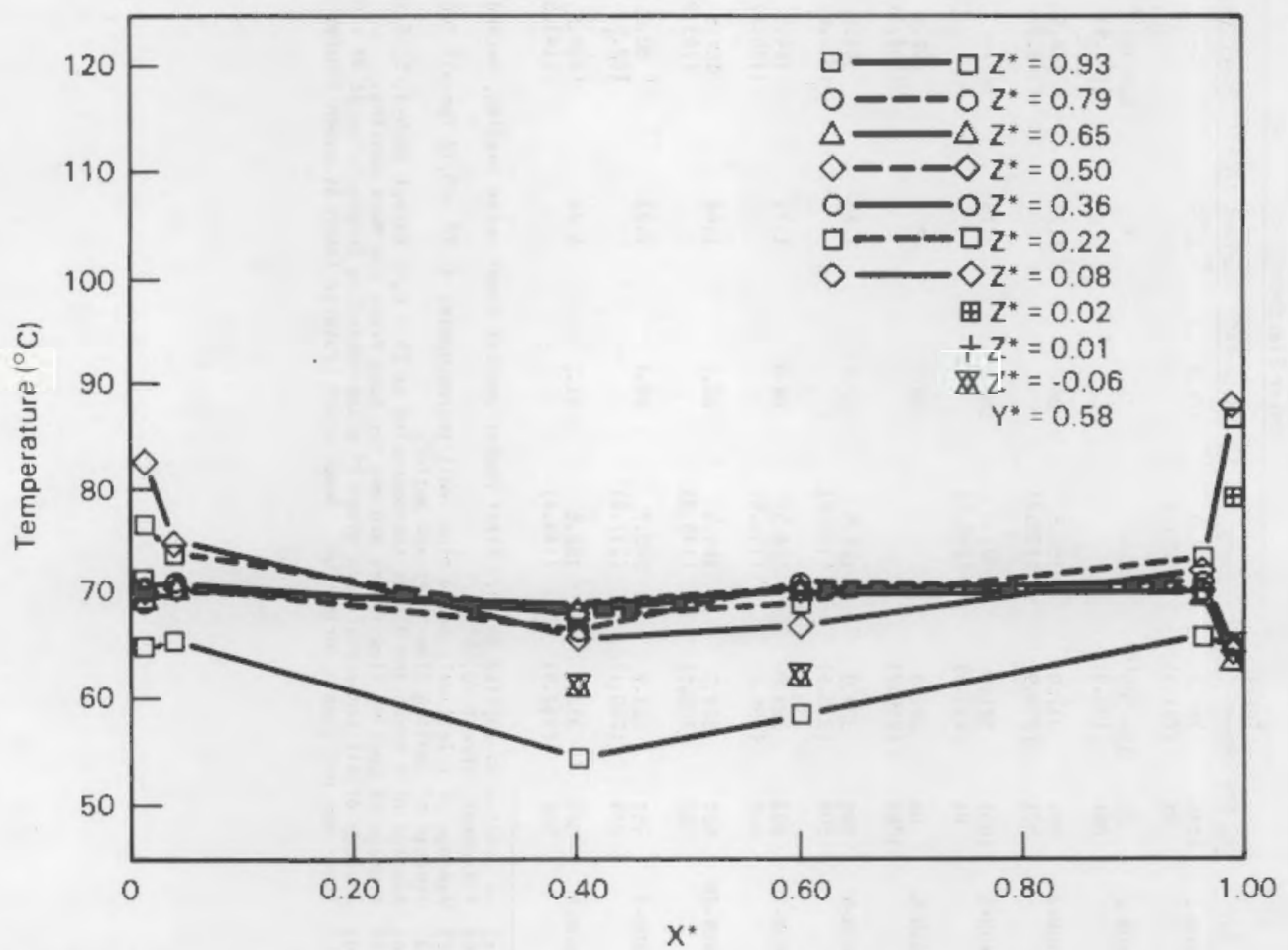

FIGURE 3.9. Horizontal Temperature Profile for Test Run BRUN-? 


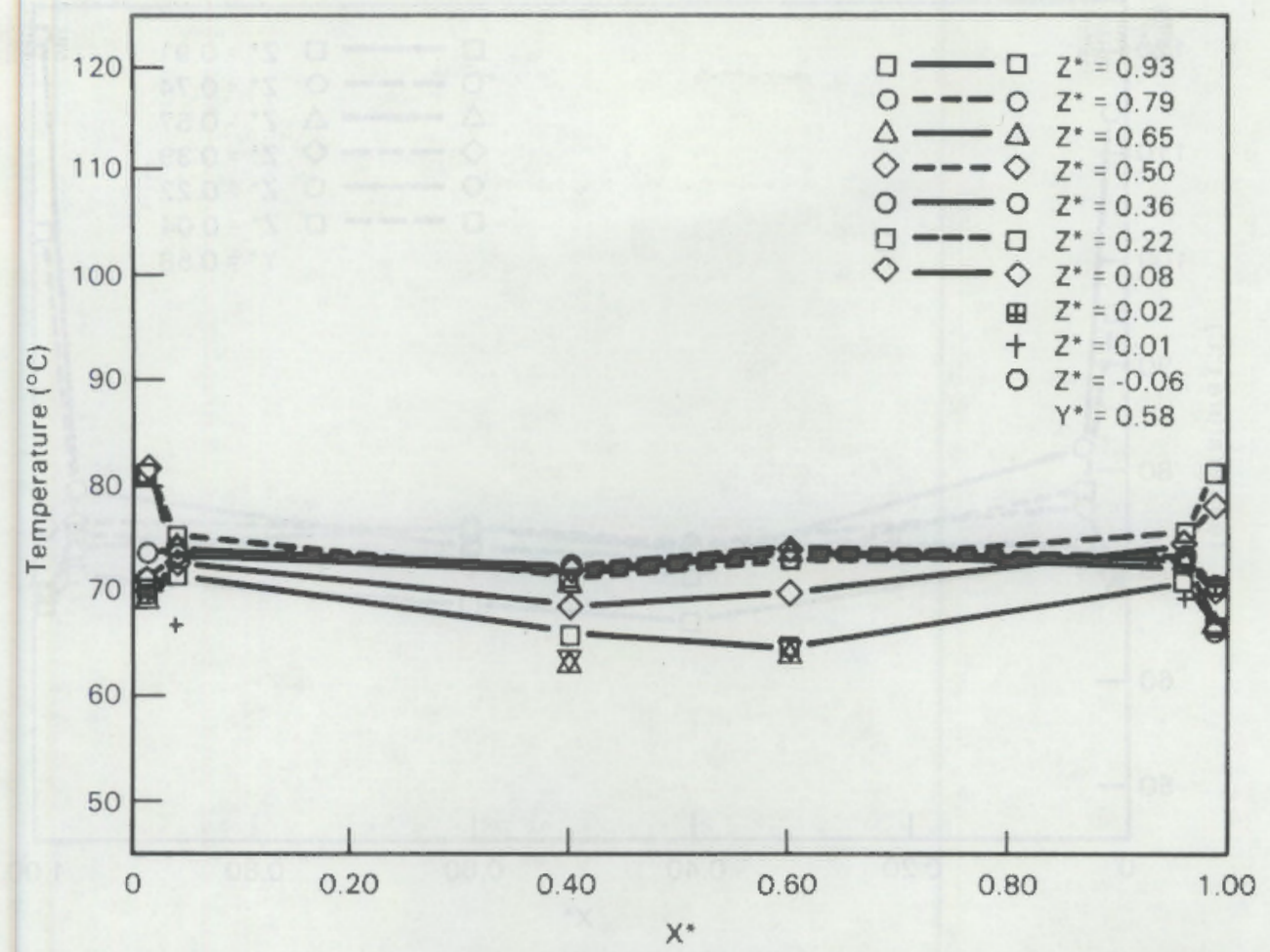

FIGURE 3.10. Horizontal Temperature Profile for Test Run BRIJN-3

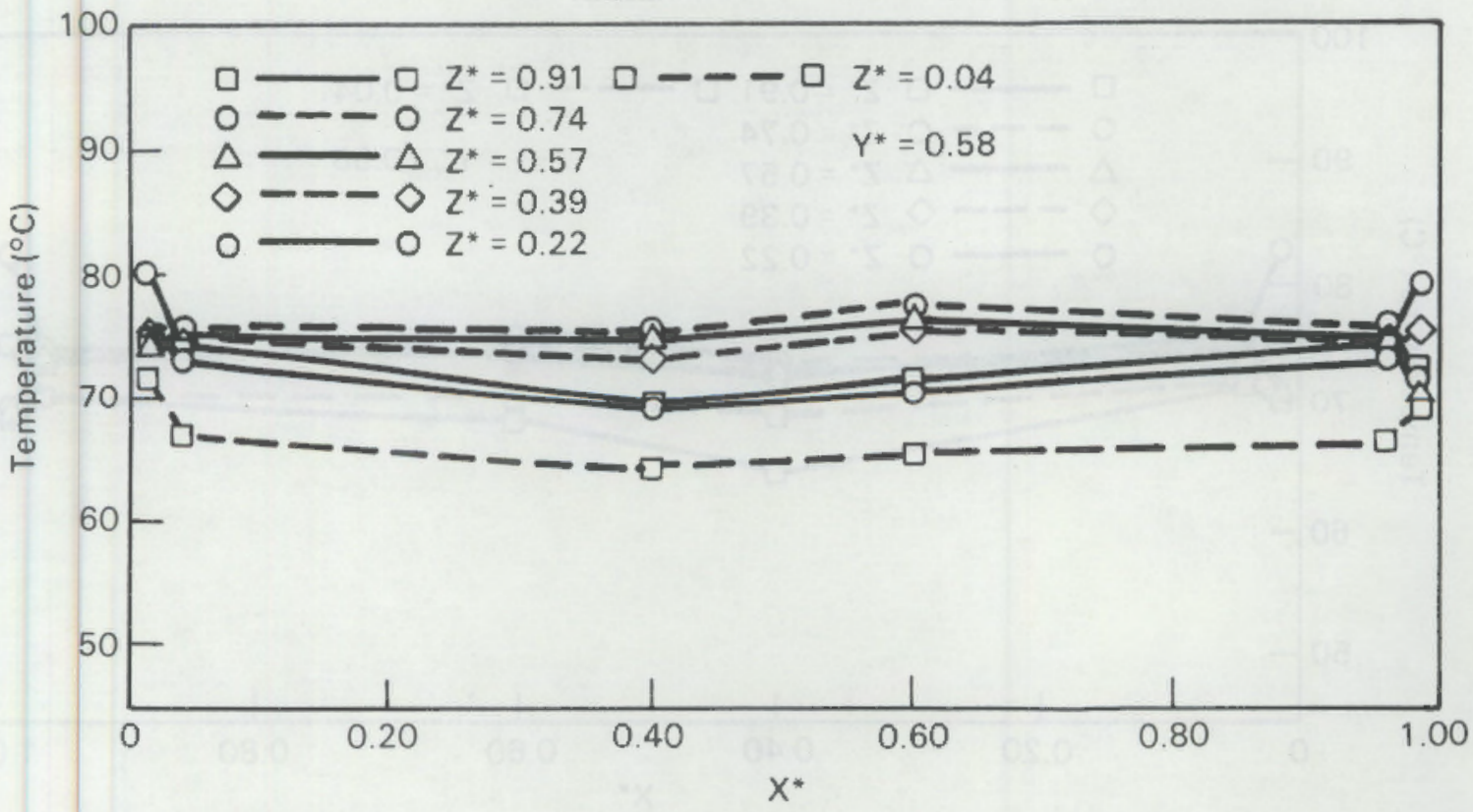

FIGURE 3.11. Horizontal Temperature Profile for Test Run BRUN-4 


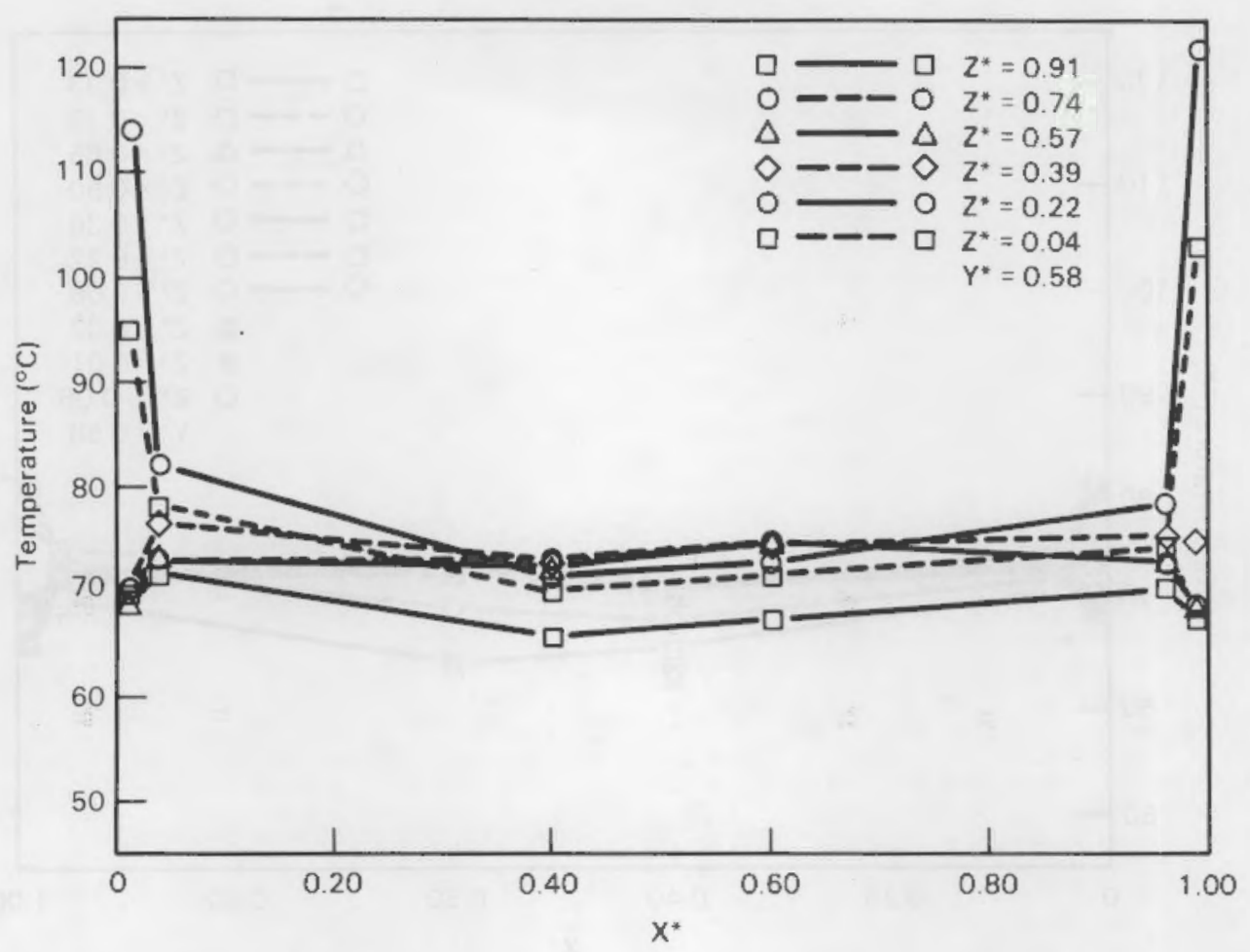

FIGURE 3.12. Horizontal Temperature Profile for Test Run BRUN-5

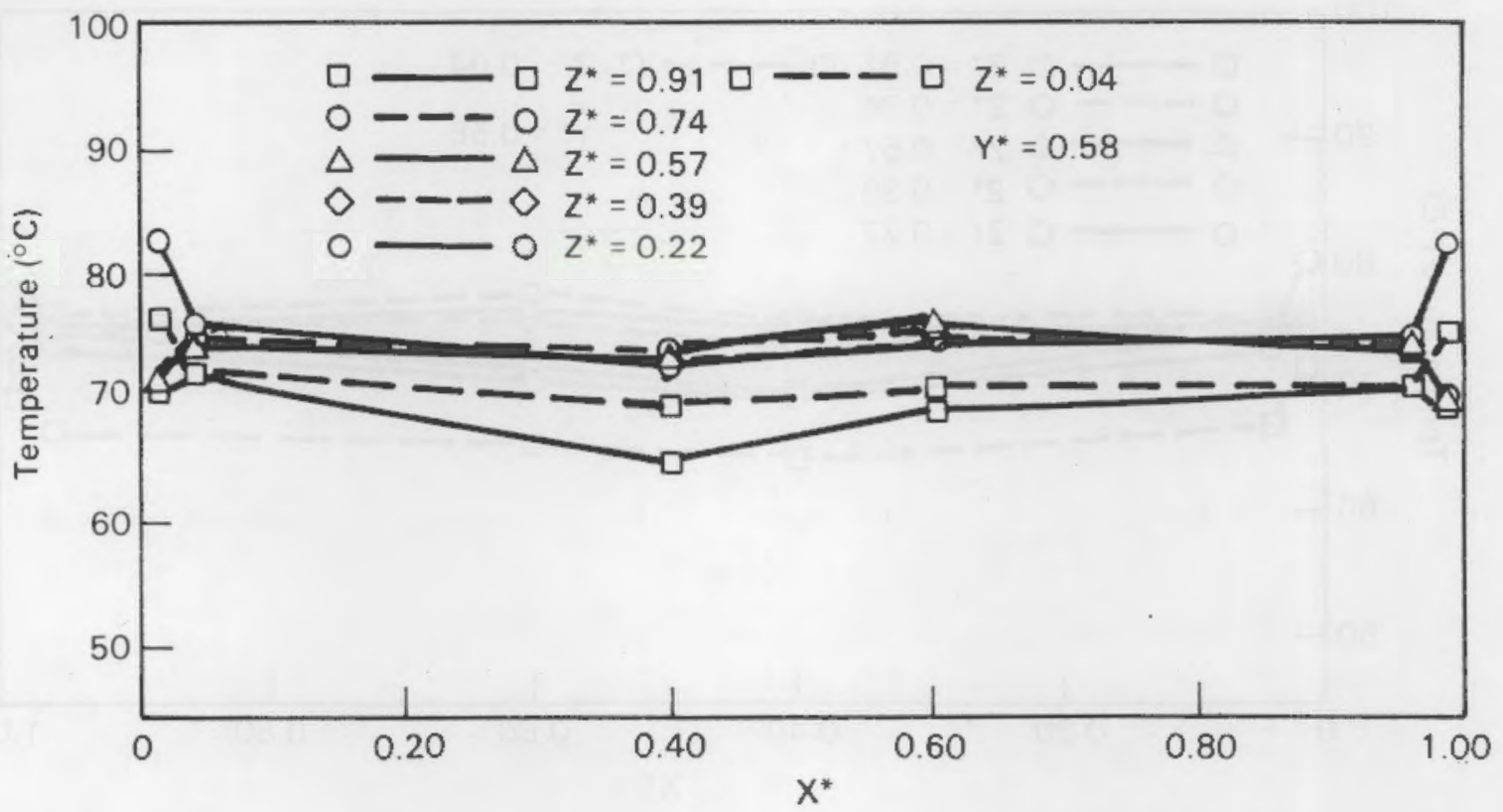

FIGURE 3.13. Horizontal Temperature Profile for Test Run BRUN-6 


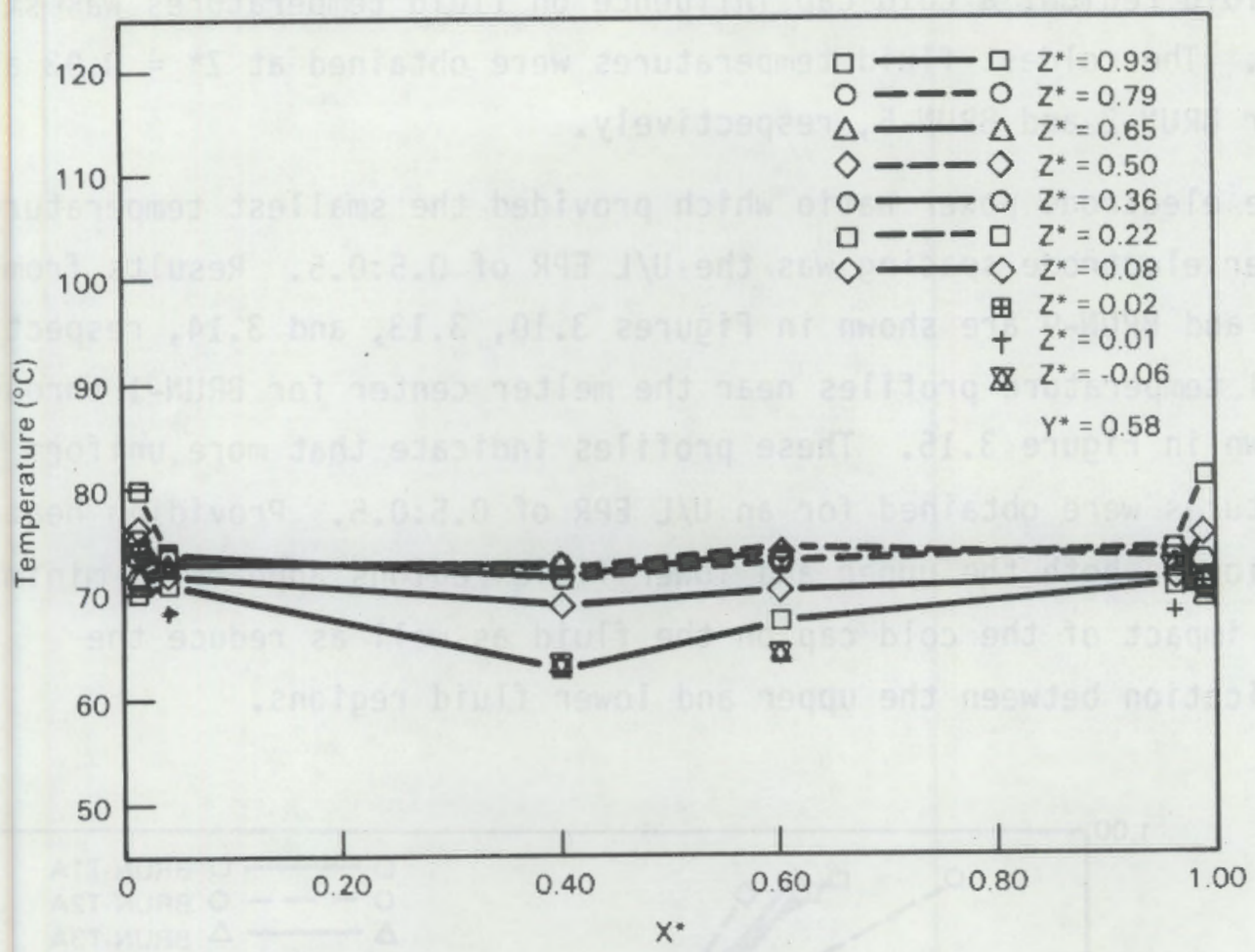

FIGURE 3.14. Horizontal Temperature Profile for Test Run BRUN-9

Aside from "near-electrode" temperature gradients, the largest temperature stratification occurred during test runs BRUN-1 and BRUN-4 when total power was applied to the upper electrodes. With only the upper electrode pair in operation, less Joule heating occurs in the cooler, denser, and more electrically resistive fluid beneath these electrodes. Mixing of the fluid in the upper and lower fluid layers is deterred and results in temperature stratification in the vertical direction, as depicted in Figures 3.8 and 3.11. These results are consistent with preliminary BIPP model results (Skarda et al. 1985).

When power is supplied to only the lower electrodes, fluid in lower model regions is Joule heated, which promotes buoyancy-induced mixing. Fluid rises as a result of the density decrease from being heated between the lower electrodes. Approaching the cold cap, the fluid once again cools and sinks. Again aside from near-electrode effects, results from BRUN-2 and BRUN-5, shown in Figures 3.9 and 3.12, indicate smaller temperature variation relative to the BRUN-1 and BRUN-4 test results. However, with little Joule heating in the 
upper fluid region, a cold cap influence on fluid temperatures was still evident. The coldest fluid temperatures were obtained at $Z^{\star}=0.93$ and $X^{\star}=$ 0.91 for BRUN-2 and BRUN-5, respectively.

The electrode power ratio which provided the smallest temperature gradient at either electrode spacing was the U/L EPR of $0.5: 0.5$. Results from BRIIN-3, BRUN-6, and BRUN-9 are shown in Figures 3.10, 3.13, and 3.14, respectively. Vertical temperature profiles near the melter center for BRUN-1 through BRUN- 6 are shown in Figure 3.15. These profiles indicate that more uniform temperatures were obtained for an $U / L$ EPR of 0.5:0.5. Providing heat generation to both the upper and lower fluid regions appears to minimize the cooling impact of the cold cap on the fluid as well as reduce the stratification between the upper and lower fluid regions.

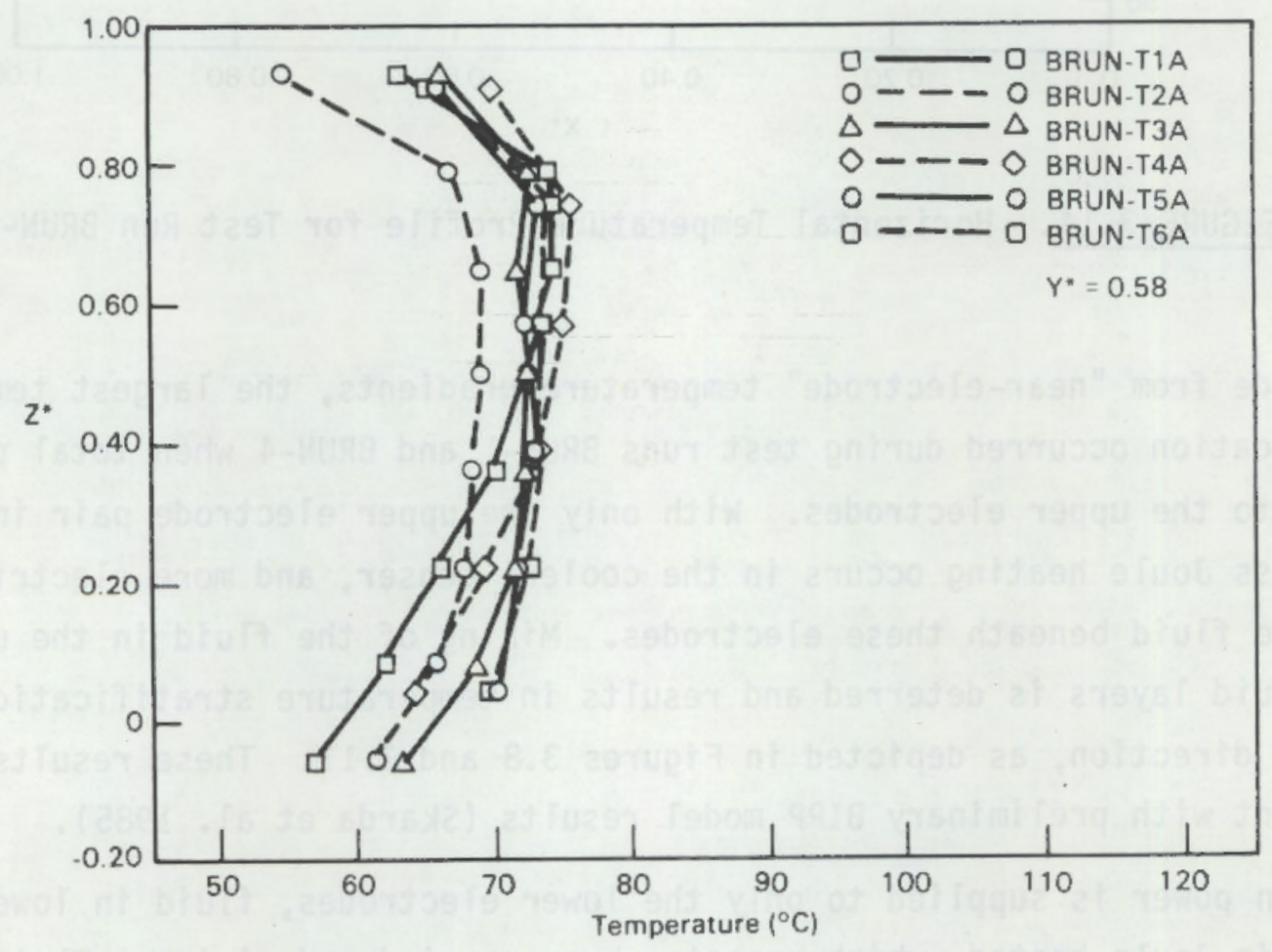

FIGURE 3.15. Vertical Temperature Profile at Model Center 
Average temperatures, $\mathrm{T}_{\mathrm{avg}}$, standard deviations, $\mathrm{T}_{\sigma}$, maximum temperature, $T_{\max }$, and minimum temperature, $T_{\min }$, were determined from tabulated temperature values in Appendix 4 for a given $y$-plane. These quantities were then used to estimate bulk (volume-averaged) fluid temperature and provide a measure of temperature variation in each run. Recause the temperature gradient, aside from near-electrode effects, is largest in the vertical direction, these values should provide a measure of the buoyancy-related temperature stratification. Large temperature gradients in the small fluid volume very near the electrode faces are not thought to be sufficient to provide a great error in planeaveraged values and bulk temperature. Therefore, fluid temperature averages and temperature variation quantities were determined based on "including near electrode values" (INEV) and "excluding near electrode values" (ENEV). Simall variations between ENEVs and INEVS, with the exception of BRUN-5 results, are observed in Table 3.4 which supports the above statement. A $4.1 \%$ and $72 \%$ deviation occurred in $T_{a v g}$ and $T_{\sigma}$, respectively, for ENEVs and INEVs of BRUN-5. The localized high temperatures exceeding $120^{\circ} \mathrm{C}$ were responsible for the ENEV and INEV discrepancies in BRUN-5.

The temperature differential, $\Delta T_{0}$, determined from $T_{\max }$ and $T_{\min } E N E V s$ for each test run is shown in Table 3.4. Near-electrode values were excluded to more accurately represent buoyancy-induced stratifications. These temperature differences correspond to the following melter temperature differences: $114.8^{\circ} \mathrm{C}, 120.1^{\circ} \mathrm{C}, 72.5^{\circ} \mathrm{C}, 77.1^{\circ}, 95.7^{\circ} \mathrm{C}, 64.4^{\circ} \mathrm{C}$, and $67.9^{\circ} \mathrm{C}$ for BRIJN-1 through BRUN-6, and BRUN-9, respectively. The large temperature differences during BRUN-1 and BRUN-2 may be undesirable because of the possibility of crystallization and excess electrode cross firing. Although the maximum permissible glass temperature differential is strongly dependent on the proposed glass operating temperature and the glass composition, the predicted glass ENEV temperature differences of $77.1^{\circ} \mathrm{C}$ and smaller are considered sufficiently small to avoid these problems (Chick et al. 1984, and Mendel 1977).

Figures 3.8 through 3.10 depict temperature profiles for the large electrode spacing of $6.35 \mathrm{~cm}$, while results in Figure 3.11 through 3.13 correspond to a small electrode spacing of $2.59 \mathrm{~cm}$. Effects from changing electrode spacing are not readily observahle from these figures. However, a comparison 
TABLE 3.4. Plane-Averaged Bulk Fluid Temperature Characterization

\begin{tabular}{|c|c|c|c|c|c|c|c|c|c|}
\hline \multirow[b]{2}{*}{ Test } & \multirow{2}{*}{$\begin{array}{l}\text { Data } \\
\text { Table } \\
\text { (a) }\end{array}$} & \multicolumn{2}{|c|}{$\mathrm{T}_{\mathrm{avq}}\left({ }^{\circ} \mathrm{C}\right)$} & \multicolumn{2}{|c|}{$\mathrm{T} \sigma\left({ }^{\circ} \mathrm{C}\right)$} & \multicolumn{2}{|c|}{$T_{\max }\left({ }^{\circ} \mathrm{C}\right)$} & \multicolumn{2}{|c|}{$\mathrm{T}_{\min }\left({ }^{\circ} \mathrm{C}\right)$} \\
\hline & & ENEV (b) & $\operatorname{INEV}(c)$ & $\operatorname{ENEV}^{(b)}$ & $\operatorname{INEV}(c)$ & ENEV ${ }^{(b)}$ & $\operatorname{INEV}(c)$ & ENEV (b) & $\operatorname{INEV}(\mathrm{c})$ \\
\hline BRUN-1 & A. 1 & 70.1 & 71.5 & 5.9 & 5.9 & 76.5 & 82.0 & 56.7 & 56.7 \\
\hline BRUN-2 & A.2 2 & 68.1 & 69.4 & 4.4 & 6.1 & 75.0 & 87.8 & 54.3 & 54.3 \\
\hline BRUN-3 & A. 4 & 71.5 & 71.8 & 3.3 & 4.0 & 75.7 & 81.8 & 63.2 & 63.2 \\
\hline BRUN-4 & A. 6 & 72.6 & 73.1 & 3.8 & 3.5 & 77.5 & 80.2 & $64 . ?$ & $64 . ?$ \\
\hline BRUN-5 & A. 7 & 73.3 & 76.4 & 3.5 & 12.5 & 82.1 & 122.0 & 65.6 & 65.6 \\
\hline BRIJN-6 & A. 9 & 73.0 & 73.1 & 2.6 & 3.4 & 76.0 & 83.0 & 64.9 & 64.9 \\
\hline BRUN-7 & A. 9 & 70.2 & 70.8 & 3.4 & 4.7 & 76.1 & 93.9 & 62.0 & 62.0 \\
\hline BRUN-8 & A. 10 & $68 . ?$ & 68.7 & 3.4 & 3.7 & 73.3 & 80.3 & 59.9 & 59.9 \\
\hline BRUN-9 & A. 1 ? & 71.3 & 72.0 & 3.1 & 3.4 & 74.4 & 81.0 & 6?. .7 & 62.7 \\
\hline
\end{tabular}

( ${ }^{a}$ ) Y- $\rho l$ ane values correspond to temperature profile tabulations in Table A.8.

$\left({ }^{b}\right)$ ENEV - excluding near-electrode values--measurements at $x *<0.01$ and $x^{*}>0.90$

(c) INEV - including near-electrode values 
of the $y$-plane(s) temperature field standard deviations, $T_{\sigma}$, maximum temperature, $T_{\max }$, and minimum temperature, $T_{\min }$, in Table 3.4 suggest that a greater temperature variation occurs for larger electrode spacings. Increasing electrode spacing for these test runs also increases the aspect ratio (model depth-to-width ratio), which is a governing parameter for buoyancy-induced flow. Thus greater temperature stratification would be expected.

\subsubsection{Temperature Results (Near Electrode Region)}

The vertical temperature profiles shown in Figures 3.16 and 3.17 are near the left and right electrode, respectively. All test runs show an increase in temperature at approximately $Z^{*}$ of 0.22 . This location is just above the top of the lower electrode. The interaction of the following factors are believed to be responsible for the temperature profile near the electrode:

- cooling effect near the electrodes as a result of electrodes being water cooled

- crossfiring hetween upper and lower electrode on a respective model side

- thermal conductivity ratio between copper electrode and acrylic sheet spacer of $2000: 1$

- possible cooling fin effect from the top portion of the top electrode in contact with air.

The cooling effect of electrodes is observed in Figures 3.8 through 3.13 at $Z^{\star}$ $>0.36$. Additional cooling may also occur because of convective heat loss from the upper portion of the upper electrodes, which is in contact with the air. Potential measurements, as well as temperatures profiles, in Figures 3.16 and 3.17 suggest that current flow or electrode crossfiring occurs between the upper and lower electrodes. The highest fluid temperatures occur in front of the acrylic sheet spacer between the electrodes. Temperature increase is most probably the result of current flow between the upper and lower plates on a respective side. However, the low thermal conductivity of the acrylic sheet may also contribute to higher temperatures in this region because of the 


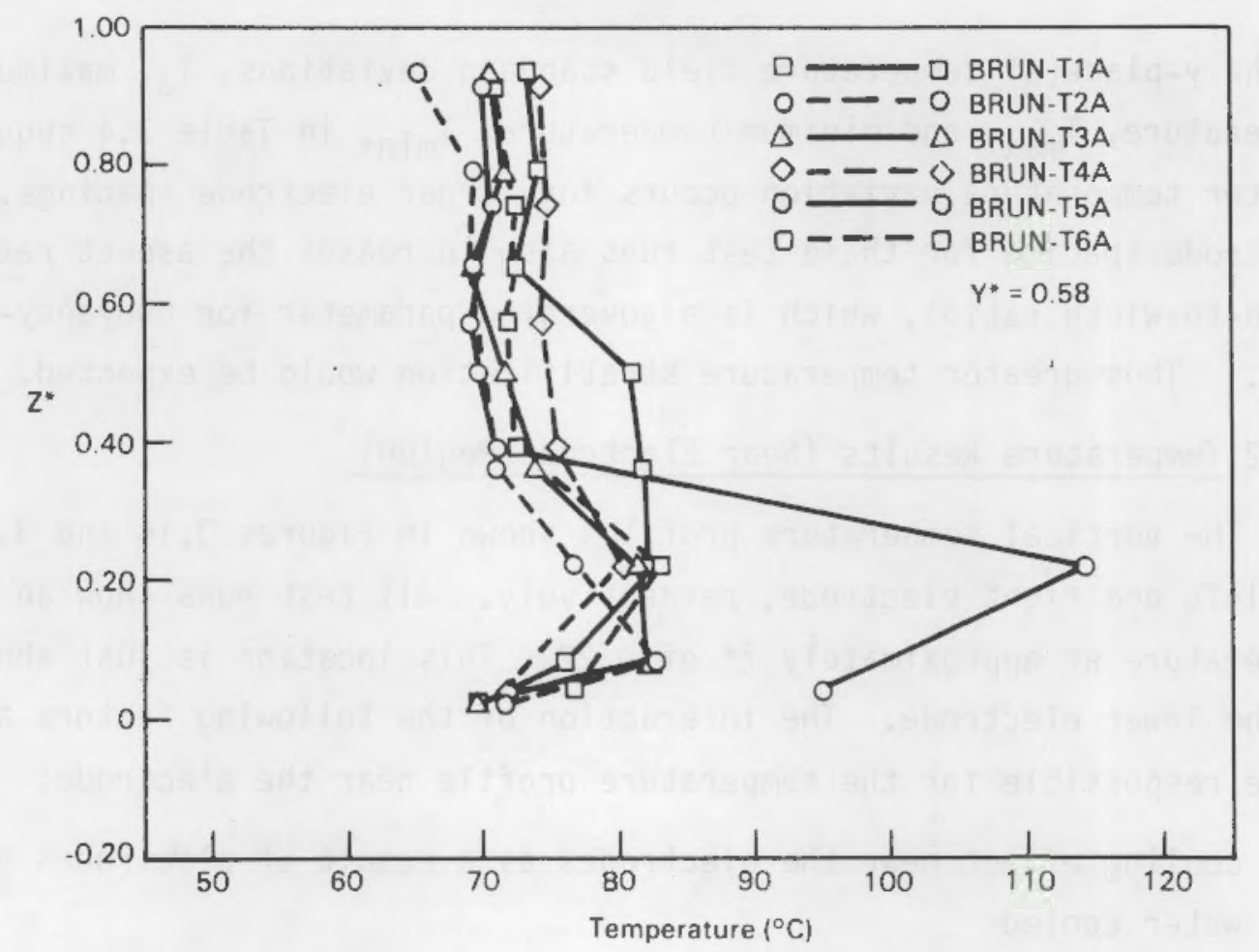

FIGURE 3.16. Vertical Temperature Profile Near Left Electrode

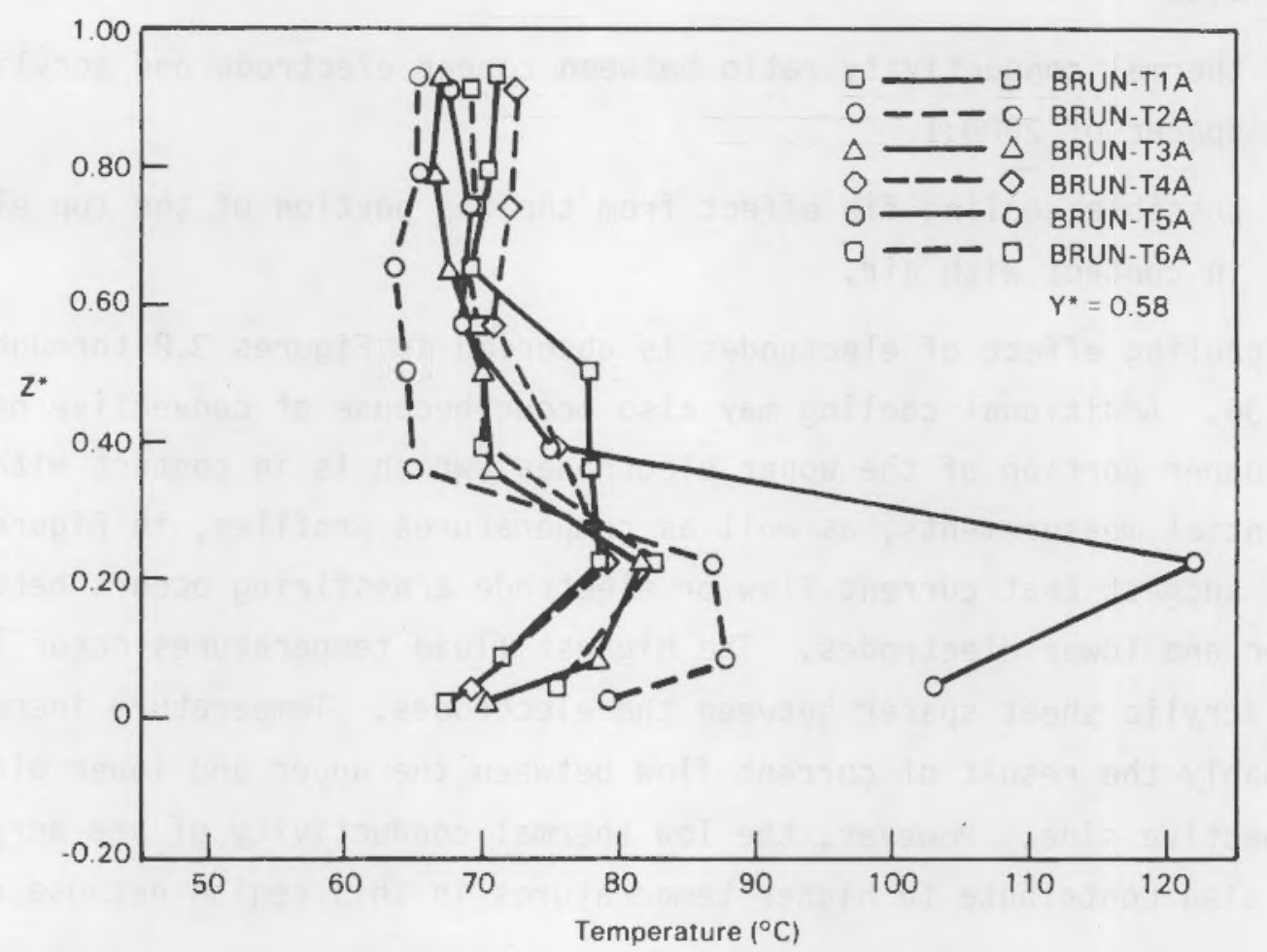

FIGURE 3.17. Vertical Temperature Profile Near Right Electrode 
inability of the fluid in front of the acrylic sheet to dissipate the heat generated relative to fluid in front of the electrode plates.

The highest local temperatures occurred when power was applied to only the lower electrodes. Since a larger potential difference between the upper and lower plate occurs for a U/L EPR of 1.0:0.0 or 0.0:1.0 than for an U/L EPR of 0.5:0.5, higher temperatures would be expected. As noted previously, when power is applied to only the upper electrodes, the colder, more resistive fluid resides beneath the lower electrodes. Therefore less current flows between the upper and lower electrodes in BRIIN-1 and BRIN-4 because of the higher resistance between upper and lower electrode plates. In addition, the much higher temperatures of BRUN-5, as compared with BRIJN-2, are attributed to the smaller electrode spacing used in BRUN-5, which provides a shorter or less resistive current path between electrodes.

Time series results are shown in Figures 3.18 through 3.23. The largest temperature variations typically occur over the central region of the model, while temporal temperature measurements near the electrodes had the smallest variation. This generalization did not always hold, as is the case in Figure 3.20. Some periodicities appear to exist in most of the times series' shown. Times series analysis, such as autocorrelations and/or spectral analysis, of these data could be used to determine and characterize the existence of periodicities, but this was not done as part of this work.

\subsubsection{Electrical Potential Results}

Electrical potential data are presented in graphical form in Figures 3.24 through 3.31 and are tabulated in Appendix B. The figures all represent the floating ground case of BRUN-1 through BRUN-6, and BRUN-9. Figure 3.24 is a plot of potential variation in the $X^{*}$ or horizontal direction for BRUN-3, whereas Figures 3.25 through 3.31 are plots of potential profiles in the vertical or $Z^{*}$ direction for each run individually.

Figure 3.?.4 is representative of all plots showing the potential in the horizontal or $x^{*}$ direction. At all depths within the melter, the potential variation with respect to horizontal position is essentially linear with the exception of the regions very near the electrodes. 


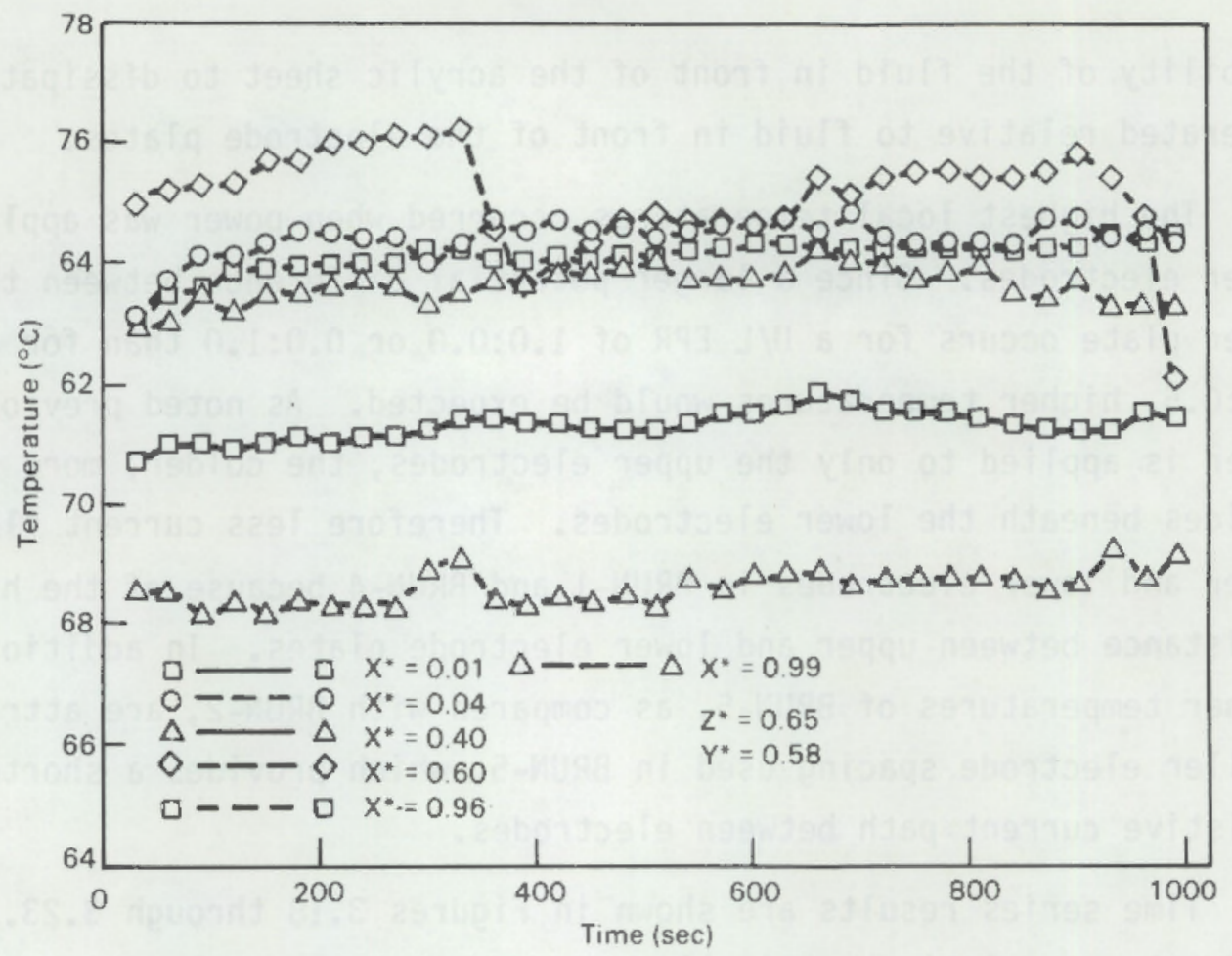

FIGURE 3.18. Fluid Temperature Time Series for BRUN-1

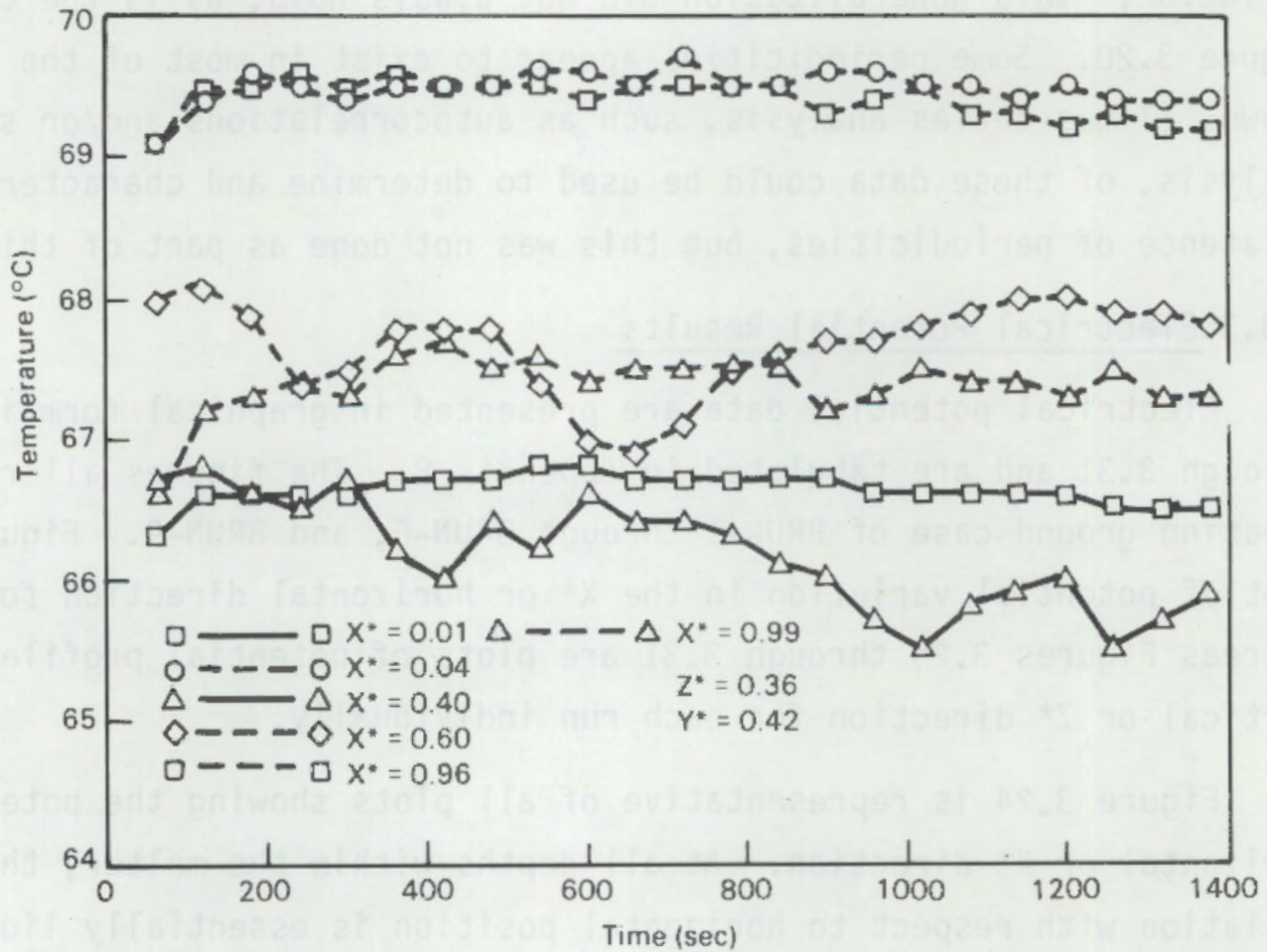

FIGURE 3.19. Fluid Temperature Time Series for BRUN-2 


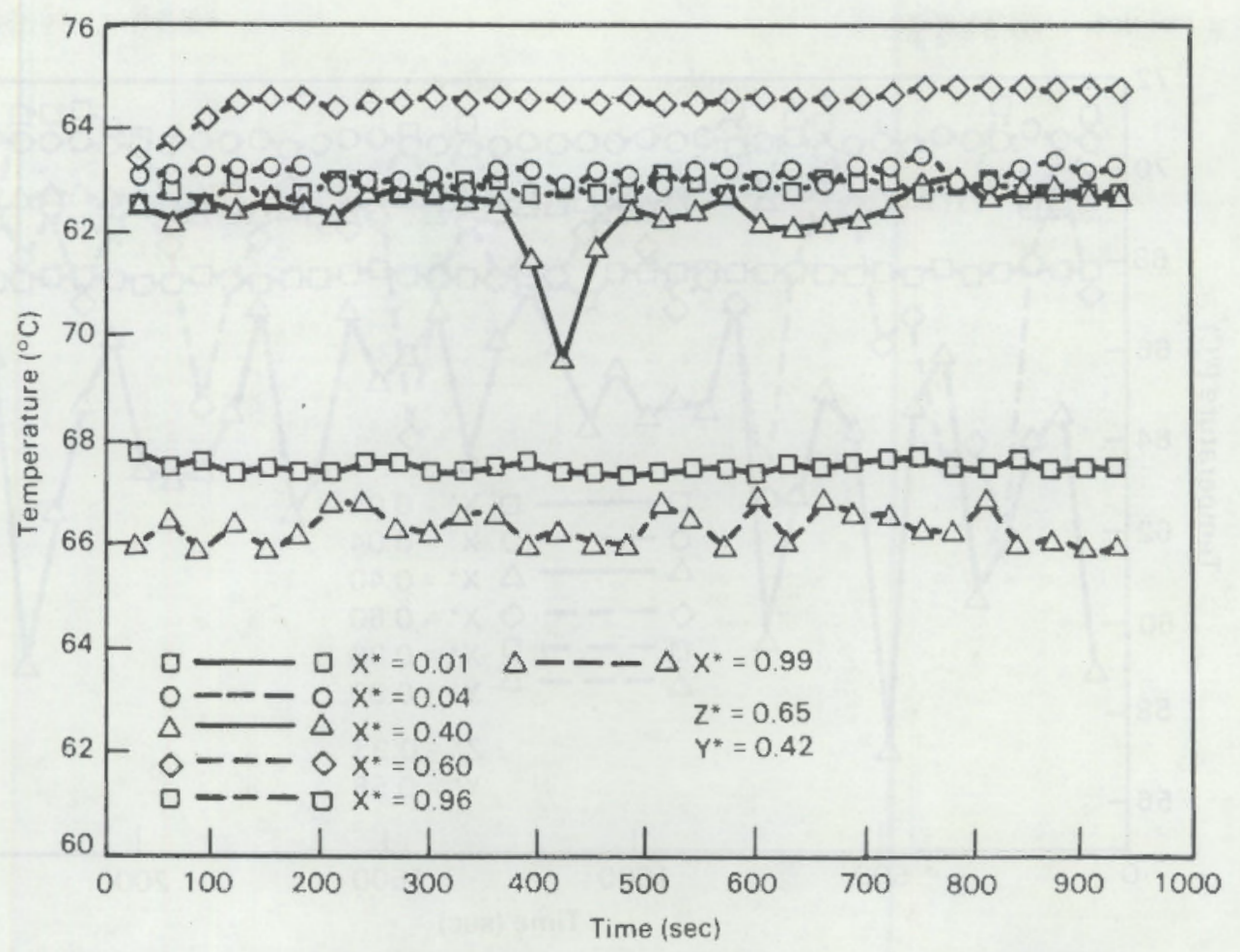

FIGURE 3.20. Fluid Temperature Time Series for BRUN-3

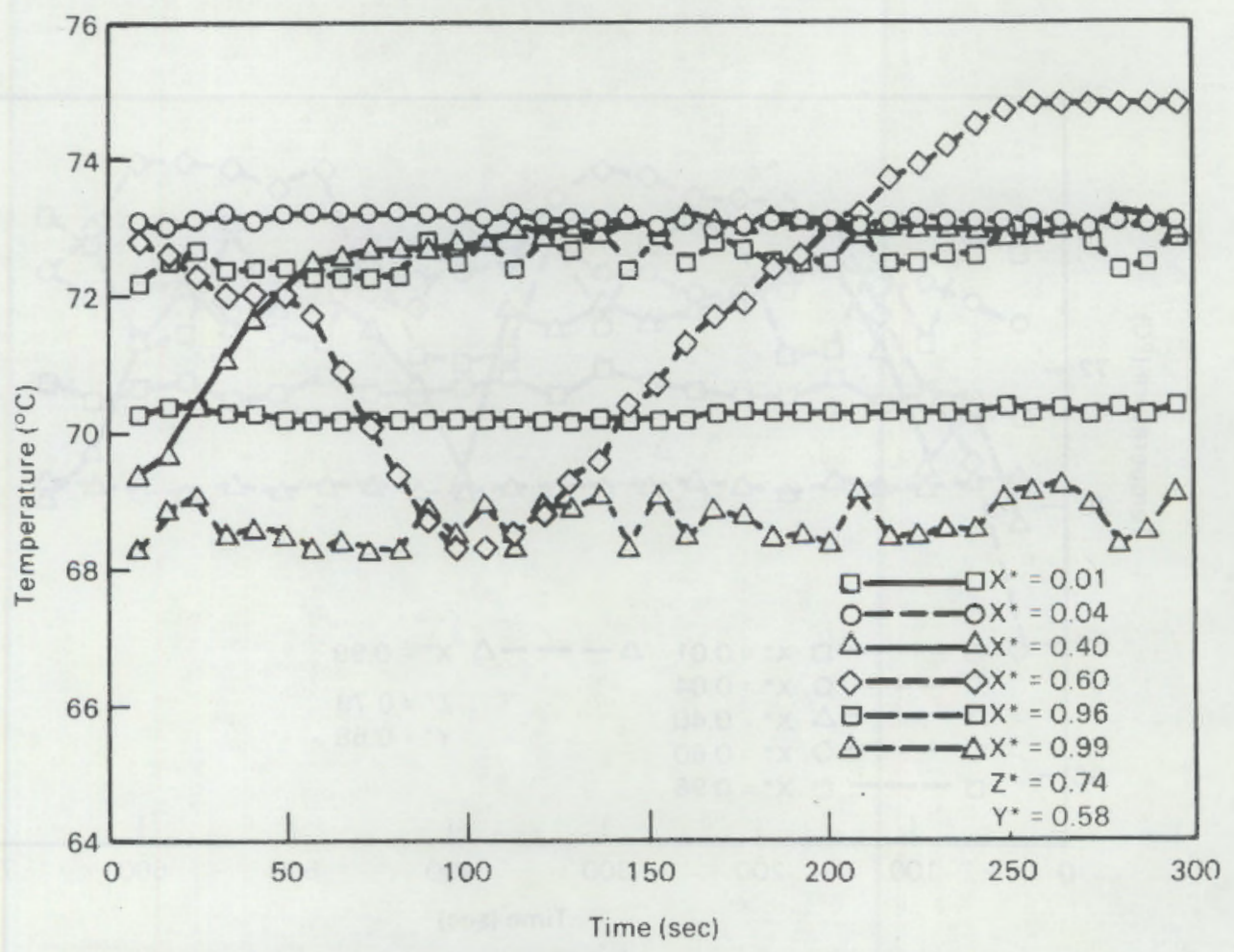

FIGURE 3.21. Fluid Temperature Time Series for BRUN-5 


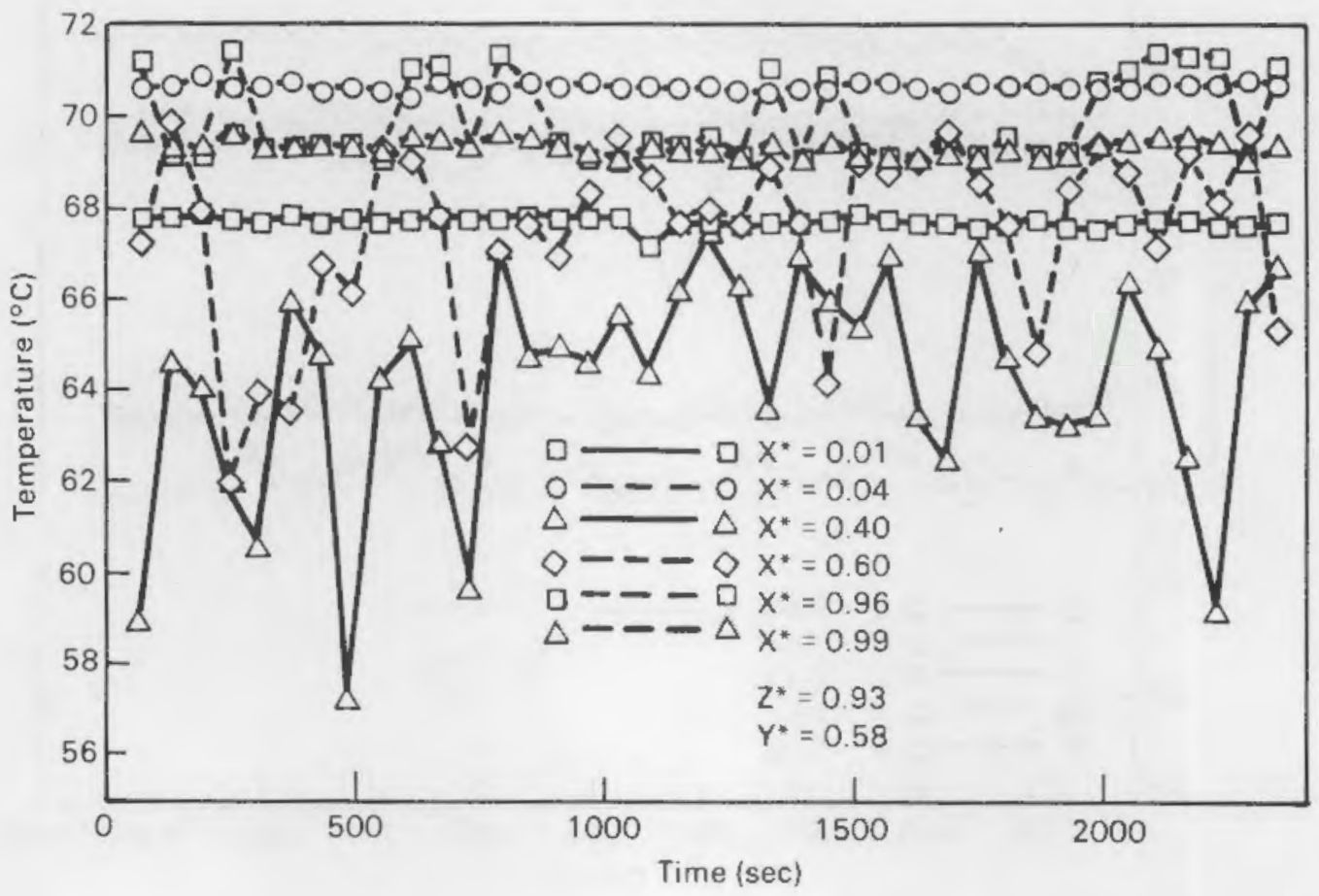

FIGURE 3.22. Fluid Temperature Time Series 1 for BRUN-9

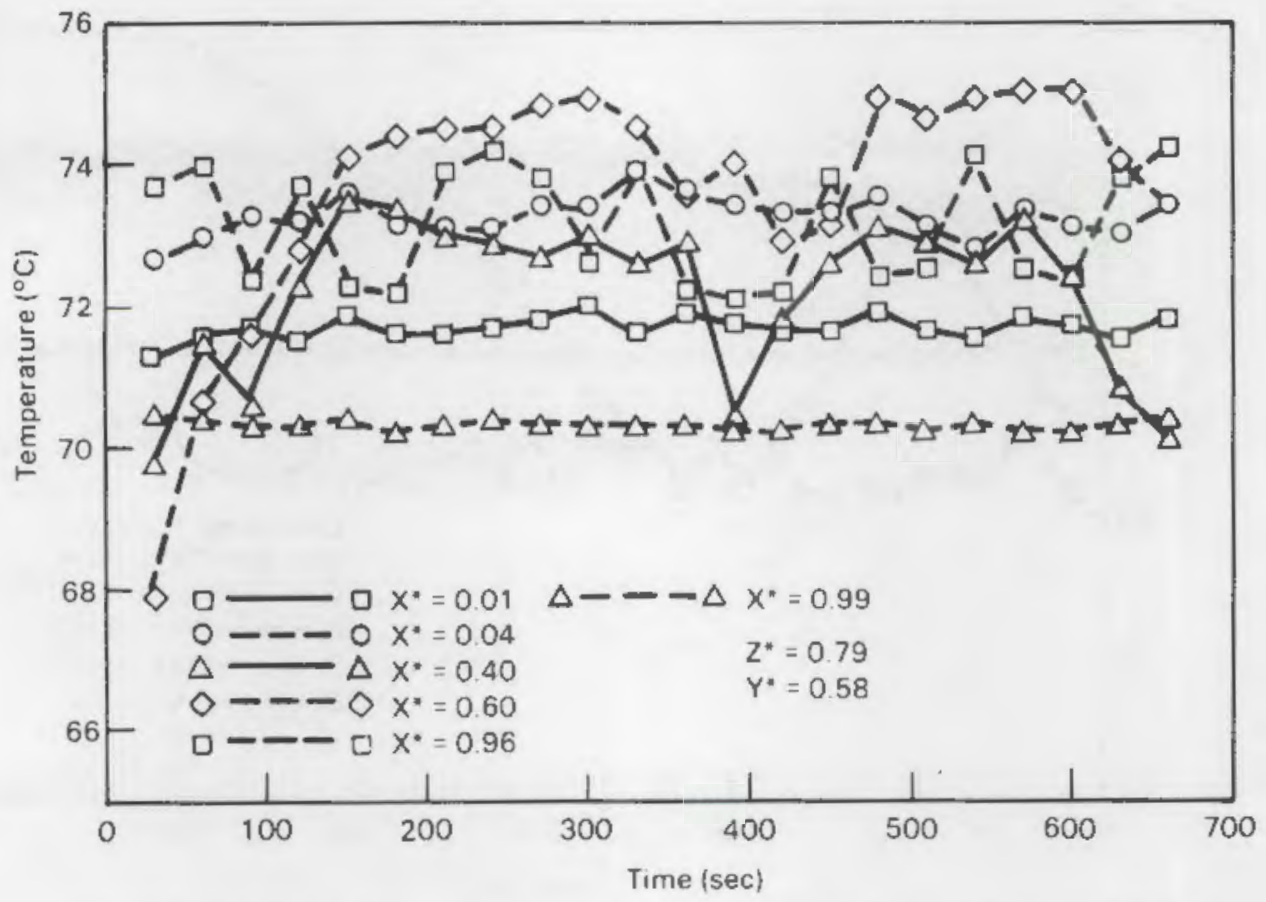

FIGURE 3.23. Fluid Temperature Time Series 2 for BRUN-9 


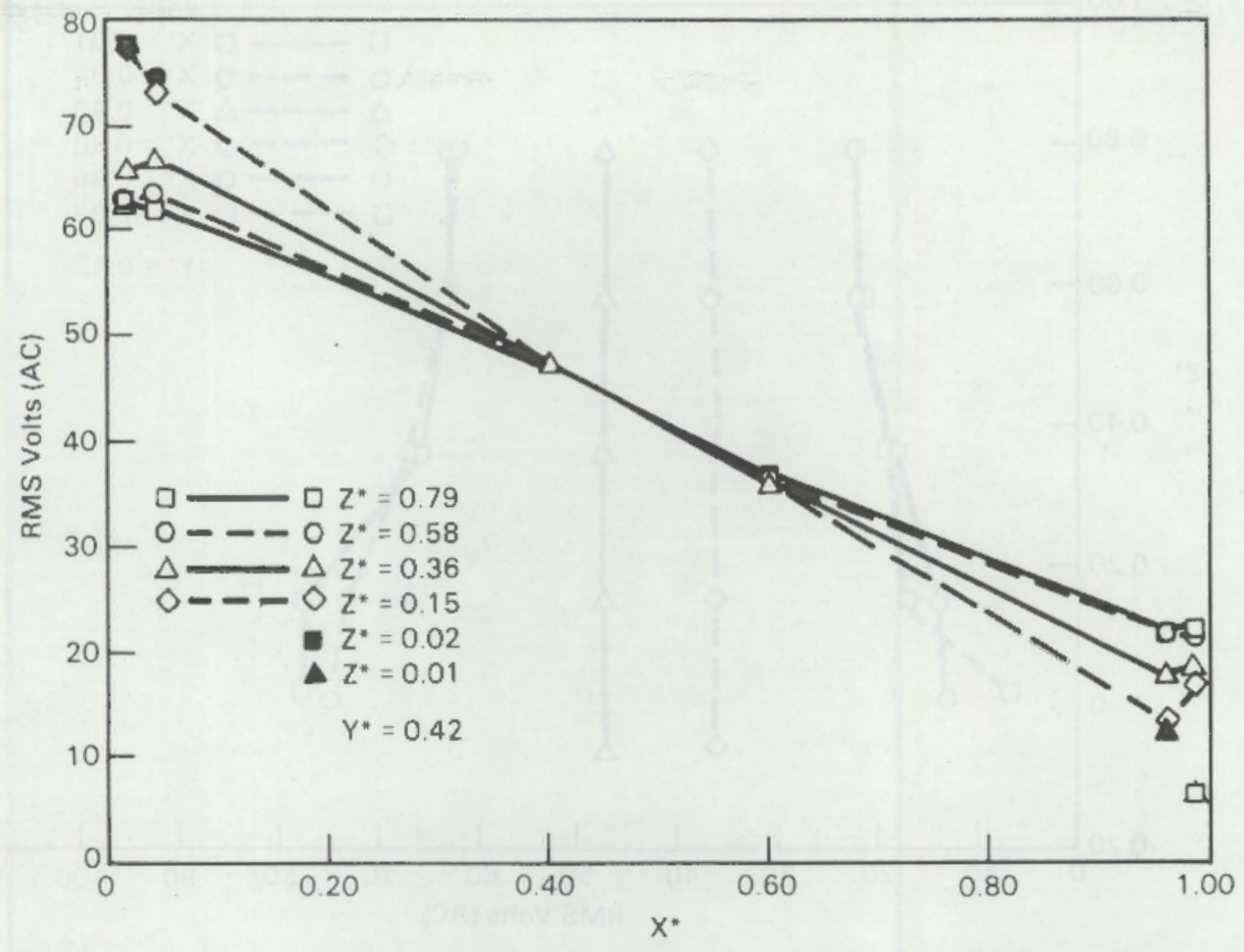

FIGURE 3.24. Horizontal Potential Profile Test for Run BRUN-3

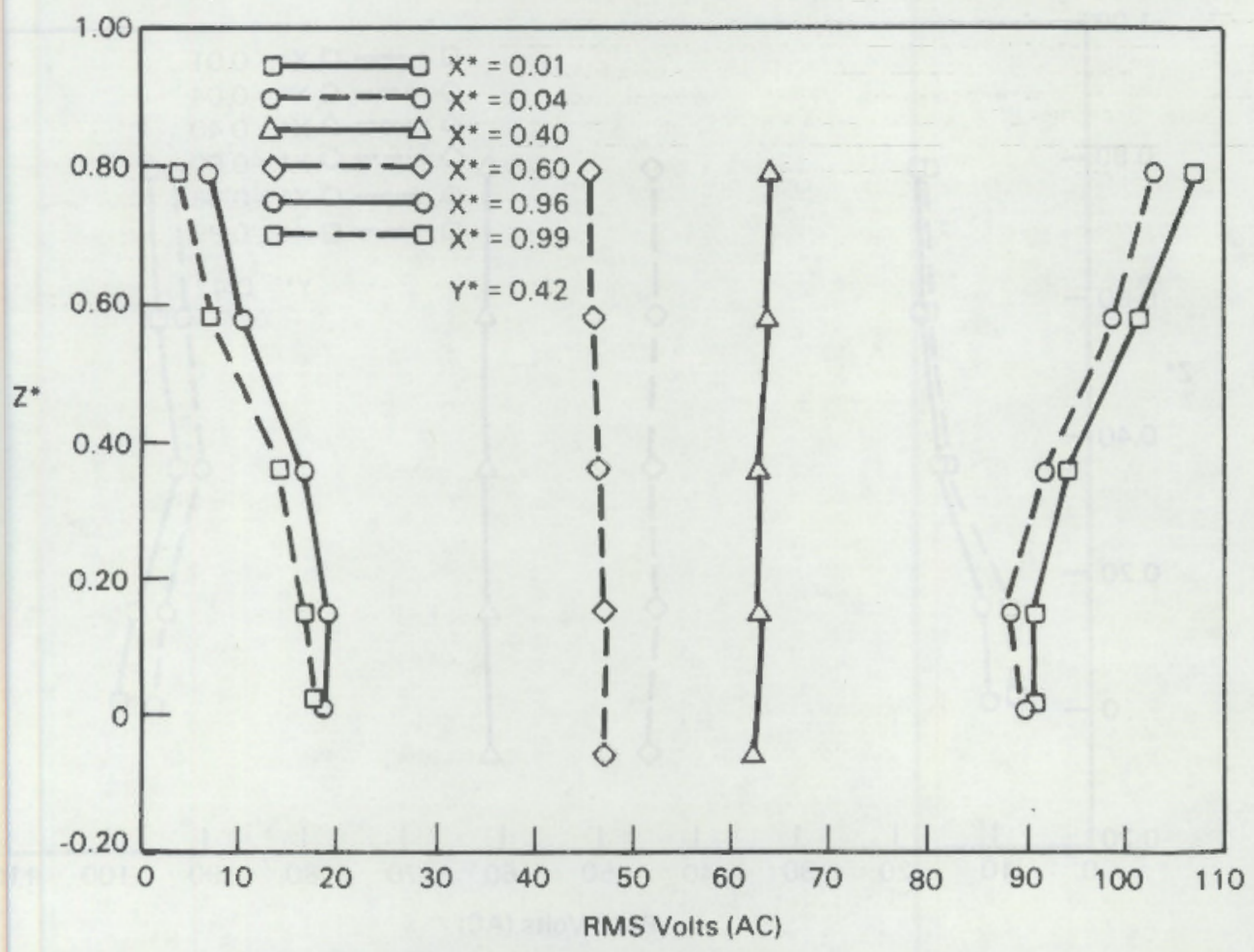

FIGURE 3.25. Vertical Potential Profile Test for Run BRUN-1 


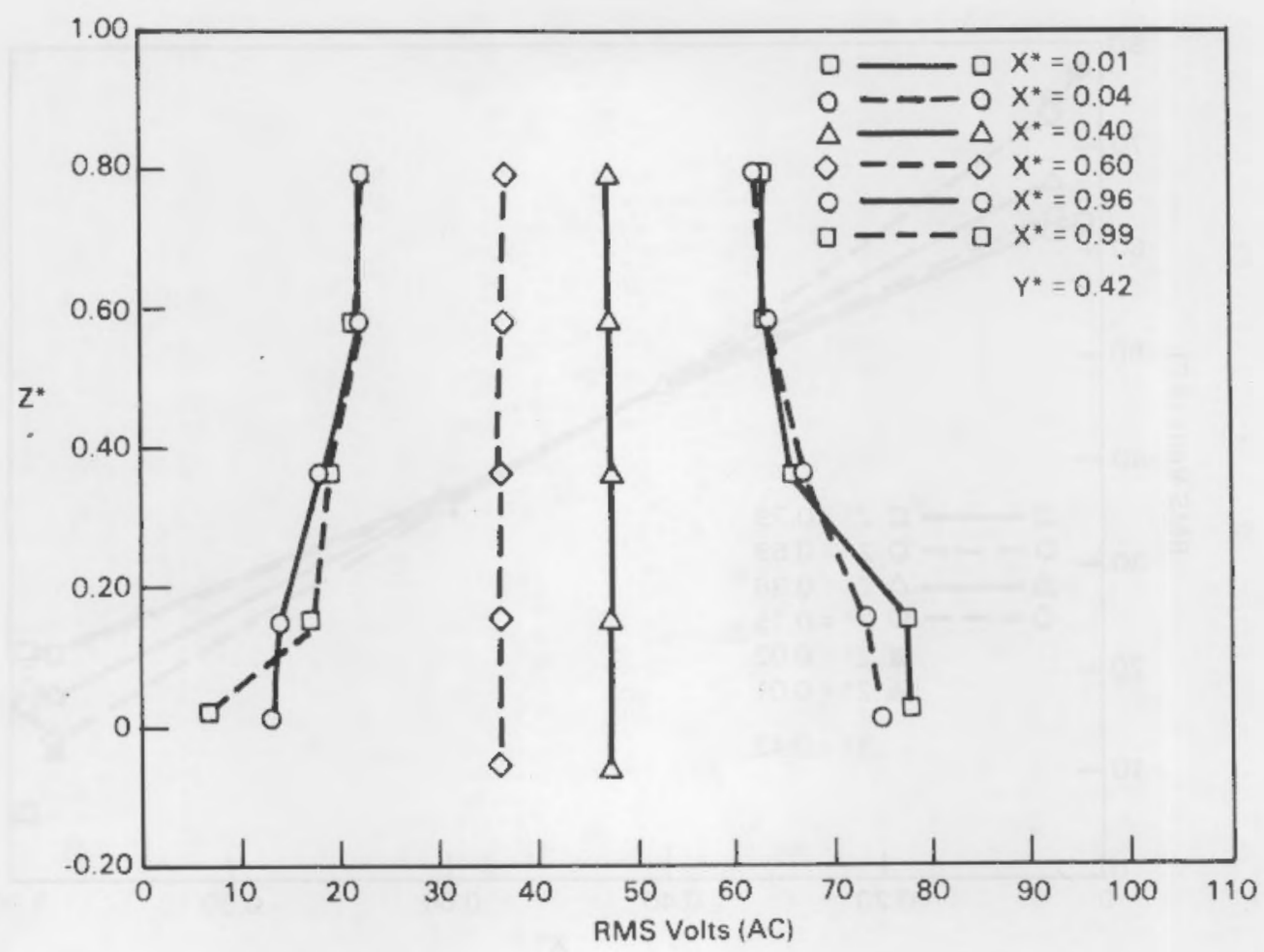

FIGURE 3.26. Vertical Potential Profile Test for Run BRUN-2

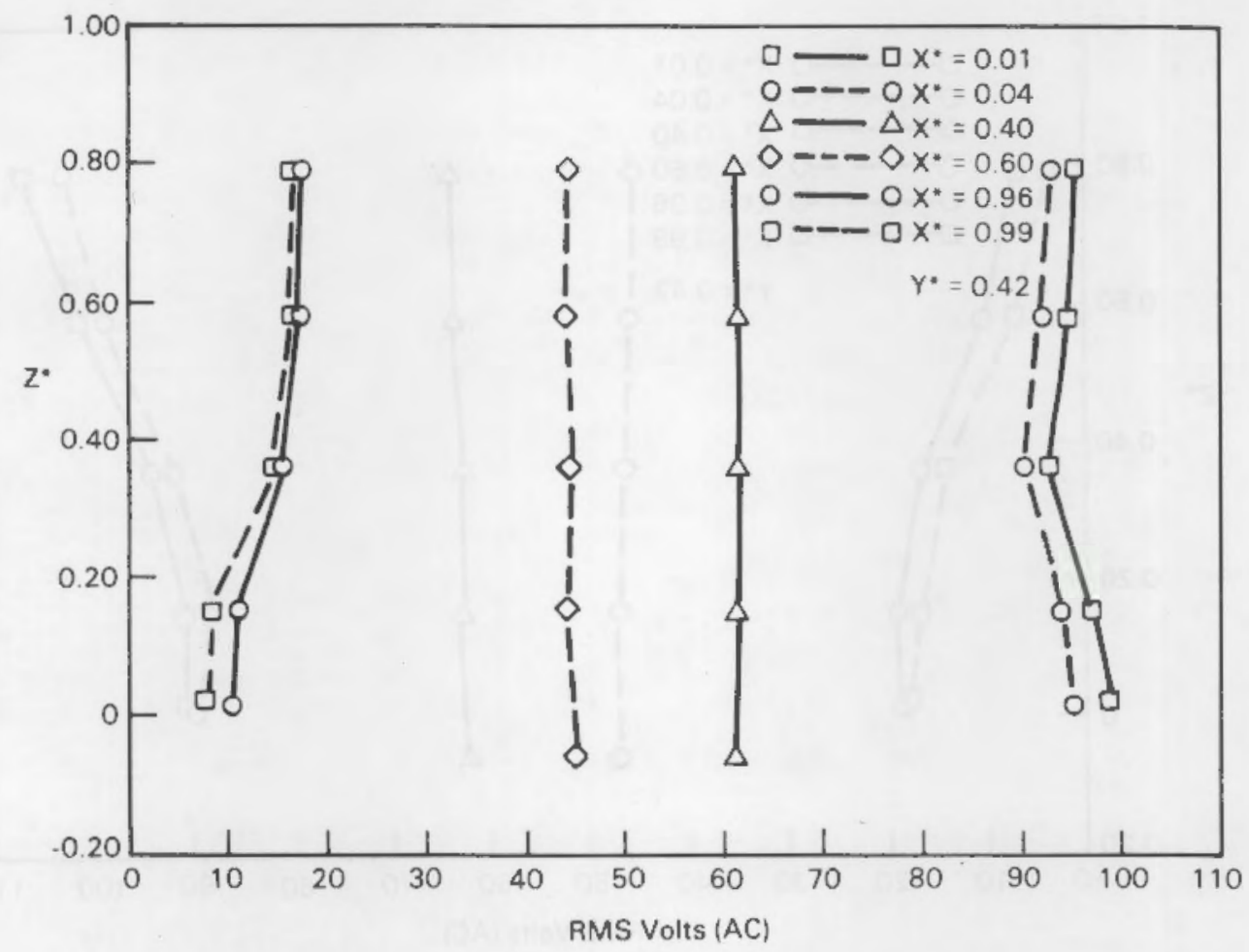

FIGURE 3.27. Vertical Potential Profile Test for Run BRUN-3 


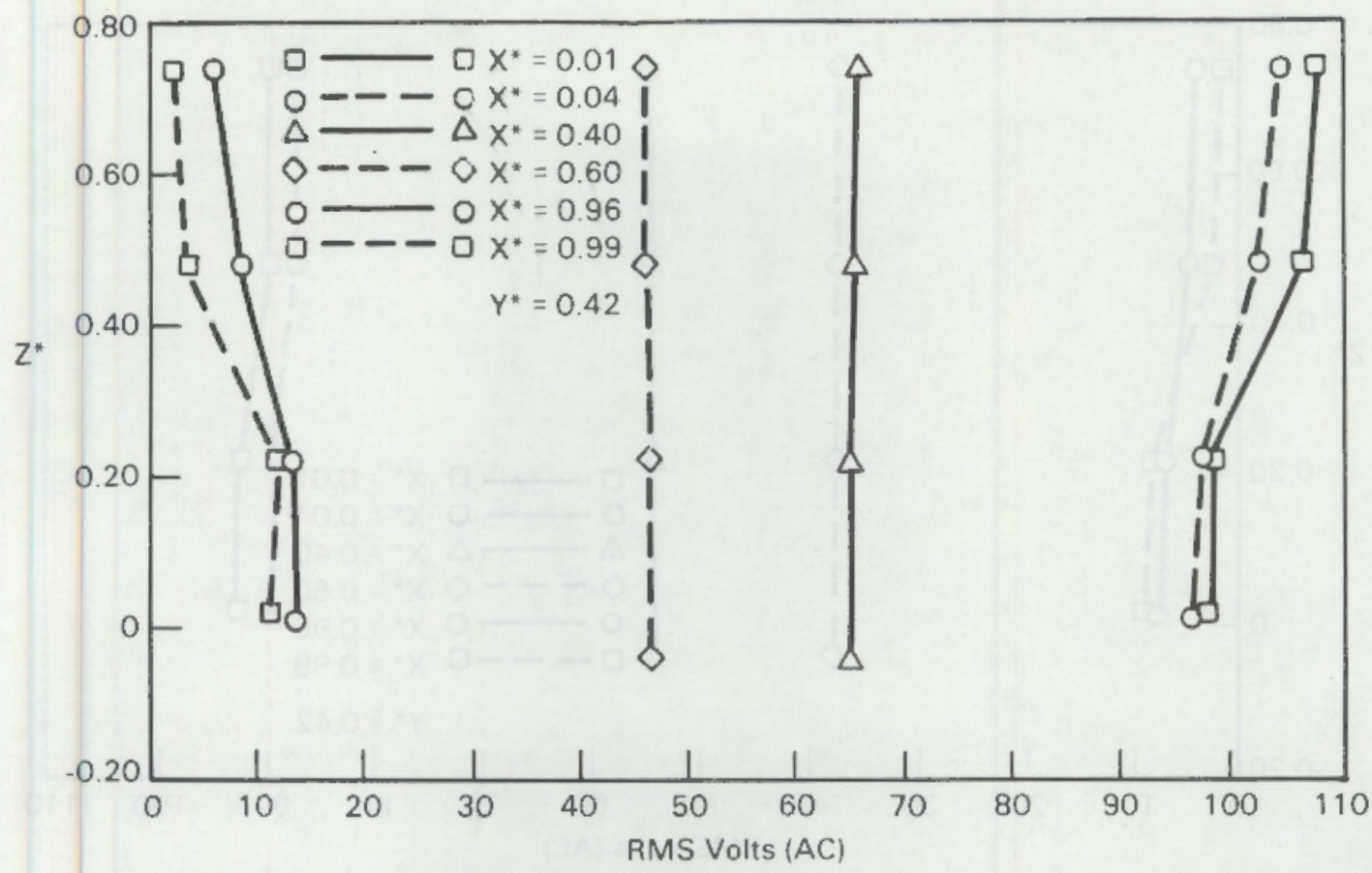

FIGURE 3.28. Vertical Potential Profile Test for Run BRIIN-4

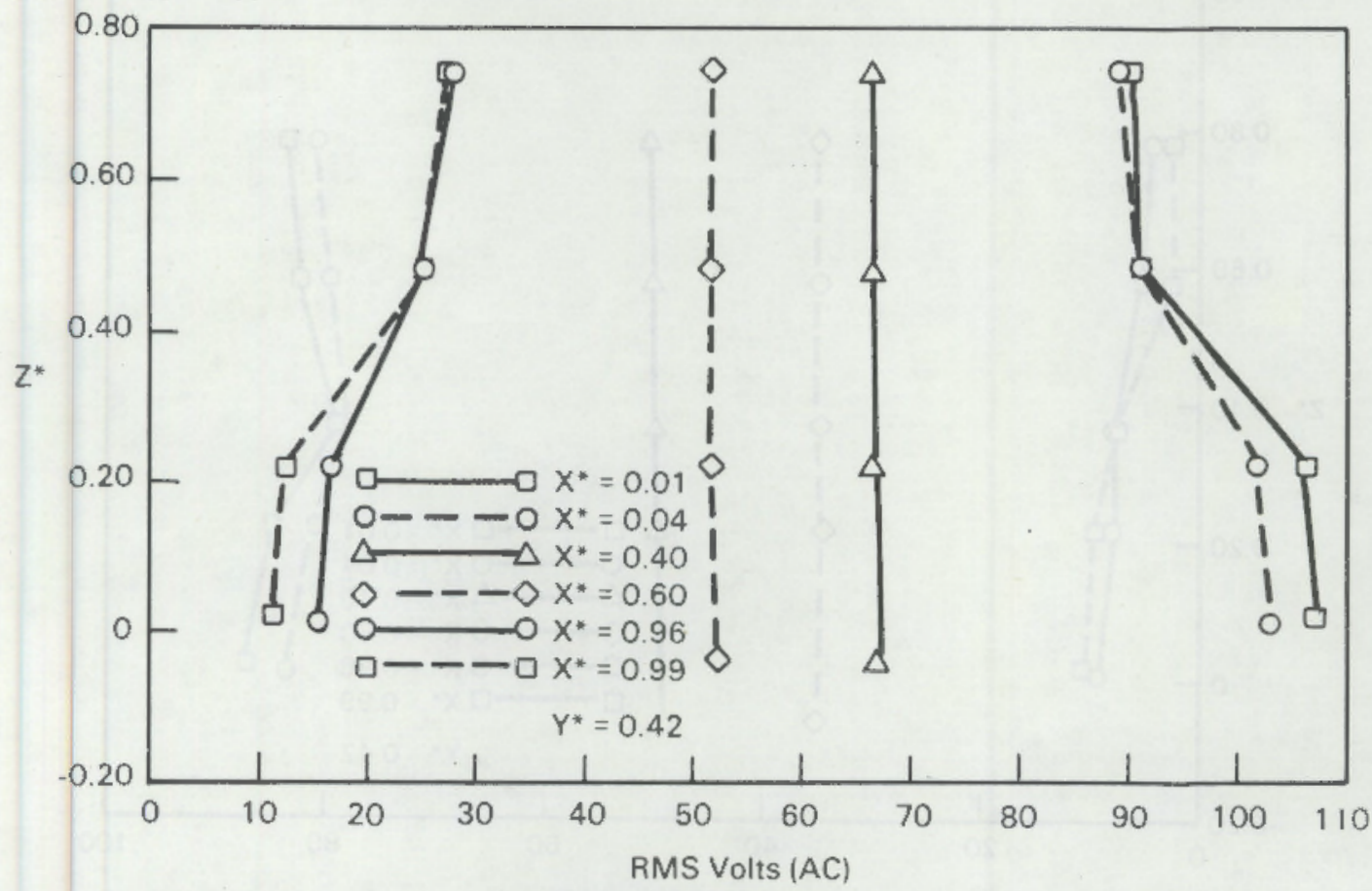

FIGIIRE 3.29. Vertical Potential Profile Test for Run BRIJN-5 


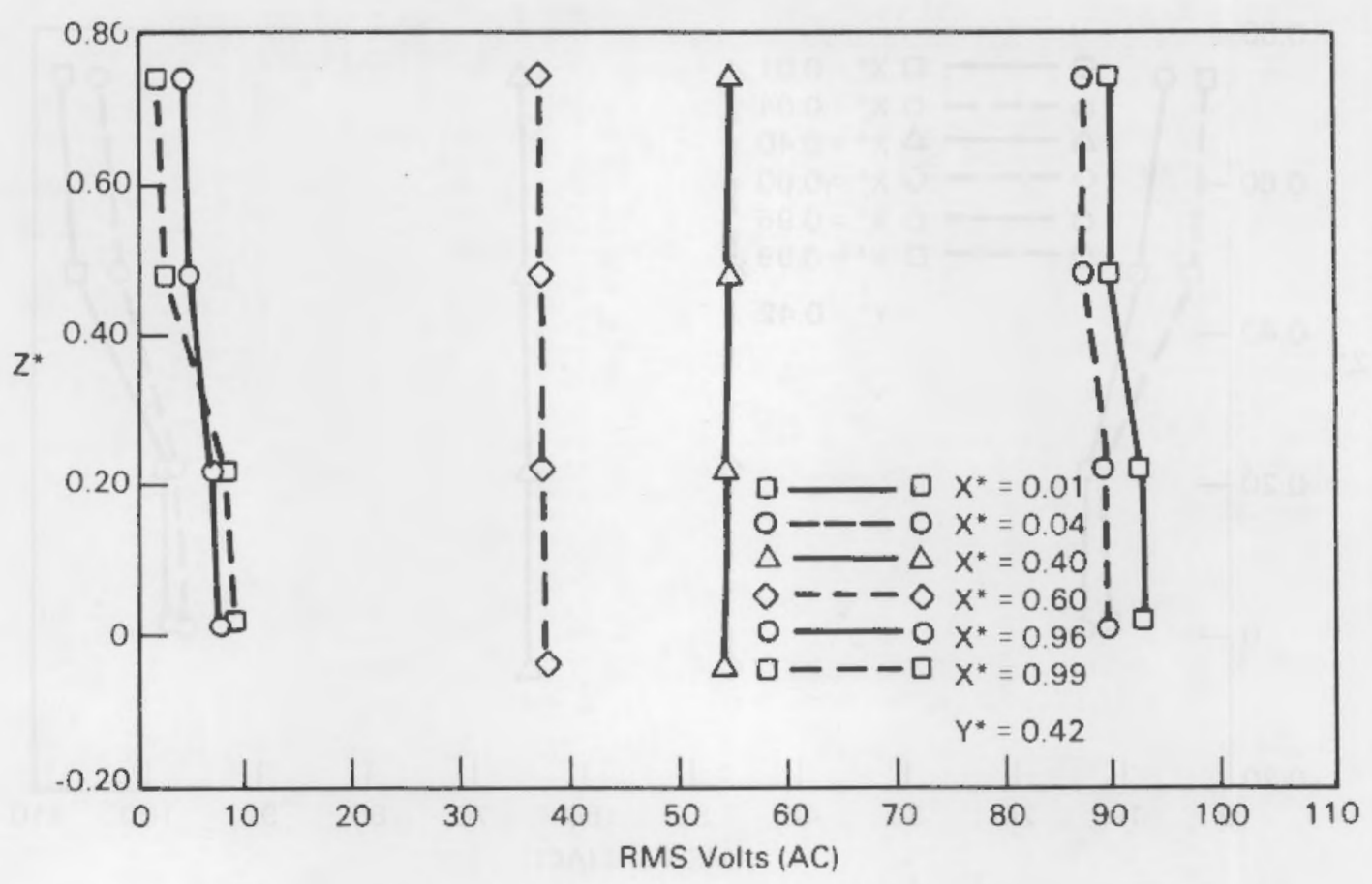

FIGURE 3.30. Vertical Potential Profile Test for Run BRUN-6

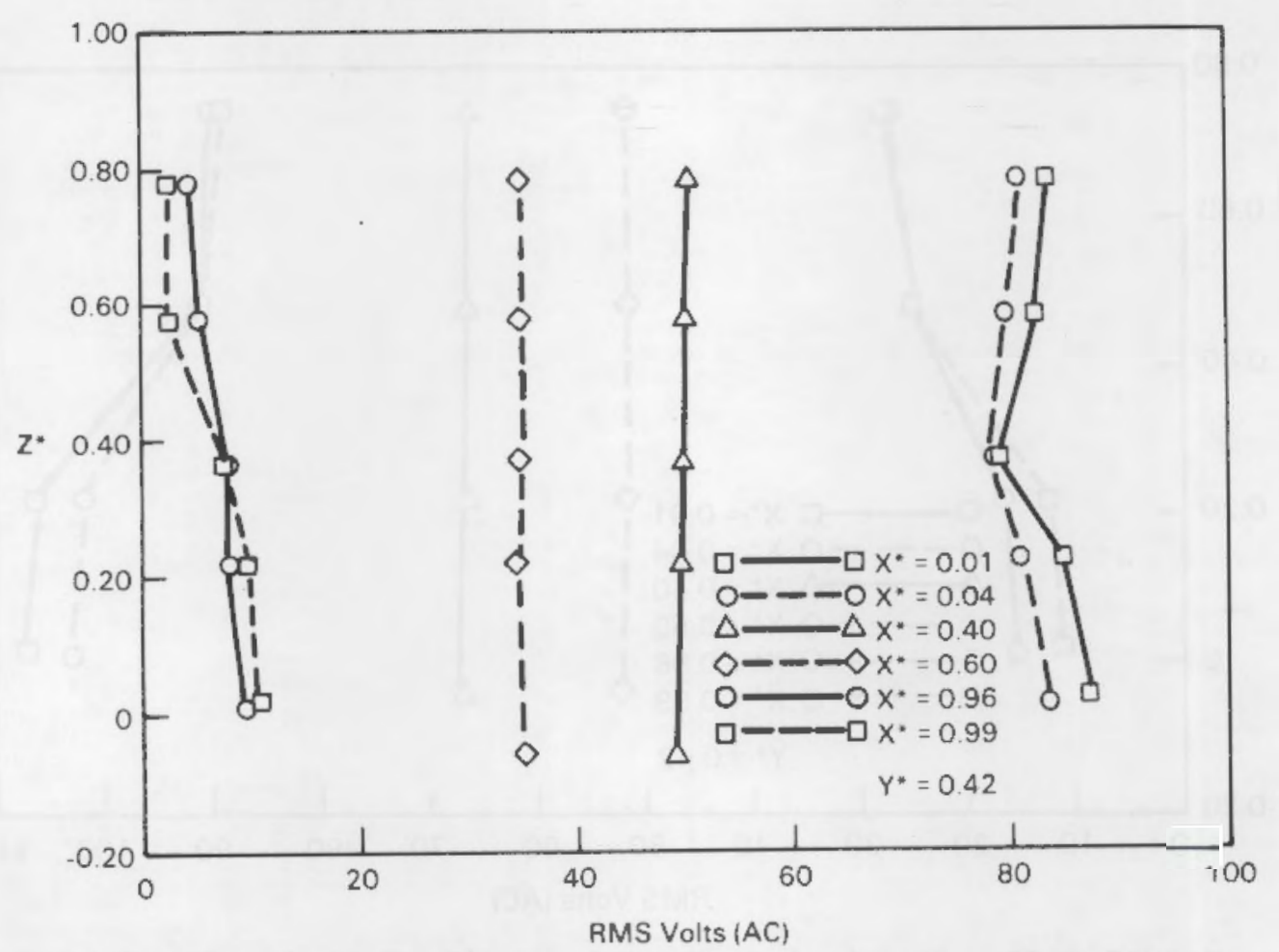

FIGURE 3.31. Vertical Potential Profile Test for Run BRUN-9 
The vertical potential profiles in Figures 3.25 through 3.31 indicate that the potential is essentially constant near the center of the melter. However, a potential gradient exists in the vertical direction in the regions near the electrodes. This potential difference establishes a current path between the upper and lower electrodes on a given side in addition to the current paths which are established between the upper electrode pair and the lower electrode pair. As a result, crossfiring occurs between the electrodes on a given side, which gives rise to additional heat generation in the fluid near the electrodes.

A simplified schematic of the model and possible current paths which illustrate this situation are shown in Figure 3.32. The two desired current paths which existed during model operation are represented by $S_{U}-11{ }_{1}-1 I_{n}$ and $S_{L}-L_{1}-L_{0}$. A third current path leading to electrode cross firing is represented by $S_{U}-U_{1}-L_{1}-S_{L}-L_{0}-L_{1}$. This latter path appears to allow a current path and, hence, localized Joule heating, which would correspond to local perturbations observed in the measured temperature field.

Figures 3.25 and 3.28 show that for an U/L EPR of 1.0:0.0, the upper electrode pair to which the power was supplied had the larger potential difference. Similarly, with an U/L EPR of 0.0:1.0, a larger potential difference existed between the lower electrode pair, as shown in Figures 3.26 and 3.29. In the case of the $U / L$ EPR of $0.5: 0.5$, as shown in Figure 3.26 , where the reference ground was taken as one of the lower electrode plates, the larger potential difference was between the lower electrodes. An U/L EPR of $0.5: 0.5$ was used for the runs shown in Figures 3.30 and 3.31 , but in these cases the reference ground was taken as the upper electrode plate. Because an rms voltmeter was used for making the potential measurements and because this type of rms voltmeter registers only the absolute value of an AC potential, it is postulated that choosing the lower electrode as the reference ground would have produced potential for these runs consistent with the plot shown in Figure 3.27 .

The difference in potentials between electrodes on a given side was much greater when power was applied to only one electrode pair than when power was 


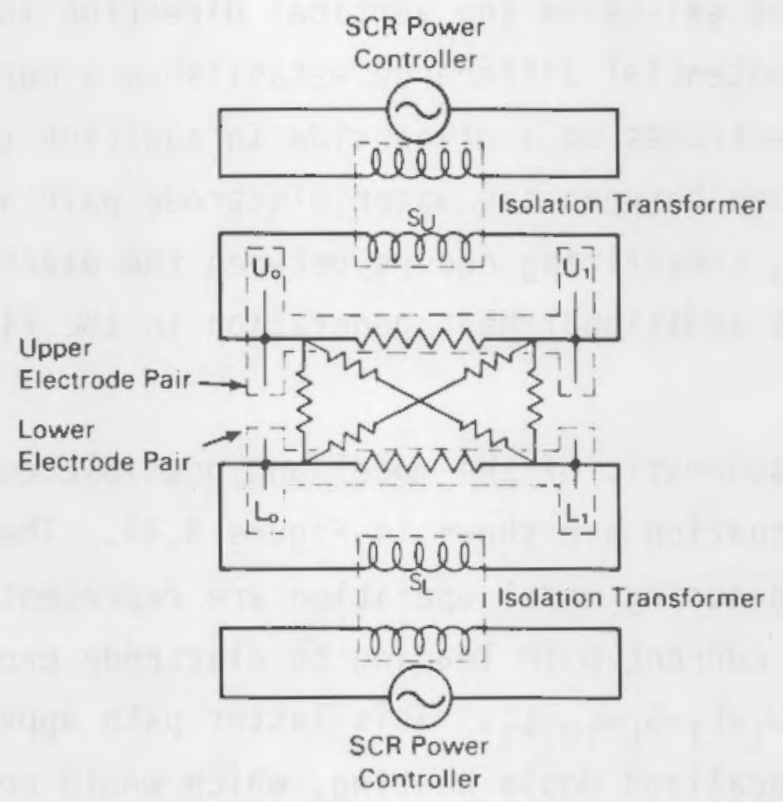

FIGURE 3.32. Schematic of SCR Power Supply Configuration

applied to both pairs of electrodes. Crossfiring between electrodes therefore occurred more readily with large power skews than when power was distributed more equally between the upper and lower electrode pairs. Increased crossfiring results in more localized heating near the electrodes, whereas decreased crossfiring promotes a more uniform heat generation throughout the entire fluid volume.

\subsection{ELECTRODE POWER SUPPLY SIGNAL ANALYSIS}

The voltage signals of the upper and lower electrode pair were investigated to characterize the interaction between the electrode pairs, provide peak voltages for numerical modeling input, and evaluate voltage wave shape. Appropriate modeling of the voltage signals of the upper and 1 ower electrode pair is necessary to accurately predict the fluid/glass electric field and subsequent power density of the fluid. In this section, firing 
characteristics of the power supply are reviewed, results from the dual electrode investigation are presented, and a comparison of the calculated rms voltages based on the signal wave shape and measured rms voltages is provided.

Power is supplied to the modeling fluid by two independently controlled (SCR) power controllers which are phase-angle fired. A typical time-dependent voltage wave shape for a single SCR is shown in Figure 3.33. At full power, the wave shape is a full AC voltage sinusoidal shape. Average power and root mean square voltage, $V_{r m s}$, are decreased by "chopping" the SCR input voltage signal. That is, the SCR can allow current to flow at any starting time during the line voltage half cycle. For the voltage wave shape in Figure $3.33, V_{\text {rms }}$ is determined as

$$
v_{r m s}=v_{p}\left[\frac{1}{2}-\frac{t_{a}}{T}+\frac{\sin \left(2 \omega t_{a}\right)}{2 \pi}\right]^{1 / 2}
$$

Given that the wave shape is sinusoidal, the peak voltage, $v_{p}$, can be determined from Equation 3.1 using known or measured values of the firing time and rms voltage, or from the relation

$$
v_{p}=v\left(t_{a}\right) / \sin \left(\omega t_{a}\right)
$$

and using an oscilloscope to determine $t_{a}$ and $v\left(t_{a}\right)$. 


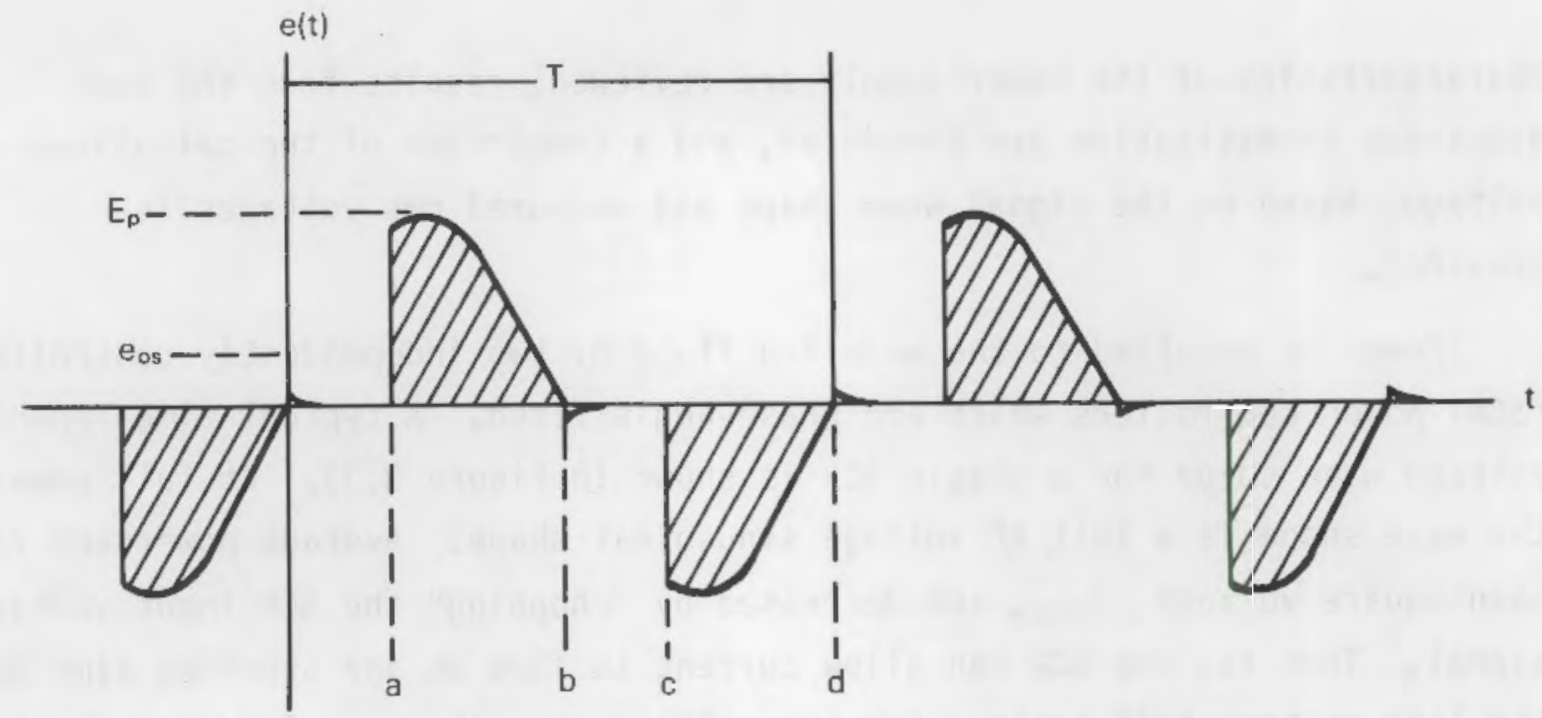

$$
\begin{aligned}
E & =\text { potential (voltage) } & T & =\text { period } \Rightarrow 1 / f=0.01667 \text { second } \\
V_{p} & =\text { peak voltage } & \omega & =\text { angular frequency }\left(\mathrm{S}^{-1}\right) \\
t & =\text { time } & & =\frac{2 \pi}{T}=2 \pi f \\
f & =\text { frequency } \Rightarrow 20 \mathrm{~Hz} & & =377\left(\mathrm{~S}^{-1}\right)
\end{aligned}
$$

\section{FIGURE 3.33. SCR Power Supply Voltage Signal (Phase-Angle Fired)}

However, Equation 3.1 is inadequate to calculate the rms voltage for an electrode pair that is subjected to both an induced and applied voltage as shown in Figure 3.34. The induced voltage occurs from the applied voltage across the other electrode pair, which initiated firing at $t_{j}$. At $t_{a}$, voltage is applied across the electrode from its own power supply. If both the induced portion and applied portion of the voltage signal are assumed to be sinusoidal, the rms voltage can be expressed as

$$
v_{\text {rms }}=\frac{2}{T}\left[v_{p_{i}}^{2} \int_{t_{i}}^{t_{a}} \sin ^{2}(\omega t) d t+v_{p_{a}}^{2} \int_{a}^{T / 2} \sin ^{2}(\omega t) d t\right]^{1 / 2}
$$

Evaluating Equation 3.3 results in 


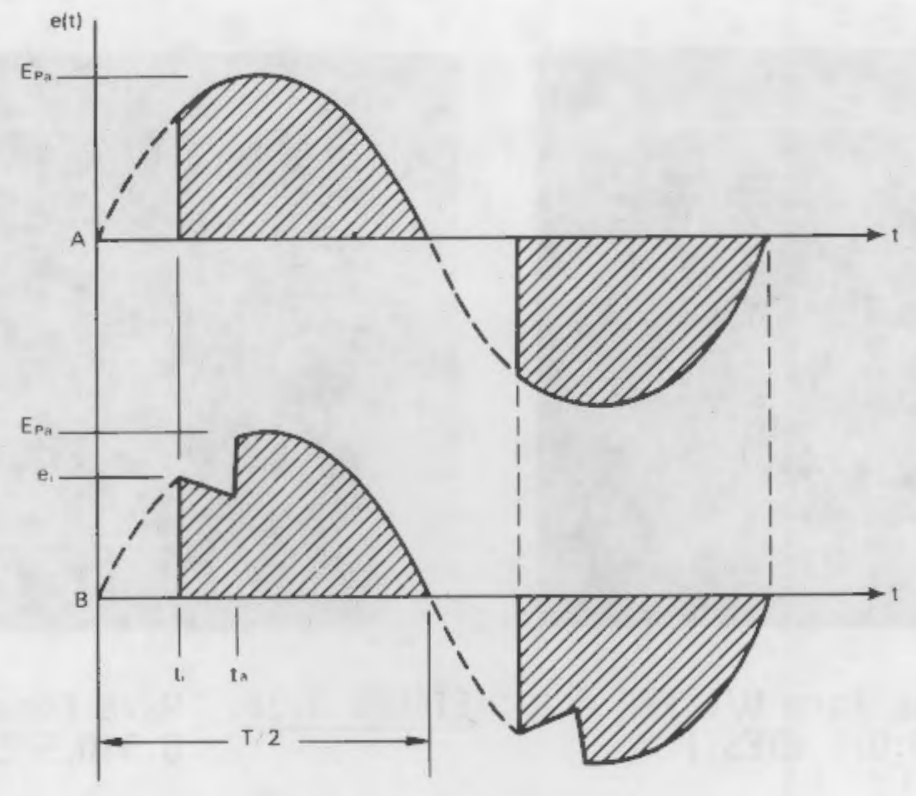

$$
\begin{aligned}
\mathrm{v}_{\mathrm{p}_{\mathrm{a}}} & =\text { peak-applied vol tage } \\
\mathrm{v}_{\mathrm{p}_{\mathbf{j}}} & =\text { peak-induced voltage } \\
\mathrm{t}_{\mathbf{i}} & =\text { time-induced voltage initiated } \\
\mathrm{t}_{\mathbf{a}} & =\text { time-applied voltage initiated } \\
T / 2 & =1 / 2 \text { period }=(30)^{-1} \mathrm{~s} \\
\omega & =377 \mathrm{r} / \mathrm{s}
\end{aligned}
$$

FIGURE 3.34. Applied and Induced Voltage Signals from Dual Electrode System

$v_{\text {rms }}=V_{P_{a}}\left[1 / 2-t_{a} / T+\frac{\sin \left(2 \omega t_{a}\right)}{4 \pi}\right]^{1 / 2}+V_{P_{i}}\left[\frac{t_{a}-t_{i}}{T}+\frac{\sin \left(2 \omega t_{j}\right)}{4 \pi}-\frac{\sin \left(2 \omega t_{a}\right)}{4 \pi}\right]^{1 / 2}$

Because both induced and applied voltages were assumed sinusoidal, $V_{p a}$ and $V_{p i}$ can be determined from Equation 3.2. Values of $v\left(t_{a}\right), v\left(t_{j}\right), t_{a}$, and $t_{j}$ must still be known.

Electrode pair voltage signals from four tests designated as ETEST1 through ETEST4 are shown in Figures 3.35 through 3.38. These figures are photographs of the time-dependent voltage wave forms from the upper and lower 


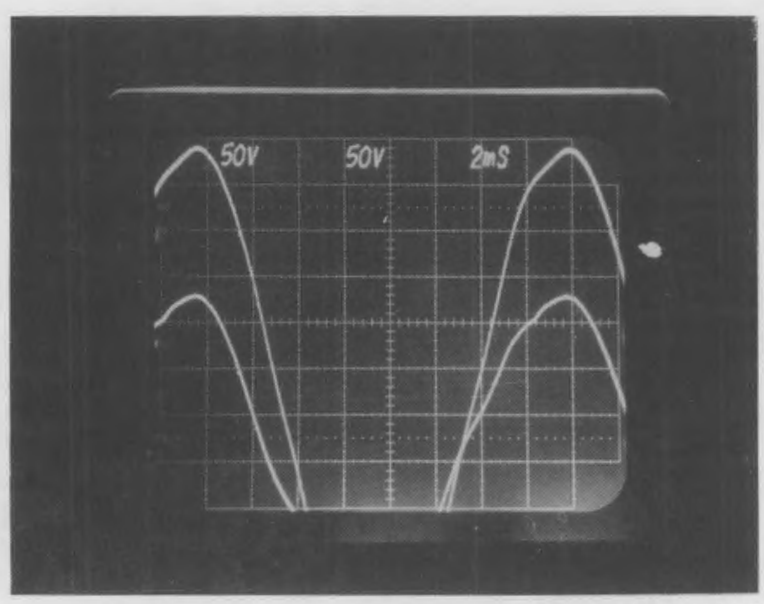

FIGURE 3.30. Wave Form U/L EPR $=$ 1.0:0.0 ETEST1

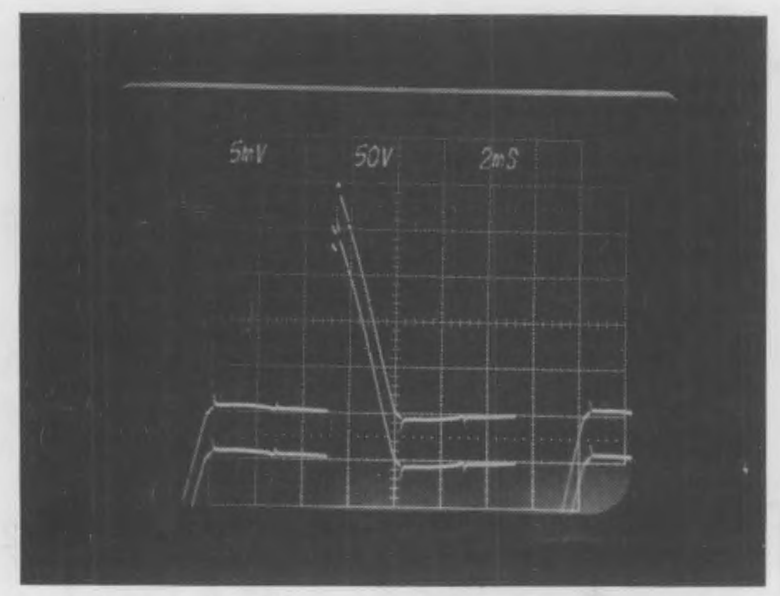

FIGURE 3.37. Wave Form U/L EPR = $0.5: 0.5$ ETEST3

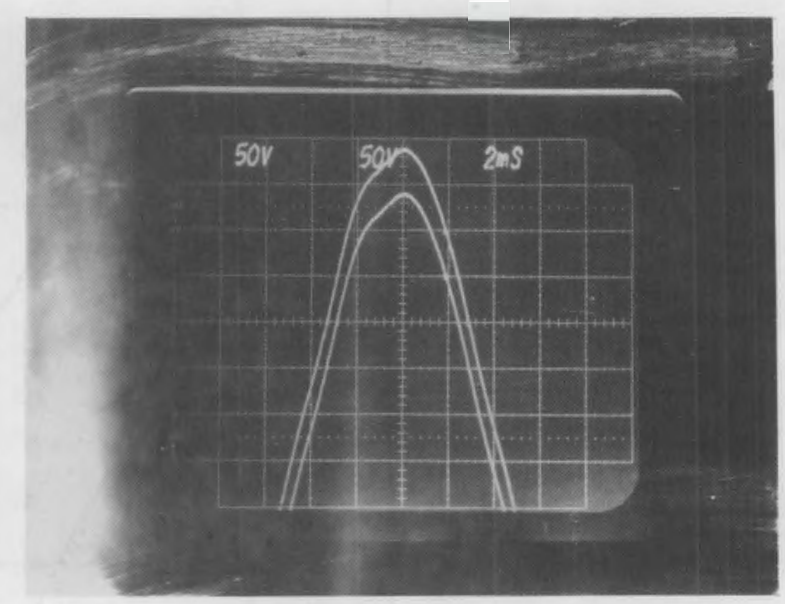

FIGURE 3.36. Wave Form U/L EPR = 0.5:0.5 ETEST2

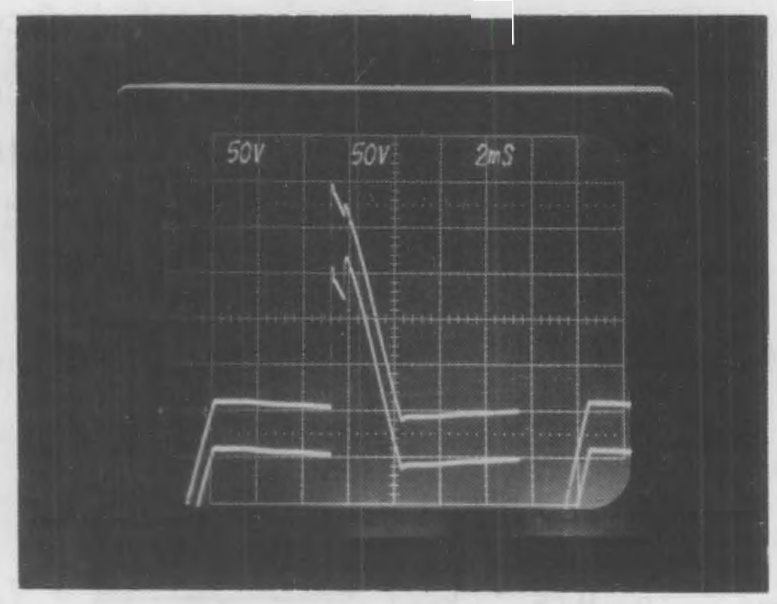

FIGURE 3.38. Wave Form U/L EPR $=$ $0.75: 0.25$ ETEST4 
electrode pairs. Peak voltages and firing times were measured from these photographs and used to characterize the upper/lower electrode pair interaction. Two of the tests, ETEST3 and ETEST4, were performed to investigate signal interaction at intermediate SCR power levels which were at typical model operating conditions. ETEST2 was intended to investigate voltage wave shape interaction when both SCRS were at full power, while ETEST1 was made with maximum power supplied by one SCR and no power supplied using the other SCR. Peak voltages, firing times, measured rms voltages, calculated rms voltages, and the error between measured and calculated ms voltages for the ETEST series are tabulated in Table 3.5 .

Voltage signals in the photographs are given as 50 volts/division along the vertical axis. Time is given as $2 \mathrm{~ms} /$ division along the horizontal axis. The reference or zero-volt axes are the first and second divisions up from the bottom line for the lower and upper electrode pair, respectively.

In ETEST1, a voltage was applied across the upper electrode pair at full SCR power, while no power was supplied to the lower electrode pair. An induced voltage across the lower electrodes, which is in phase with the applied voltage across the upper electrodes, is observed in Figure 3.35. From Table 3.5, the measured-to-calculated $V_{\text {rms }}$ errors $\left(\varepsilon_{V} s\right)$ were $0.79 \%$ and $2.5 \%$ for the upper and lower electrodes, respectively. These small errors suggest that the voltage signals can adequately be described as sine functions. Some distortion in applied signal is seen near the peak voltage. This distortion is probably the result of imperfect isolation transforms as well as SCR noise. Nonuniform fluid resistances in addition to transformer signal distortion and SCR noise are believed to be responsible for the additional "waviness" observed in the induced voltage signal. The larger $2.5 \%$ of the lower electrode pair may be due to the additional degradation of the induced voltage signal. 
TABLE 3.5. Summary of Upper \& Lower Electrode Pair Voltage Signal Measurements

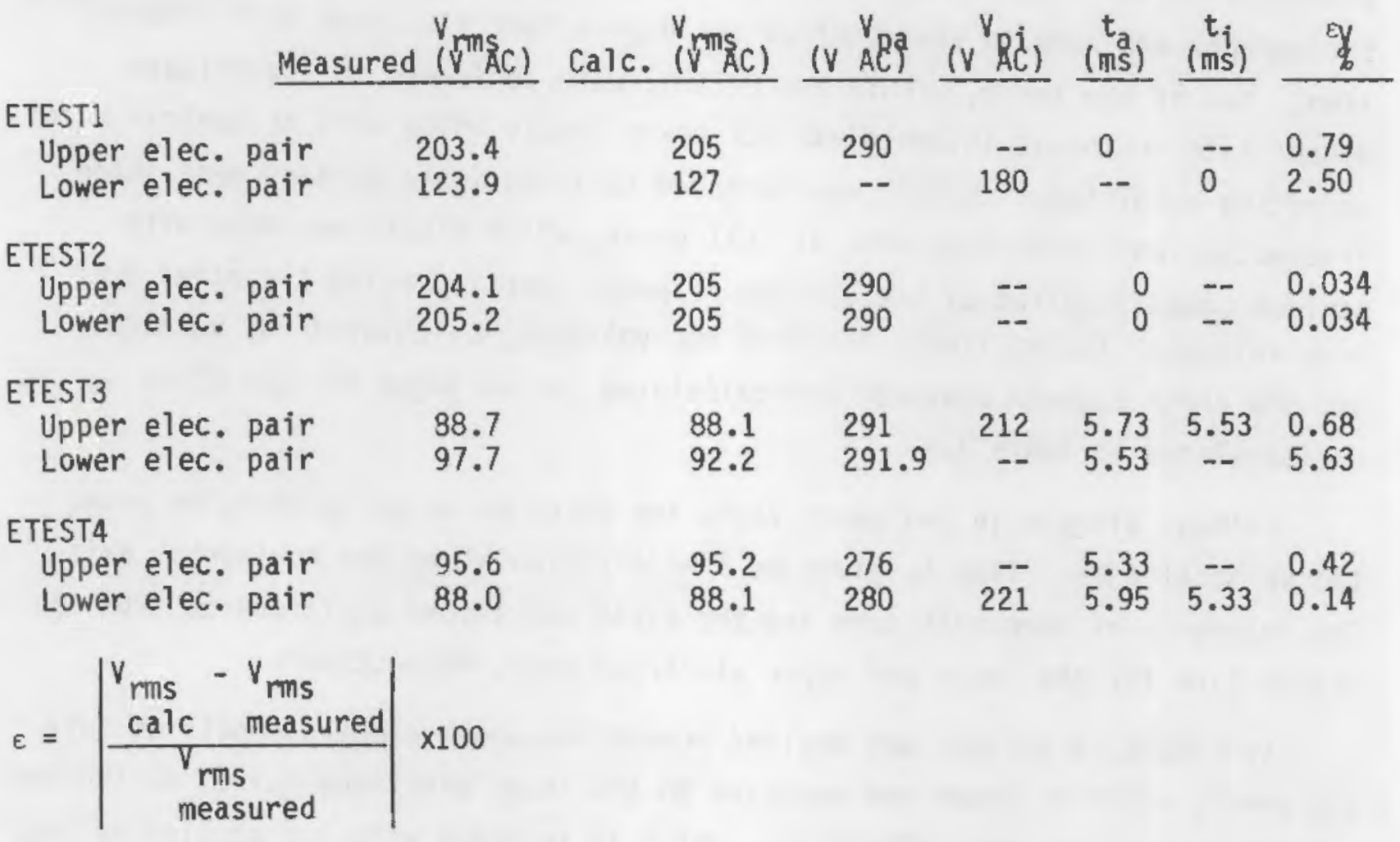

Subscripts

rims $=$ root mean square

$p=$ peak

$\mathrm{a}=$ applied

$i=$ induced

For ETEST2, an applied vol tage was supplied at full SCR power to each electrode pair. Peak voltages for both electrode pairs were measured at $290 \mathrm{~V}$ AC. A $0.5 \%$ variation occurred between calculated and measured ms voltages as given in Table 3.5. Two independent true rms voltage meters were used to measure the voltage applied across each electrode pair, which accounts for the slight variation in measured $V_{\text {rms }}$ values across each pair. Line ms voltage was measured at $204.2 \mathrm{VAC}$, which confirms proper operation of the SCR power controller. That is, the SCR voltage signal is identical to the line voltage at full power. It is also illustrated in Figure 3.36 that the applied voltage signal of one electrode pair does not distort the applied voltage signal of the other electrode pair in this mode. As in ETEST1, some distortion of signal is observed near the peak voltage. 
Tests ETEST3 and ETEST4 were performed as part of test runs BRUN-7 and BRUN-8, respectively, which are runs typical of model operating power and conditions. The lower electrode power supply is believed to fire earlier than the upper electrode power supply in ETEST3. However, overlapping of the upper and lower voltage signals in Figure 3.37 makes it difficult to determine for sure. The larger $v_{\text {mms }}$ of the lower electrode pair supports the earlier conclusion. In ETEST4, the upper electrode power supply fires prior to the lower electrode power supply. The electrode pair which fired first in Figures 3.37 and 3.38 show, at most, slight discontinuity when the second electrode pair fires. The rms voltages calculated using Equation 3.4 are in good agreement with measured values in Table 3.5 .

Two characteristic peaks are observed in the voltage signal of the latter firing electrode pair. The first peak appears to be an induced voltage resulting from the applied voltage across the first electrode pair. A second peak occurs when the electrode's own power supply initiates firing as illustrated in Figure 3.34. Both the induced voltage and applied voltage signal were assumed to be of sinusoidal shape. Equation 3.3 was used to calculate the rms voltage of the electrode pair experiencing both an induced and applied voltage signal. The rms voltages were calculated from Equation 3.1 for the electrode pair with only an applied voltage signal. The maximum error in measured and calculated rms voltages from Equation 3.4 was $0.68 \%$ while $5.6 \%$ maximum error occurred between calculated and measured rms voltages for the electrode pair which initiated firing in the half cycle.

Additional observations show a slight overshoot, to a maximum of $10 \mathrm{~V} \mathrm{AC}$ at the end of each half cycle. The peak voltage of ETEST4 was approximately $5 \%$ lower than the peak voltages of the other three tests. This is believed to be the result of testing during a high electrical power demand time (late afternoon) during which the line voltage was actually pulled down or reduced. Some argument might be made from Figure 3.37 that firing of the second electrode pair during a half cycle might contribute to the voltage signal and increase the rims voltage of the first electrode. However, comparison of Figures 3.35 and 3.36 clearly show that an induced voltage across an electrode pair to full applied power across the same electrode pair had no measurable effect on the 
applied voltage signal of the other electrode pair. Results from these tests suggest that:

- applied voltage of one electrode pair is not measurably effected by the firing of another electrode pair

- during a time that a voltage is applied across one electrode pair and not the other, an induced voltage occurs across the latter

- both induced and applied voltage signals can be approximated as sinusoidal waves

- both upper and lower voltage signals are in phase.

\subsection{COMMON GROUNDED ELECTRODE EXPERIMENTAL RESULTS}

The test plan for this work included obtaining flow visualization data from which velocity and flow direction data were to be obtained. The two test runs performed to acquire this data were BRUN-7 and BRUN-8. These tests used U/L EPRs of 0.5:0.5 and 0.75:0.25, respectively. During these tests, a dualtrace oscilloscope was connected to each electrode pair to perform the signal analysis discussed in the previous section. Post-test analysis of the flow, temperature, and electric potential data reveal some peculiar characteristics not evident in previous test runs.

Measured temperature results are presented in Figures 3.39 through 3.41 . Flow photographs are in Figures 3.42 through 3.44. (Conditions for runs BRUN-7A and BRUN-7B are the same, but data were taken with power leads reversed for the latter half of the run.) The foremost characteristic observed is the strong asymmetry occurring in both the measured temperature field and the observed flow field.

The only difference in procedure for these two runs, BRUN-7 and BRUN-8, was that time-dependent voltage signals from the upper and lower electrode pairs were simultaneously monitored on an oscilloscope which led to the asymmetric results. It was believed that an input lead from each electrode pair had been grounded through the oscilloscope. Follow-up diagnostic testing of the electrode system was performed to detemine if grounding through the 


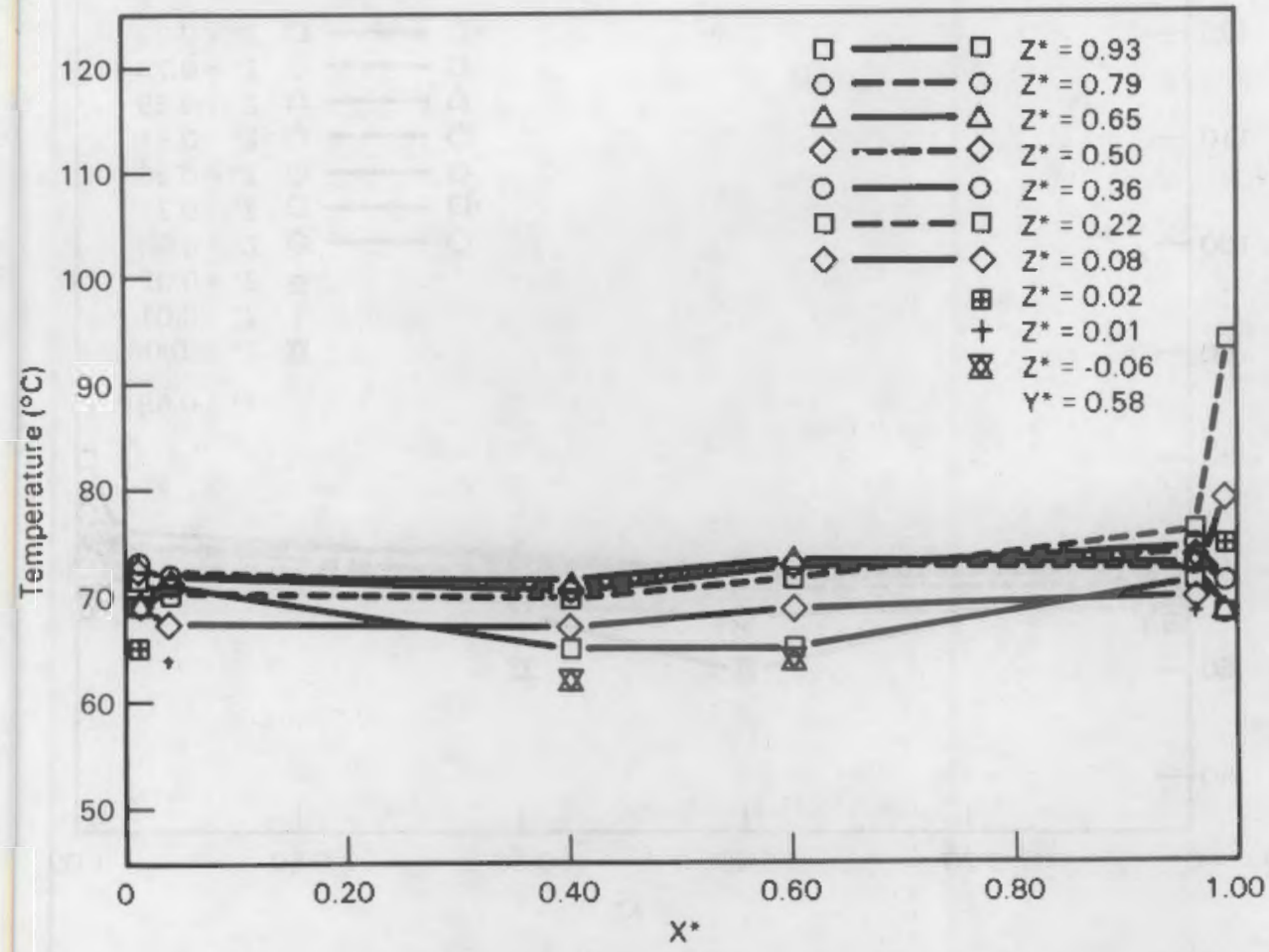

FIGURE 3.39. Horizontal Temperature Profile Test for Run BRUN-7A

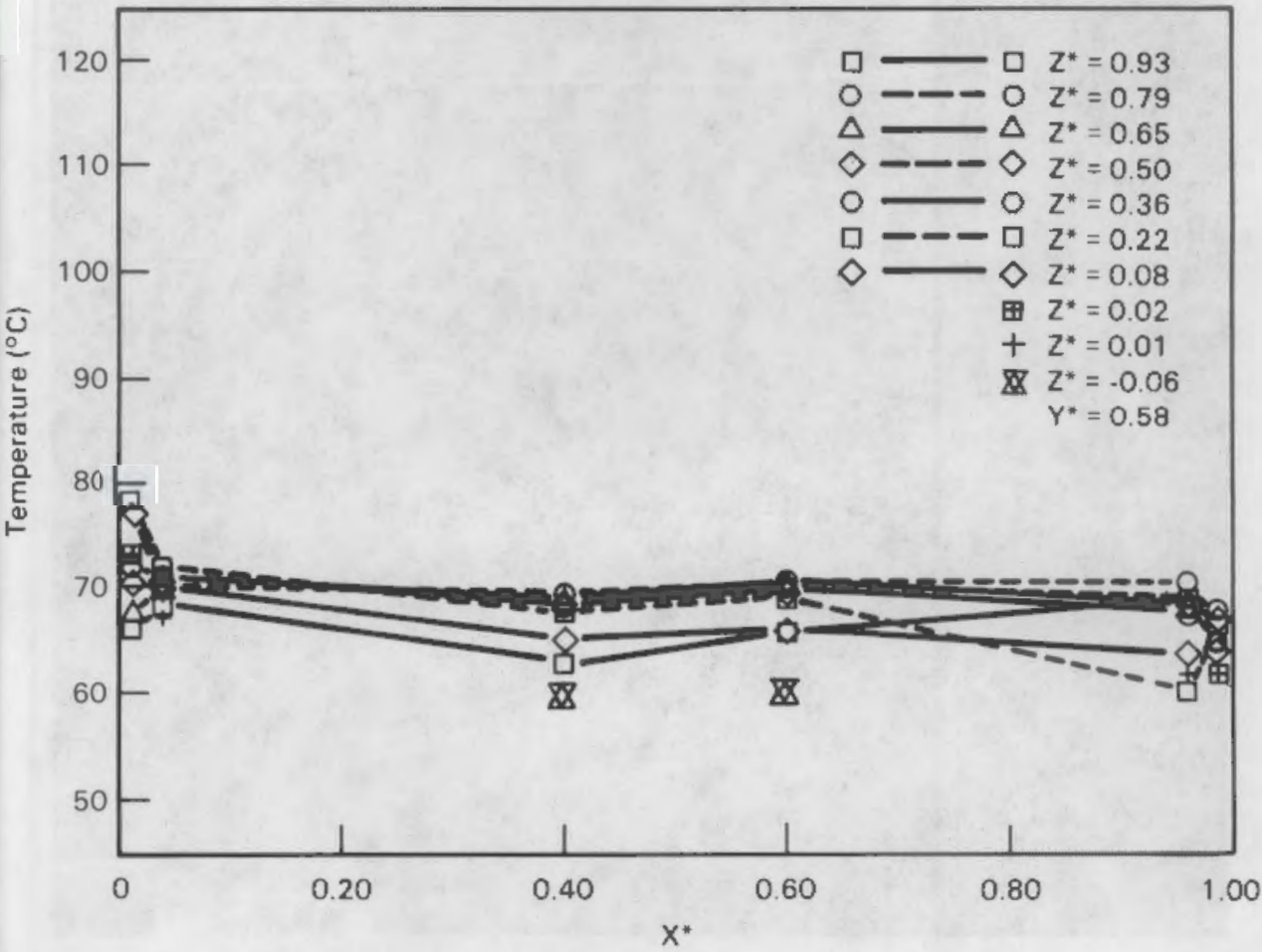

FIGURE 3.40. Horizontal Temperature Profile Test for Run BRUN-7B 


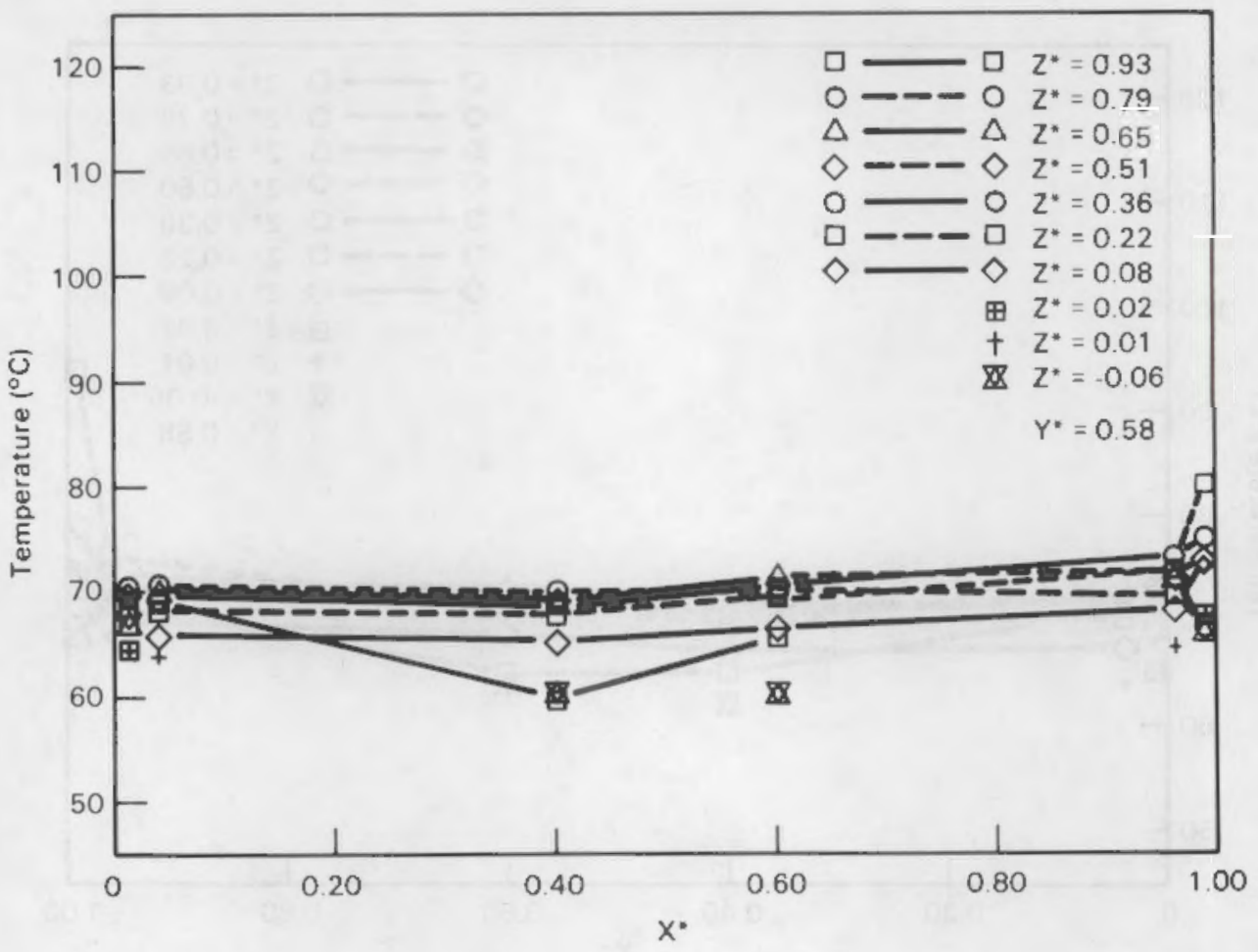

FIGURE 3.41. Horizontal Temperature Profile Test for Run BRUN-8

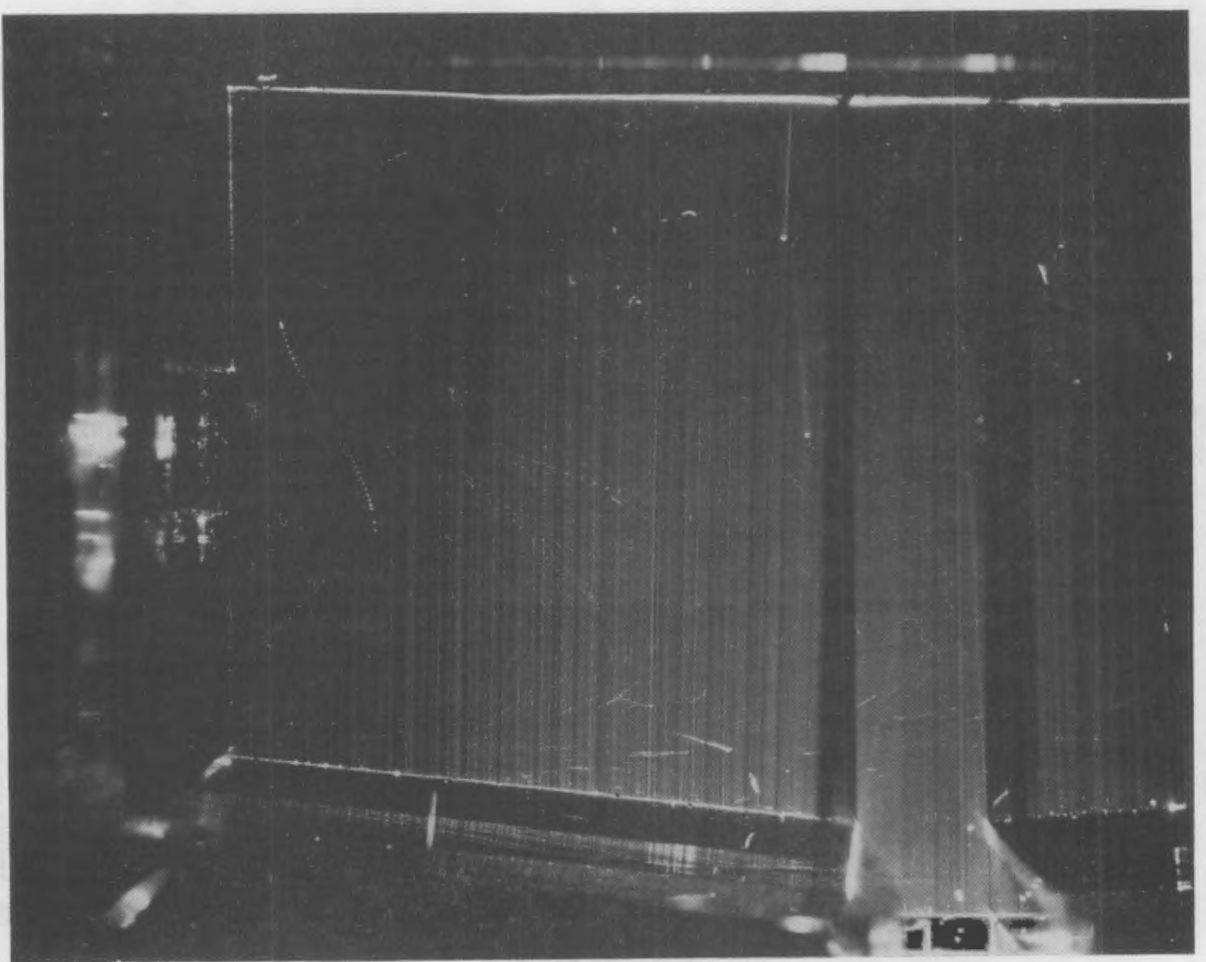

FIGURE 3.42. Flow Field Stroboscopic Photograph for BRUN-7A $\left(Y^{\star}=0.51\right)$ 


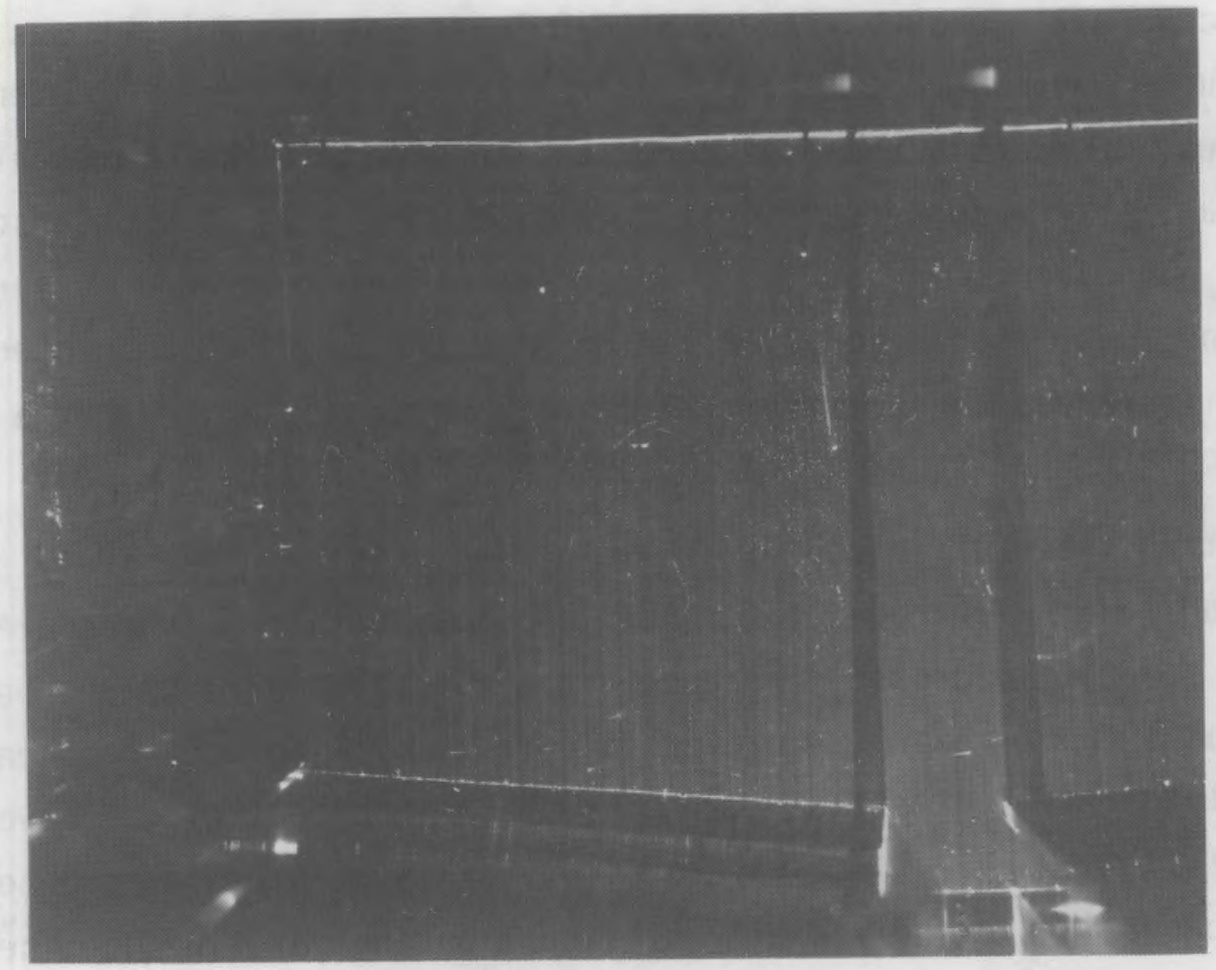

FIGURE 3.43. Flow Field Stroboscopic Photograph for BRUN-7A $(Y *=0.66)$

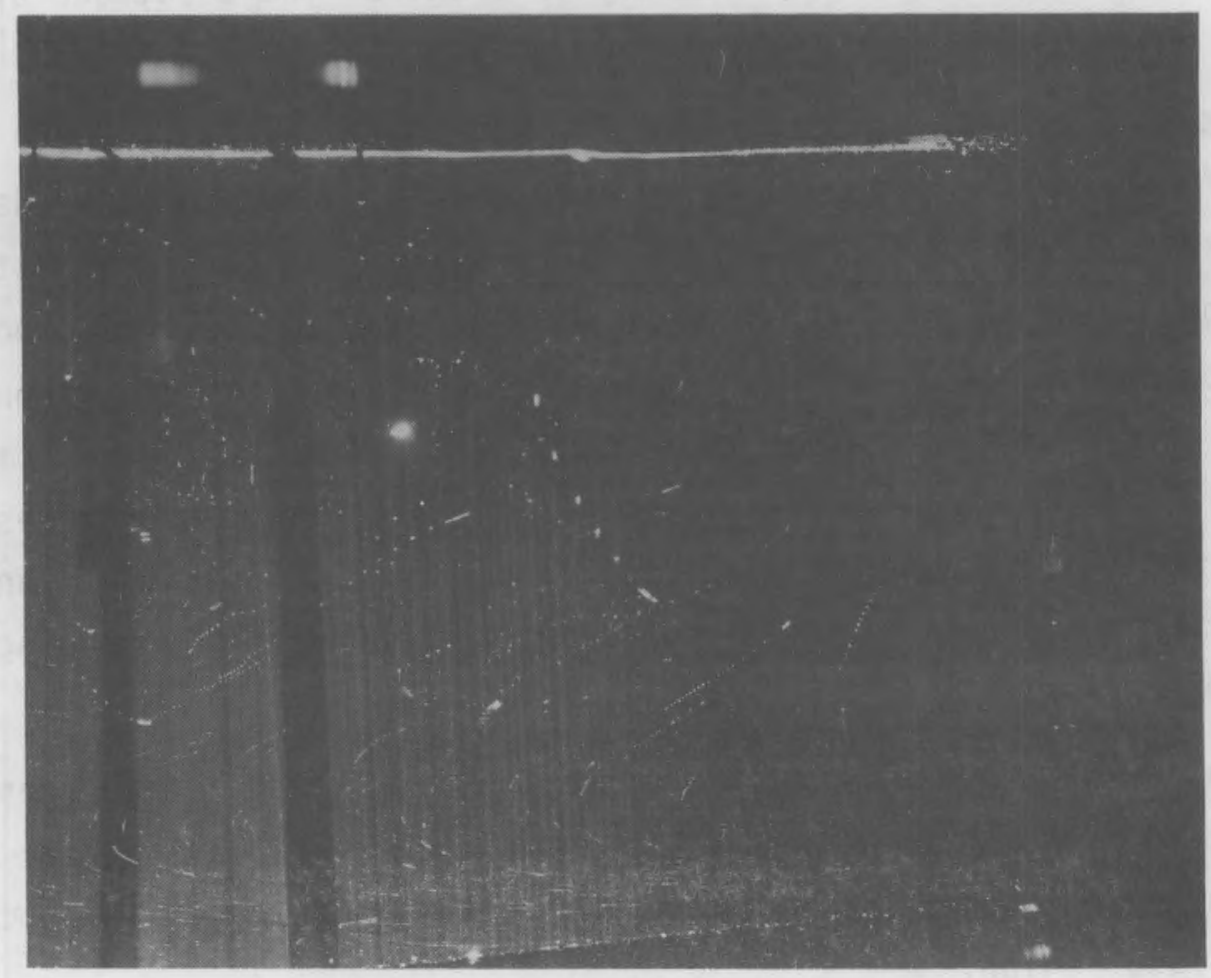

FIGURE 3.44. Flow Field Stroboscopic Photograph for BRUN-8 $\left(Y^{*}=0.65\right)$ 
scope had occurred. For BRUN-7A and BRUN-8 tests, an rms voltage was measured across the upper and lower electrode plate at side 1, while zero potential difference was measured across the upper and lower electrode plates at side 0 . Potential difference measurements from side 0 to reference or absolute ground were also zero. In addition, potential differences were measured across the upper and lower electrode at each side with the scope disconnected. These potential differences agreed within $\pm 0.4 \mathrm{~V} \mathrm{AC}$, which suggested that a floating ground was obtained after removing the oscilloscope from the system.

Connecting the oscilloscope to the electrode system effectively shorted the upper and lower electrodes to ground. Because both electrodes are grounded to the same potential, crossfiring does not occur, and current flow between the electrodes at side 0 is zero. However, a potential difference between upper and lower plates still exists at side 1, such that current flows between the electrode plates $U_{1}$ and $L_{1}$ (see Figure 3.45 ). This results in more heat generation occurring in the vicinity of side 1 but not at side 0 . The difference in heat generation rates induces an asymetric temperature profile with locally higher temperatures directly in front of the electrode at side 1 , the side at which a crossfire current flow occurs.

Figures 3.46 and 3.47 present electric potential results. These are for tests BRUN-7B and BRUN-8, respectively. (Note that power supply leads are reversed for these two tests.) For the former case, the vertical distribution near the high potential (side 1) is more asymmetric than for the common grounded side 0 . The same is true for the latter case. In comparison of temperature distributions for the tests BRUN-7 and BRUN-8 (Figures 3.39 through 3.41), little difference in results occurs. Locally high temperatures occur, however, directly in front of the electrodes on the high potential (ungrounded) side, thus supporting the hypothesis of crossfire current flow causing locally high heat generation.

Temperature time series results for tests BRUN-7A and $7 B$ are presented in Figures 3.48 to 3.50 . Rather 1 arge $\pm 9^{\circ} \mathrm{C}$ temperature oscillations are evident, especially near the model cold cap top. Relatively quiescent fluid occurs in the middle fluid region. 


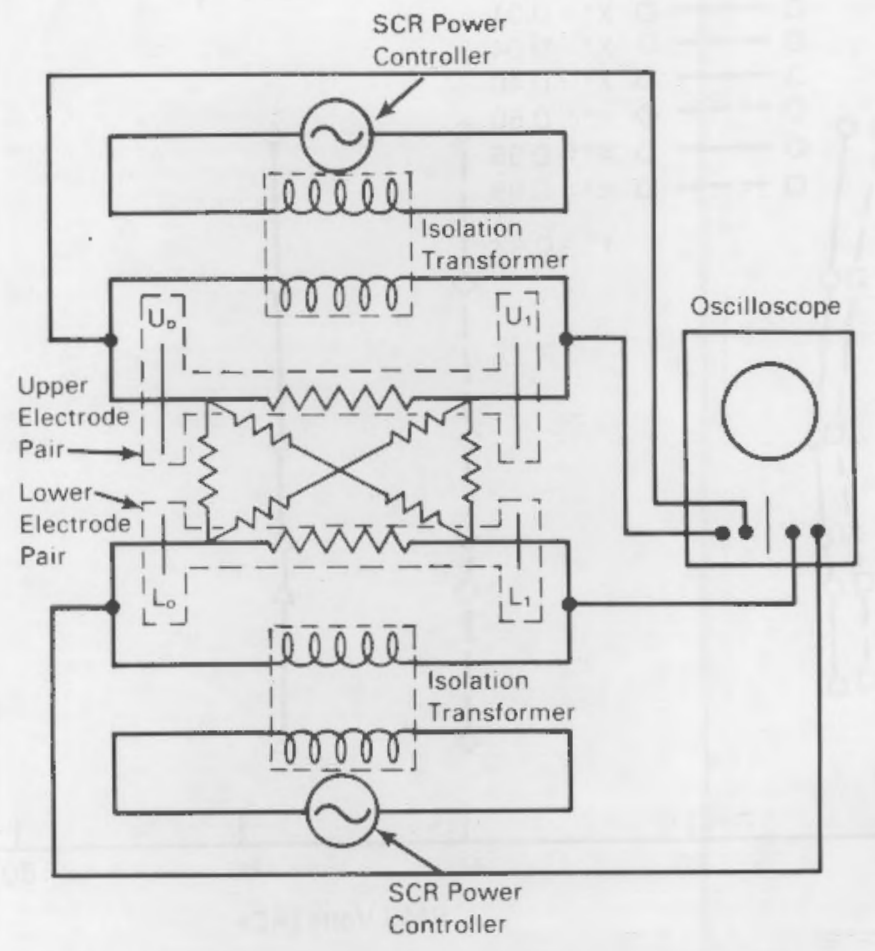

a. Model Sketch With Scope Connected

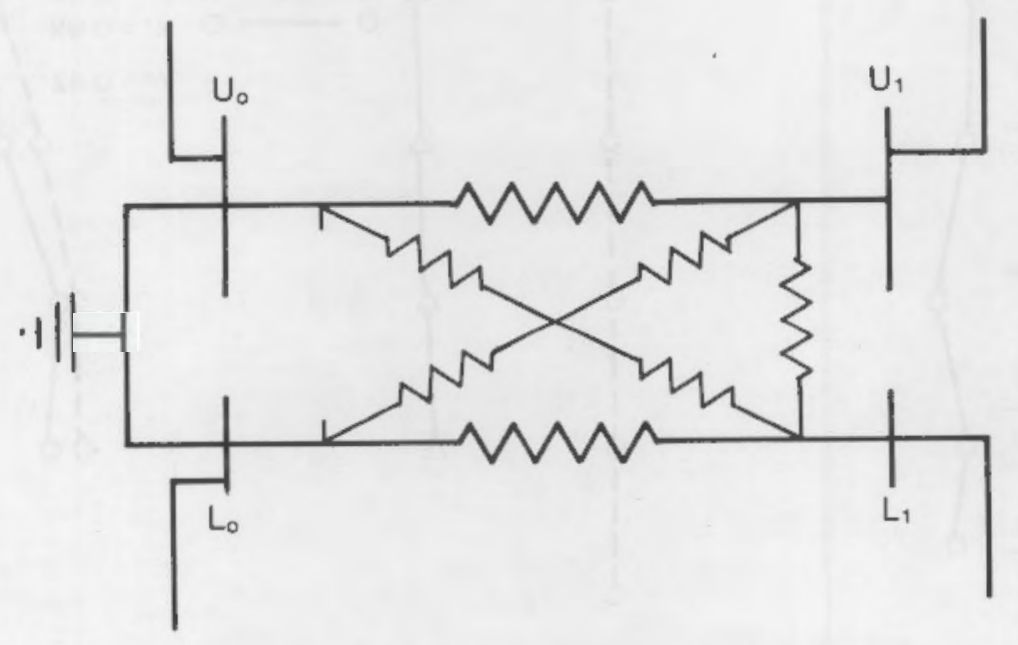

b. Scope Grounded Equivalent Circuit

FIGURE 3.45. Power Supply Schematic Showing a) Scoped Connected and b) Common Grounded Equivalent Circuit 


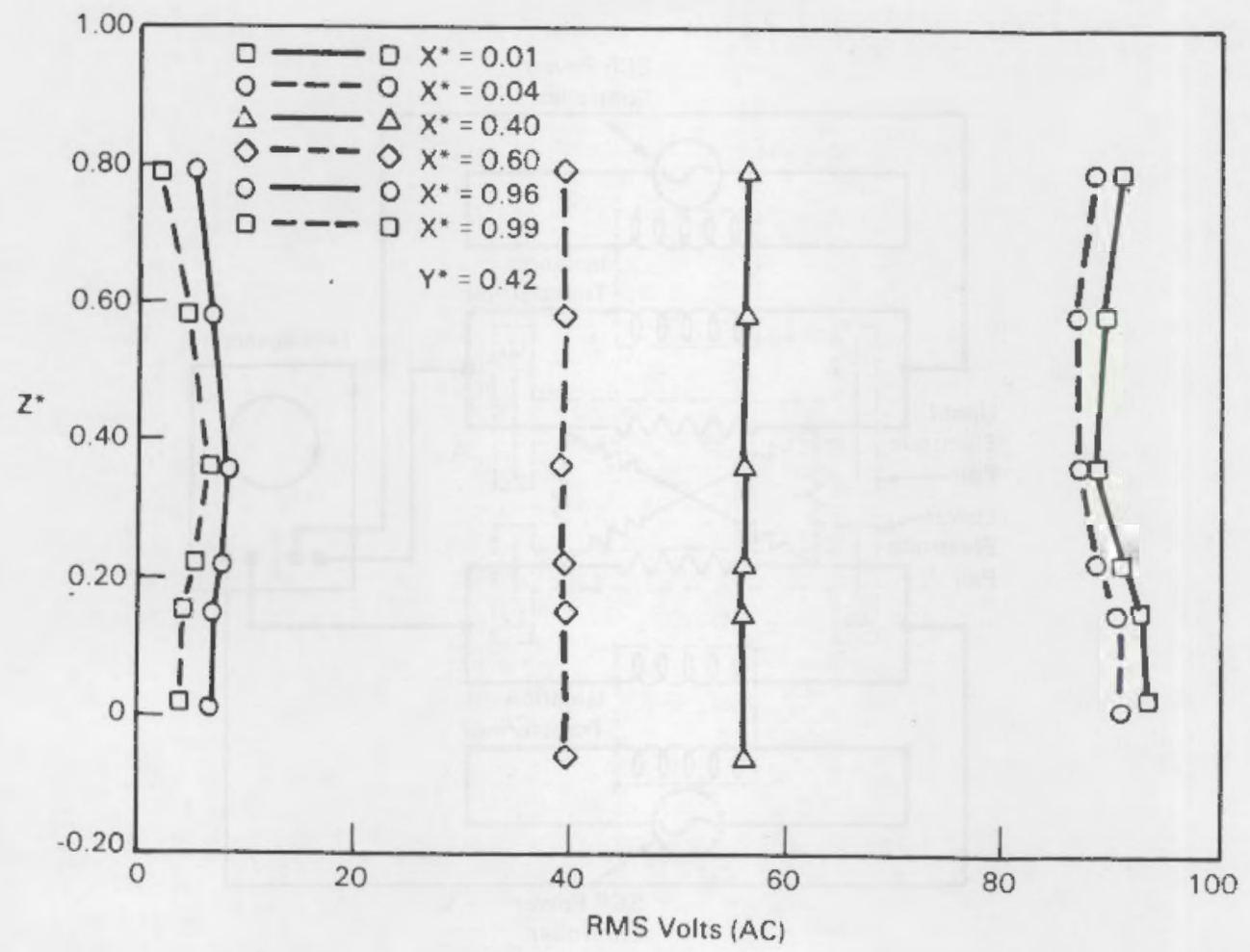

FIGURE 3.46. Electric Potential Distribution for Test BRUN-7B

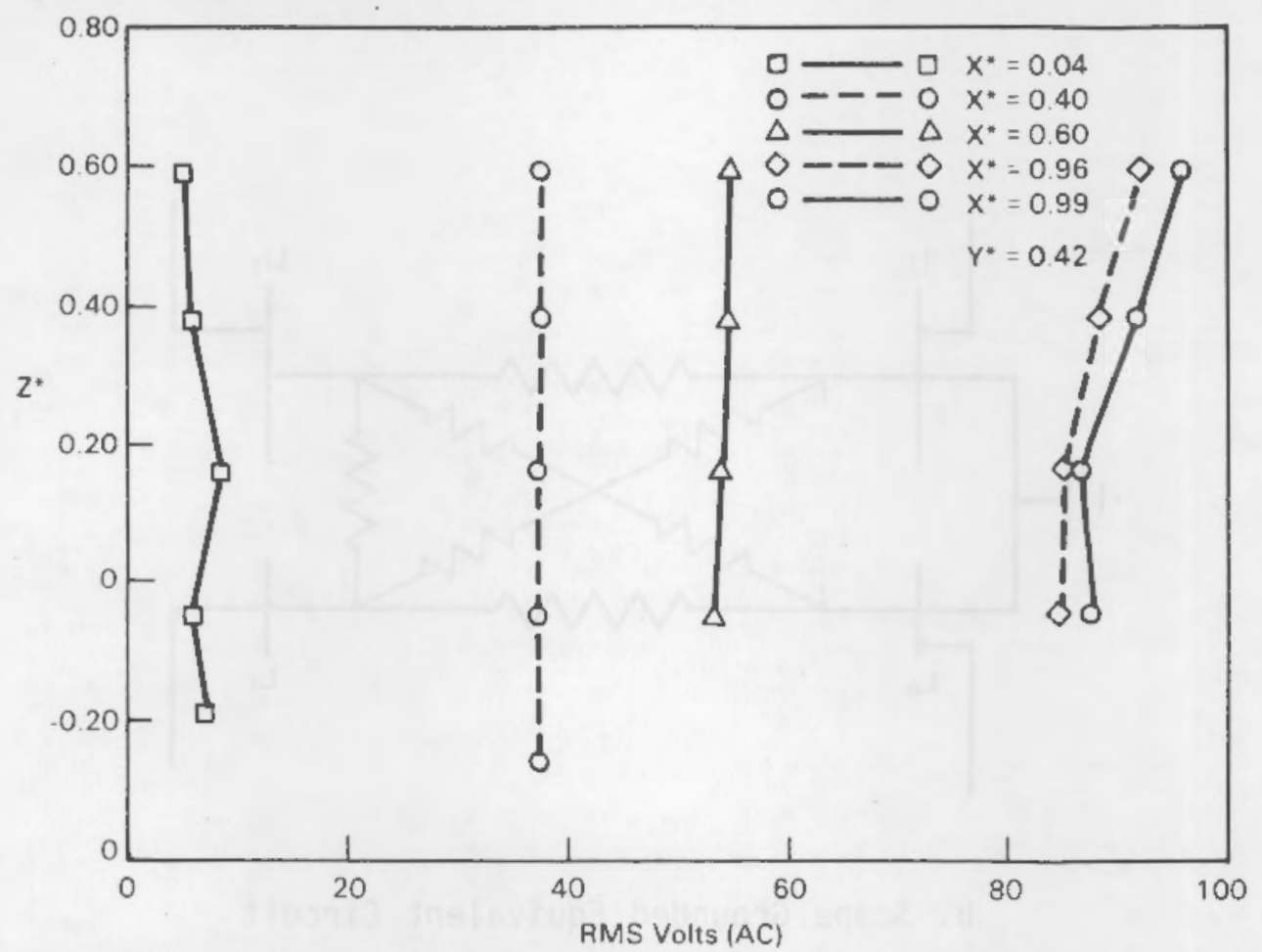

FIGURE 3.47. Electric Potential Distribution for Test BRUN-8 


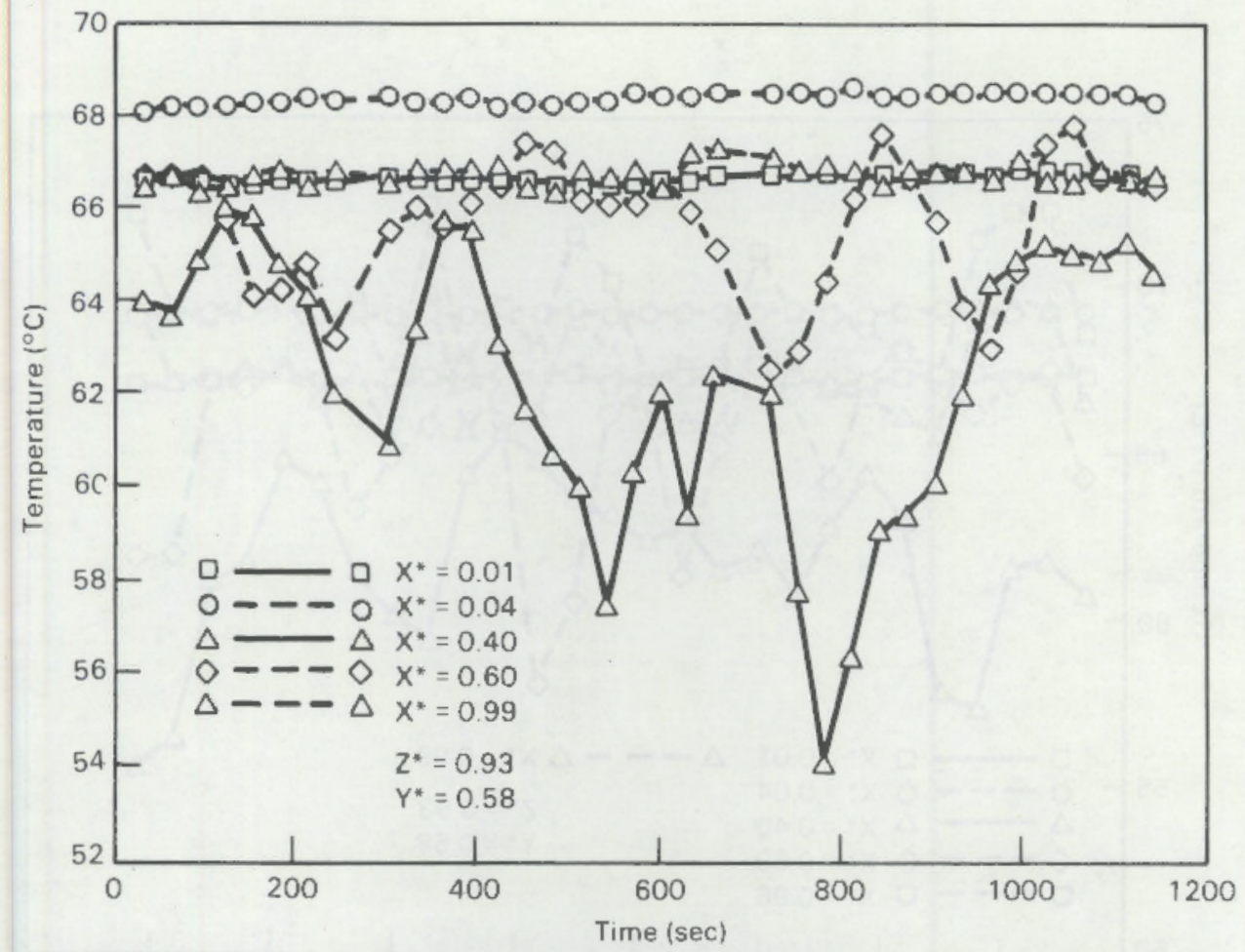

FIGURE 3.48. Fluid Temperature Time Series for Test BRUN-7B

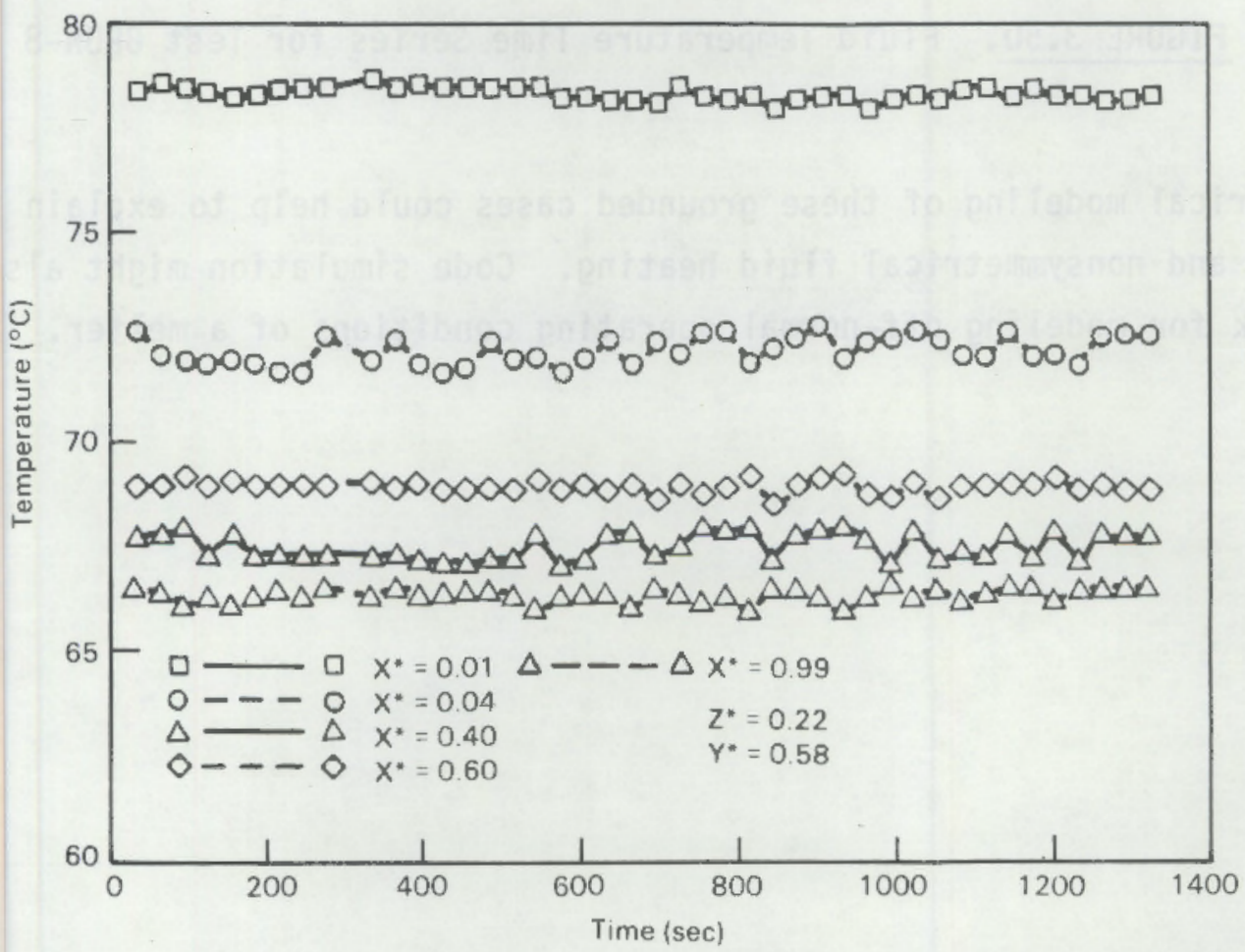

FIGURE 3.49. Fluid Temperature Time Series for Test BRUN-7B 


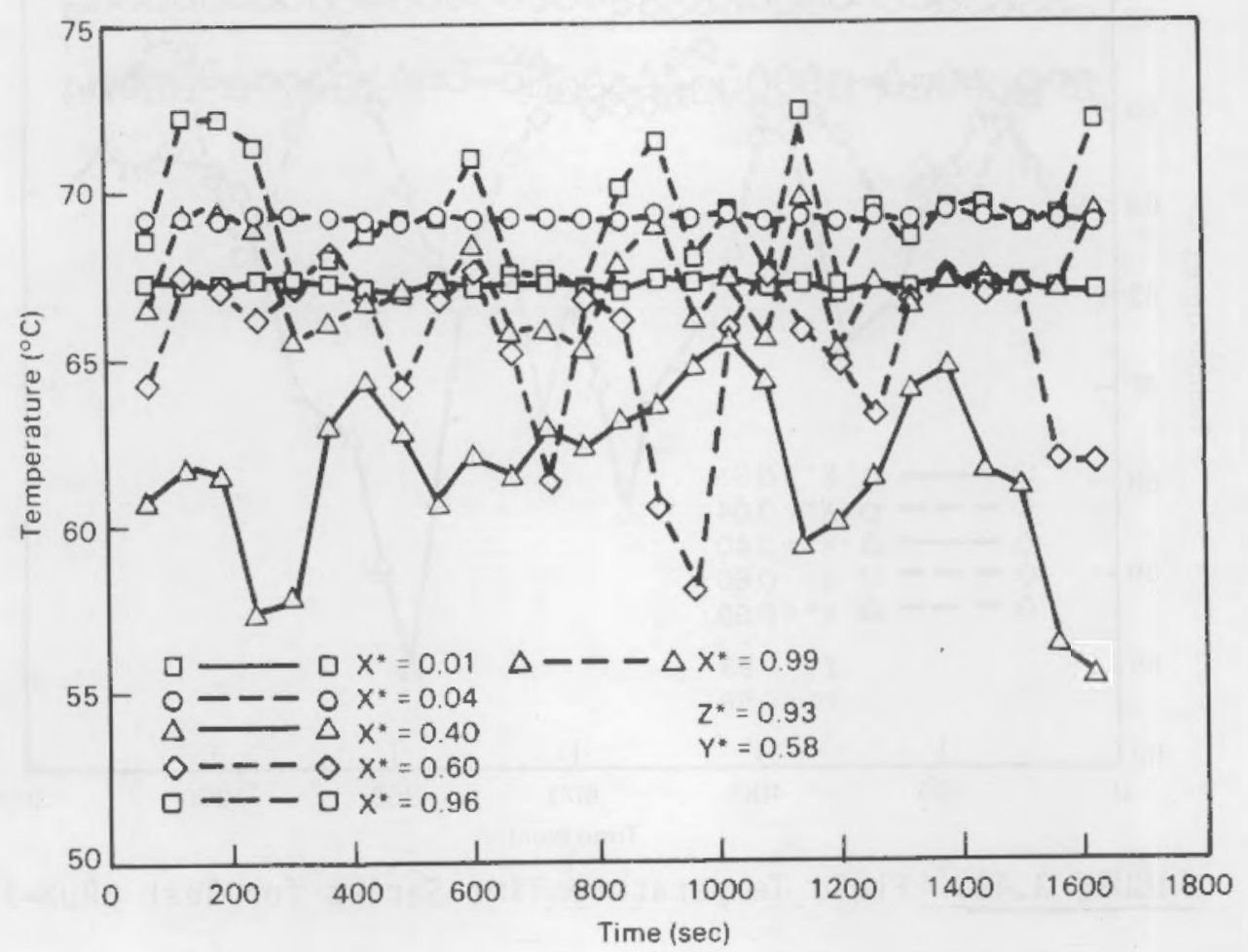

FIGURE 3.50. Fluid Temperature Time Series for Test BRUN-8

Numerical modeling of these grounded cases could help to explain the localized and nonsymmetrical fluid heating. Code simulation might also serve as a check for modeling off-normal operating conditions of a melter. 


\section{4.ก THEORETICAL BASIS FOR NUMERICAL MODELING OF JOILE-HEATEN MELTERS}

The physical behavior of waste glass processing in a loule-heated nelting furnace involves rather complex interaction between fluid flow, heat transfer, and electrical current. Generally, the physical processes will exhibit a three-dimensional and transitory behavior depending on the melter operation conditions and design parameters. Matters are further complicated in that the transport properties associated with the flow of material, heat, and electricity are highly temperature dependent and can vary over several orders of magnitude within the melter during operation.

As complex as these processes are, they can nevertheless be accurately described using well-known mathematical formulations based on fundamental physical laws and the principles of continuum mechanics. Nhtaining solutions to the resulting highly nonlinear partial differential equations is accomplished using numerical methods with the aid of a high-speed digital computer.

In this section, background information is provided which provides the basis for the electric field solution methodology used in TEMPEST. Included is a discussion of governing equations and solution procedure for the coupled flow, heat, and electric field problems. Special attention is given to describing the assumptions and basis for treating dual-electrode-pair melter configurations in which each pair can be separately and individually power controlled.

\subsection{GOVERNING EQUATIONS}

The governing partial differential equations (expressed in vector form for simplicity) required for melter simulations are as follows (Bird et al. 1950): 
Continuity

$$
\nabla \cdot u=0
$$

Momentum

$$
\rho_{0}\left[\frac{\partial \mathbf{u}}{\partial t}+(\boldsymbol{\nabla} \cdot \mathbf{u} \mathbf{u})\right]=-\mathbf{p}+\rho \mathbf{g}-\nabla \cdot \tau
$$

Energy

$$
\rho_{0} C_{p}\left[\frac{\partial T}{\partial t}+\nabla \cdot u T\right]=\nabla \cdot(k \nabla)+Q_{j}-\nabla \cdot q_{r}
$$

Electric Field

$$
\nabla \cdot \mathbf{J}=0 .
$$

The glass is assumed to be an incompressible, Newtonian fluid having variable transport coefficients. Further assumptions are: 1) the Boussinesq approximation holds (i.e., $|\Delta p| / \rho_{0} \ll 1$ ), 2) viscous dissipation is small, and $3)$ the electric field is stationary. Ancillary relationships are required such as an equation of state, $\rho=\rho(T)$, and the expression for current flux, $J=-\sigma \nabla \phi$. Additionally, the stress tensor, $\tau$, is assumed be expressed in terms of the Stokes viscosity relationships for a Newtonian fluid.

Symbols are defined as follows:

$\nabla$ gradient operator

$r^{2} \quad$ Laplace operator 


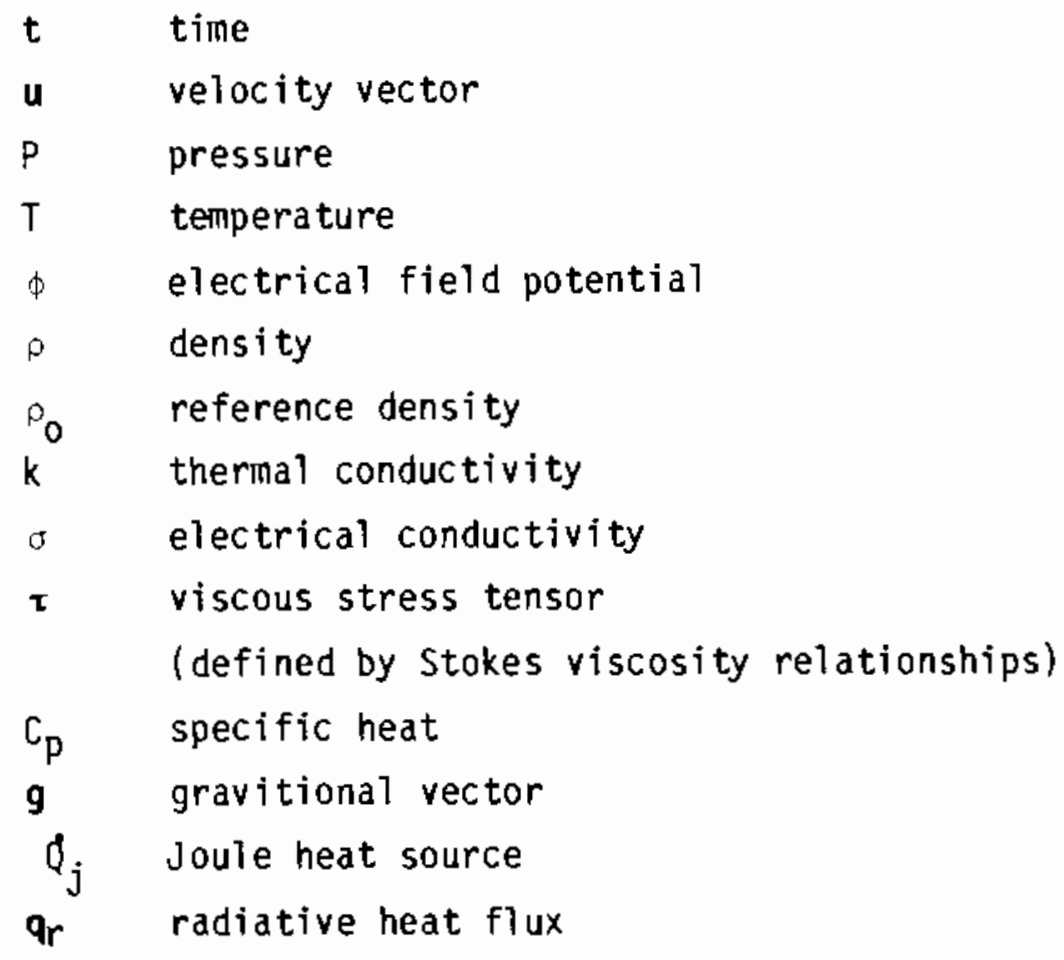

$$
\mathbf{u}=\boldsymbol{\nabla} \times \boldsymbol{\phi}
$$

and vorticity 8 as

$$
\boldsymbol{Q}=\nabla \times \mathbf{u} .
$$

A Poisson equation for the vector potential can be derived by taking the curl of Equation 4.5 with subsequent application of Equations 4.1 and 4.6 to obtain 


$$
\nabla^{2} \phi=-0
$$

By taking the vector curl of the momentum Equation 4.2, one obtains the vorticity equation

$$
\rho_{0}\left[\frac{\partial Q}{\partial t}+\nabla \cdot u Q-Q \cdot \nabla u\right]=\nabla \times B-\nabla \times(\nabla \cdot \tau)
$$

where $\boldsymbol{Q}$ is the vector vorticity and $\mathbf{B}=\rho \mathbf{g}$.

In two dimensions, the vector Equations 4.7 and 4.8 are dramatically simplified to scalar form for the ordinary stream function, $\psi$, and vorticity, $w^{(a)}$, or

$$
\begin{aligned}
& \nabla^{2} \psi=-\omega \\
& \rho_{0}\left[\frac{\partial \omega}{\partial t}+\nabla \cdot u \omega\right]=\nabla \times B-\nabla \times(\nabla \cdot \tau)
\end{aligned}
$$

where the velocity vector is defined as

$$
\mathbf{u}=-\nabla \psi
$$

(a) The variable, $w$, is used here for vorticity and should not he confused with use of welsewhere in this report as frequency. 


\subsection{SOLUTION APPROACH}

The governing equations discussed above indicate a choice of equation sets that can be solved numerically to obtain the molten glass velocity field. Equations 4.1 and 4.2 are referred to as the velocity-pressure ( $V-P)$ set, and Equations 4.7 and 4.8 are referred to as the vorticity-vector potential (\&- $)$ set or vorticity-stream function $(\omega-\psi)$ set for two-dimensional flows (Equations 4.9 and 4.10). Both approaches have been used for simulation of the velocity in Joule-heated melters at PNL (Donovan and Hjelm 1979).

For two-dimensional flow fields, the vorticity-stream function approach is attractive because pressure is eliminated from the analysis. Additionally, the equation set is quite simple, if viscosity is assumed to be constant, involving only two differential equations: one having elliptic form and the other having parabolic form. In both cases, the boundary conditions are easily handled for melter geometries. A wealth of information in the literature is related to the numerical solution of the $w$ - $\psi$ equation set and is directly applicable to Jouleheated melters. The equation for vorticity does become somewhat complicated, however, if viscosity is treated as temperature dependent with resulting spatial variations. The velocity-pressure method, on the other hand, requires the solution of three equations in two-dimensional flows. This is an elliptic equation for continuity/pressure and a parabolic equation for each of the two velocity components. One of the major considerations with the $V-P$ method is that mass must be rigorously conserved using an iterative process, whereas in the $w$ approach mass is conserved by definition of the stream function. Additionally, boundary conditions for the elliptic equation describing mass continuity are in slope form (Neumann type), which requires special numericai consideration to obtain a reasonable convergence rate.

The simplicity of the vorticity-stream function approach is completely lost, however, when three-dimensional flow fields are considered. In this case, the vorticity-vector potential set must be dealt with, which introduces the need to solve six differential equations, and possibly seven, if flow boundaries are considered. The complexity of the viscous stress terms increases significantly, and boundary conditions become more complex. Typically, viscosity is assumed constant to avoid handling the many terms required of temperature dependence. 
On the other hand, the velocity-pressure method requires the solution of only one additional equation (for the third velocity component). Additional terms are required in each equation, but they are few and easily treated numerically. Temperature-dependent viscosity does not require a great deal of additional computation. The $V$-P method is also much more flexible, since flow and internal boundaries are easily handled and various forcing functions and drag forces can be easily incorporated.

From an engineering applications perspective, a single software package should be capable of simulating a wide variety of design configurations and operating conditions without special considerations. In this case, design analysts need to be familiar with only one computer program, and either two or three-dimensional simulations can be conducted using the same numerical procedures. A major benefit is that the relative importance of threedimensional behavior can be established by investigating a 1 imited number of three-dimensional and two-dimensional comparisons. If three-dimensional effects are found to be of minor importance, virtually the same input data file can be used to conduct detailed analysis in two dimensions.

Because of the above considerations, the $\omega-\psi$ approach is no longer in use at PNL. In spite of the relative simplicity of the two-dimensional vorticity-stream function formulation, we have found that the $V-P$ formulation is considerably more flexible, is easier to use, and, in general, is the superior approach. To achieve the required three-dimensional simulation capability, an existing three-dimensional hydrothermal computer code named TEMPEST (Trent et a1. 1983), was modified to accommodate the special considerations needed for glass melter simulations.

The TEMPEST computer code was developed by PNL to simulate a wide variety of multidimensional, transient fluid flow and heat transfer phenomena in reactor systems. The Joule-heated melter version of the code solves Equations 4.1 through 4.5 in either two or three dimensions using a combination of implicit and explicit finite-difference procedures. Simulations are completely controlled by input, which is convenient for modeling various geometric configurations and operating conditons. TEMPEST has the capability 
of modeling multiple electric fields and electrode configurations. Additionally, turbulent flow can be modeled using a two-equation turbulence model, and the capability exists for modeling transport (with settiing) of up to nine chemical species.

A companion software package named SEQUEL has been developed to postprocess TEMPEST output and is used to create velocity and current vector maps and contours of temperature, electrical potential, and Joule heating. A second companion software package uses the TEMPEST output to create movies that illustrate the time-varying flow and temperature fields in any two-dimensional plane through the melter. This latter software package is very useful in interpreting complex flow phenomena, especially in three-dimensional models.

The base version of the TEMPEST code was modified to address special considerations in modeling the fluid dynamic and thermal behavior of Jouleheated glass melter operations. Specifically, new algorithms were implemented to handle the high-viscosity flow and the electric field simulation. To meet computational requirements for highly viscous fluids, viscous terms in the momentum equations are approximated using implicit procedures that are not 1 imited in time step by momentum diffusivity numerical stability criteria. A Courant number criterion is used to control the time integration step size. The Courant number restriction limits the time step size to the time required for a fluid particle to traverse the width of the most restrictive computational cell. This limitation is consistent with the time step size needed to achive accurate simulation of transitory behavior and is not overly restrictive from a computation time view point.

In TEMPEST, the electric field solution is based on stationary field theory and can accommodate multiple electrode configurations. The solution procedure is also designed so that a variety of operating conditions can be accommodated, including independent or simultaneous electrode firing. Because melters may be current controlled or power controlled, either electrode current density or power level may be the input data used to drive the electric field solution. The electric field is simulated throughout the melter, including the process glass, refractory, electrodes, and sludge deposit, if present. Once 
the electric potential and current flux are computed throughout the melter, the local Joule, or resistive, heating is calculated using

$$
Q_{J}=-\iint \omega \cdot \hat{n d A}
$$

for each computational cell. The symbol $A$ is area and $\hat{n}$ is an outward-directed normal unit vector.

As in the case of the electric field solution, TEMPEST computes the temperature distribution throughout the melter, including both solid and fluid regions. An implicit procedure is used in this matter so that time-step size is not limited by numerical stability considerations. Since the Hanford glass is optically thick, radiative considerations within the media can be simplified using a diffusion theory approach (Siegel and Howe11, 1972). That is

$$
\mathbf{q}_{r}=-k_{r} \nabla T .
$$

A method that will allow the TEMPEST code to handle the radiation component in more general participating media is currently being developed under a separate activity.

The TEMPEST code is designed to be controlled entirely by user input and does not require internal coding changes to address different problems. For instance, geometric configurations for both Cartesian and cylindrical geometry are constructed by specifying computational cell types and material types. Drag coefficients and forcing functions can be specified in several ways, including use of temperature-dependent input tables for material properties. Two-dimensional simulations are set up by specifying a single cell depth in the third dimension or by specifying all cells in a three-dimensional input file to be null except for the two-dimensional plane of interest. A single input parameter will activate the turbulence model if the flow field is expected to be generaliy or locally turbulent. 
A number of available user controls include control for line printer, postprocessing, and movie output files. The code can be stopped and restarted at any specified time and can be run in a variable or fixed time-step mode. operation in a heat-transfer-only mode is also possible with both transient and steady-state procedures available by input selection.

Flexibility of the TEMPEST code makes it particularly well suited for melter design analysis. Special considerations such as the effect of bubbles, coid cap fomation, and sludge buildup can be modeled by input. The code is under continued development, and work is continuing on improving the numerical algorithms, modeling, preprocessing, and formal radiation modeling.

TEMPEST was designed to run on a CDC-7600 computer. The base version will al so run on smaller machines such as a DEC VAX $11 / 780$ or CDC 180/830 and on larger machines such as a CRAY 1 or CRAY X-MP. A7though two-dimensional simulations can be effectively executed on smaller machines, large threedimensional simulations should be executed on a CRAY-class supercomputer. The Joule-heated melter version in current use at PNL is designed for use on a CRAY 15 computer.

The base version of the TEMPEST computer code has an extensive accuracy verification and assessment history (Eyler. Trent and Budden 1983). This assessment history has covered comparisons with analytical solutions and experimental data for a variety of flow and heat transfer conditions. Application of the code to Joule-heated melter analysis and modification of the code to accommodate high-viscosity fluids and electric fields required further assessment and verification. To this end, experimental data obtained by PNL from physical models of melter designs and electric field studies are used. These results are addressed in Section 5.0 of this report.

\subsection{CONSIDERATIONS AND BASIS FOR DUAL-ELECTRIC-FIELD CASES}

If capacitive effects within the melters are small and the computational time step is much larger than the period of electrical signal, the single electric field solution can be obtained as a direct current (DC) problem using root mean square (rms) current density as input. However, plans for the 
Hanford Waste Vitrification Program (HWVP) call for a melter with an electrical system consisting of two pairs of electrodes powered with separate AC power sources. Because of the interactions in both time and space between the electric fields produced by both pairs of electrodes, it becomes no longer possible to treat the electrical solution in a strictly DC manner. This section will discuss the treatment of the dual-electric-field solution and the TEMPEST option which allows the user to specify the desired electrical power level in each electrode pair instead of the current to each electrode.

\subsubsection{Theoretical Basis}

Calculation of the mean Joule heating rate in a melter having two pairs of electrodes includes time-dependent emfs [(Electro Motive Forcels)] $E_{A}(t)$ and $E_{B}(t)$ applied to electrode pairs $A$ and $B$, respectively. Because capacitive effects are small, it can be assumed that the currents and voltages are in phase. The condition assuring that capacitive effects are small is that

$$
\sigma>E_{\omega}
$$

where $\sigma$ is electrical conductivity, $E$ is dielectric permittivity, and $\omega$ is the angular frequency of the signal. This condition must be satisfied at all points along at least one significantly broad path leading from each electrode to its opposite driven electrode.

The instantaneous total power being delivered to the melter by power supplies $A$ and $B$ is

$$
P(t)=P_{A}(t)+P_{B}(t)
$$

where the instantaneous power of each electrode pair is

$$
\begin{aligned}
& P_{A}(t)=I_{A}(t) E_{A}(t) \\
& P_{D}(t)=I_{B}(t) E_{B}(t)
\end{aligned}
$$


The above expressions follow from the principle that the work done by a cell is the product of the charge flowing through it and the work per unit charge (potential difference).

Even though capacitive effects are neglected and hence any phase difference between current and voltage, there is a significant departure from a strictly $D C$ analysis. Namely, during the time that one of the emfs has been turned off, it is effectively removed from the circuit and does not provide a path for current generated by the other emf source. However, it is still possible to do a $D C-l i k e$ analysis, if each of the on-off combinations are treated separately.

Figure 4.1 shows the configuration and an "equivalent" circuit of resistors for 2 of 4 possible on-off combinations. The four on-off combinations for the melter with two electrode pairs are:

Condition (a): Power to Pair A on, Power to Pair B off, then

$$
\begin{array}{ll}
V_{A}(t)=E_{A}(t) & V_{B}(t)=k_{a} E_{A}(t) \\
I_{A}(t)=E_{A}(t) / R_{A A} & I_{B}(t)=0
\end{array}
$$

where

$k_{a}$ and $R_{A A}$ are determined by resistivities 

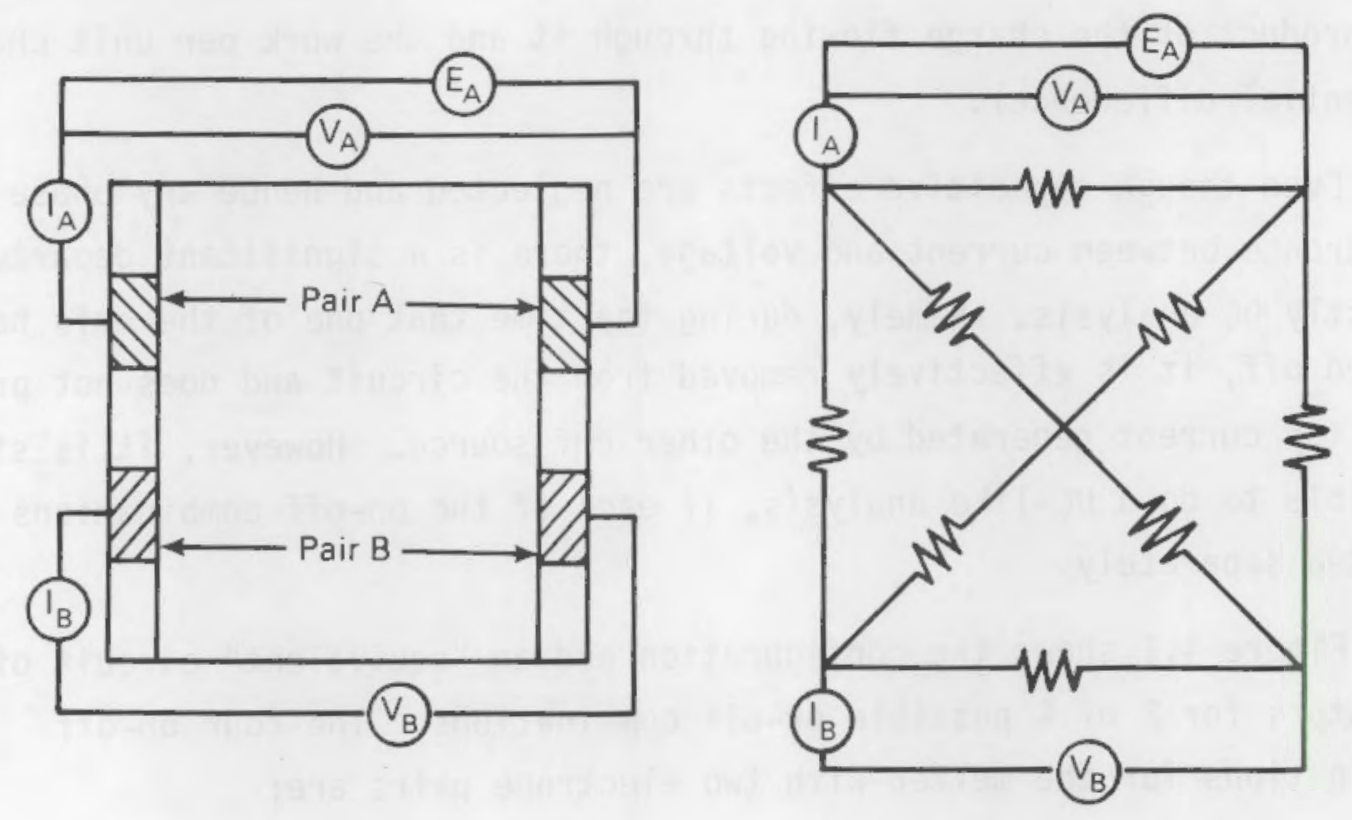

condition a
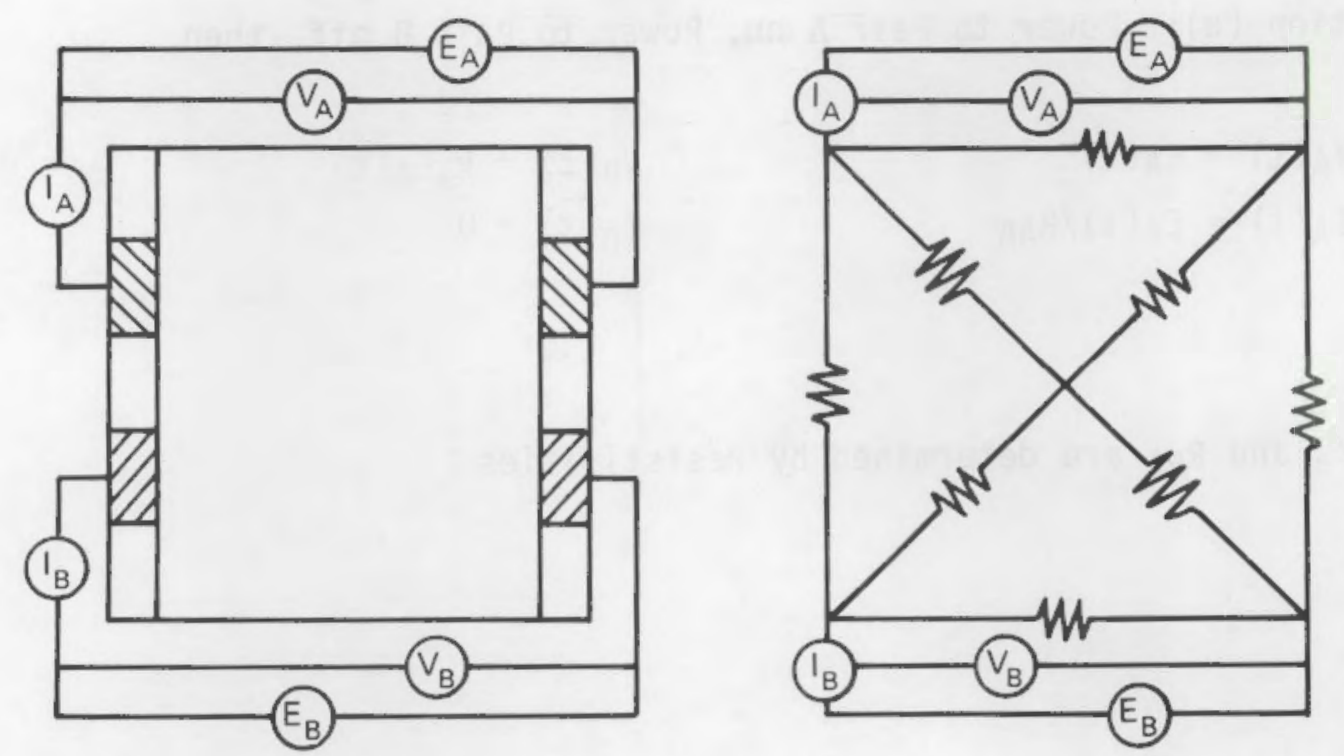

condition b

FIGURE 4.1. Two of the Four on-off Conditions for voltage Sources $E_{A}(t)$ and $E_{B}(t)$ 
Condition (b): Power to Pair A on, Power to Pair B on, then:

$$
\begin{array}{ll}
V_{A}(t)=E_{A}(t) & V_{B}(t)=E_{B}(t) \\
I_{A}(t)=k_{A A} E_{A}(t)+k_{A B} E_{B}(t) & I_{B}(t)=k_{B A} E_{A}(t)+k_{B B} E_{B}(t)
\end{array}
$$

Condition (c): Power to Pair A off, Power to Pair B on, then:

$$
\begin{array}{ll}
V_{A}(t)=k_{b} E_{B}(t) & V_{B}(t)=E_{B}(t) \\
I_{A}(t)=0 & I_{B}(t)=E_{B}(t) / R_{B B}
\end{array}
$$

where

$$
k_{b} \text { and } R_{B B} \text { are determined by resistivities }
$$

Condition (d): Power to Pair A off, Power to Pair B off, then:

$$
I_{A}=0 \quad I_{B}=0
$$

Detemination of the coefficients $k_{a}, k_{b}, k_{A A}, k_{A B}, k_{B A}$ and $k_{B B}$ is discussed subsequently. That the voltage $V_{B}(t)$ is nonzero for condition (a) despite the off position for $E_{B}(t)$ is evident in Figure 4.1a, particularly from the equivalent circuit. The linear relationship between $V_{B}(t)$ and $E_{A}(t)$ can also be seen in the equivalent circuit. During melter operation, resistances pictured in the equivalent circuits would be different and strongly dependent on the instantaneous temperature distribution.

In condition (b) (both emfs on), the currents $I_{A}(t)$ and $I_{B}(t)$ are linear combinations of the emfs $E_{A}(t)$ and $E_{B}(t)$. This can be determined by setting up equations for the six currents in the circuit $\left(I_{A}(t), I_{B}(t)\right.$, and four loop currents). The ms voltage in tems of the emfs during period $T$ can be written as:

$\left.V_{A, \text { rms }}=\left[\int_{(a)} E_{A}^{2}(t) d t+\int_{(b)} E_{A}^{2}(t) d t\right]+\int_{(c)} k_{b}^{2} E_{B}^{2}(t) d t\right]^{1 / 2} / T^{1 / 2}$ 
$V_{B, r m s}=\left[\int_{(a)} k_{a}^{2} E_{A}^{?}(t) d t+\int_{(b)} E_{B}^{2}(t) d t+\int_{(c)} E_{B}^{2}(t) d t \tau^{1 / 2} / T^{1 / 2}\right.$

Correspondingly, the rms current can be determined as:

$$
\begin{aligned}
& I_{A, r m s}=\left[\int_{(a)}\left[\frac{E_{A}(t)}{R_{A A}}\right]^{2} d t+\int_{(b)}\left[k_{A A} E_{A}(t)+k_{A B} E_{B}(t)\right]^{2} d t\right]^{1 / 2} / T^{1 / 2} \\
& I_{B, r m s}=\left[\int_{(b)}\left[k_{B A} E_{A}(t)+k_{B B} E_{B}(t)\right]^{2} d t+\int_{(c)}\left(\frac{E_{B}}{R_{B B}}\right)^{2} d t\right]^{1 / 2} / T^{1 / 2}
\end{aligned}
$$

In the above equation the symbol, $\int_{(a)}$ refers to an integral over time for which condition (a) applies, for example.

To calculate the electric field using TEMPEST, a DC current source or sink can be specified for each electrode; the potential field is then solved over the calculation domain. From two such calculations for a given set of resistivity conditions (temperature distribution), it is possible to determine the variables $k_{a}, k_{b}, k_{A A}, k_{A B}, k_{B A}, k_{B B}, R_{A A}$, and $R_{B B}$.

As an example, for condition (b) relations (Equation 4.17), the coefficients $k_{A A}, k_{A B}, k_{B A}$, and $k_{B B}$ can be determined from TEMPEST information as follows. Take a pair of current values $\left(I_{A}^{1}, I_{B}^{1}\right)$ as source/sink terms in electrode pairs $A$ and $B$. Use TEMPEST to solve for the corresponding emfs $\left(E_{A}^{-1}, E_{B}^{-1}\right)$. Take another, linearly independent, pair of current sources $\left(I_{A}^{2}, I_{B}^{2}\right)$ and find the corresponding emfs $\left(E_{A}^{2}, E_{B}^{2}\right)$. The coefficients $k_{A A}, k_{A B}, k_{B A}, k_{B B}$ can then be found by solving: 


$$
\begin{aligned}
& I_{A}^{1}=k_{A A} E_{A}^{1}+k_{A B} E_{B}^{1} \\
& I_{A}^{2}=k_{A A} E_{A}^{2}+k_{A B} E_{B}^{2} \\
& I_{B}^{1}=k_{B A} E_{A}^{1}+k_{B B} E_{B}^{1} \\
& I_{B}^{2}=k_{B A} E_{A}^{2}+k_{B B} E_{B}^{2}
\end{aligned}
$$

Condition (a) is just a special case of condition (b) obtained by setting $I_{B}=0$. Similary, condition $(c)$ is a special case of (b) obtained by setting $I_{A}=0$.

It is convenient to choose the two independent cases that determine the coefficients to be exactly conditions (a) and $(c)$. From the potential differences $E_{A}^{1}$ and $E_{B}^{2}$ resulting from the TEMPEST simulation of condition (a) the variables $R_{A A}$ and $k_{a}$ are calculated as:

$$
R_{A A}=E_{A}^{1} / 1_{A}^{1} \quad k_{a}=E_{B}^{1} / E_{A}^{1}
$$

Similarly, TEMPEST simulation of condition (c) allows the calculation of $R_{B B}$ and $\mathrm{k}_{\mathrm{b}}$ as:

$$
R_{B B}=E_{B}^{2} / I_{B}^{2} \quad K_{b}=E_{A}^{2} / E_{B}^{2}
$$


Since conditions (a) and (c) are special cases of condition (b), Equations 4.25 and 4.26 can be substituted into Equation 4.24 to yield the following expressions for $k_{A A}, k_{A B}, k_{B A}, k_{B B}$ :

$$
\begin{array}{ll}
k_{A A}=\frac{1}{\left(1-k_{a} k_{b}\right) R_{A A}} ; & k_{A B}=-k_{b} k_{A A} \\
k_{B B}=\frac{1}{\left(1-k_{a} k_{b}\right) R_{B B}} ; & k_{B A}=-k_{a} k_{B B}
\end{array}
$$

So far no assumptions have been made about the time-dependent nature of the applied emfs $\left(E_{A}(t), E_{B}(t)\right)$. The analysis will now be specialized for the voltage supplies that are proposed for NWTP. The power sources consist of two in-phase, $60-\mathrm{Hz}$ power sources controlled by silicon-controlled rectifiers (SCRs). The resulting time-dependent shapes of the voltage sources are shown in Figure 4.2. The source voltages are:

$$
\begin{aligned}
& E_{A}(t)= \begin{cases}0 & 0 \leq t<t_{a} \\
E_{A}^{0} \sin (\omega t) & t_{a} \leq t<T / 2\end{cases} \\
& E_{B}(t)= \begin{cases}0 & 0 \leq t<t_{b} \\
E_{B}^{0} \sin (\omega t) & t_{b} \leq t<T / 2\end{cases}
\end{aligned}
$$

Where $T$ is the period of the cycle defined as $T=2 \pi / \omega$ and $E_{A}^{0}$ and $E_{B}^{0}$ are peak voltages. Substituting Equation 4.28 into Equations 4.20 through 4.23 gives: 


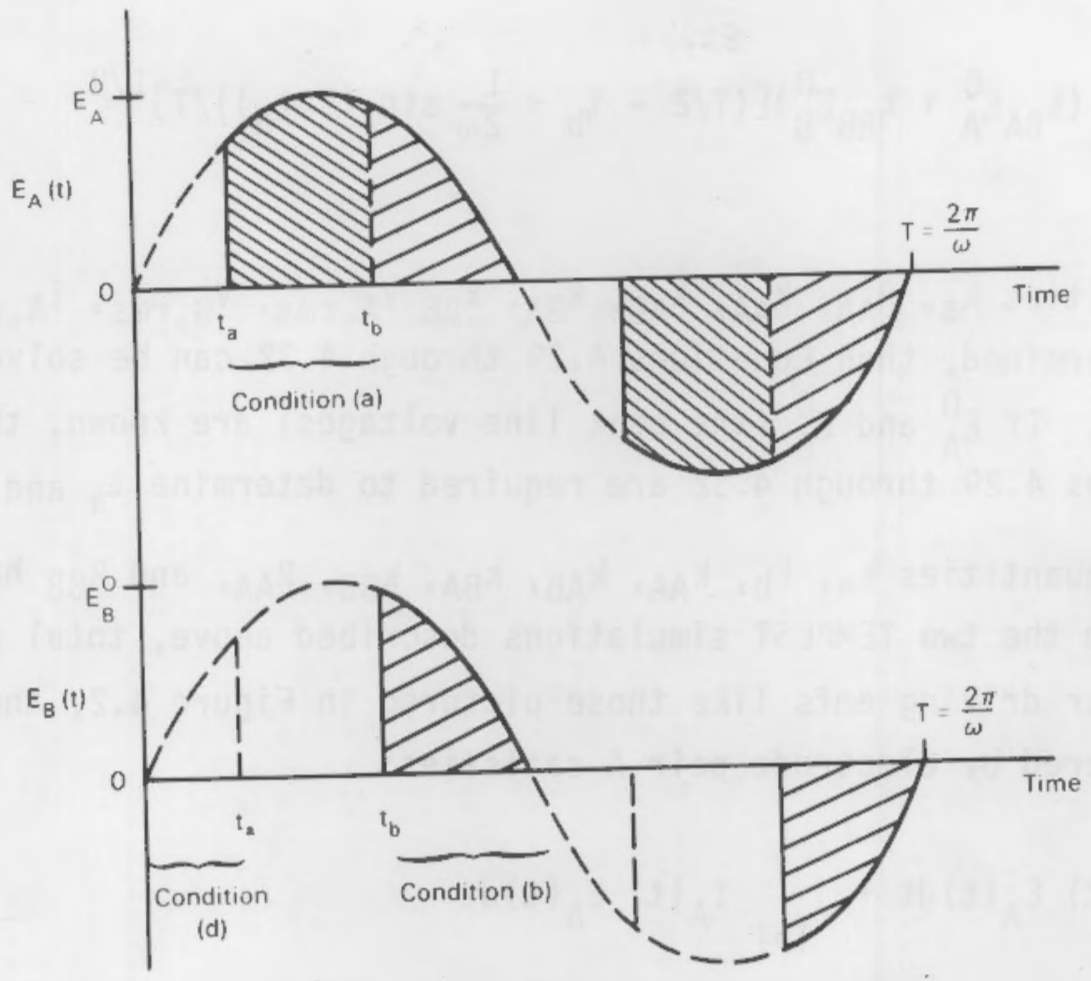

FIGURE 4.2. Dual Electrode Pair Time-Dependent Voltage Shape

$$
\begin{aligned}
V_{A, r m s}= & E_{A}^{0}\left[\left(T / 2-t_{a}+\frac{1}{2 \omega} \sin \left(2 \omega t_{a}\right)\right) / T\right]^{1 / 2} \\
V_{B, r m s}= & \left\{\left(k_{a} E_{A}^{0}\right)^{2}\left[t_{b}-t_{a}-\frac{1}{2 \omega}\left(\sin \left(2 \omega t_{b}\right)-\sin \left(2 \omega t_{a}\right)\right)\right]\right. \\
& \left.+E_{B}^{0^{2}}\left[T / 2-t_{b}+\frac{1}{2 \omega} \sin \left(2 \omega t_{b}\right)\right]\right\}^{1 / 2} / T^{1 / 2} \\
I_{A, r m s}= & \left\{\left(\frac{E_{A}^{0}}{R_{A A}}\right)^{2}\left[t_{b}-t_{a}-\frac{1}{2 \omega}\left(\sin \left(2 \omega t_{b}\right)-\sin \left(2 \omega t_{a}\right)\right)\right]\right. \\
& \left.+\left(k_{A A} E_{A}^{0}+k_{A B} E_{B}^{0}\right)^{2}\left(T / 2-t_{b}+\frac{1}{2 \omega} \sin \left(2 \omega t_{b}\right)\right)\right\}^{1 / 2} / T^{1 / 2}
\end{aligned}
$$




$$
I_{B, r m s}=\left(k_{B A} E_{A}^{0}+k_{B B} E_{B}^{0}\right)\left[\left(T / 2-t_{b}+\frac{1}{2 \omega} \sin \left(2 \omega t_{b}\right)\right) / T\right]^{1 / 2}
$$

Once the quantities $k_{a}, R_{A A}, k_{A A}, k_{A B}, k_{B A}, k_{B B} V_{A}, r m s, V_{B}, r m s, I_{A}$, rms , and $I_{B}$, rms are determined, then Equations 4.29 through 4.32 can be solved for $t_{a}$, $t_{b}, E_{A}^{0}$, and $E_{B}^{0}$. If $E_{A}^{0}$ and $E_{B}^{0}$ (the peak line voltages) are known, then only two of the Equations 4.29 through 4.32 are required to determine $t_{a}$ and $t_{b}$.

Once the quantities $k_{a}, k_{b}, k_{A A}, k_{A B}, k_{B A}, k_{B B}, R_{A A}$, and $R_{B B}$ have been determined from the two TEMPEST simulations described above, total power can be determined. For driving emfs like those pictured in Figure 4.2, the average power $F_{A}$ delivered by electrode pair A satisfies:

$$
\begin{aligned}
& \bar{P}_{A} T=\int_{(a)} I_{A}(t) E_{A}(t) d t+\int_{(b)} I_{A}(t) E_{A}(t) d t \\
& =\left(\frac{E_{A}^{0}}{R_{A A}}\right)^{2} \int_{(a)} \sin ^{2}(\omega t) d t+\left(k_{A A} E_{A}^{0}+k_{A B} E_{B}^{0}\right) E_{A}^{0} \int_{(b)} \sin ^{2}(\omega t) d t
\end{aligned}
$$

Similarly the average power $\bar{P}_{B}$ from electrode satisfies

$$
\begin{aligned}
& P_{B} T=\int_{(b)} I_{B}(t) E_{B}(t) d t+\int_{(c)} I_{B}(t) E_{B}(t) d t \\
& =\left(k_{B A} E_{A}^{0}+k_{B B} E_{B}^{0}\right) \int_{(b)} \sin ^{2}(\omega t) d t+\left(\frac{E_{B}^{0}}{R_{B B}}\right)^{2} \int_{(c)} \sin ^{2}(\omega t) d t
\end{aligned}
$$

The average total power is the sum:

$$
P=P_{A}+P_{B}
$$


There is a contribution to the heat generation from each one of the conditions (a), (b), and (c) during a cycle. The electric field patterns for cases (a) and (c) have already been calculated with an arbitrary current source in the course of finding $k_{a}, k_{b}$, etc. Having saved these solutions, they can be used to calculate the contributions from conditions (a) and (c) for the correct current amplitudes of:

$$
\begin{aligned}
& I_{A, a}^{0}=E_{A}^{0} / R_{A A} \quad \text { from condition (a) } \\
& I_{B, c}^{0}=E_{B}^{0} / R_{B B} \text { from condition (c) }
\end{aligned}
$$

For condition (b) the correct current amplitudes can be found from Equation 4.17 as:

$$
\begin{aligned}
& I_{A, b}^{0}=k_{A A} E_{A}^{0}+k_{A B} E_{B}^{0} \\
& I_{B, b}^{0}=k_{B A} E_{A}^{0}+k_{B B} E_{B}^{0}
\end{aligned}
$$

Note that the ratio $I_{A} / I_{B}$ is constant during condition (b) for the in-phase emfs of Figure 4.2. TEMPEST could be used again with current sources/sinks of $I_{A, b}^{0}$ and $I_{B, b}^{0}$ in electrode pairs $A$ and $B$, respectively. This would solve for the potential pattern for condition (b) with its amplitude multiplied by $\sin (\omega t)$. The solution to the potential problem with sources $I_{A, b}^{0}$ and $I_{B, b}^{0}$ is designated as $\phi_{A B}$. But it is possible to avoid calculating a new potential 
solution by recalling that the potential function is linear. Because of this, superposition of the two previous TEMPEST simulation can be used to calculate $\phi_{A B}$, to within an additive constant, as follows:

$$
\phi_{A B}=\left(\frac{I_{A, b}^{0}}{I_{A}^{1}}\right) \phi_{A}^{1}+\left(\frac{I_{B, b}^{0}}{I_{B}^{2}}\right) \phi_{B}^{2}
$$

where $\phi_{A}^{1}$ and $\phi_{B}^{2}$ are the potential solutions for current sources in only one electrode pair, namely $I_{A}^{1}$ in pair $A$ for $\phi_{A}^{1}$, and $I_{B}^{2}$ in pair $B$ for $\phi_{B}^{2}$.

The instantaneous Joule-heating power density is given by:

$$
P_{v}=\sigma \underline{E}^{2}=\sigma(\nabla \phi)^{2}
$$

From the previous discussion it can be seen that for the given system the average power density is

$$
\begin{aligned}
& P_{V} T=\left(\int_{(a)} \sin ^{2}(\omega t) d t\right)\left(\frac{I_{A}^{0}, a}{I_{A}^{I}}\right)^{2} \sigma\left(\nabla \phi_{A}^{1}\right)^{2} \\
& +\left(\int_{(b)} \sin ^{2}(\omega t) d t\right) \sigma\left(\nabla \phi_{A, B}\right)^{2}+\left(\int_{(c)} \sin ^{2}(\omega t) d t\right)\left(\frac{I_{B, C}^{0}}{I_{B}^{2}}\right)^{2} \sigma\left(\nabla \phi_{B}^{2}\right)^{2}
\end{aligned}
$$

\subsubsection{TEMPEST SOlution Procedure}

TEMPEST is currently set up to solve the dual-electric-field problem in two ways, depending on type of input data available. One mode is based on knowing (or assuming) current and time-split data. The other mode, referred to as the power-split mode, is based on knowing (or assuming) power levels applied to each electrode pair. 
In the current input mode it is necessary to know the amount of current supplied to each electrode pair during both of the time conditions (a) and (b). To calculate this, $I_{A, a}^{0}, I_{A, b}^{0}, I_{B, b}^{0}, t_{a}$, and $t_{b}$ must be known. The solution procedure is similar to that used for a single-electrode-pair case. The current density is specified as a source or sink in each electrode; TEMPEST then calculates $\phi_{A_{0}}^{1}$ with current source $I_{A, a}^{0}$ only; then $\phi_{A B}$ with current sources $I_{A, b}^{0}$ and $I_{B, b}^{0}$; and finally, the power densities are calculated using Equation 4.40 .

The power-split mode has been added to TEMPEST to help in the design of the NWTP melter. The only input that is required is peak line voltages for each power source $\left(E_{A}^{0}, E_{B}^{0}\right)$ and the desired power dissipation for each electrode pair $\left(\bar{P}_{A}, \bar{P}_{B}\right)$. To solve this problem TEMPEST first solves for $\phi_{A}^{1}, \phi_{B}^{\text {? }}$, and the related constants $k_{a}$, $k_{b}$, etc., assuming arbitrary currents. Then the nonlinear Equations 4.33 and 4.34 are solved for $t_{a}$ and $t_{b}$, which satisfy the power split. Once all these quantities are known, the potential solutions $\phi_{A}^{1}$ and $\phi_{B}^{2}$ are multiplied by the proper time and current amplitude factors. Finally, the average power densities are computed using Equation 4.40 .

One deficiency of the code as it currently stands is that the potential $\phi_{A B}$ is determined locally and not saved for output. As such, comparison to locally measured electric potential data for cases of both electrodes firing cannot currently be made, as discussed in Section 5.4 .

Table 4.1 compares the computational speeds of the current-input mode and the power-split mode of TEMPEST operation. The results show that specifying only the power split between the two pairs of electrodes increases the computer time needed to solve the electric field problem by typically $10 \%$. This increase in computational time is expected because of the less detailed input data provided. 
TABLE 4.1. Computational Time Comparision for Code Operational Modes

\begin{tabular}{cllll} 
Test No. & $\begin{array}{c}\text { TEMPEST } \\
\text { Solution } \\
\text { Mode }\end{array}$ & & $\begin{array}{c}\text { Electrical } \\
\text { Conductivity }\end{array}$ & $\begin{array}{c}\text { Electric } \\
\text { Field Solution } \\
\text { msec/Time Step-Cell }\end{array}$ \\
\cline { 1 - 1 } 1 & Current & Constant & 0.0514 \\
2 & Power-Split & Constant & 0.0557 \\
3 & Current & Variable & 0.1625 \\
4 & Power-Split & Variable & 0.1674
\end{tabular}




\subsection{ELECTRIC FIELD SOLUTION AND NUMERICAL MELTER MODELING}

This section describes simulations used to test the logic and verify the numerics of the TEMPEST electric field solution and numerical modeling of Joule-heated melters. Verification and model testing fall into several categories. Included herein are results of simulations of electric field solution and simulation of melter models in which coupling occurs between electric field and thermal hydraulics. Limited data on the sensitivity of melter predictions to changes in input parameters are also presented.

\subsection{ELECTRIC FIELD SDLUTION VERIFICATION}

The process of modifying the base version of TEMPEST to perform electric field calculations required incorporation of additional subroutines. One subroutine solves the finite-difference approximated form of Equation 4.4 for the electric field potential using the definition $\mathrm{J}=-\sigma \nabla \phi$. More minor modifications were made to couple Joule heating through the heat generation source term in the energy equation, and to provide appropriate input, output, and changes necessary for internal bookkeeping. Facilitating these latter changes required that they be checked to assure that correct data was available for internal computation to the code, that boundary conditions were treated correctly, and that numerical control parameters were correctly decisioning logic flow path. This checking was done continually as an integral part of the modification process through the use of hand calculations, logic flow tracing, and good engineering judgement in ascertaining that computed output actually corresponded to input for simple test cases.

Electric field solution is accomplished in the subroutine EFIELD using the same numerical solution procedure as for the energy equation in the well-tested base version. The electric potential equation is very similar in form to the energy equation without the time derivative and convection terms. The principal difference is that thermal conductivity is the physical property in the energy equation, and electrical conductivity is the physical property in the electric potential equation. Testing the coding, finite-differencing, and numerical solution procedure was done using simpler one- and two-dimensional problems amenable to certain hand calculations. 
As a validation of the overall electric field solution, TEMPEST was used to calculate the electric field in a simulated one-armed animal. This work was in support of a related project in which electric fields and induced currents occur in homogenous bodies because of imposed external electric fields. This particular geometry was chosen as a test because it is environmentally significant, has been difficult to accurately model with other codes, and leads to laboratory verification.

Figure 5.1 shows the physical dimensions used for the TEMPEST representation of a one-dimensional animal body. The boundary conditions were: 1) the normal current density at the top electrode was constant, 2) the lower grounded boundary was modeled by the image method, and 3) the normal components of the current density at the side walls were zero. The electrical conductances used in the simulations were $0.1(\Omega-m)^{-1}$ for the body and $3.3 \times 10^{-9}(8-m)^{-1}$ for the surrounding air.

A laboratory model with the cross-sectional shape shown in Figure 5.1 was made from lumber and covered with copper foil. The central $0.303 \mathrm{~m}$ of the $1.980-\mathrm{m}$ long model was electrically isolated to allow measurement of the induced current. The model was placed on a grounded electrode and exposed to a $3.45-\mathrm{kV} / \mathrm{m}$ electric field.

The TEMPEST prediction for the induced current in the body was $3.32 \mu \mathrm{A}$, which is in excellent agreement with the measured value of $3.33 \pm 0.10 \mu \mathrm{A}$. The surface electric field at the midpoint of the top of the model was measured to be $8.8 \mathrm{kV} / \mathrm{m}$. This corresponds to a surface enhancement. factor of $2.6+0.1$. The TEMPEST prediction of the surface enhancement value was 2.56, again in excellent agreement with the experimental results.

Figures 5.2 and 5.3 show the calculated current densities and equipotential surfaces for this simulation. It is important to note that the predicted current in the arm flows in the opposite direction to the current in the body. This experimentally observed phenomena has not been predicted by other computer codes. 


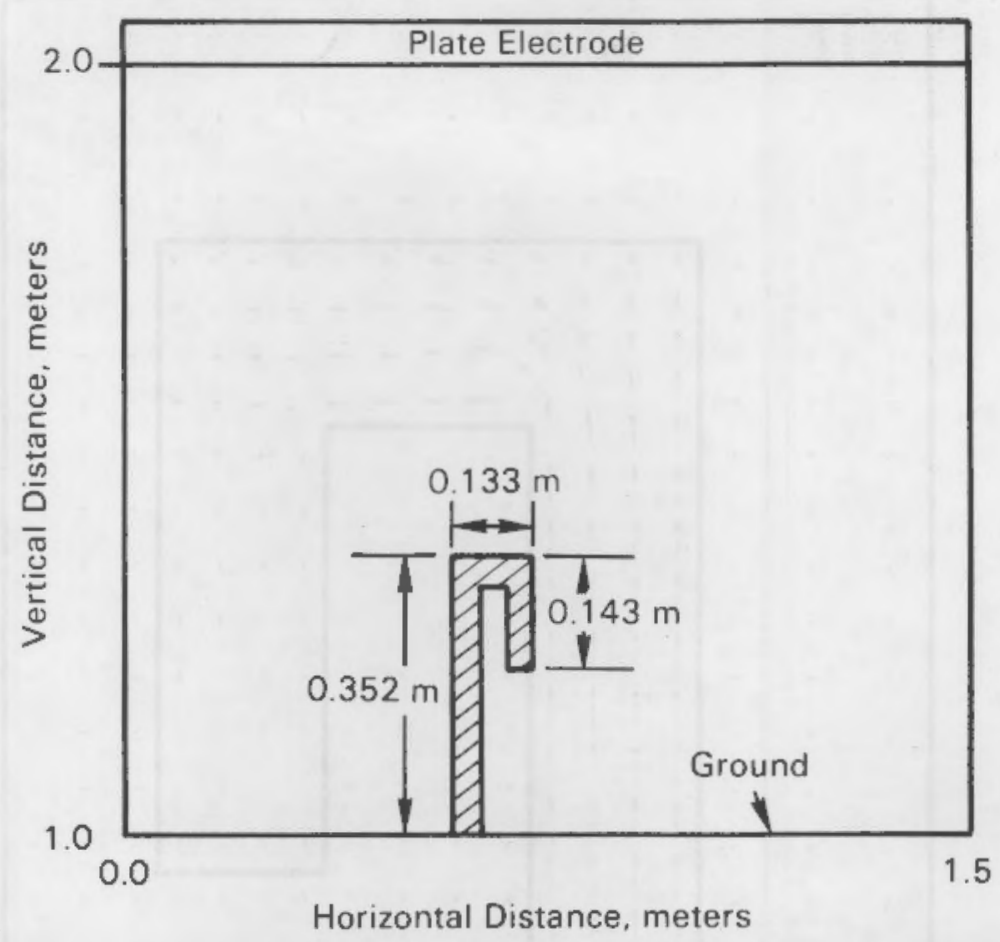

FIGURE 5.1. Schematic Representation of One-Armed Body Model in An Electric Field

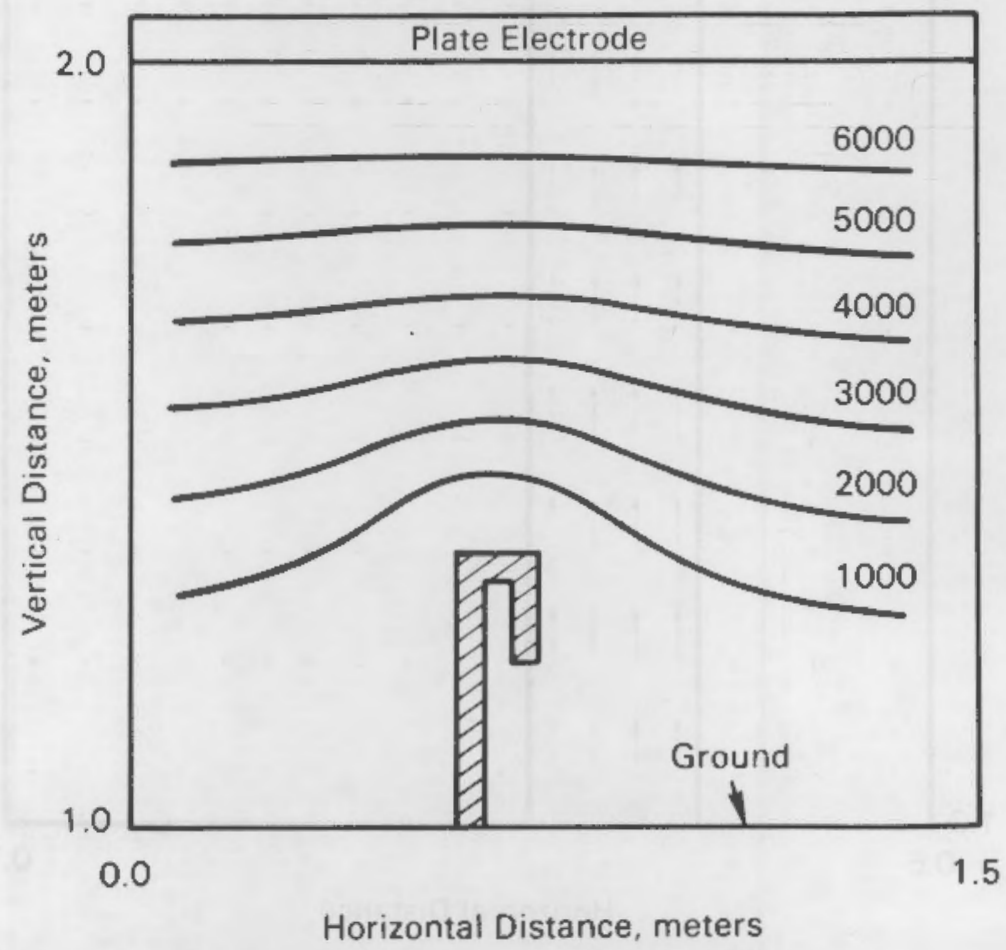

FIGURE 5.2. Calculated Equipotential Surfaces at 1000-Volt Increments for the One-Armed Body Model 


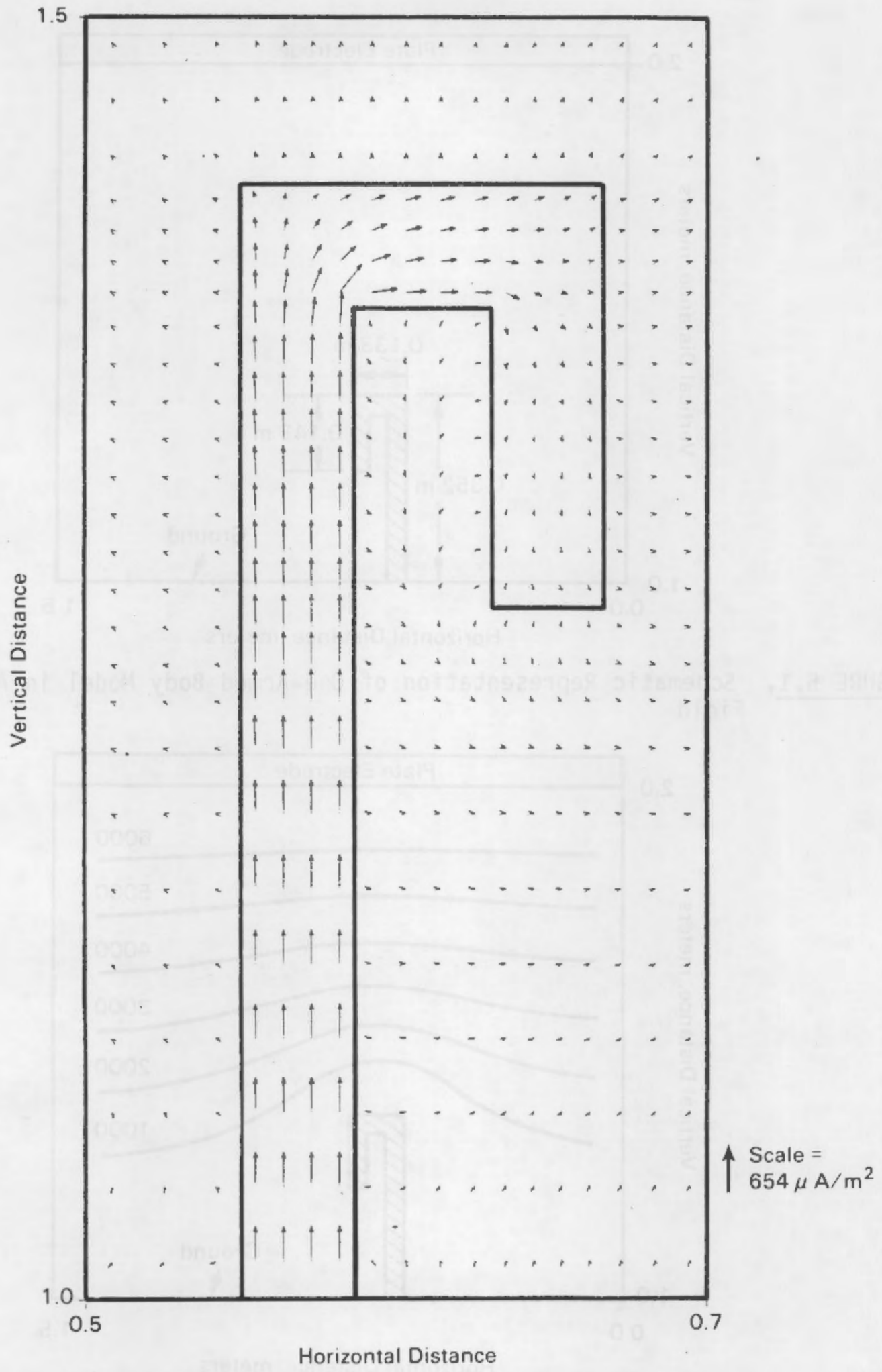

FIGURE 5.3. Calculated Conduction Current Inside the Structure and Displacement Current Outside Dne-Armed Body Model 


\subsection{PHYSICAL MELTER MODEL SIMULATION - SINGLE ELECTRODE PAIR}

During the past several years, physical melter model experiments have been conducted at PNL. Quigley and Kreid (1979) reported results in which a glycerin-base modeling fluid was used. Their tests were small-scale, lowtemperature tests in a clear acrylic facility. Temperature, electric field, and flow visualization data obtained in well-controlled laboratory conditions provided a basis for evaluating TEMPEST prediction of electric field and coupled Joule-heated hydrodynamics.

Figure 5.4 presents a schematic of the test apparatus and a vertical cross-sectional plane of the TEMPEST model. Boundary conditions were chosen to simulate physical model run number 15 . In this test, water cooling jackets maintained boundary temperatures constant on the exterior of the test container. In the numerical analysis, temperature drop through the walls was neglected and constant-temperature boundary conditions were set at the interior surface of the modeling fluid container. Current density was input to a computational region with copper properties which simulated the electrode pair. Physical properties used for the numerical simulations were taken as those reported by Quigley and Kreid. Five numerical simulation cases were run as listed in Table 5.1. Results of overall voltage drop and bulk temperatures predicted by TEMPEST and measured during experiments are compared in Table 5.2. Agreement, in general, is very good with (two-dimensional) best results obtained for Case 4 using an expanding grid and the smallest cell next to the electrode. Predicted voltage drop is within $3 \%$ of data and bulk temperature within $1 \%$ for this case. The fact that best resuits are obtained for the case of the smallest cell next to the electrode plate is not surprising. In this region, temperature gradients are large. Electrical conductivity, being a strongly temperature-dependent property, requires adequate resolution. 


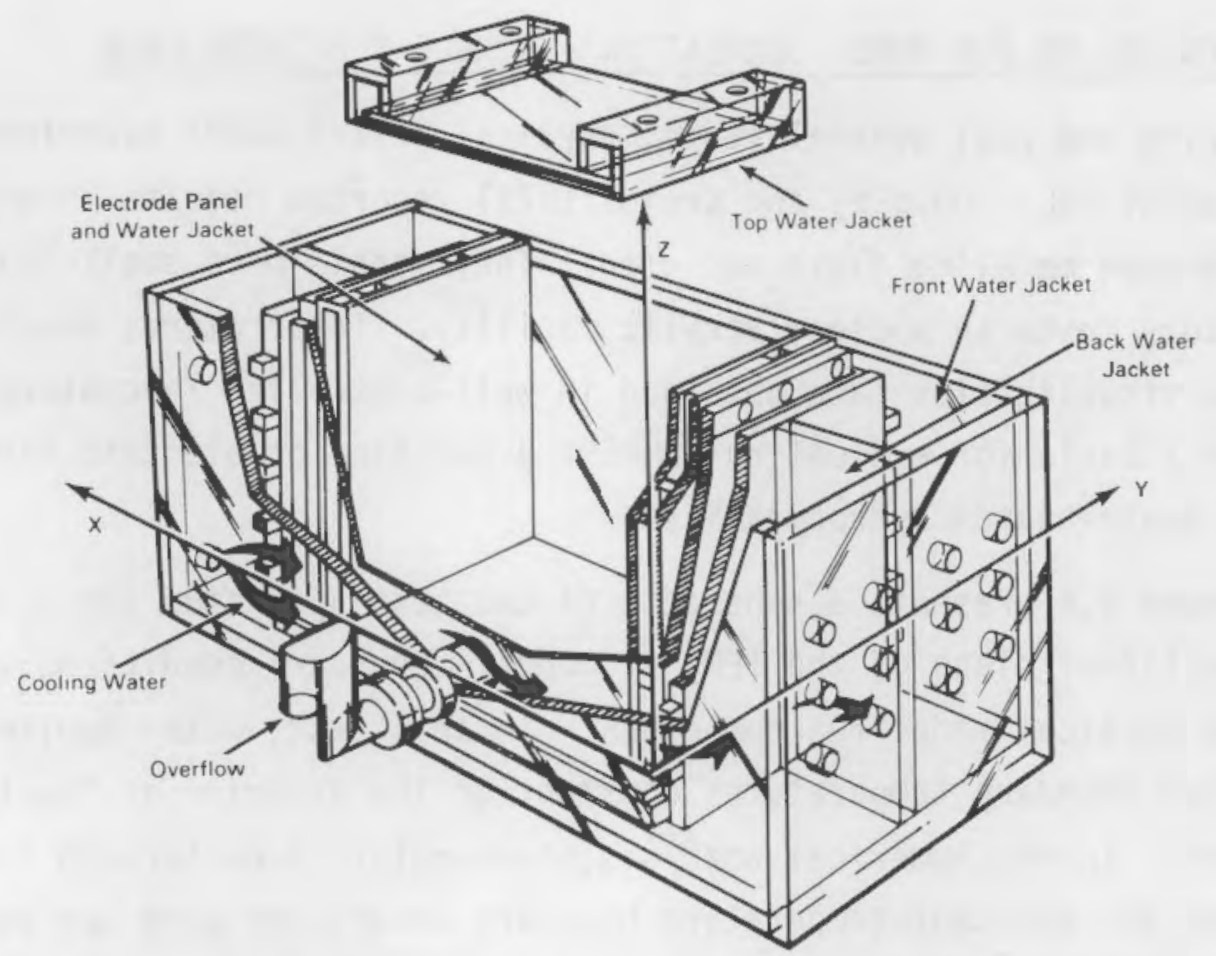

a) Experimental Facility Schematic

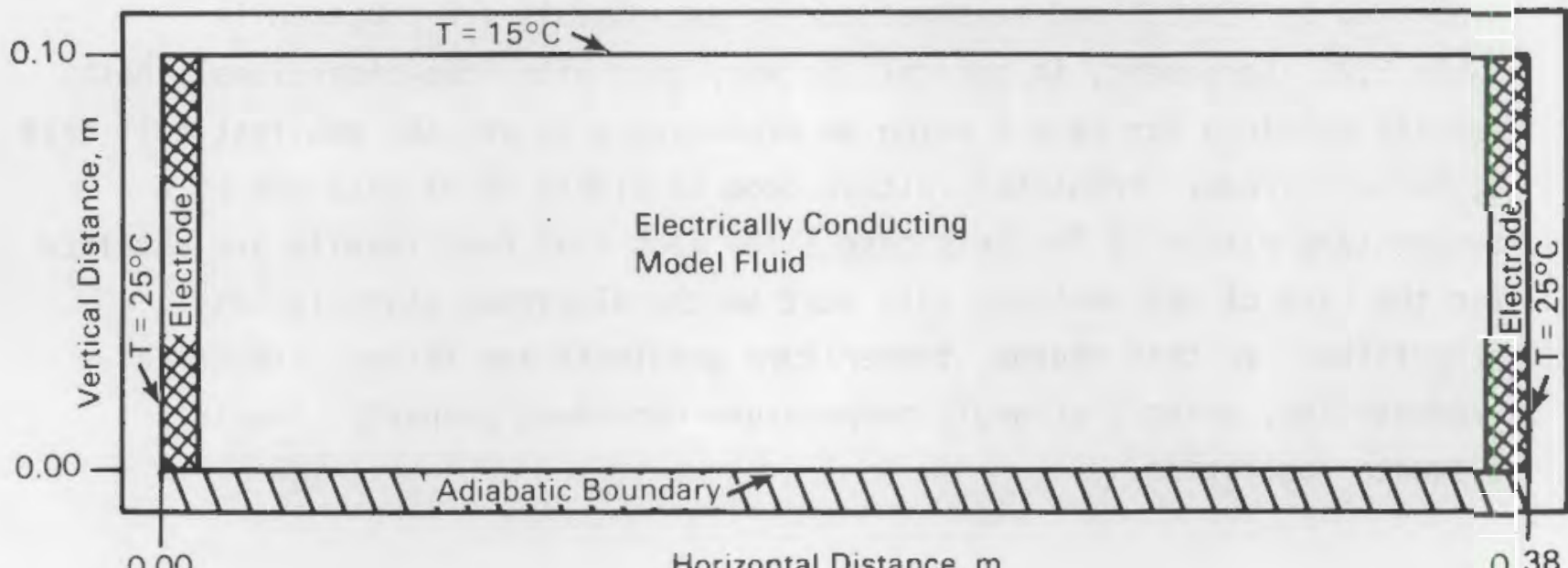

b) Numerical Model Cross Section

FIGURE 5.4. Schematic of Quigley and Kreid (1979) Physical Melter Model 
TABLE 5.1. TEMPEST Representations of Quigley and Kreid Run \#15

\begin{tabular}{|c|c|c|c|}
\hline $\begin{array}{l}\text { Case } \\
\text { No. }\end{array}$ & $\begin{array}{l}\text { Model } \\
\text { Type } \\
\end{array}$ & Grid Type & $\begin{array}{l}\text { Cell Thickness } \\
\text { at Electrode Face, cm } \\
\end{array}$ \\
\hline 1 & $2-D$ & $35 \times 10$ constant & 1.025 \\
\hline 2 & $2-0$ & $70 \times 20$ constant & 0.512 \\
\hline 3 & $2-D$ & $35 \times 10$ expanding & 0.525 \\
\hline 4 & $2-0$ & $35 \times 10$ expanding & 0.250 \\
\hline 5 & $3-D$ & $26 \times 8 \times 13$ expanding & 0.423 \\
\hline
\end{tabular}

TABLE 5.2. Grid Refinement Study Results

\begin{tabular}{|c|c|c|c|c|}
\hline Case & Overal & ol tage Drop, & Bulk & rature, ${ }^{\circ} \mathrm{C}$ \\
\hline & TEMPEST & Experimental & TEMPEST & Experimental \\
\hline 1 & 140.6 & 172.3 & 56.7 & 55.8 \\
\hline 2 & 150.3 & 172.3 & 55.8 & 55.8 \\
\hline 3 & 148.5 & 172.3 & 55.9 & 55.8 \\
\hline 4 & 167.4 & 172.3 & 55.2 & 55.8 \\
\hline 5 & 165.5 & 172.3 & 56.4 & 55.8 \\
\hline
\end{tabular}


Case 5, a three-dimensional numerical model, was run to ascertain if three-dimensional effects are significant. Based on comparison of predicted voltage drop and bulk temperature for this experiment, they do not seem to be significant. This observation is consistent with design of the experimental apparatus, which was to minimize three-dimensional effects.

Comparison of Case 3 to Case 4, in which the total number of nodes is the same but the spacing near the electrode is different, points to the fact that proper noding consideration is important to obtain accurate predictions. Unfortunately, there is no exact method for a priori determination of noding. There are, however, certain considerations which can be taken in to account as discussed subsequently in Section 6.1.

Other aspects of these results are worth noting. Experimental observation indicated that quasi-periodic flow chacteristics occurred. These were of the nature of rising and falling columns of fluid which were neither steady nor completely chaotic. TEMPEST predicted results of a very similar character which are best viewed in a computer-generated movie. Figure 5.5 presents a "snapshot" of velocity vectors and temperature contours at one point in time. These give an indication of the circulation patterns and show the rising/falling character of the flow.

\subsection{PHYSICAL MELTER MOOEL SIMULATION - DUAL ELECTRODE PAIR}

The basis for predicting electric potential and power densities in a melter with two independently powered electrode pairs is presented in Section 4.3. This modeling capability allows prediction of melter operation in which two pairs of electrodes are used. For testing purposes, experiments were conducted to provide a data base for code evaluation. These data are reported in Section 3.0 of this report. Comparisons of the dual-electrode-field capability or power-split model in TEMPEST with experimental data are made here. 


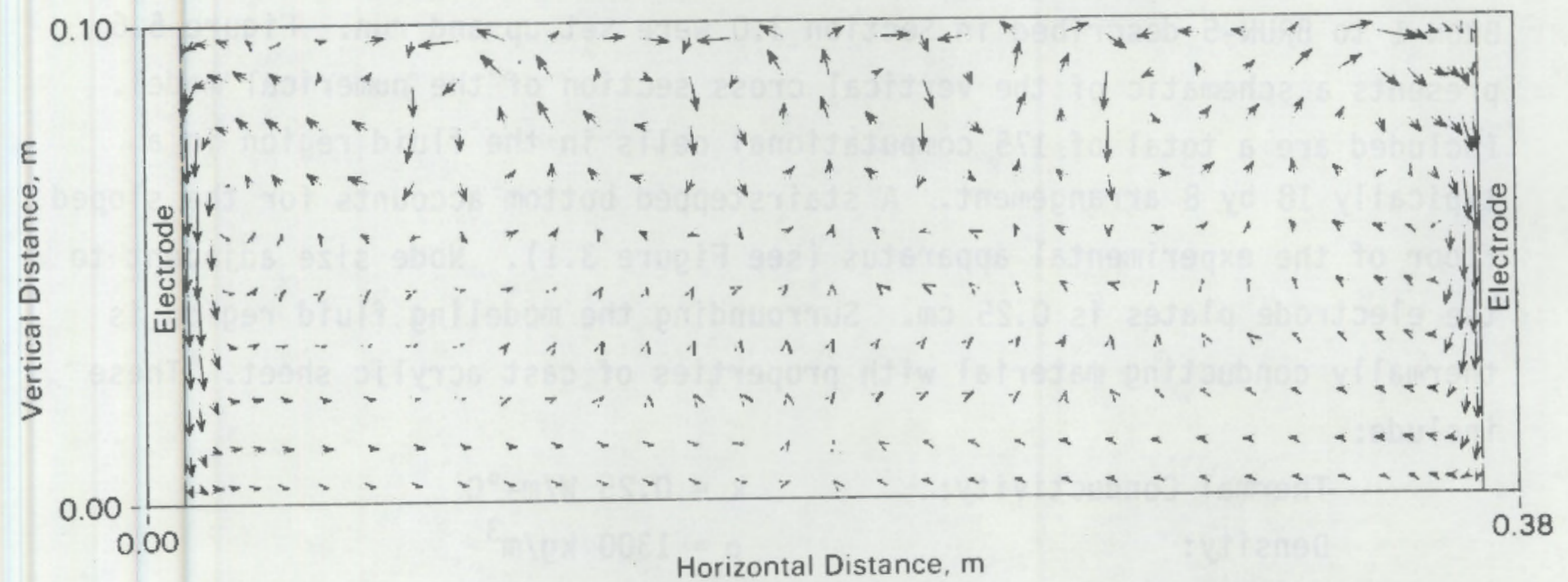

a) Flow Field

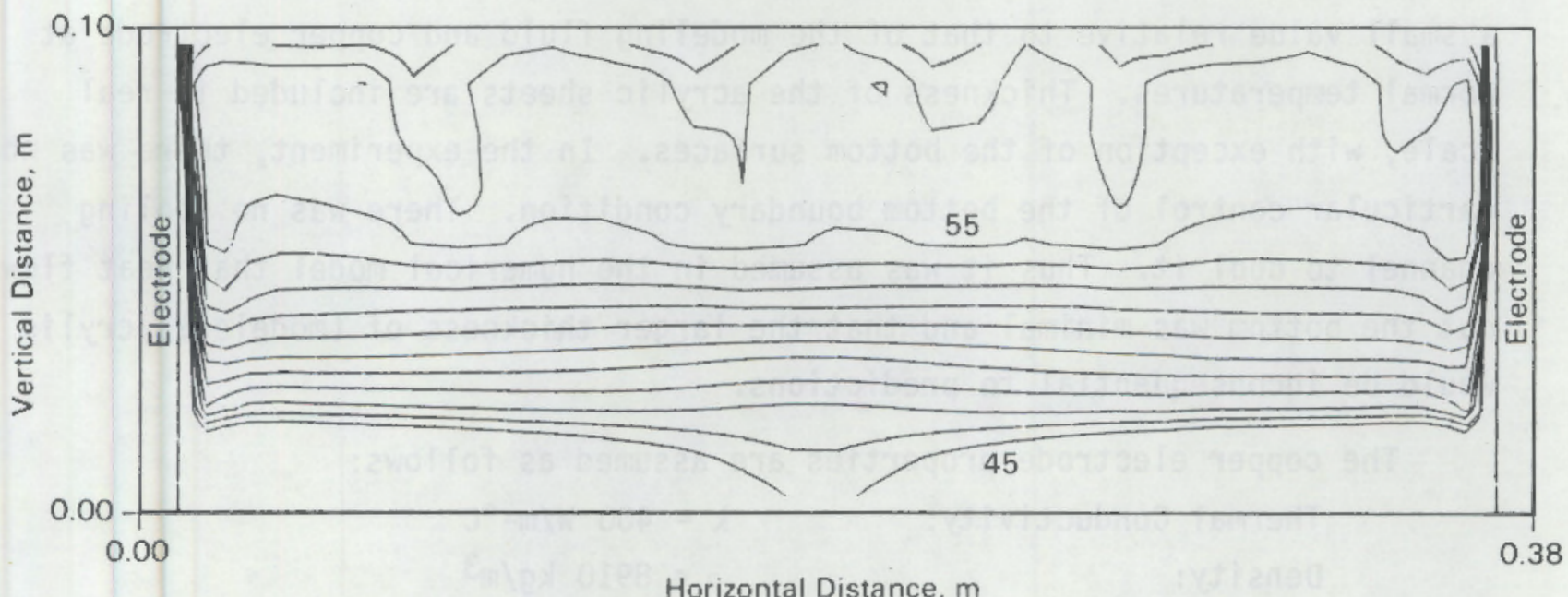

b) Temperature Contours $\left({ }^{\circ} \mathrm{C}\right)$

FIGURE 5.5. Single-Electrode Physical Melter Flow Field and Temperature Contours 


\subsubsection{Numerical Model Description and Analysis Approach}

Based on results presented in Section 5.2, principally noding considerations, two-dimensional numerical models of experimental test runs BRUN-1 to BRUN-5 described in Section 3.0 were set up and run. Figure 5.6 presents a schematic of the vertical cross section of the numerical model. Included are a total of 175 computational cells in the fluid region in a typically 18 by 8 arrangement. A stairstepped bottom accounts for the sloped floor of the experimental apparatus (see Figure 3.1). Node size adjacent to the electrode plates is $0.25 \mathrm{~cm}$. Surrounding the modeling fluid region is thermally conducting material with properties of cast acrylic sheet. These include:

$$
\begin{array}{lll}
\text { Thermal Conductivity: } & k=0.25 \mathrm{~W} / \mathrm{m}^{\circ}{ }^{\circ} \mathrm{C} \\
\text { Density: } & \rho & =1300 \mathrm{~kg} / \mathrm{m}^{3} \\
\text { Specific Heat: } & C_{p}=1674 \mathrm{j} / \mathrm{kg}^{\circ} \mathrm{C} \\
\text { Electrical Conductivity: } & \sigma & =1 \times 10^{-5}(\Omega-\mathrm{m})^{-1}
\end{array}
$$

These properties are typical values and are taken from a buyer's guide for commercially available cast acrylic plastic, with the exception of electrical conductivity. Electrical conductivity of the acrylic is arbitrarily assumed as a small value relative to that of the modeling fluid and copper electrode at normal temperatures. Thickness of the acrylic sheets are included in real scale, with exception of the bottom surfaces. In the experiment, there was no particular control of the bottom boundary condition. There was no cooling channel to cool it. Thus it was assumed in the numerical model that heat flow out the bottom was minimal and that the larger thickness of (modeled) acrylic would be inconsequential to predictions.

The copper electrode properties are assumed as follows:

$$
\begin{array}{llrl}
\text { Thermal Conductivity: } & k=400 \mathrm{~W} / \mathrm{m}-{ }^{\circ} \mathrm{C} \\
\text { Density: } & \rho & =8910 \mathrm{~kg} / \mathrm{m}^{3} \\
\text { Specific Heat: } & C_{p}=385 \mathrm{j} / \mathrm{kg}-{ }^{\circ} \mathrm{C} \\
\text { Electrical Conductivity: } & \sigma & =882(\Omega-m)^{-1}
\end{array}
$$

These values are from Weast (1973). 


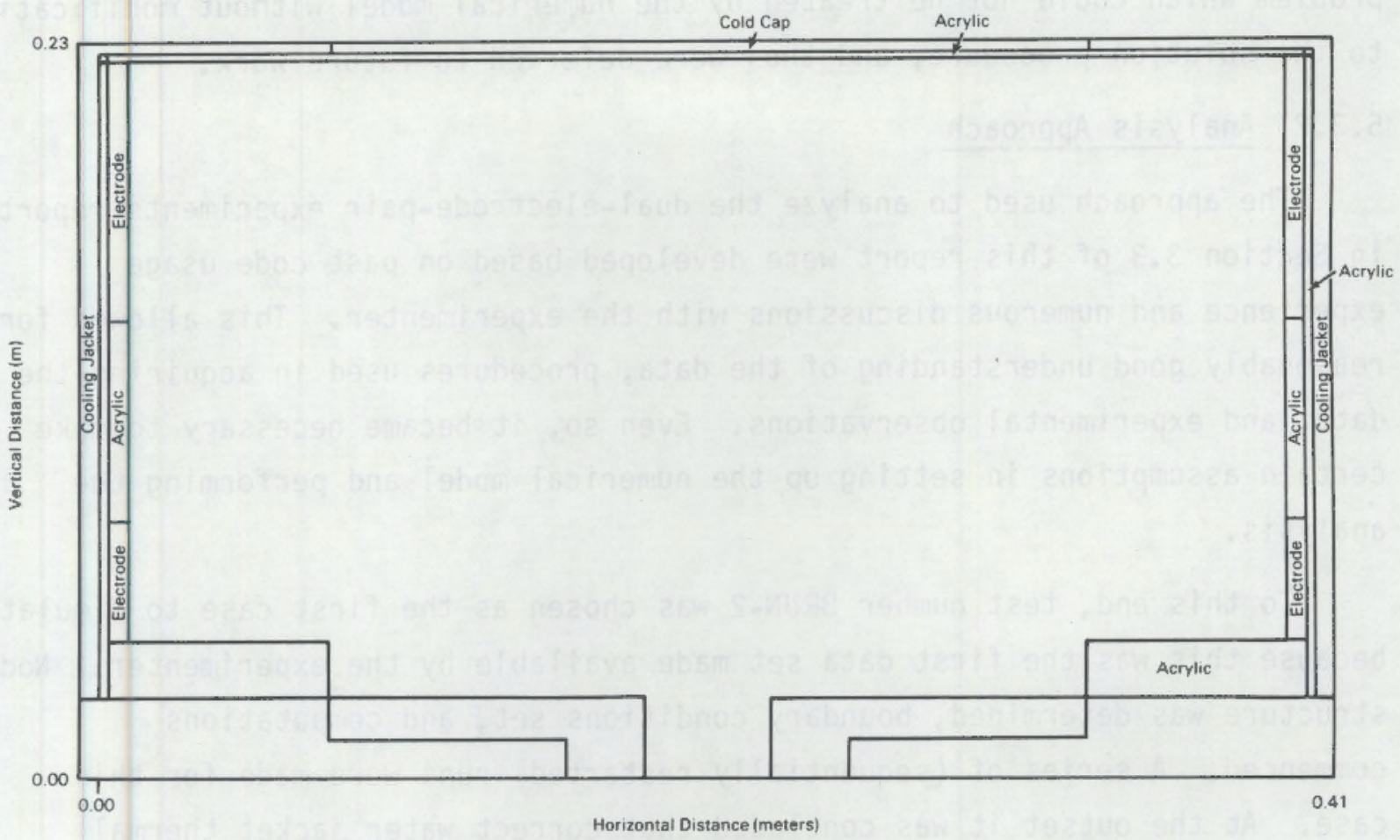

FIGURE 5.6. Numerical Model Vertical Cross Section

In the experiment, water cooling jackets maintain nearly constant boundary temperature conditions. nata for cooling jacket temperatures are used as constant temperature boundary conditions to the exterior surfaces of the numerical model. The cold cap cooling region is included also. Thickness of the top surface acrylic sheet is set at $0.16 \mathrm{~cm}$, the thickness in the experiment between the cold cap cooling channel and the modeling fluid. On either side of this central cooling region, the thickness is less than actual, but this is deemed to be only a minor deficiency to the numerical model. Ambient external conditions in the experiment over this region are unknown.

For tests BRUN-1 to BRUN-3 the distance between electrodes on a wall is $6.35 \mathrm{~cm}$, whereas for runs 4 and 5 it is $2.54 \mathrm{~cm}$. For the former cases, modeling fluid depth is $17.9 \mathrm{~cm}$, whereas it is $14.6 \mathrm{~cm}$ for the latter cases. Test BRUN-6 was not simulated in being deferred to doing BRIN-7 and BRUN-8. Asymmetric results of tests BRIJN-7 and RRINN-8 were caused by a common grounding 
problem which could not he treated by the numerical model without modification to the solution procedure, and thus were deferred to future work.

\subsubsection{Analysis Approach}

The approach used to analyze the dual-electrode-pair experiments reported in Section 3.3 of this report were developed based on past code usage experience and numerous discussions with the experimenter. This allowed for reasonably good understanding of the data, procedures used in acquiring the data, and experimental observations. Even so, it became necessary to make certain assumptions in setting up the numerical model and performing the analysis.

To this end, test number BRUN-2 was chosen as the first case to simulate because this was the first data set made available by the experimenter. Noding structure was determined, boundary conditions set, and computations commenced. A series of (sequentially restarted) runs were made for this case. At the outset it was concluded that correct water jacket thermal boundary conditions were required to obtain good agreement with experimental data for predicted voltage drop across electrodes and temperature field data in the modeling fluid.

Once reasonably good agreement and confidence in the model had been obtained, simulation of test run BRUN-? was computed for an hour of real time over a time span from 280 to 340 minutes. At the end of this time, results, presented in subsequent sections, indicate excellent agreement with data. However, rather large variations in field temperatures and electrode voltage drop over the simulated time span occur.

Upon completion of simulating BRUN-2, test run BRUN-3 was simulated by restarting at a time of 280 minutes and ramping power applied to each electrode pair to the appropriate experimental value. Once full power (or zero) to each pair was attained over a period of 30 minutes, the simulation was carried out for an additional hour. Runs BRUN-1, BRIJN-4, and BRUN-5 were correspondingly restarted from time $t=30$ of $B R U N-3$, ramping to appropriate power levels over a 20-minute time span, and computing to 1 hour of simulation time. Table 5.3 presents the summary of the interrelationships of the simulation runs. 
TABLE 5.3. Sequential Simulation Summary and Interrelationship of Numerical Model Runs

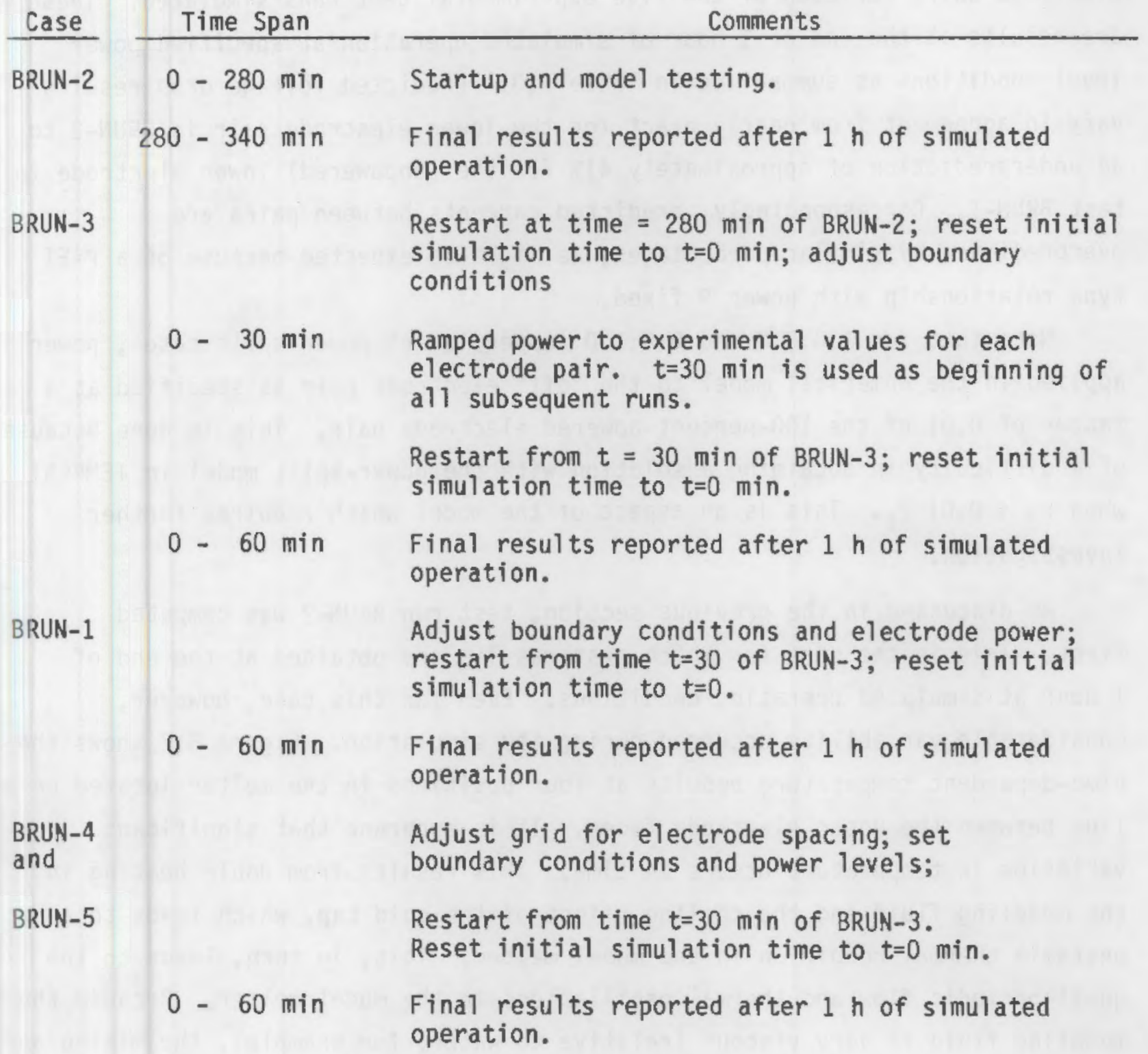




\subsubsection{Numerical Melter Model Results (Two-Dimenisonal)}

A comparison is made in Table 5.4 of the predicted voltage drop across electrode pairs for each of the five experimental test runs simulated. These are results at the end of 1 hour of simulated operation at specified power level conditions as summarized in Table 5.3. Predicted voltage drop results vary in agreement from nearly exact for the lower electrode pair in BRUN-2 to an underprediction of approximately $41 \%$ for the (unpowered) lower electrode in test BRUN-1. Correspondingly, predicted currents between pairs are overpredicted by similar percentages, as might be expected because of a $P=E I$ type relationship with power $p$ fixed.

Note that for 1.0:0.0 and 0.0:1.0 (upper/lower) power-split cases, power applied in the numerical model to the "off" electrode pair is specified at a factor of 0.01 of the 100-percent-powered electrode pair. This is done because of a difficulty in obtaining a solution with the power-split model in TEMPEST when $P_{2}<0.01 P_{1}$. This is an aspect of the model which requires further investigation.

As discussed in the previous section, test run BRUN-2 was computed first. This is the case for which best results are obtained at the end of 1 hour at simulated operating conditions. Even for this case, however, considerable variability occurred during the simulation. Figure 5.7 shows the time-dependent temperature results at four positions in the melter located on a line between the upper electrode faces. It is apparent that significant variation in temperature occurs in time. This results from Joule heating in the modeling fluid and the cooling effect of the cold cap, which leads to an unstable thermal condition in the model melter. This, in turn, leads to the quasi-periodic flow and thermal oscillations in the model melter. Because the modeling fluid is very viscous (relative to water, for example), the mixing and thermal oscillations in the fluid are very slow. As a result of these very slowly changing, thermally induced effects, it is difficult to determine when quasi-steady conditions are reached in the numerical simulations.

Predicted voltage drop between electrode pairs is sensitive to temperatures through the temperature dependence of electrical conditivity. As 
TABLE 5.4. Two-Dimensional Numerical Model Voltage Drop Results After 1 Hour at Simulated Operating Conditions

\begin{tabular}{|c|c|c|c|c|c|c|c|}
\hline \multirow[b]{2}{*}{ Test Run } & \multirow[b]{2}{*}{ Time } & \multirow{2}{*}{\multicolumn{2}{|c|}{ Variable }} & \multicolumn{2}{|c|}{ Upper Electrode } & \multicolumn{2}{|c|}{ Lower Electrode } \\
\hline & & & & Data ${ }^{(a)}$ & TEMPEST ${ }^{(b)}$ & $\operatorname{DATA}^{(a)}$ & TEMPEST ${ }^{(b)}$ \\
\hline BRUN-1 & 60 min & $\begin{array}{r}\text { power (W) } \\
\text { voltage (V) } \\
\text { current (A) }\end{array}$ & $\begin{array}{l}= \\
= \\
=\end{array}$ & $\begin{array}{c}291.3 / 297.4 \\
104.4 / 106.6 \\
2.79 / 2.79\end{array}$ & $\begin{array}{l}295.0 \\
64.6 \\
4.57\end{array}$ & ${ }^{\star *} 65.9 / 58.5$ & $\begin{array}{l}2.96 \\
34.0 \\
0.27\end{array}$ \\
\hline BRUN-2 & $340 \mathrm{~min}$ & $\begin{array}{r}\text { power (W) } \\
\text { voltage (V) } \\
\text { current (A) }\end{array}$ & $\begin{array}{l}= \\
= \\
=\end{array}$ & ${ }^{\star *} 31.6 / 39.5$ & $\begin{array}{l}1.14 \\
24.8 \\
0.15\end{array}$ & $\begin{array}{c}105.9 / 113.0 \\
80.2 / 84.3 \\
1.32 / 1.34\end{array}$ & $\begin{array}{l}113.0 \\
82.3 \\
1.38\end{array}$ \\
\hline BRUN-3 & $60 \mathrm{~min}$ & $\begin{array}{r}\text { power }(W) \\
\text { voltage }(\mathrm{V}) \\
\text { current }(\mathrm{A})\end{array}$ & $\begin{array}{l}= \\
= \\
=\end{array}$ & $\begin{array}{c}150.7 / 155.0 \\
88.1 / 89.6 \\
1.71 / 1.73\end{array}$ & $\begin{array}{l}151.9 \\
61.3 \\
2.55\end{array}$ & $\begin{array}{c}149.2 / 151.4 \\
102.9 / 104.4 \\
1.45 / 1.45\end{array}$ & $\begin{array}{l}152.0 \\
78.5 \\
1.99\end{array}$ \\
\hline BRUN-4 & $60 \mathrm{~min}$ & $\begin{array}{r}\text { power (W) } \\
\text { voltage (V) } \\
\text { current (A) }\end{array}$ & $\begin{array}{l}= \\
= \\
=\end{array}$ & $\begin{array}{c}290.1 / 293.2 \\
105.5 / 106.6 \\
2.75 / 2.75\end{array}$ & $\begin{array}{l}295.0 \\
82.9 \\
3.56\end{array}$ & ${ }^{\star \star} \quad 74.3 / 74.3$ & $\begin{array}{l}2.96 \\
57.0 \\
0.21\end{array}$ \\
\hline BRUN-5 & $60 \mathrm{~min}$ & $\begin{array}{r}\text { power }(W) \\
\text { voltage }(\mathrm{V}) \\
\text { current }(\mathrm{A})\end{array}$ & $\begin{array}{l}= \\
= \\
=\end{array}$ & $\stackrel{\star \star \star}{*} 60.6 / 60.6$ & $\begin{array}{l}2.61 \\
45.9 \\
0.25\end{array}$ & $\begin{array}{c}259.7 / 261.0 \\
114.9 / 115.5 \\
2.26 / 2.26\end{array}$ & $\begin{array}{l}260.0 \\
94.0 \\
2.77\end{array}$ \\
\hline
\end{tabular}

(a) low/high for successive experimental runs; * indicates $\mathrm{I}<0.15 \mathrm{~A}$;

* indicates power-off condition

(b) power specified; voltage and current computed. 


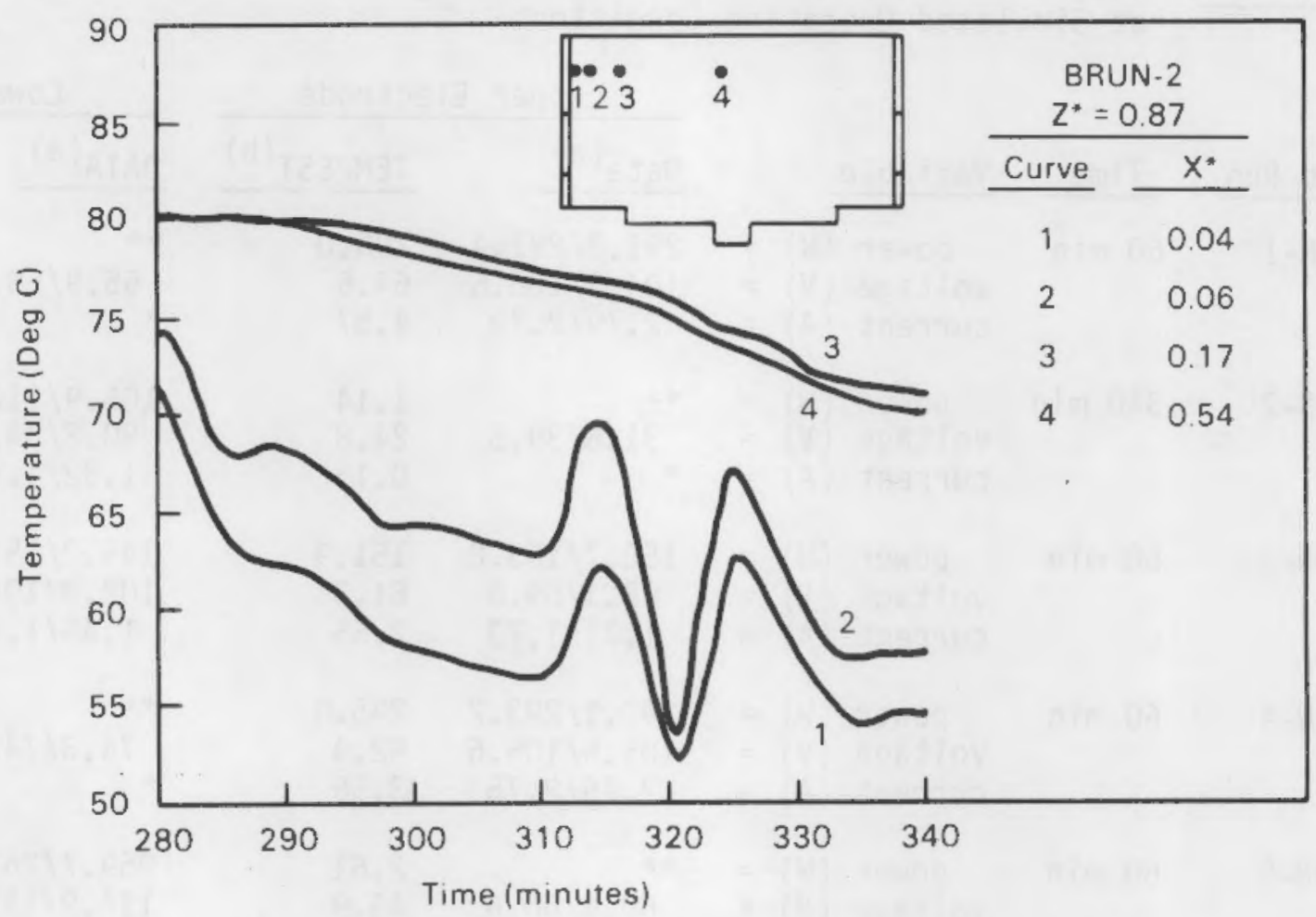

FIGURE 5.7. Transient Temperatures - Test Run BRUN-2

an example, for the temperature results in Figure 5.7, predicted voltage drops vary correspondingly as presented in Table 5.5. It is apparent from this table that agreement of predicted results and experimental data may be falsely interpreted if quasi-steady conditions are concluded when in reality they have not been reached. In this regard, additional work needs to be done to ascertain when quasi-steady results are obtained. Alternatively, timedependent experimental data acquired over a longer period of time may be useful. 
TABLE 5.5. Time-Dependent Voltage Drop Across Lower Electrode for Test Run BRUN-2

$\begin{array}{cc}\text { Time, min } & \text { Voltage Drop, } V \\ 280 & 58.3 \\ 290 & 64.9 \\ 300 & 66.3 \\ 310 & 68.6 \\ 320 & 70.8 \\ 320 & 72.4 \\ 330 & 77.8 \\ 340 & 82.3\end{array}$

Transient temperature results of other tests are included in Figures 5.8 to 5.11. Corresponding predicted voltage drops are presented in Table 5.6 for several points in time. For test run BRUN-1, a $100 \%$ upper $/ 0 \%$ lower power split test, temperatures are slowly increasing with time. Correspondingly, predicted voltage drops are slowly decreasing in time. BRUN-4 is also a $100 \%$ upper/0\% lower test but with a lesser distance between electrodes. Temperature results (Figure 5.10) show a generally increasing trend with a corresponding voltage drop (Table 5.6). However, just prior to 60 minutes, a strong perturbation to the flow and, hence, thermal field, develops as an unstable buoyancy effect induces a large turnover. Test runs BRUN-2 and BRUN-5, which are $0 \%$ upper $/ 100 \%$ lower tests, show more agitation or oscillatory behavior near the walls. Test run BRUN-3, on the other hand, is reasonably quiescent over the time from 15 to 45 minutes, whereafter it also experiences a buoyancy-induced perturbation. 


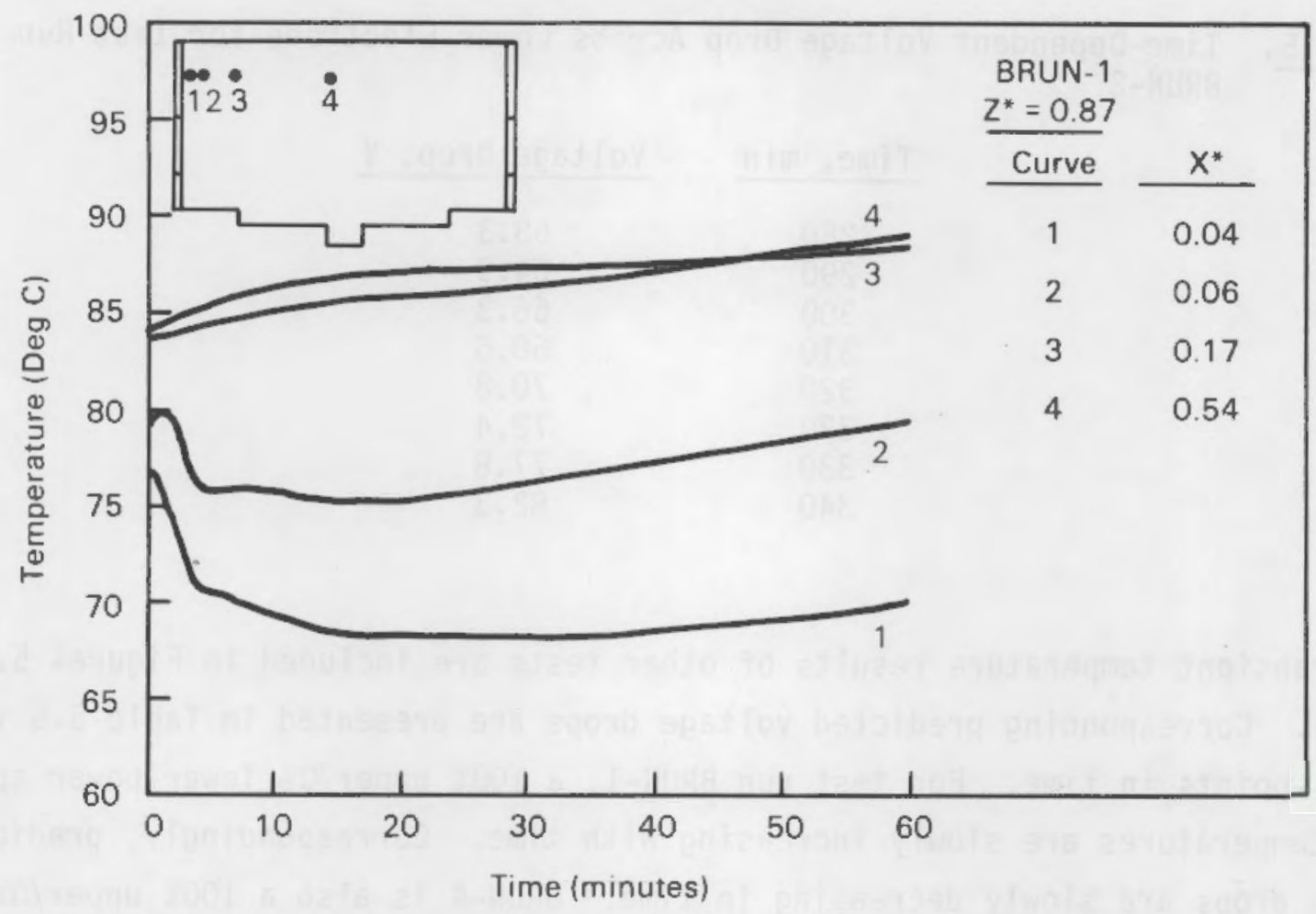

FIGURE 5.8. Transient Temperatures Test for Run BRUN-1

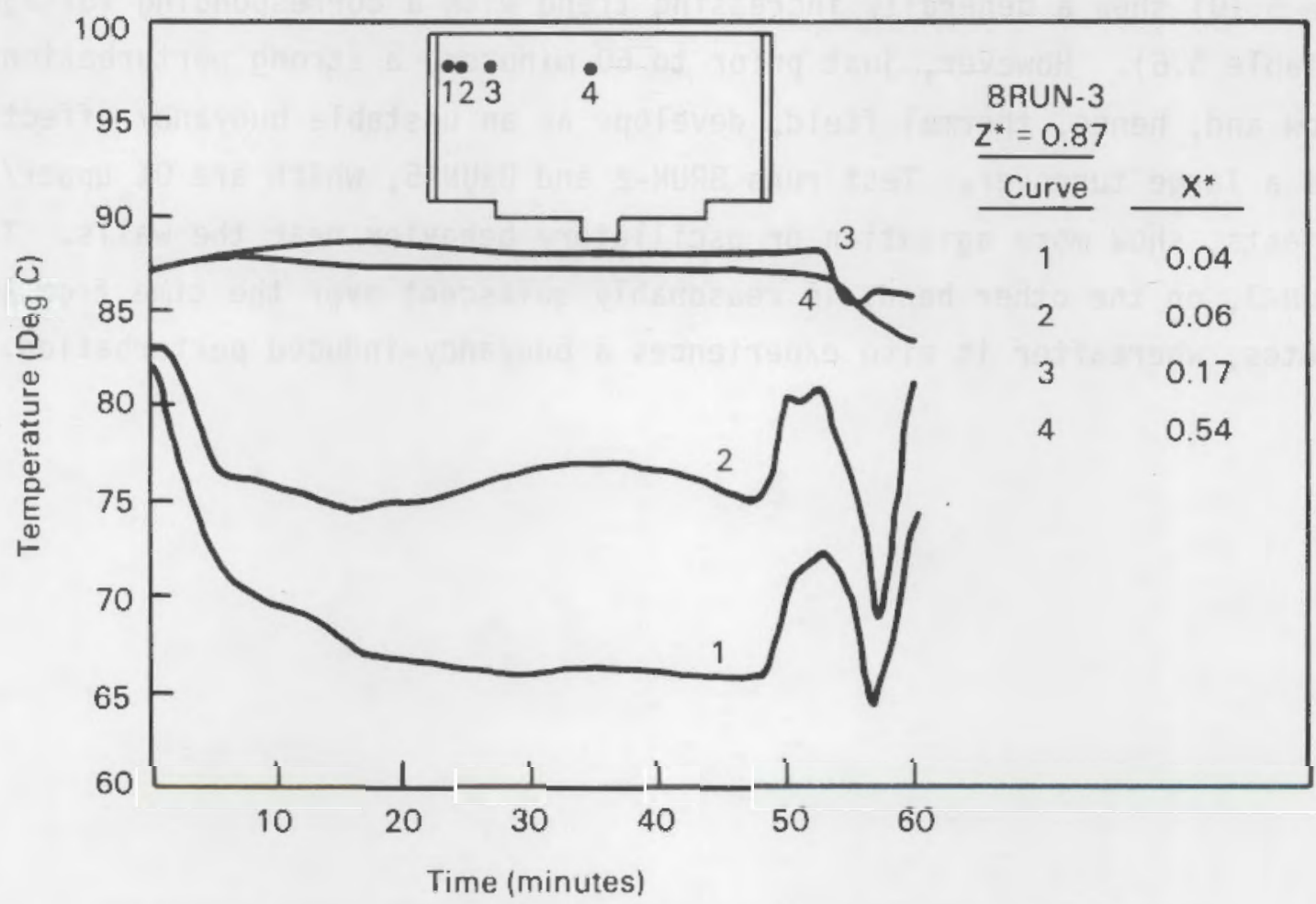

FIGURE 5.9. Transient Temperatures Test for Run BRUN-3 


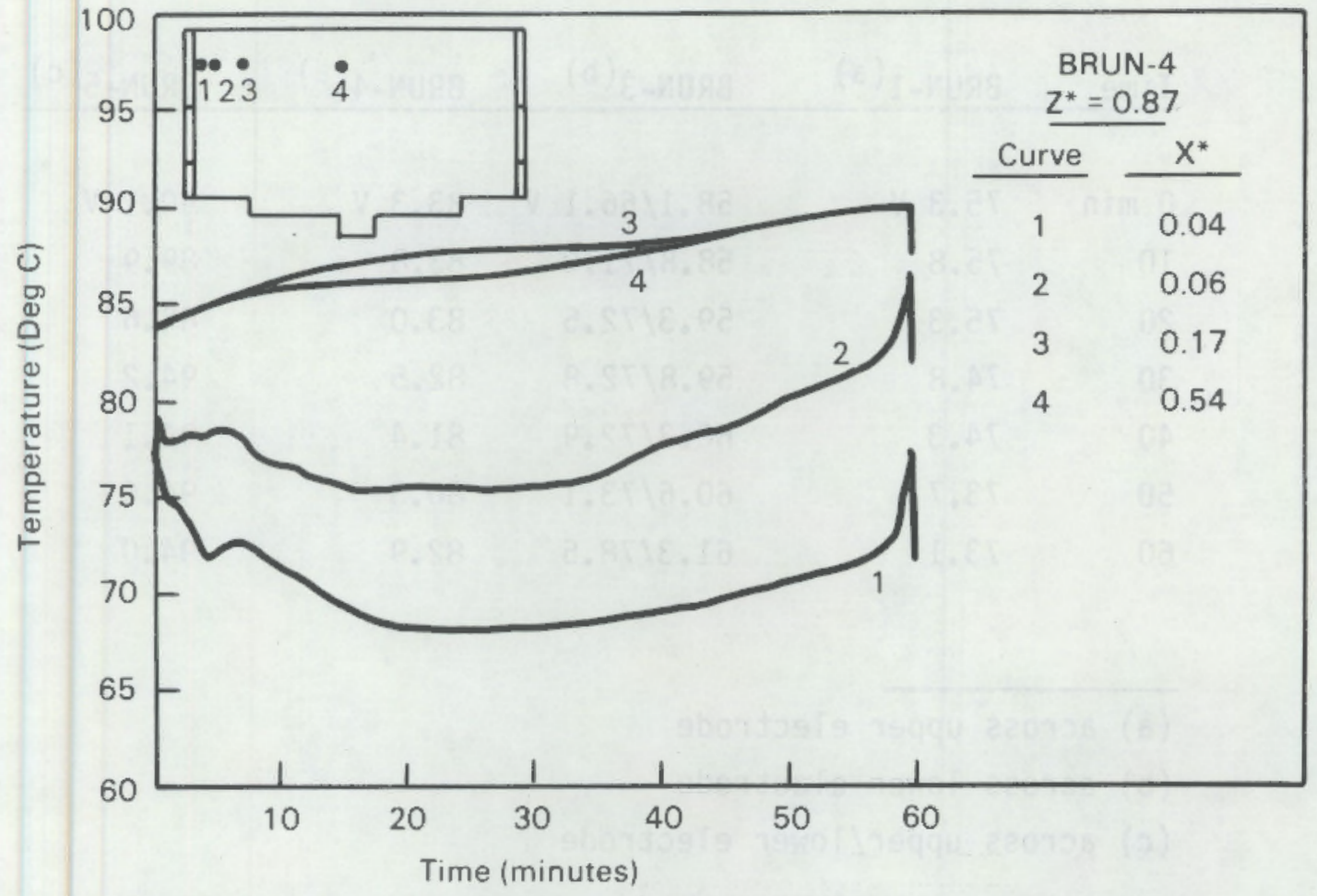

FIGURE 5.10. Transient Temperatures Test for Run BRUN-4

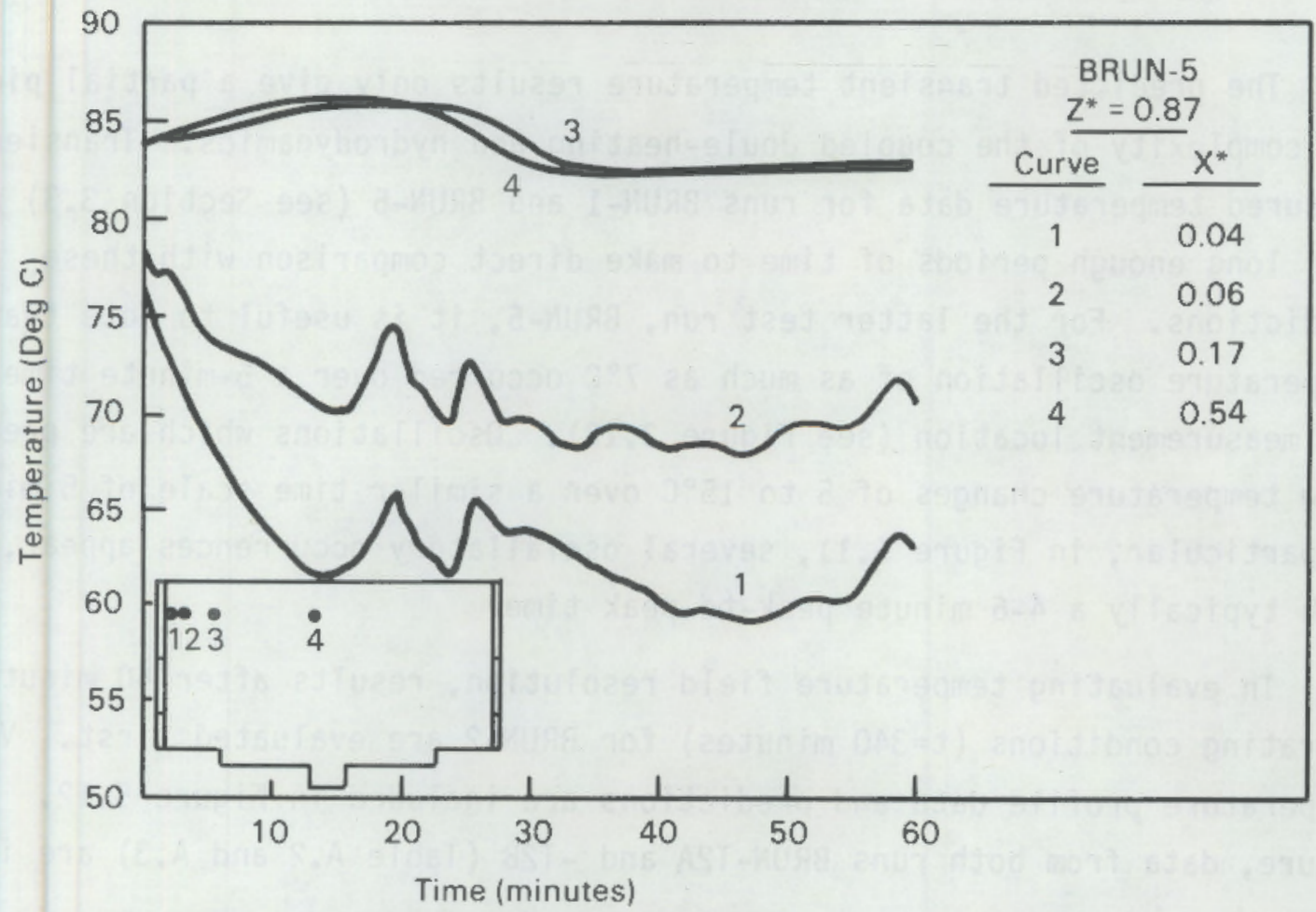

FIGURE 5.11. Transient Temperatures Test for Run BRUN-5 
TABLE 5.6. Time-Dependent Voltage Drop Results

\begin{tabular}{|c|c|c|c|c|}
\hline Time & BRUN-1 (a) & BRUN-3 ${ }^{(b)}$ & BRUN-4 (a) & BRUN-5 (c) \\
\hline $0 \mathrm{~min}$ & $75.3 \mathrm{~V}$ & $58.1 / 66.1 \mathrm{~V}$ & $83.3 \mathrm{~V}$ & $90.1 \mathrm{~V}$ \\
\hline 10 & 75.8 & $58.8 / 71.0$ & 83.8 & 89.9 \\
\hline 20 & 75.3 & $59.3 / 72.5$ & 83.0 & 88.6 \\
\hline 30 & 74.8 & $59.8 / 72.8$ & 82.5 & $94 . ?$ \\
\hline 40 & 74.3 & $60.3 / 72.9$ & 81.4 & 94.1 \\
\hline 50 & 73.7 & $60.6 / 73.1$ & 80.3 & 94.5 \\
\hline 60 & 73.1 & $61.3 / 78.5$ & 82.9 & 94.0 \\
\hline
\end{tabular}
(a) across upper electrode
(b) across lower electrode
(c) across upper/lower electrode

The predicted transient temperature results only give a partial picture of the complexity of the coupled Joule-heating and hydrodynamics. Transient measured temperature data for runs BRUN-1 and BRUN-5 (see Section 3.3) are not over long enough periods of time to make direct comparison with these predictions. For the latter test run, BRUN-5, it is useful to note that a temperature oscillation of as much as $7^{\circ} \mathrm{C}$ occurred over a 5 -minute time span at one measurement location (see Figure 3.13). Oscillations which are predicted show temperature changes of 5 to $15^{\circ} \mathrm{C}$ over a similar time scale of 5 minutes. In particular, in Figure 5.11, several osciallatory occurrences appear, each with typically a 4-6 minute peak-to-peak time.

In evaluating temperature field resolution, results after 60 minutes at operating conditions ( $t=340$ minutes) for BRUN-2 are evaluated first. Vertical temperature profile data and predictions are included in Figure 5.12. In the figure, data from both runs BRUN-T2A and - T2B (Table A.? and A.3) are included 
for the six positions across the horizontal direction. In the central region, $0.40 \leq x^{\star} \leq 0.60$, very good agreement is found over the whole vertical line. The cold cap cooling very near the top wall is evident in both data and predictions at these locations. Nearer the walls where the electrodes are, predictions are typically $10^{\circ} \mathrm{C}$ colder than data over the upper two-thirds of the region. Note that, for several locations, data deviation between runs -T2A and $-\mathrm{T} 2 \mathrm{~B}$ are as much as between data and predictions.

For this $100 \%$ lower $/ 0 \%$ upper case, data show considerably warmer fluid very near the lower (powered) electrode pair faces. This trend, also apparent in several other runs presented subsequently, is not predicted in these calculations. The reason for not predicting such a locally warmer fluid has not been confirmed. Several causes have been postulated. It is possible that too much heat is being removed through the walls directly behind the electrodes. In one test case where thermal conductivity of acrylic sheet was decreased arbitrarily by a factor of 5 , relative temperatures increased by $10^{\circ} \mathrm{C}$ to $15^{\circ} \mathrm{C}$ throughout the modeling fluid, but no locally high temperatures directly in front of the powered electrode faces were predicted.

The side walls removing too much heat may also be an artifice of the twodimensional mode1. Without front and back walls, over one-third of the effective heat transfer area is not present. Thus, proportionally more heat has to flow out through the top, bottom, and side walls. Insufficient data are available from cooling flow channels to adequately determine relative percentages of heat being removed through each wall. If such a ratio could be determined, further numerical evaluations could be made to determine if heat flow path or other effects were causal. If a thermocouple were actually buried in each electrode, then actual electrode temperatures could be set in a numerical model and other effects evaluated. 


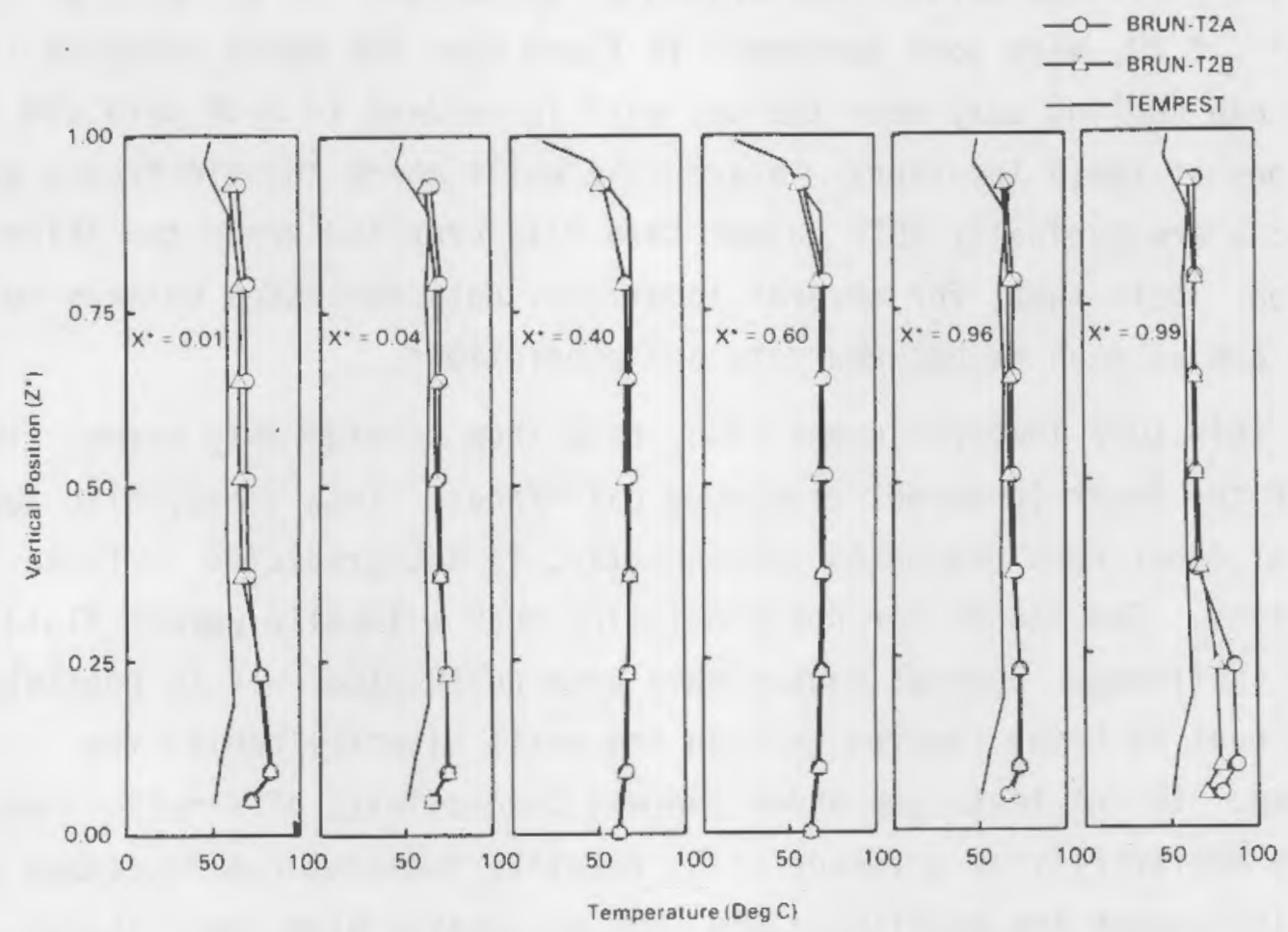

FIGURE 5.12. Temperature Distrubtions in Modeling Fluid, Test Run BRUN-2

One very significant effect may result from not accurately predicting the locally higher temperatures directly in front of the electrode face. Hotter fluid there would lead to a more positive buoyancy force along a side wall and thus induce a stronger upflow. This, in turn, should induce enhanced circulation throughout the model melter. The higher temperature would also have an effect on predicted voltage drop through temperature-dependent electrical conductivity.

Vertical temperature distribution comparisons for test runs BRUN-1, -3 , -4 , and -5 are included in Figures 5.13 to 5.15 , respectively. Figure 5.13 is for test run BRUN-T1A, a case of $100 \%$ upper/0\% lower power split. For this test, predictions are typically $10^{\circ} \mathrm{C}$ higher than data in the central region. Adjacent to each powered electrode face, temperatures are overpredicted, whereas they are underpredicted for near the lower, unpowered electrode. It is interesting to note that, for this test, there is not an 


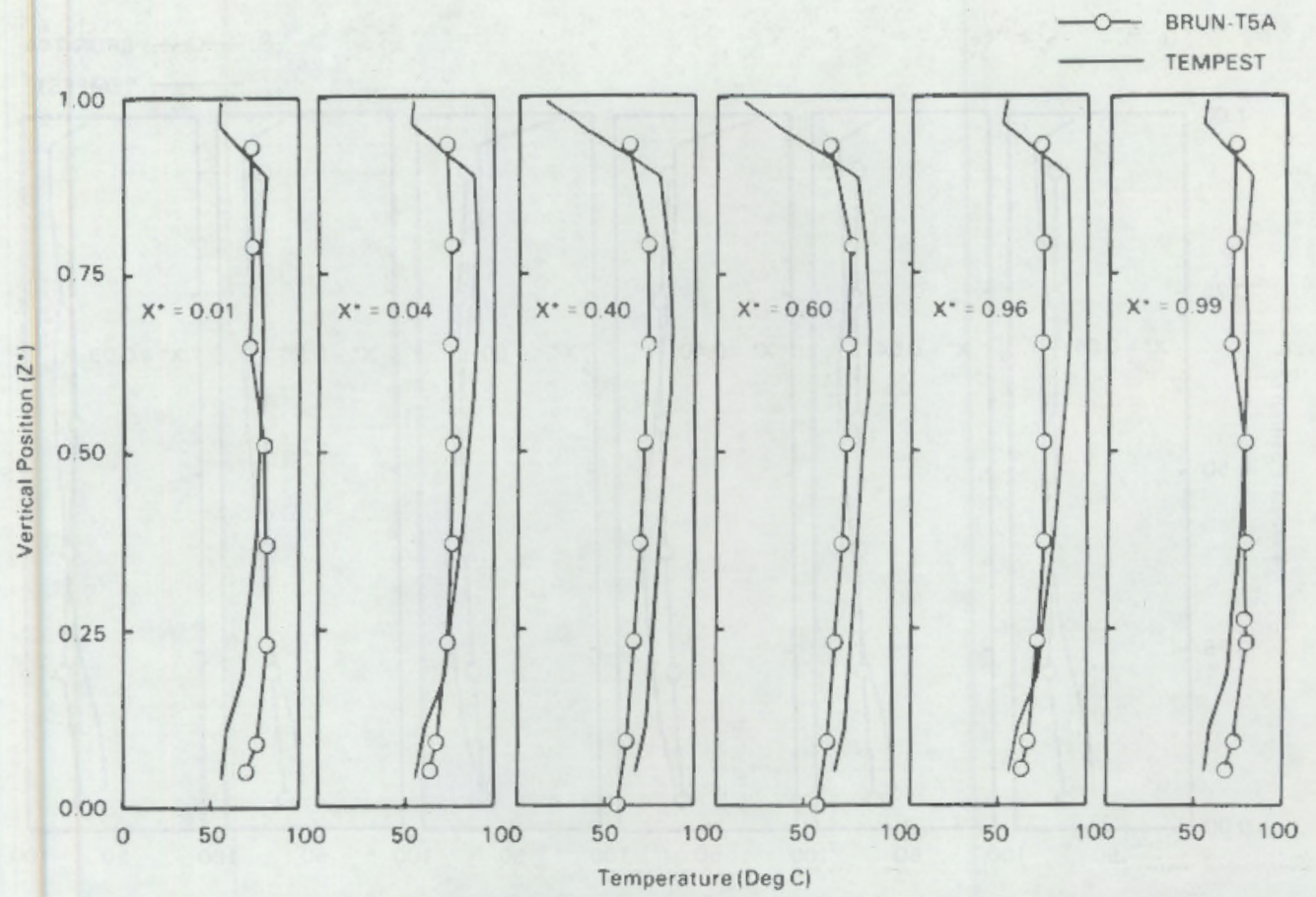

FIGURE 5.13. Temperature Distributions in Modeling Fluid, Test Run BRUN-1

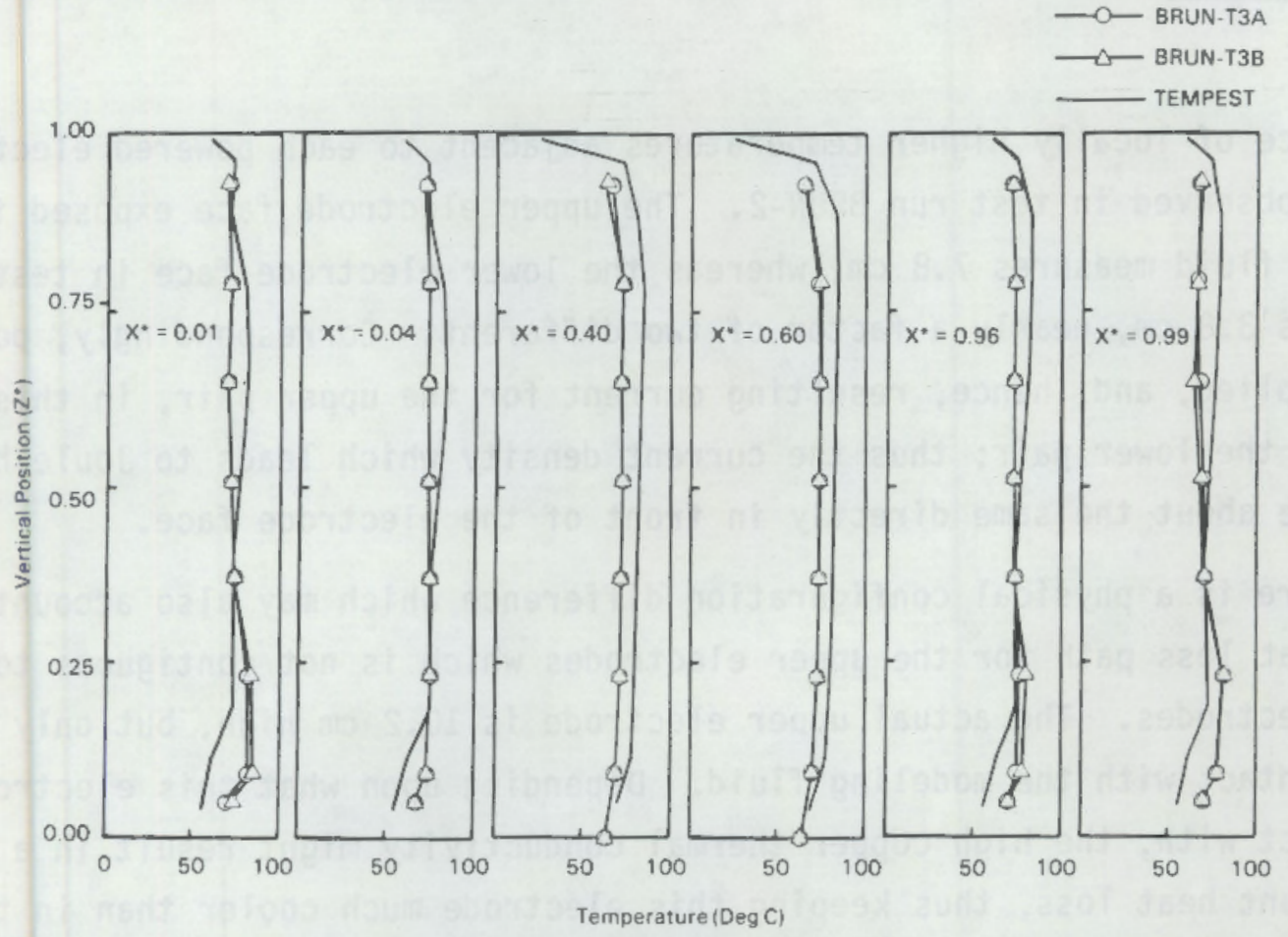

FIGURE 5.14. Temperature Distribution in Modeling Fluid, Test Run BRUN-3 


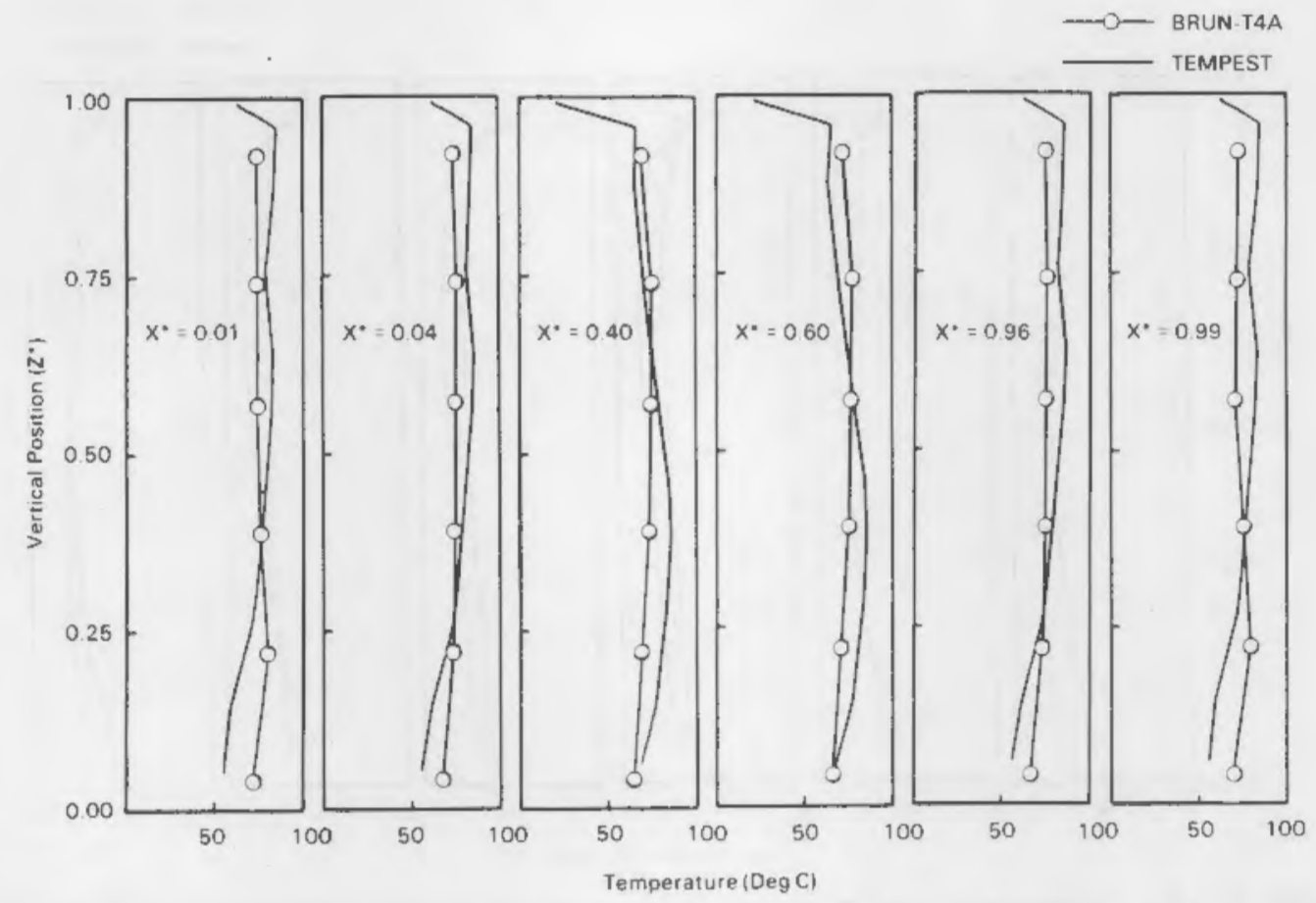

FIGURE 5.15. Temperature Distribution in Modeling Fluid, Test Run BRUN-4

occurrence of locally higher temperatures adjacent to each powered electrode face as observed in test run BRUN-2. The upper electrode face exposed to modeling fluid measures $7.8 \mathrm{~cm}$, whereas the lower electrode face in test run BRUN-2 is $3.8 \mathrm{~cm}$, nearly a factor of two different. Correspondingly, power level applied, and, hence, resulting current for the upper pair, in this test is twice the lower pair; thus the current density which leads to Joule heating should be about the same directly in front of the electrode face.

There is a physical configuration difference which may also account for an added heat loss path for the upper electrodes which is not contiguous to the lower electrodes. The actual upper electrode is $10.2 \mathrm{~cm}$ high, but only $7.8 \mathrm{~cm}$ is in contact with the modeling fluid. Depending upon what this electrode is in contact with, the high copper thermal conductivity might result in a significant heat loss, thus keeping this electrode much cooler than in the $100 \%$ powered lower pair cases. This possible enhanced heat flow path was not 
included explicitly in the numerical model, but in fact may have occurred because of noding configuration and specification of external ambient condition.

Results for test run RRUN-3, a 1nก\% upper/100\% lower power-split test, are included in Figure 5.14. Predictions are in good agreement with data in certain regions and at variance by $10^{\circ} \mathrm{C}$ to $12^{\circ} \mathrm{C}$ in other regions. As in simulation of test run BRUN-2, predictions do not show locally higher temperatures directly in front of the lower electrode faces.

Results in Figure 5.15 are for test run BRUN-4. This is a $100 \%$ upper $/ 0 \%$ lower power-split test, similar to BRUN-1, but with a modeling fluid depth of $14.6 \mathrm{~cm}$ and a $2.54 \mathrm{~cm}$ (vertical) spacing between electrodes. Comparison of data and predictions are in reasonably good agreement throughout the modeling fluid, with some temperatures underpredicted and others overpredicted.

Test run BRUN-5 results in Figure 5.16 (note the temperature axis scale change from previous figures) show an even more pronounced local heating effect in front of the lower electrode pair. Local temperatures reach as high as $122^{\circ} \mathrm{C}$. As in the previous $0 \%$ upper $/ 100 \%$ lower simulation, predicted results do not agree well with the locally higher values of temperature.

Experimental data were not obtained for tests BRIIN-1 to BRUN-5, to which predicted flow fields (velocity magnitude and direction) could be compared. Test runs BRUN-7 and BRUN-8 were designed for this purpose, but as discussed in Section 3.5, an electrode grounding problem developed. This is unfortunate, because flow data would be useful to qualify statements concerning buoyancyinduced effects, flow direction along electrode faces, and quasi-periodic oscillatory behavior. These are effects significant to actual melter design considerations for mixing, material residence time, and potential stagnation regions.

Comparison of measured electric potential measurements in the modeling fluid is made in Figures 5.17 to 5.20. Presented are vertical distributions at normalized horizontal positions of $x^{*}=0.04,0.40,0.60$, and 0.96 . Electric 


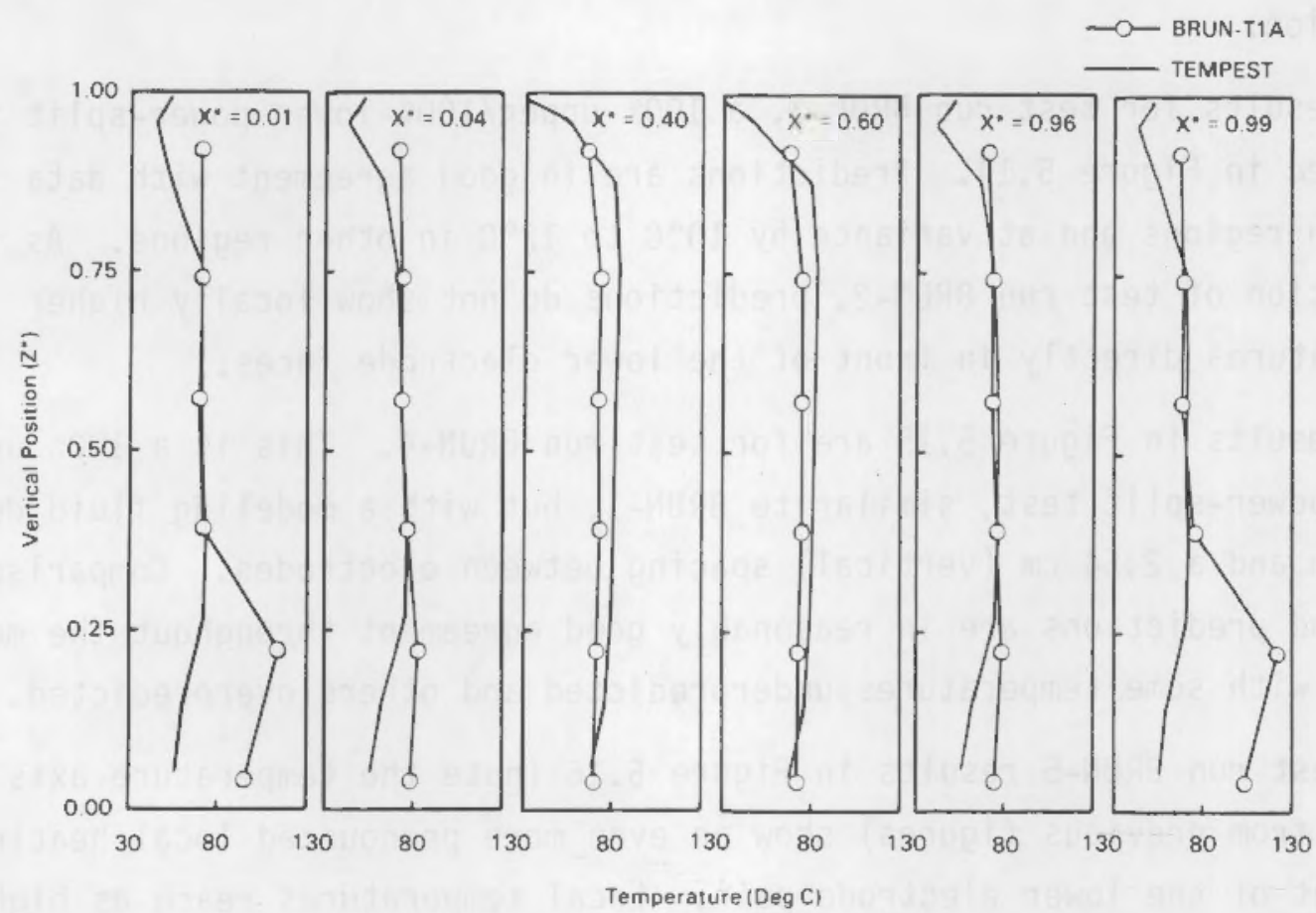

FIGURE 5.16. Temperature Distribution in Modeling Fluid, Test Run BRUN-5

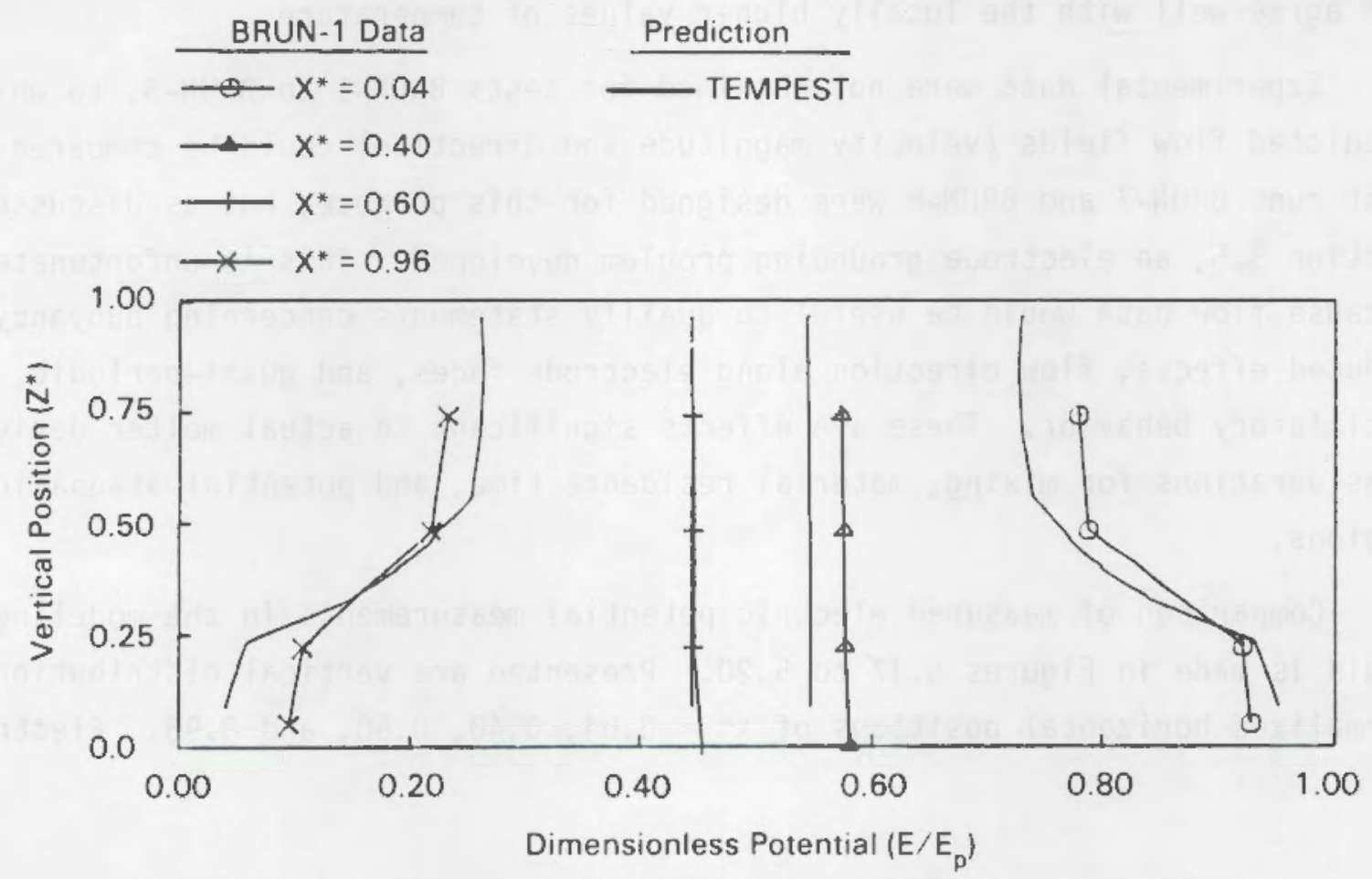

FIGURE 5.17. Normalized Electric Potential, Test Run BRUN-1 


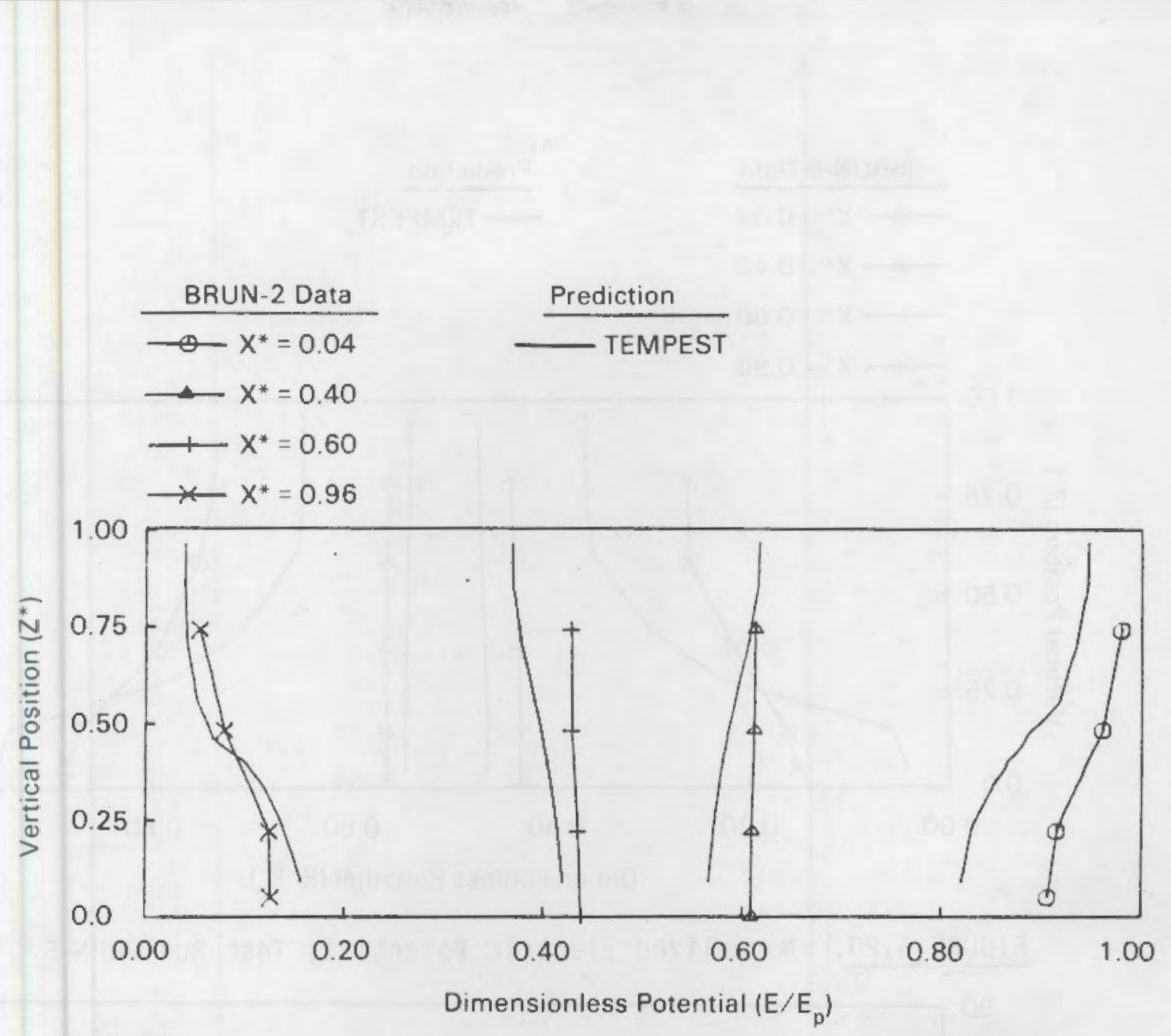

FIGURE 5.18. Normalized Electric Potential, Test Run BRUN-2

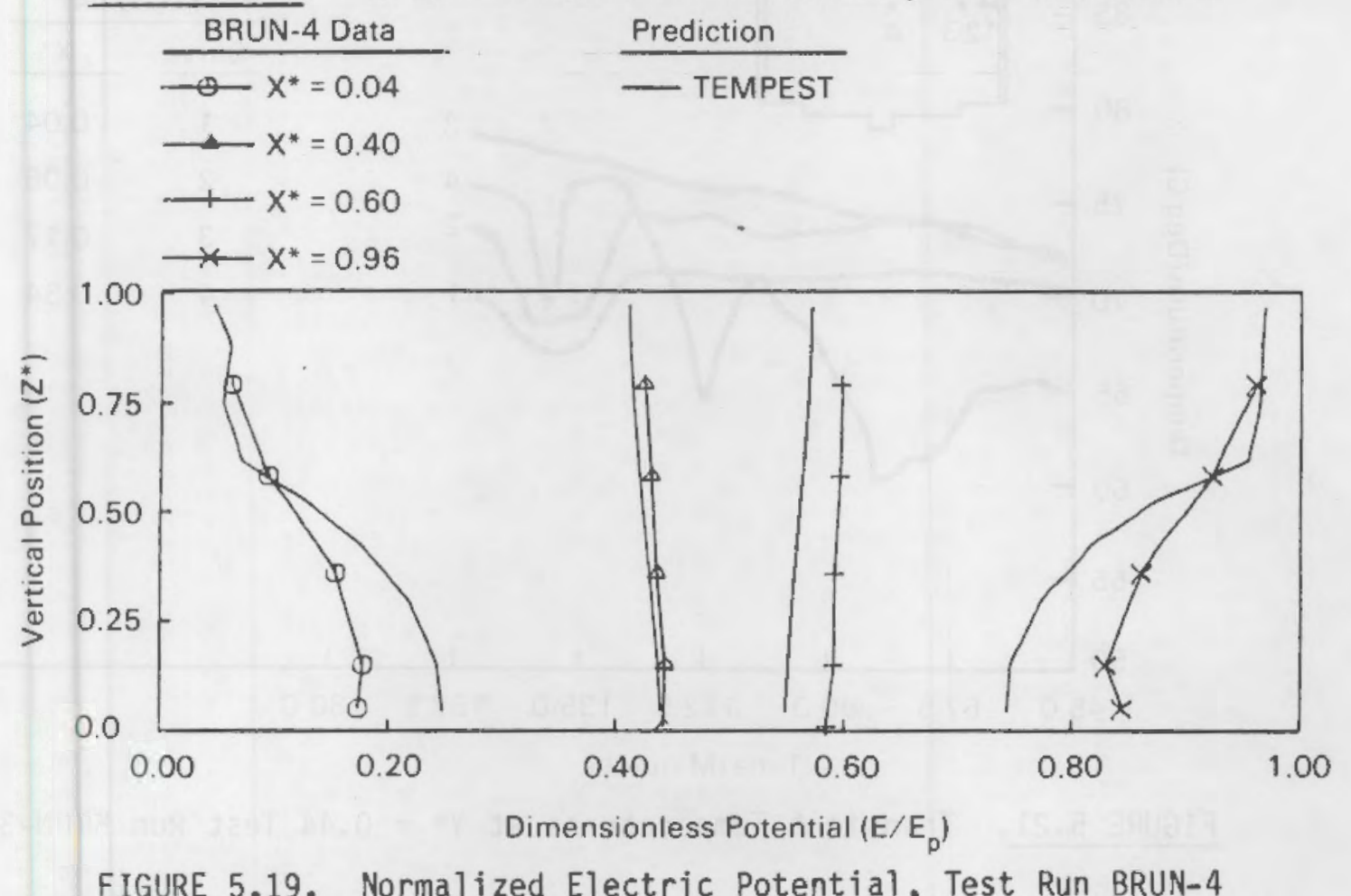

FIGURE 5.19. Normalized Electric Potential, Test Run BRUN-4 


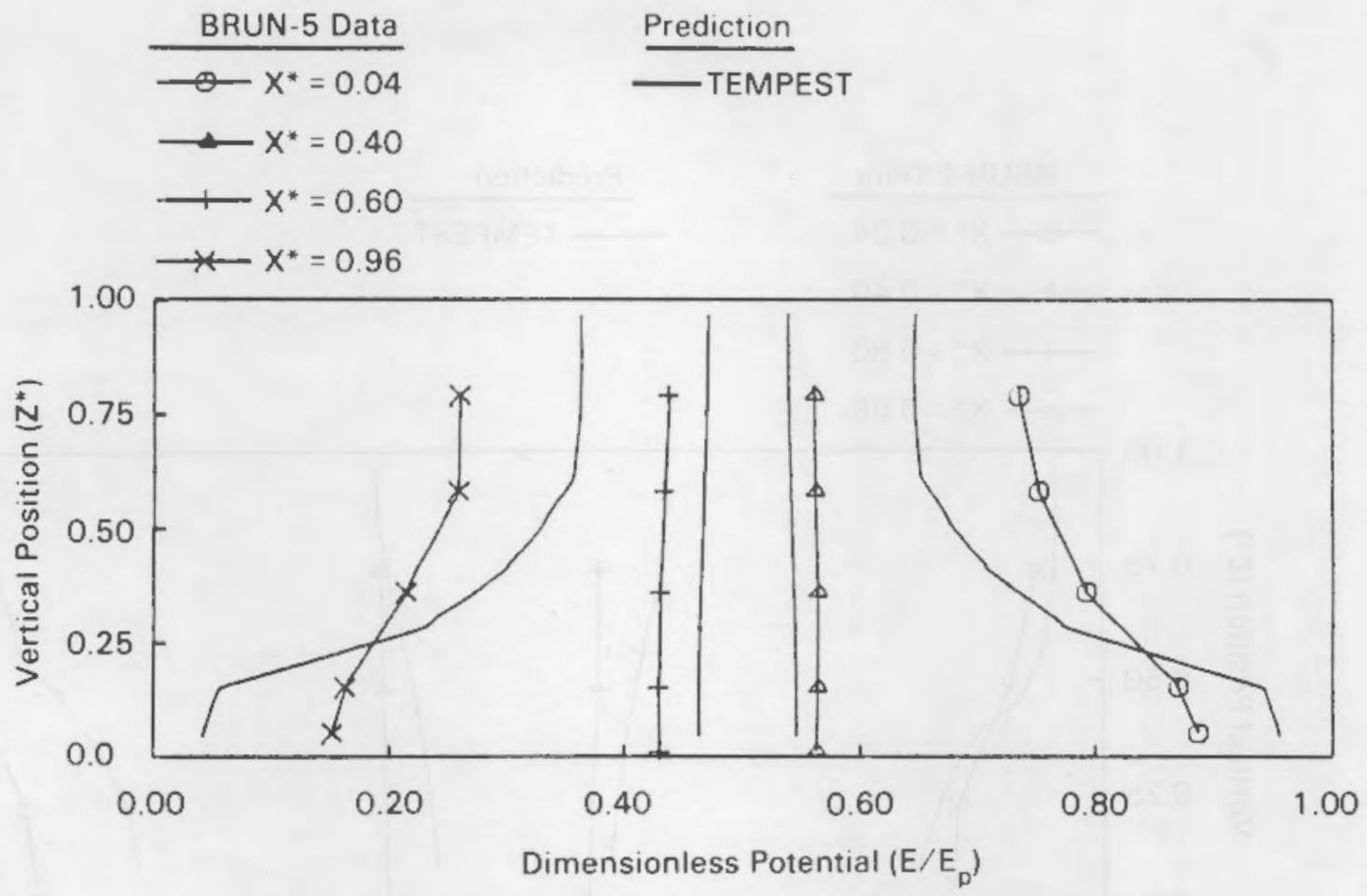

FIGURE 5.20. Normalized Electric Potential, Test Run BRIIN-5

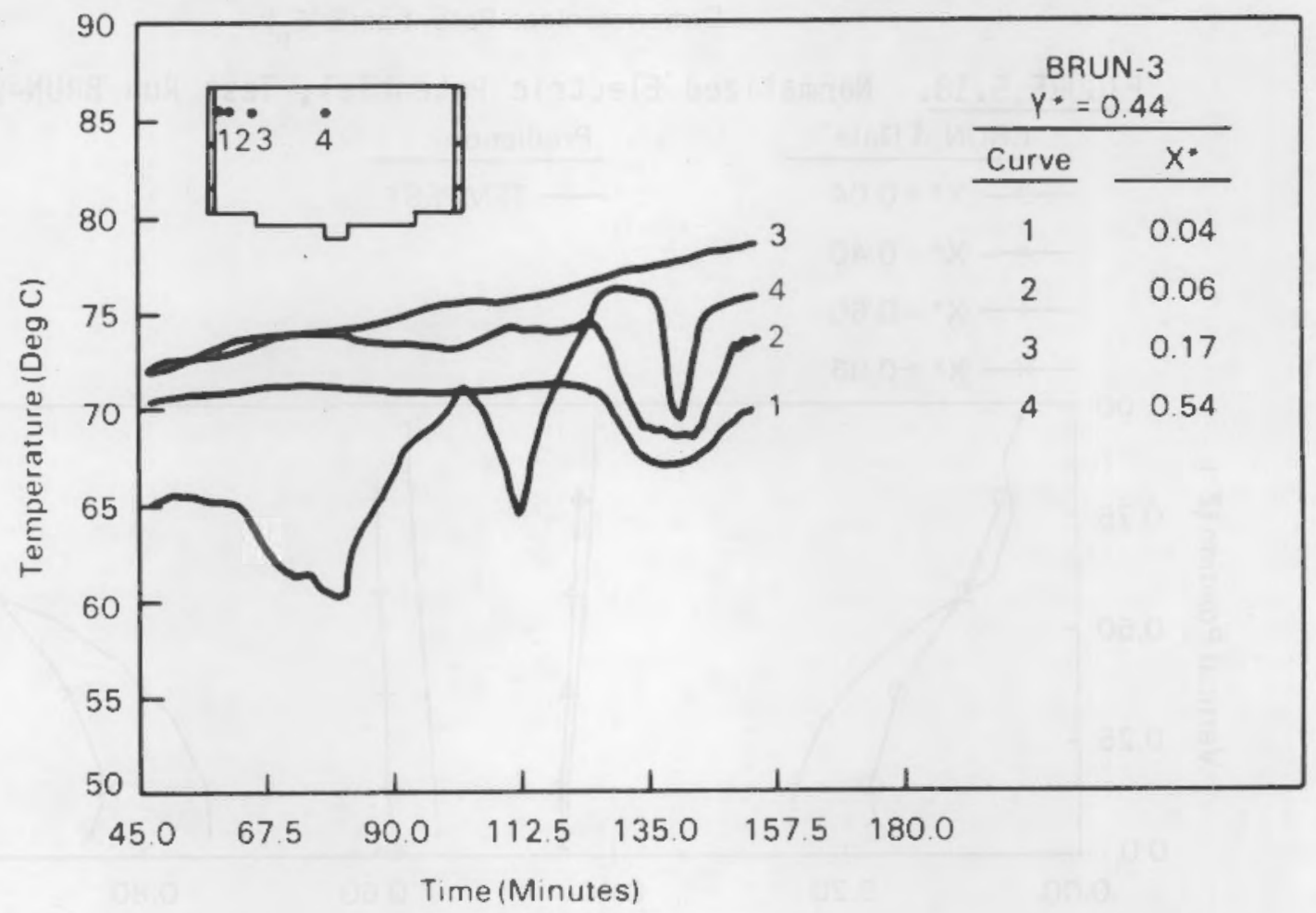

FIGURE 5.21. Transient Temperatures at $\gamma^{*}=0.44$ Test Run BRUN -3 
potential is normalized to the total voltage drop measured across an electrode pair, or $E / E_{p}$ where $E_{p}$ is listed for each run in Table 5.3. Data are normalized to $E_{p}$,meas, and predictions are normalized to $E_{p, p r e d}$ Comparison made in this manner, instead of actual electric potential (in volts), removes discrepancies between $E_{p}$,pred and $E_{p}$,meas from the comparison and allows evaluation of the general character of the electric potential field.

Test run BRUN-1 (Figure 5.17) is a 100\% upper/0\% lower power-split test. In the central region $\left(0.40<x^{*}<0.60\right)$, agreement of the results is very good. Experimental data are more asymmetric (i.e., shifted) than are the predictions. Nearer each powered electrode face, normalized electric potential is in good agreement also. In the lower corners, while predictions demonstrate the same characteristics as data, there is signficant discrepancy in local values.

Similar observations apply to test run BRUN-2 results (Figure 5.8 ). Predictions show much steeper gradients of electric potential than do data, both in the line between electrode plates and in the vertical direction directly in front of the electrodes. To a large degree, this trend can be related through temperature-dependent electrical conductivity and to discrepancies between temperature field data (see Figure 5.12).

In Figure 5.19, data for test run BRUN-4 in the central region show a more uniform vertical distribution than do predictions. This observation is consistent with discrepancies in temperature distribution for the same locations (see Figure 5.15). Temperature data showed only a small gradient top-to-bottom, whereas predictions showed a $10^{\circ} \mathrm{C}$ to $15^{\circ} \mathrm{C}$ temperature differential top-to-bottom, with colder results at the top. Colder temperatures lead to lowered electrical conductivity which, in turn, leads to increased voltage drop or potential gradient prediction, as results in Figure 5.18 show. An explanation for the discrepancy near the right electrode ( $X^{*}=0.96$ ) is unavailable. For this case, it should be noted that one local field result is reported ( 107.8 volts, see Table $B .4$ ) which is greater than the reported total drop across the electrode plates (106.5 volts). This may indicate that the total measured voltage drop may have drifted during the 
acquisition of local field data. If the total drop were larger than the reported 106.6 volts, the normalization of results in Figure 5.19 would show better overall agreement with data.

For test run BRUN-5, good overall agreement is indicated by results in Figure 5.20. In this case, as in runs BRUN-1 and BRUN-4, there is evidence indicating that measured data are shifted toward one or the other of the electrode plates. This indication, which may or may not be significant, could be the result of several factors. An asymmetry in cooling effect of the left and right walls, or a drift in overall voltage drop during data acquisition caused by slow transient thermal effects, would cause such an indicated shift. Without a closer examination of data measurement procedures, experimental apparatus, and cooling jacket flow and temperature data, a confirmed explanation for the observed shift is unavailable.

Comparison of electrical potential data and predictions has only been made for the tests in which a 1.0:0.0 or a 0.0:1.0 power split is present. For other combinations, an additional computation is required in TEMPEST during solution of the power-split mode. This computation, as described in Section 4.3.2, must be incorporated to provide required information to code users.

\subsubsection{Numerical Melter Model Results (Three-Dimensional)}

Upon recognizing that results obtained using a two-dimensional numerical model of the flow system showed certain discrepancies which could not be rectified, a three-dimensional simulation model was set up and run. This model used the same grid structure, noding, and materials in the vertical plane $(x-z)$ as was used in the two-dimensional model. In the depth $(y)$ direction, 18 computational grids were added between the front and back. Constanttemperature boundaries exterior to a 1/4-in.-thick acrylic sheet were used. Total spacing distance between the front and back walls is $27.9 \mathrm{~cm}$, as in the experiment.

For this simulation, test run BRUN-3 was chosen for comparison. This run was chosen because it is a test where both electrode pairs are powered. 
Table 5.7 presents a comparison of overall voltage drops across electrode pairs at a time of 90 minutes. In relation to the two-dimensional results (Table 5.4) these represent significant improvements. Deviation of predicted voltage drop is typically only $5 \%$ from data. Voltage drop at selected $10-$ minute time intervals are included in Table 5.8. Little variation occurs over time relative, for example, to two-dimensional BRUN-2 results (Table 5.5).

Transient temperature results at four locations are included in

Figure 5.21. These results are computed out to 150 minutes in real time, with the first 30 minutes being a transient startup as power applied to each pin is ramped up to full power. Temperatures appear to be reasonably steady over the time in the figure, particularly for the locations nearest the wall (curves 1, 2, and 3). In the central region, the effect of cold cap cooling is evident, as indicated by the transient decrease in temperatures.

Figure 5.22 presents vertical temperature distributions at a time of 90 minutes. TEMPEST predictions are at horizontal locations where data were measured. Agreement for this three-dimensional case is excellent. With the exception of the locally high temperatures measured directly in front of the lower electrode plates, deviation of data and predictions is typically less than 1 to $2^{\circ} \mathrm{C}$. This result confirms observations made concerning insufficiency of the two-dimensional model (see Figure 5.14) to correctly account for all the possible heat flow paths.

TABLE 5.7. Three-Dimensional Numerical Model Voltage Drop Results (Test Run BRUN-3)

\begin{tabular}{|c|c|c|c|c|c|}
\hline Time & Variable & Data(a) & TEMPEST (b) & $\operatorname{Data}(a)$ & TEMPEST (b) \\
\hline 86 min & $\begin{array}{r}\text { Power }(W)= \\
\text { Voltage }(V)= \\
\text { Current }(A)=\end{array}$ & $\begin{array}{c}150.7 / 155.0 \\
88.1 / 80.6 \\
1.71 / 1.73\end{array}$ & $\begin{array}{l}152.0 \\
86.1 \\
1.78\end{array}$ & $\begin{array}{c}149.2 / 151.4 \\
102.9 / 104.4 \\
1.45 / 1.45\end{array}$ & $\begin{array}{l}149.2 \\
98.6 \\
1.53\end{array}$ \\
\hline
\end{tabular}

(a) low/high for successive runs

(b) power specified; voltage and current computed 
TABLE 5.8. Three-Dimensional Numerical Model Time-Dependent Voltage Drop Results (Test Run BRUN-3)

\begin{tabular}{ccc} 
Time & $\begin{array}{c}\text { Upper Pair } \\
\text { Voltage Drop, V }\end{array}$ & $\begin{array}{c}\text { Lower Pair } \\
\text { Voltage Drop, V }\end{array}$ \\
\cline { 1 - 1 } $90 \min$ & 86.1 & 98.5 \\
100 & 85.6 & 98.2 \\
110 & 85.6 & 98.1 \\
120 & 85.2 & 97.7 \\
130 & 84.8 & 97.2 \\
140 & 84.8 & 97.2 \\
150 & 84.7 & 96.8
\end{tabular}

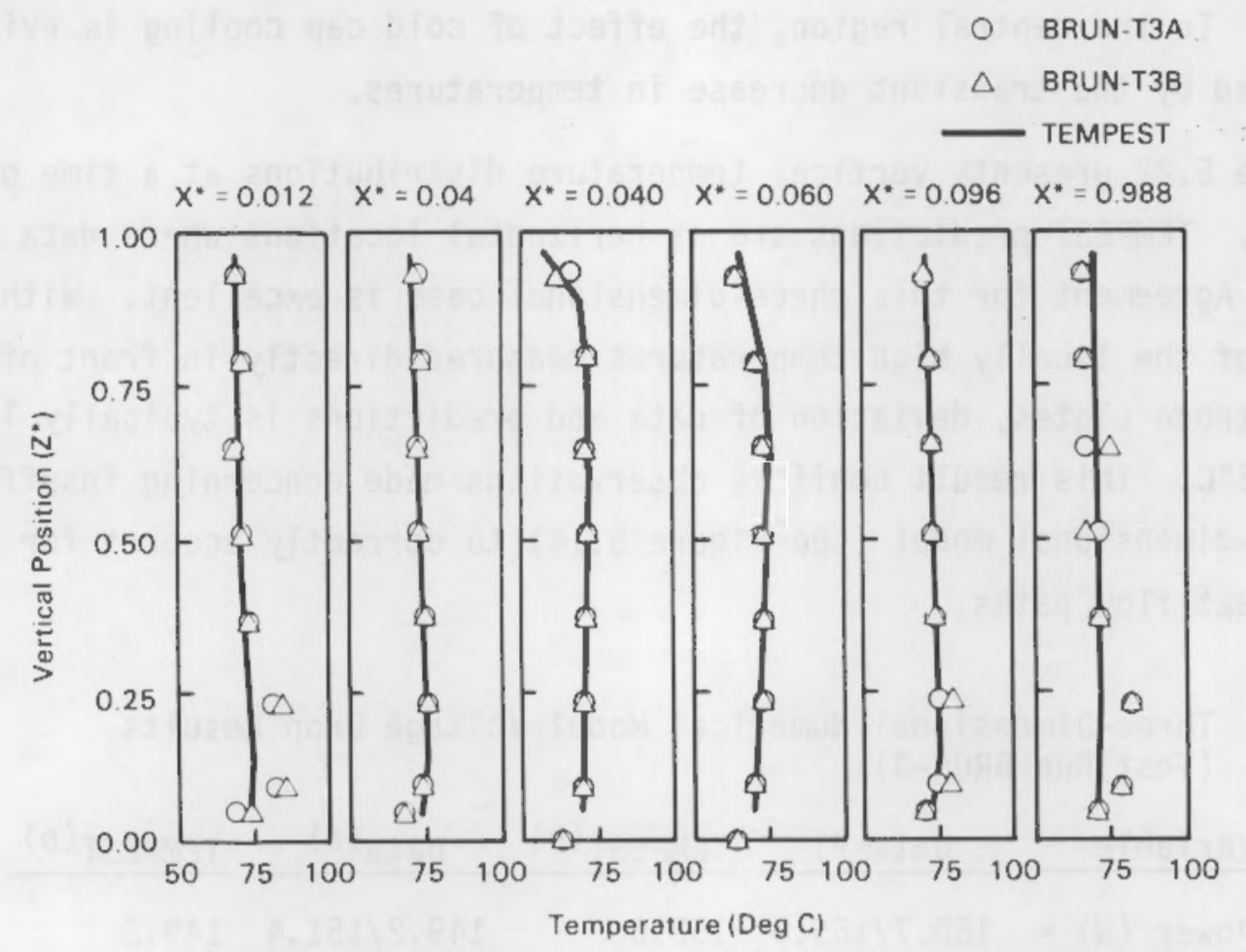

FIGURE 5.22. Temperature Distribution in Modeling Fluid at $\gamma^{\star}=0.44$ Test Run BRUN-3 
While the three-dimensional numerical simulation results are in quite good agreement with all the data, including total voltage drop, electrode current, and temperature data, there is one disadvantage. That is the amount of computer time required. For the two-dimensional models described in Section 5.3.3, computation of 1 hour of (simulated) real time required typically 3 CPU minutes of computer time on a CRAY-1S computer. The threedimensional model used here, which contained 2436 computational fluid cells and additional 1628 computational heat transfer and electrically conducting solid cells, required slightly over 1 minute of CPU time to compute 1 minute of (simulated) real time. Thus, while three-dimensional modeling results in significantly improved results, it is computationally very expensive. Thus, it would be advantageous to further analyze two-dimensional modeling assumptions to qualify applicable limitations. 



\subsection{SIMULATIONS OF THE PILOT SCALE CERAMIC MELTER (PSCM)}

The melter version of TEMPEST was used during FY84 to simulate both idle and feed modes of PSCM operation. These simulations were conducted subsequent to code evaluation simulations and noding studies contained in Sections 5.1 and 5.2 of this report, but prior to the validation and evaluation comparisons to data contained in the physical melter modeling experiments for the dualelectrode power split included in Section 5.3 of this report.

Initial analysis of the PSCM simulation results and comparison to a very 1 imited experimental data base led to conclusions that the results were in very good agreement. However, subsequent re-evaluation conducted as part of the current FY85 work identified certain discrepancies. The reason for these discrepancies has not been fully resolved. A much more detailed evaluation of the numerical model and simulation results needs to be conducted. In light of present work conducted with the power-split mode of code operation, these areas need to be addressed in more detail in any subsequent analysis. These include: glass properties, thermal boundary conditions, and numerical model noding resolution.

\subsection{GLASS PROPERTIES}

The glass properties as a function of glass temperature used in the PSCM simulations were compiled from a number of sources because properties of the glass actually used in the PSCM test runs were not measured. As such, properties used in the simulations represent a best-available estimate of the temperature-dependent properties of the actual glass.

The thermal conductivity and specific heat were taken from data measured for SRL-411 glass at the Purdue University Thermophysical Properties Research Laboratory (Taylor et a1. 1979). The electrical conductivity and viscosity were taken from data collected on WV-131S glass by G. Mellinger of PNL. The density was synthesized by adding the difference between the room temperature density of WV-131S and SRL-411 glasses to the SRL-411 density-versustemperature relationship. 
Before the PSCM simulations were performed with synthesized glass properties, the sensitivity of the predictions to variations in themal conductivity and specific heat of the glass was determined. These two physical properties were chosen for variation because they are the two glass properties which are not measured by the Material Science Group at PNL. The other requisite properties, viscosity, density, and electric conductivity, are generally measured as part of glass analysis for the melter development program. So that a consistent set of properties was used for the sensitivity study, BNW-6832 glass was assumed for these sensitivity studies.

The sensitivity of predictions to variations in themal conductivity and specific heat was estimated in a simplified two-dimensional model with characteristic internal dimensions of the PSCM melter. A single pair of plate electrodes were used on either end of the glass region. The electrode temperatures were specified as constant. This geometry and electrode plate configuration provided a model in which property sensitivity could be determined without unnecessary geometric complexity.

Results of the physical property sensitivity study are listed in Table 6.1. Variation in thermal conductivity results in variation in predicted voltage drop. This results from the temperature dependence of electrical conductivity. As themal conductivity is decreased, voltage drop decreases because electrical conductivity for BNW-6832 glass decreases with decreasing temperature. The alternate occurs for an increase in thermal conductivity.

Variation in specific heat has no effect on predicted results, at least in this test. This result is because specific heat, a measure of the heat capacity of the glass, has a principal effect on time rate of heatup or cooldown and would be most significant in a transient situation.

Results in Table 6.1 indicate that overall voltage drop varies almost linearly with glass themal conductivity. An explanation for this trend is based on a simplified thermal boundary layer model (Figure 6.1). Consider heat transfer at the surface of the electrode. The surface heat flux, $q_{w}^{\prime \prime}$, can be expressed as 
TABLE 6.1. GIass Property Sensitivity Results

\section{Variation in Thermal Conductivity}

\begin{tabular}{|c|c|c|c|}
\hline $\begin{array}{l}\text { Thermal } \\
\text { Conductivity }\end{array}$ & $\begin{array}{c}\text { Specific } \\
\text { Heat }\end{array}$ & $\begin{array}{l}\text { Overall } \\
\text { Vol tage } \\
\text { Drop, }\end{array}$ & $\begin{array}{c}\text { Bulk } \\
\text { Temperature, }{ }^{\circ} \mathrm{C} \\
\end{array}$ \\
\hline $\begin{array}{l}-10 \text { percent } \\
\text { nominal } \\
+5 \text { percent } \\
+10 \text { percent }\end{array}$ & $\begin{array}{l}\text { nominal } \\
\text { nominal } \\
\text { nominal } \\
\text { nominal }\end{array}$ & $\begin{array}{l}102.5 \\
110.2 \\
112.6 \\
115.5\end{array}$ & $\begin{array}{l}1215 \\
1208 \\
1205 \\
1202\end{array}$ \\
\hline
\end{tabular}

Thermal Conductivity

$\begin{array}{lcc}\begin{array}{c}\text { Specific } \\ \text { Heat }\end{array} & \begin{array}{c}\text { Overall } \\ \text { Voltage } \\ \text { Drop,V }\end{array} & \begin{array}{c}\text { Bulk } \\ \text { Temperature, }{ }^{\circ} \mathrm{C}\end{array} \\ \begin{array}{l}\text { nominal } \\ \text { +10 percent }\end{array} & \begin{array}{ll}110.2 \\ 110.2\end{array} & 1208 \\ & & 1208\end{array}$

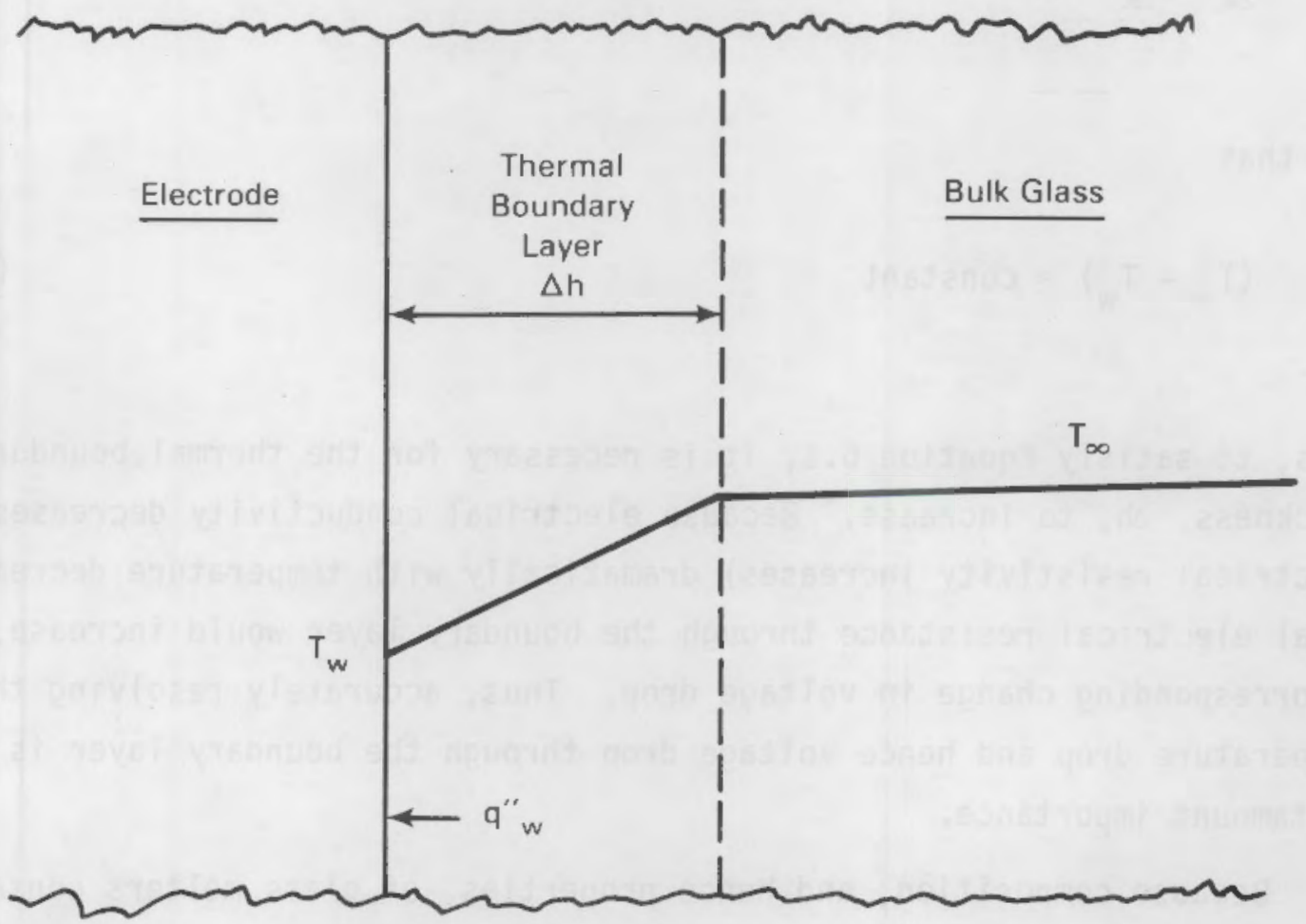

FIGURE 6.1. Simplified Themal Boundary Represenation 


$$
q_{w}^{\prime \prime}=-k \frac{d T}{d x} \approx-\frac{k}{\Delta h}\left(T_{\infty}-T_{w}\right)
$$

where

$$
\begin{aligned}
k & =\text { effective thermal conductivity } \\
\Delta h & =\text { thermal boundary layer thickness } \\
T_{W} & =\text { electrode surface temperature } \\
T_{\infty} & =\text { bulk glass temperature. }
\end{aligned}
$$

For a constant current between electrodes and at equilibrium conditions, the total power $(P=E I)$ should equal the total heat loss $\left(Q=q_{w}^{\prime} A\right)$. Thus, it is reasonable to assume a change in voltage drop, $\triangle E$, would be proportional to a change in heat flux, $\Delta q_{w}^{\prime \prime}$. Predictions show that

$$
\frac{\Delta E}{\Delta k} \approx \frac{\Delta q_{w}^{\prime \prime}}{\Delta k}<1
$$

and that

$$
\left(T_{\infty}-T_{w}\right) \approx \text { constant }
$$

Thus, to satisfy Equation 6.1 , it is necessary for the thermal boundary layer thickness, $\Delta h$, to increase. Because electrical conductivity decreases (e.g., electrical resistivity increases) dramatically with temperature decrease, the total electrical resistance through the boundary layer would increase, causing a corresponding change in voltage drop. Thus, accurately resolving the temperature drop and hence voltage drop through the boundary layer is of tantamount importance.

Because composition, and hence properties, of glass melters containing nuclear wastes vary widely, it is very beneficial to melter design to be able 
to predict performance of an operating melter subjected to different glass compositions. The sensitivity of voltage drop to changes in thermal conductivity is but one of many possible parameter dependencies. Additional parametrization may be useful to future analysis.

\section{6.? PILOT SCALE CERAMIC MELTER}

Operation of the PSCM is in either one or the other of two modes. In the idling mode, the melter is just that--idling. No solid or molten material is being added or removed from the melter. Powered electrodes maintain the melter in a hot standby as molten glass material is heating up or being maintained in preparation for a pour. In the feeding mode, solid material is being slowly added to the melt. This material tends to spread out over the surface while it heats up to melting temperature. During the time the solid material is present on the surface, thermal radiation heat transfer from the surface is reduced, producing a surface condition referred to as a cold cap. Each of these two modes of PSCM operation has been modeled with the melter version of TEMPEST.

\subsubsection{Idling Mode Operation}

The idling mode of the PSCM was simulated with both two-dimensional and three-dimensional models. Thermal boundary conditions for these models were taken from PSCM run 11. Figure 5.2 presents a cross sectional schematic of the two-dimensional model. Interior dimensions of the melter is $117 \mathrm{~cm}$ between electrodes, $36.5 \mathrm{~cm}$ in depth of molten $\mathrm{glass,} \mathrm{and} 61 \mathrm{~cm}$ from front to back. Refractory layers of $\mathrm{K}-3$, ALFRAX, and Zirmul were included in the model using thermal and electrical properties from manufacturers' specification data. The top surface was assumed to thermally radiate to a constant sink temperature of $834^{\circ} \mathrm{C}$. Water cooling jacket temperatures are set as constant-temperature boundaries per data for the run.

The purpose of the two-dimensional model was to validate the material properties, as they were obtained rather obtusely from several sources. Previous work (see Section 5.2) had indicated that two dimensional modeling could yield accurate voltage drop results at considerable computational time savings over three-dimensional modeling. Thus obtaining correct results in 


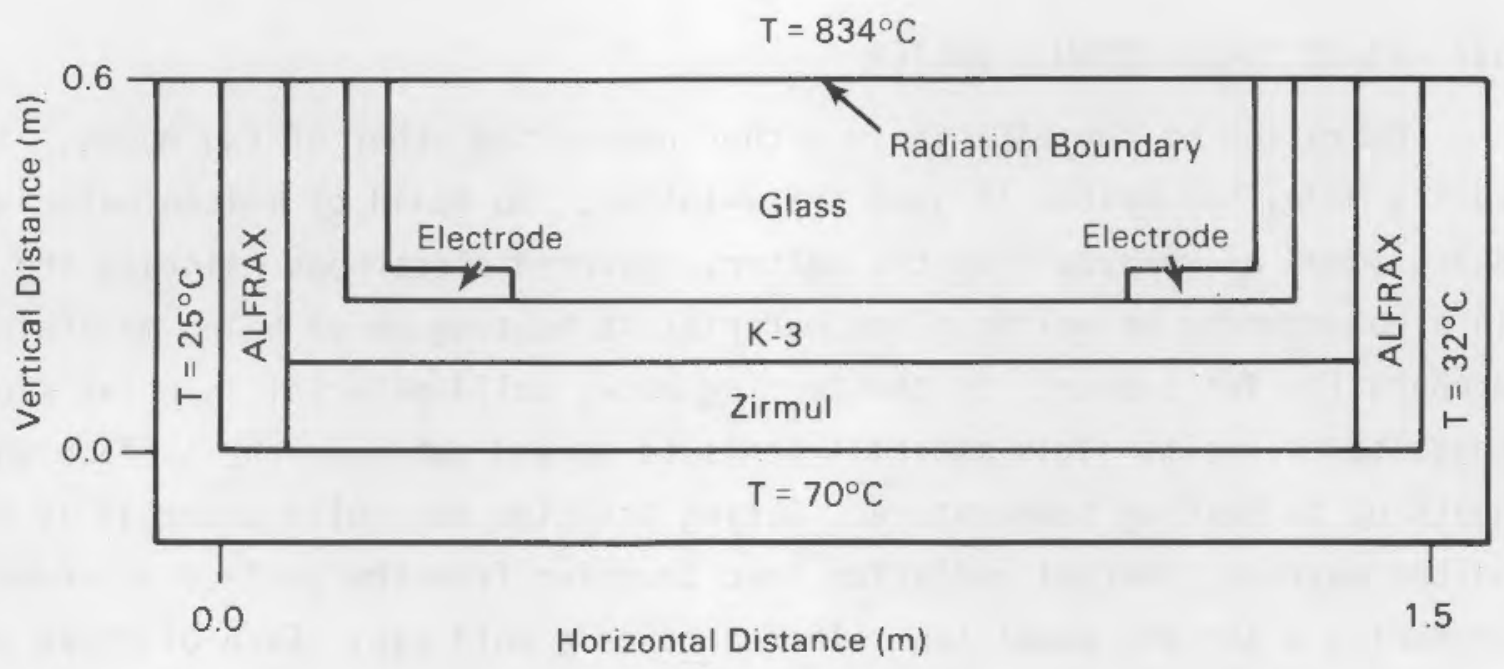

FIGURE 6.2. PSCM Two-Dimensional Model Cross-Section Schematic

this model is the basis for "calibrating" certain unknowns prior to proceeding to the three-dimensional operational mode simulations.

Initial simulation results produced overall voltage drop results typically $40 \%$ higher than measured for the PSCM melter, while bulk temperatures were about correct. It has been shown (Section 6.1) that varying themal conductivity had a significant effect on predicted voltage drop, and that previous physical model melter simulation (Section 5.2) with a single electrode pair typically tended to underpredict voltage drops. Thus, to facilitate correct physical properties, the property which has the greatest direct effect on voltage drop was chosen to be "calibrated". To this end, temperaturedependent electrical conductivity was scaled by a constant factor over the whole temperature range until the appropriate factor resulted in both correct voltage drop and approximately correct bulk temperature. In the absence of actual glass properties, this was deemed the best method of obtaining the most overall correct results. 
Once "correct" properties had been obtained, a three-dimensional model of the PSCM in the idling mode was developed. A schematic showing top and side views of the model is given in Figure 6.3. A freeze valve and discharge region were included. The freeze valve is included as a plate of Inconel. Thermal boundary conditions for water jacket cooling were set as constant-temperature boundaries including an asymmetric cooling effect on the cooling jacket discharge side. Rather arbitrary boundary conditions were chosen for the freeze valve and discharge regions because of a lack of experimental measurements in these regions.

Development of the three-dimensional model required upwards of 6000 total cells to maintain noding resolution similar to the two-dimensional model. To simplify the model to a certain degree, $\mathrm{K}-3$ insulation surrounding the molten glass is included directly as a thermally conducting, electrically insulating material. The layers of ALFRAX and Zirmul (see Figure 6.2) however were modeled as contact resistances. This procedure was used to determine an equivalent contact coefficient, $h_{e}$, such that the temperature drop and corresponding heat flux was equivalent. This involved determining

$$
h_{e}=\frac{k_{i}}{\Delta x_{i}}
$$

where

$$
\begin{aligned}
& k_{i} \text { is the material thermal conductivity } \\
& \Delta x_{i} \text { is the material thickness, and } \\
& h_{e} \text { is the equivalent contact coefficient. }
\end{aligned}
$$

The consistency of this procedure can be seen from one-dimensional heat transfer analysis (Bird et al. 1960) where heat flux, q", is determine as

$$
q^{\prime \prime}=-k \frac{d T}{d x}=h_{e}\left(T_{2}-T_{1}\right)
$$



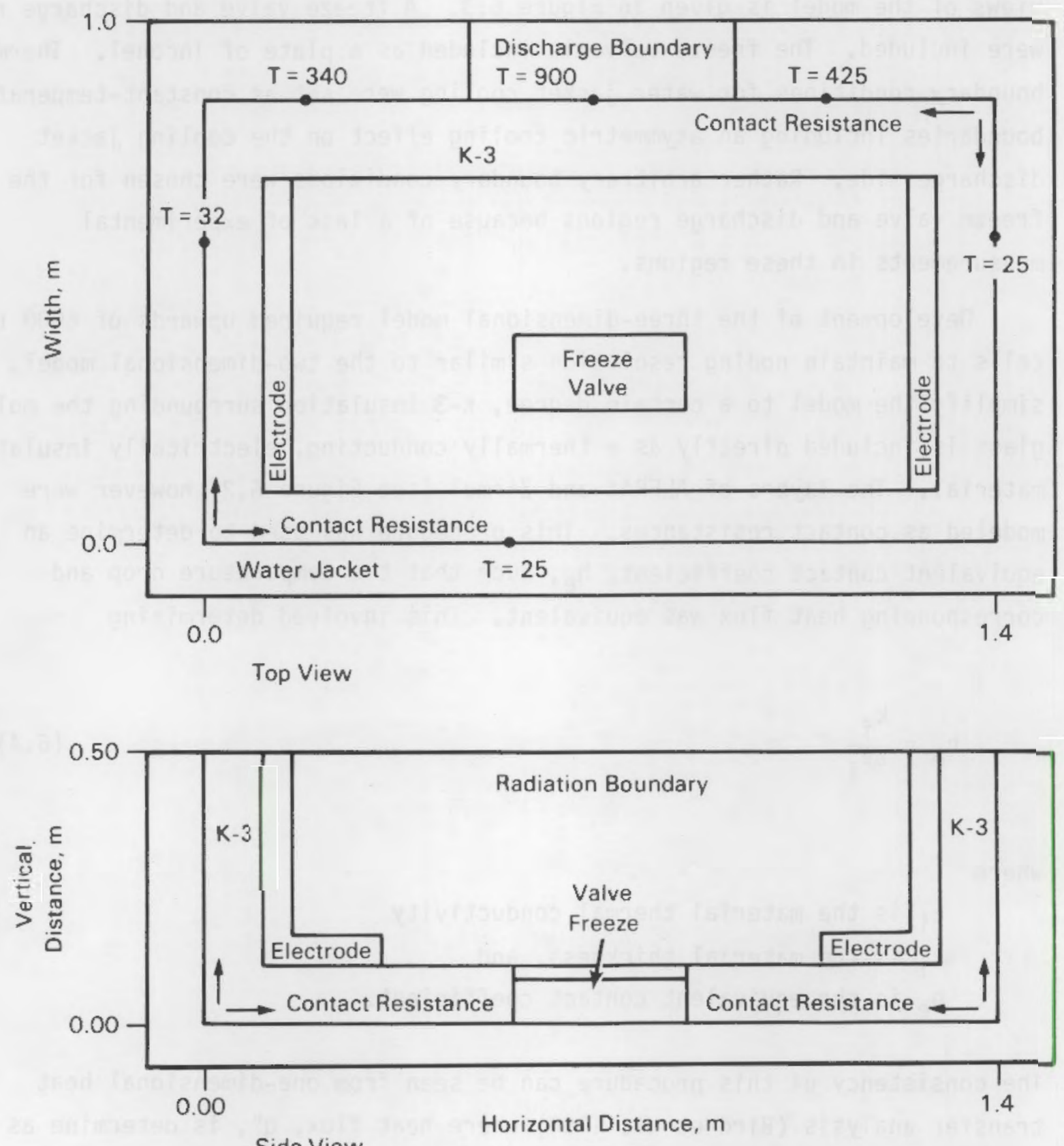

FIGURE 6.3. Three-nimensional PSCM Idling Mode Model Schematic 
Thus, if Equation 6.4 is satisfied, then the temperature drop across a layer of material of thickness $\Delta x_{j}$ is equal to the temperature drop across a contact coefficient (thermal resistance) given as $h_{e}$.

The idling PSCM model was computed to a total time of 3.6 hours at operating conditions. Table 6.2 presents a comparison of predicted voltage drop and glass temperature. In analyzing the $i d l i n g$ model results, the Inconel plate at the freeze in the bottom of the melter was found to cause an interesting result. Figure 6.4 presents contours of Joule-heating power densities in a vertical plane containing the Inconel plate and one further away. The high (electrical) conductivity of Inconel, relative to the molten glass, induces a locally high current density, and hence, locally high power densities. This effect results in locally higher temperatures which affect overall convection patterns and hence mixing.

\subsubsection{Feeding Mode Operation}

The feeding mode of PSCM operation was modeled using the three-dimensional representation. Thermal boundary conditions were taken at hour 55 of PSCM run 11. This model differs from the idling model only in that a cold cap was considered.

A cold cap is formed on the top of the hot glass melt when cold waste feed slurry is poured in. Visual observation of this cold cap during PSCM feeding operation indicates that a solid crust of material forms an oblong shape over typically $70 \%$ of the molten glass surface. Physical properties of this crust and its thickness are unknown. Violent boiling of the water component of the slurry occurs in a puddle 20 to $30 \mathrm{~cm}$ in diameter immediately under the feed nozzle and on top of the cold cap.

Because of the lack of experimental data concerning the cold cap, visual observations of PSCM operation by engineers and physical model judgements are the only basis for treatment of the cold cap in the numerical model. As such, three cold cap models were tested. These included: 
TABLE 6.2. Idling PSCM Voltage Drop

\begin{tabular}{lll} 
& Overall Voltage Drop, $V$ & Glass Temperature, ${ }^{\circ} \mathrm{C}$ \\
\cline { 2 - 2 } & 62.2 & $1040^{\circ} \mathrm{C}$ \\
TEMPEST & 67.9 & $1000^{\circ}$
\end{tabular}

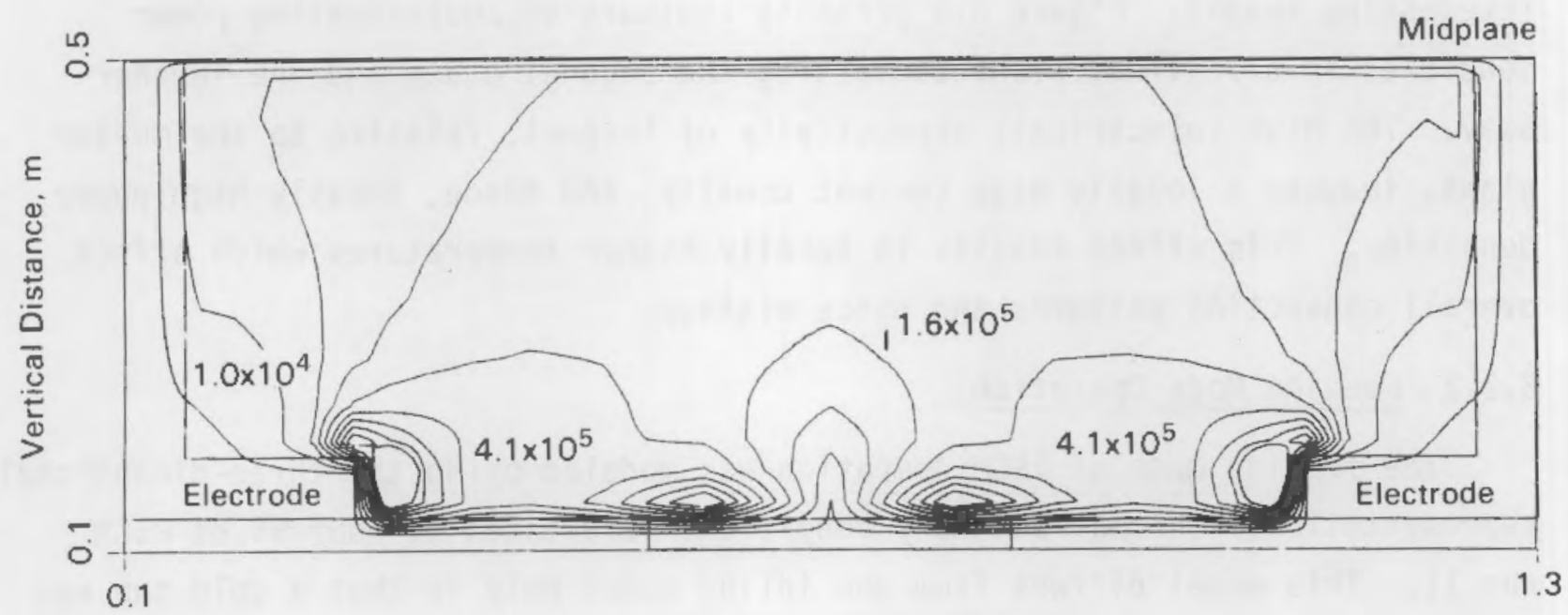

a) Central Plane with Freeze Plug

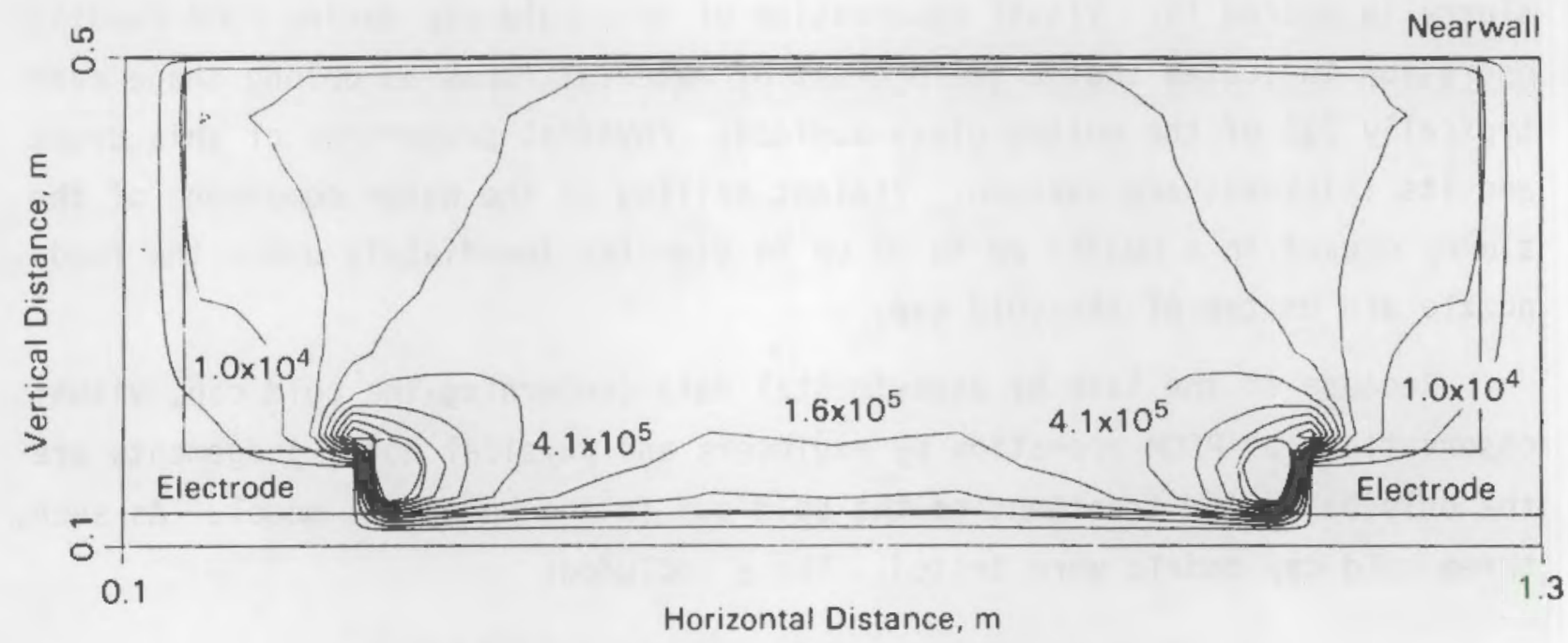

b) Off-Center Plane Without Freeze Plug

FIGURE 6.4. PSCM Idling Model Power Density 
Model 1 - The cold cap was treated as a solid layer of heat-conducting material covering the whole glass melter. Thermal conductivity was arbitrarily assumed to be rather low relative to molten gass value. The layer was assumed to thermally radiate to the top of the melter with an emissivity of 0.75 . Feed entering the melter was assumed to flow in at a central location in molten form at a low temperature. Vaporization of water was treated as a (negative) heat sink over a small region surrounding the feed.

Model 2 - This model assumed the cold cap to be formed by a cold molten glass layer $\left(T=700^{\circ} \mathrm{C}\right)$ flowing slowly into the top of the melter cavity. The flow region is assumed to be oblong, covering approximately $70 \%$ of the molten glass surface, and was not in contact with side walls. Vaporization was treated as in model 1 as a (negative) heat sink. The remaining $30 \%$ of glass melter surface was assumed to be a free surface thermally radiating to a constanttemperature sink.

Model 3 - This model assumed that the cold cap was the same shape as in model 2 , but was a thin layer of (poorly) heat-conducting solid material. Feed was treated as a mass source in the numerical model entering the top layer of glass melt.

Each of these models has certain advantages and disadvantages. Model 1 was concluded to be the least representative because thermal conductivity of the solid cold cap layer was largely unknown and because feed was too localized. Models 2 and 3 resulted in very similar computed results for melter flow and thermal conditions, and Model 2 was more computationally efficient. The model also more typically represents observations of melt surface during operation. Thus results from cold cap Model 2 are reported hereafter.

Table 6.3 presents a comparison of results. The computed results were obtained after simulation of 1.8 hours of melter feeding operation at prescribed thermal boundary conditions. Based on transient temperatures monitored throughout this time, the melter simulation results were assumed to 
be at reasonably steady conditions. Conclusions reached as part of FY84 work indicated that both the numerical model and TEMPEST were capable of accurate prediction of the PSCM operation.

TABLE 6.3. Preliminary PSCM Feeding Mode Results Comparision

\begin{tabular}{|c|c|c|c|}
\hline & Height & Experimental & TEMPEST \\
\hline Voltage Drop & & 82.4 volts & 84.2 volts \\
\hline Temperature & $\begin{array}{l}7.6 \mathrm{~cm} \\
15.2 \\
22.9 \\
30.5\end{array}$ & $\begin{array}{l}1178^{\circ} \mathrm{C} \\
1179 \\
1176 \\
1160\end{array}$ & $\begin{array}{l}1198^{\circ} \mathrm{C} \\
1215 \\
1216 \\
1208\end{array}$ \\
\hline
\end{tabular}

Subsequently, additional questions concerning certain characteristics of the predictions were raised. To answer them, the model, as previously computed, was rerun. Initially, computations were recomputed starting from a time of 1.2 hours and computed for 2 hours of simulation time. These results led to the conclusion that earlier simulation results ( 1 isted in Table 6.3) were probably not at thermal equilibrium. For further confirmation, results were computed for another 2 hours at operating conditions.

Two changes were made to the model for this latter 2-hour run. Monitor cells, locations where time-dependent variables are monitored during the simulation, were changed. This was done to obtain data to answer questions that originally led to rerunning the simulation. This change in the model had no effect on computed results. The second change made was to run the simulation using a fixed time step equal to one-half the value that was used over the first 2 hours of the (rerun) simulation. This change did have an effect and led to the conclusion that additional work needs to be done.

Figure 6.5 presents time-dependent temperatures for the rerun results at four locations in the glass. In this figure, results from 0 to 2 hour were computed using a fixed time step of 3 seconds (the same as used previously), whereas results from 2 to 4 hour were computed using a time step of 1.5 seconds. (nverlap of the two simulations between 2 and 2.4 hour result because 


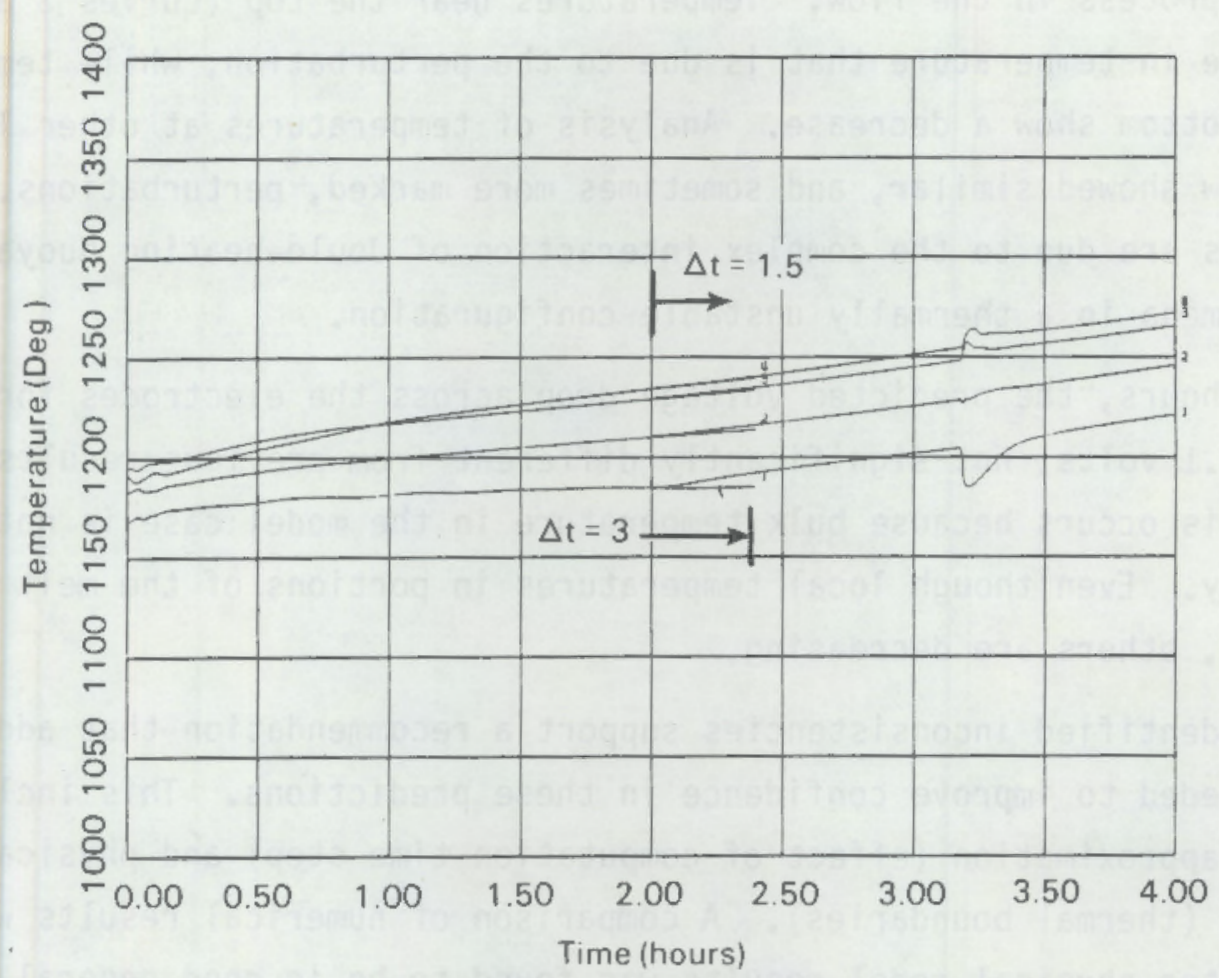

FIGURE 6.5. PSCM Feeding Time-Dependent Temperatures

a restart file dump occurred at 2 hours, but not at 2.4 hours. In the figure, the time scale is shifted relative to previously computed FY84 results. The time of 0 in Figure 6.5 corresponds to 1.2 hours of FY84 simulation time, where a restart file was available. Thus, results contained in Table 6.3 correspond to a time of 0.6 hours in the figure.)

Several observations are made from the results. Previous conclusions that equilibrium conditions had been reached are incorrect. In fact, temperatures appear to continue increasing almost linearly out to 4 hours. Other monitor locations showed similar trends, with some temperatures increasing linearly with time while others decreased. Al so note the discontinuity in slope at $t=2$ hours. This occurs as a result of using a reduced time step and leads to the conclusion that further analysis of the relation of $\Delta t$ and accuracy needs to be investigated. 
The perturbation present at time near 3.2 hours is an indication of a chug-type process in the flow. Temperatures near the top (curves 3 and 4) show an increase in temperature that is due to the perturbation, while temperatures near the bottom show a decrease. Analysis of temperatures at other locations in the flow showed similar, and sometimes more marked, perturbations. These occurrences are due to the complex interaction of Joule-heating buoyancy-driven flow phenomena in a thermally unstable configuration.

At 4 hours, the predicted voltage drop across the electrodes for the rerun case is 83.1 volts, not significantly different from previous results of $84 . ?$ volts. This occurs because bulk temperature in the model case is not changing drastically. Even though local temperatures in portions of the melt are increasing, others are decreasing.

The identified inconsistencies support a recommendation that additional work is needed to improve confidence in these predictions. This includes both numerical approximation (effect of computation time step) and physical conditions (thermal boundaries). A comparison of numerical results with smallscale, melter physical model results was found to be in good general agreement, especially for the dual-electrode-pair experiments. It was also determined that paying particular attention to thermal boundary conditions is important. With these experiences in mind, accurate prediction of operating melter characteristics is quite feasible. 


\section{REFERENCES}

Batchelor, G. K. 1967. An Introduction to Fluid Dynamics. Cambridge University Press, England.

Baxter, R. G. August 1983. "Description of Defense Waste Processing Facility Reference Waste Form and Canister," DP-1606-Rev. 1, E. I. du Pont de Nemours \& Co., Aiken, SC.

Bird, R. Byron, Warren E. Stewart, and Edwin N. Lightfoot. 1960. Transport Phenomena. John Wiley \& Sons, Inc., New York.

Chick, L. A., et al. 1984. "West Valley High-Level Nuclear Waste Glass Development: Statistically Designed Mixture Study. PNL-4997, Pacific Northwest Laboratory, Richland, Washington.

Donovan, T. E., and R. L. Hjelm. 1979. "Numerical Investigation of Electric Field Effects on Unsteady Buoyant Molten Glass Flows." 79-HT-98, The American Society of Mechanical Engineers, New York.

Eyler, L. L., D. S. Trent, and M. J. Budden. 1983. "TEMPEST--A ThreeDimensional Time-Dependent Computer Program for Hydrothermal Analysis. Volume II: Assessment and Verification Results." PNL-4348, Vol. 2, Pacific Northwest Laboratory, Richland, Washington.

Gardon, R. 1961. "A Review of Radiant Heat Transfer in Glass," J. Am. Ceramic Soc., 44, 305-317.

Gurley, R. N. and J. E. Minor. 1985. "Hanford Waste Vitrification, An Overview," in Waste Management 1985, Volume 1, pp. 179-184, University of Arizona, Tucson, Arizona.

Mendel, J. E. 1977. "Annual Report on the Characterization of High-Level Waste Glasses", BNWL-2252, Pacific Northwest Laboratory, Richland.

Quigley, M. S., D. K. Kreid. 1979. "Physical Modeling of Joule-Heated Ceramic Glass Melters for High-Level Waste Immobilization," PNL-2809, Pacific Northwest Laboratory, Richland, Washington.

Siegel, Robert, and John. R. Howel1. 1972. Thermal Radiation Heat Transfer. McGraw-Hill, New York.

Skarda, R. J., S. G. Hauser, J. A. Fort "Preliminary Evaluation of PSCM and BIPP Melter Design and Operating Conditions Using Physical Modeling," PNL-5498, Pacific Northwest Laboratory, Richland, Washington.

Taylor, R. E., et al. 1979. "Thermophysical Properties of a Glass," TPRL 191, Purdue University, West Layfayette, Indiania. 
Trent, D. S., L. L. Eyler, and M. J. Budden. 1983. "TEMPEST - A ThreeDimensional Time-Dependent Computer Program for Hydrothermal Analysis. Volume 1: Numerical Methods and Input Instructions." PNL-4348, Vol. 1, Pacific Northwest Laboratory, Richland, Washington. 
APPENDIX A

TABULATION OF MEASURED TEMPERATURE DATA 


\section{APPENDIX A \\ TABULATION DF MEASURED TEMPERATURE DATA}

Temperature data reported in Section 5.3 of this report are tabulated in this appendix. Included are results for tests BRUN-1 to BRUN-9 inclusive. Test run identification throughout the report is given as BRUN-1 for example. In the tabulations, $-T 1$ refers to BRUN-1 where temperatures were measured. An $A$ or $B$ is appended (e.g., -TIA) where multiple data sets were recorded for the same run. Thermocouple positions are identified as $T 16$, for example, and correspond to position listed in Figures 3.2 and 3.3 . 
TABLE A.I

TERPERATURE PROFILE TABULATION

BIPP Physical Model

Run BRUN-TIA

Power Supply Measurements

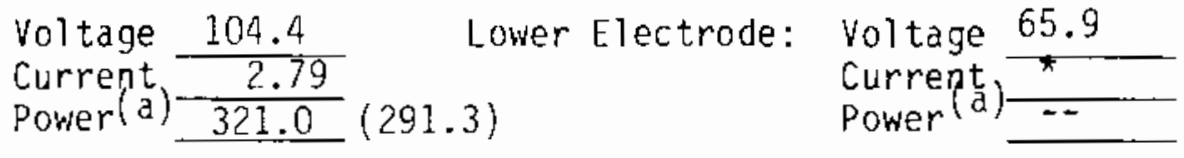

Power Skew Upper $100 \%$ Lower $0 \%$

Temperatures $\left({ }^{\circ} \mathrm{C}\right)$

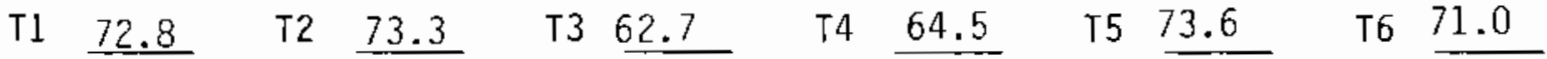

$\begin{array}{lllllll}77 & 73.7 & \text { T8 } & 75.6 & \text { T9 } 73.7 & \text { T10 } \underline{76.5} & \text { T11 }\end{array}$

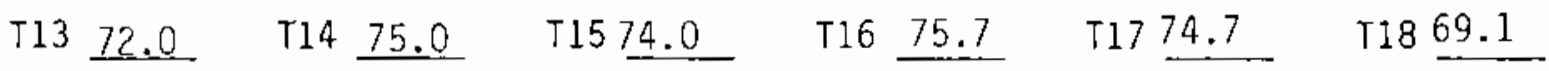

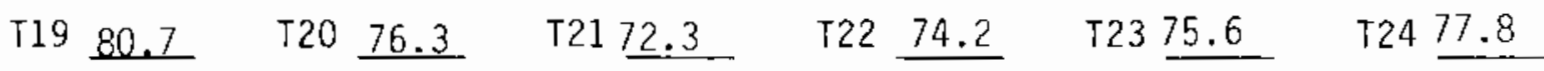

$\begin{array}{lllllll}\text { T25 81.6 } & \text { T26 76.0 } & \text { T27 } 69.9 & \text { T28 } 71.6 & \text { T29 75.2 } & \text { T30 } & \underline{77.8}\end{array}$

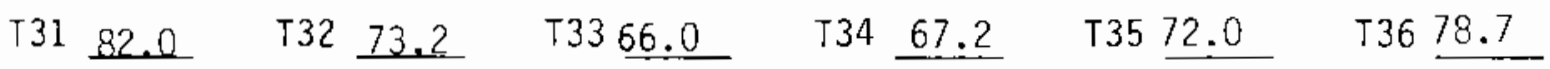

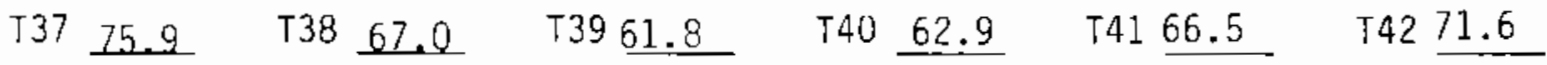

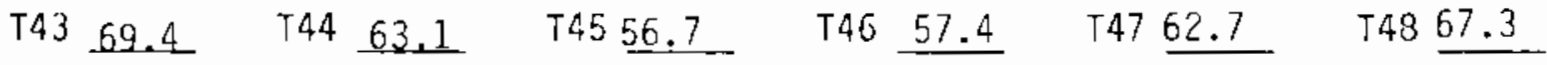

Boundary Temperatures $\left({ }^{\circ} \mathrm{C}\right)$

Front Wall (FW) 59.0

Front Cooling Jacket (FCu) 55.3

Back Wal1 (BW) 58.0

Back Cooling Jacket (BCJ) 55.2

Electrode Wall, Right (EWR) 56.4

Top Cooling Jacket (TCJ) 9.6

Electrode Wall, Left (EWL) _58.1_ Electrode Cooling Jacket (ECJ) 51.7

$Y^{*}=0.58$

* Current $<0.15 \mathrm{~A}$

(a) First number denotas power meter value, second number (in parenthesis) is RMS voltage times RMS current. 
TABLE A.2

TEMPERATURE PROFILE TABULATION

BIPP Physical Model

Run BRUN-T2A

Power Supply Measurements

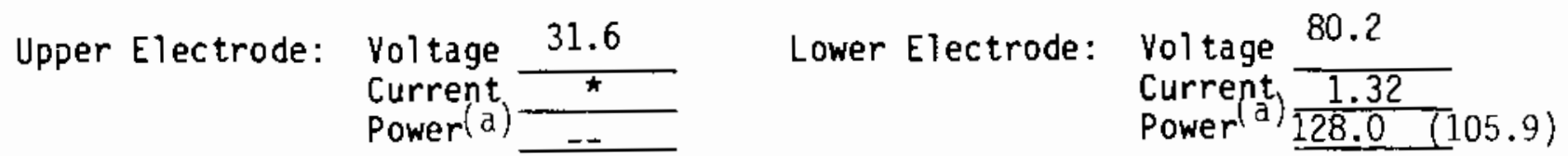

Power Skew Upper $\Omega$ Lower $100 \%$

Temperatures $\left({ }^{\circ} \mathrm{C}\right)$

T1 $\underline{64.9}$ T2 $\underline{65.4}$ T3 $\underline{54.3}$ T4 $\underline{58.4}$ T5 $\underline{56.9}$ T6 $\frac{65.2}{6.2}$

T7 $\underline{68.9}$ T8 $70.6 \quad$ T9 $\underline{.66 .4}$ T10 $\underline{71.0} \quad$ T11 $70.2 \quad$ T12 $\underline{65.3}$

T13 69.2 T14 $\underline{\text { 70.2 }} \quad$ TI5 $\underline{68.7} \quad$ T16 $\underline{69.9} \quad$ T17 $\underline{69.9} \quad$ T18 63.5

T19 $\underline{69.4} \quad$ T20 $\underline{70.1} \quad$ T21 $\underline{68.9} \quad$ T22 $\underline{70.1} \quad$ T23 $\underline{69.9} \quad$ T24 $\underline{64.4}$

T25 $\underline{70.8} \quad$ T26 $\underline{71.0} \quad$ T27 $\underline{68.2} \quad$ T28 $\underline{70.2} \quad$ T29 $\underline{71.0} \quad$ T30 64.9

T31 $\underline{76.6} \quad$ T32 $\underline{73.8} \quad$ T33 $\underline{67.7} \quad$ T34 $\underline{69.1} \quad$ T35 $\underline{73.4} \quad$ T36 86.8

T37 $\underline{82.6} \quad$ T38 $\underline{75.0} \quad$ T39 $\underline{65.6} \quad$ T40 $\underline{66.8} \quad$ T41 $\underline{72.1} \quad$ T42 $\underline{87.8}$

T43 $\underline{71.4}$ T44 $\underline{65.9} \quad$ T45 $\underline{61.2} \quad$ T46 $\underline{\underline{62.1}}$ T47 $\underline{65.8} \quad$ T48 $\underline{79.2}$

Boundary Temperatures $\left({ }^{\circ} \mathrm{C}\right)$

Front Wall (FW) 59.7

Back Wall (BW) 58.8

Electrode Kall, Right (EWR) 54.2

Electrode Wal1, Left (EWL)

Front Cooling Jacket (FCJ) 56.5

Back Cooling Jacket (BCJ) 56.9

Top Cooling Jacket (TCJ)

Electrode Cooling Jacket (ECJ) 49.8

$Y^{\star}=0.58$

* Current $<0.15 \mathrm{~A}$

(a) First number denotes power meter value, second number (in parenthesis) is RMS voltage times RMS current. 
TABLE A.3

TEMPERATURE PROFILE TABULATION

BIPP Physical Model

RUN BRUN-T2B

Power Supply Measurements

Upper Electrode:

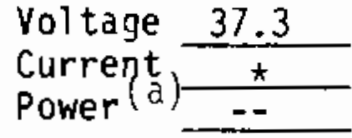

Power Skew
Lower Electrode:

Voltage 82.3

Cowrent $(a) \frac{1.32}{128.0}(108.6)$

Temperatures $\left({ }^{\circ} \mathrm{C}\right)$

T1 60.0 T2 $\underline{61.5}$ T3 $\underline{51.9}$ T4 $\quad \underline{55.3}$ T5 $\underline{63.5}$ T6 $\underline{61.4}$

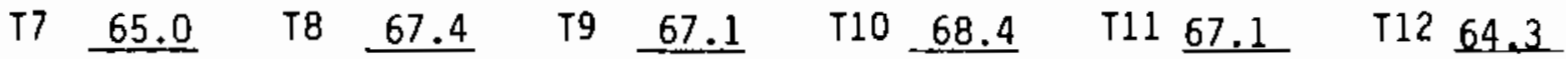

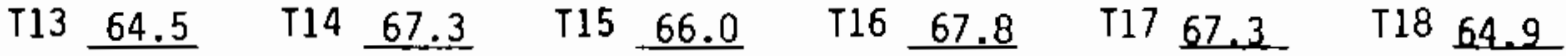

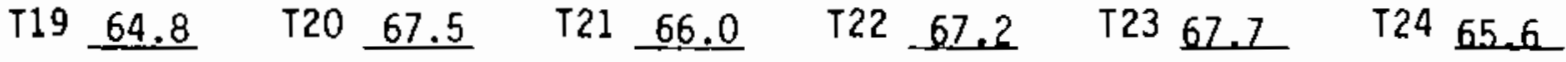

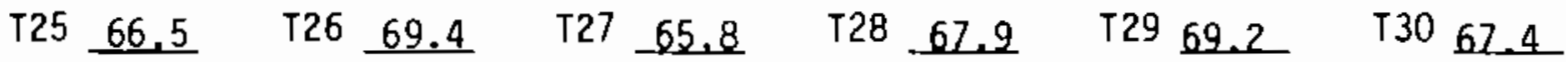

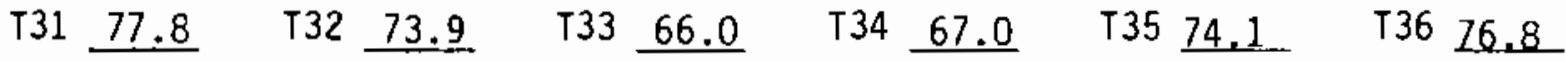

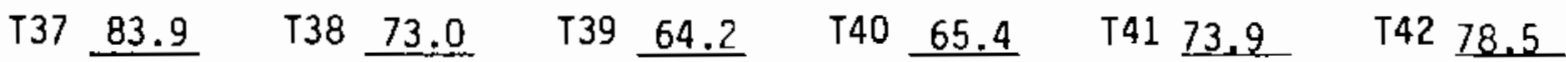

$\begin{array}{lllllllll}\text { T43 } & 72.3 & \text { T44 } 65.1 & \text { T45 } & 60.1 & \text { T46 } 60.9 & \text { T47 } 67.5 & \text { T48 } 70.1\end{array}$

Boundary Temperatures $\left({ }^{\circ} \mathrm{C}\right)$

Front Wail (FW) 59.0

Front Cooling Jacket (FCJ)

Back Wall (BW) 58.8

Back Cooling Jacket (BCJ) 56.9

Electrode Wal1, Right (EWR) 53.7

Top Cooling Jacket (TCJ)

Electrode Wal1, Left (EWL) 54.4 Electrode Cooling Jacket (ECJ) 49.8

$Y^{\star}=0.42$

* Current $<0.15 \mathrm{~A}$

(a) First number denotes power meter value, second number (in parenthesis) is RMS voltage times RMS current. 
TABLE A.4

TEMPERATURE PROFILE TABULATION

BIPP Physical Mode?

Run BRUN - T3A

Power Supply Measurements

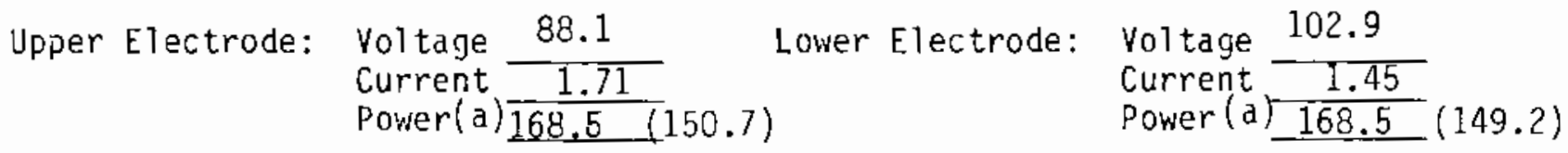

Power Skew $\quad$ Upper $50 \%$ Lower $50 \%$

Temperatures $\left({ }^{\circ} \mathrm{C}\right)$

$\begin{array}{llllllllll}\text { T1 } & 70.1 & \text { T2 } & 71.3 & \text { T3 } & 65.9 & \text { T4 } & 64.6 & \text { T5 } & \underline{70.9}\end{array}$

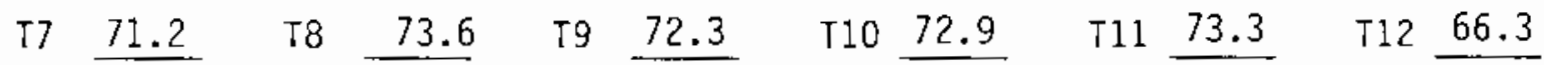

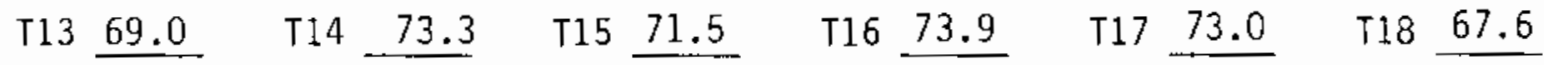

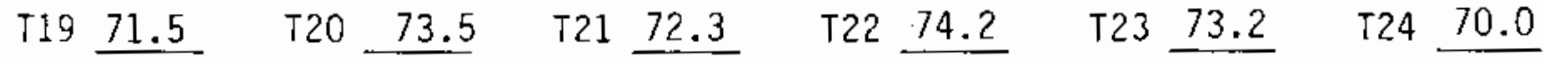

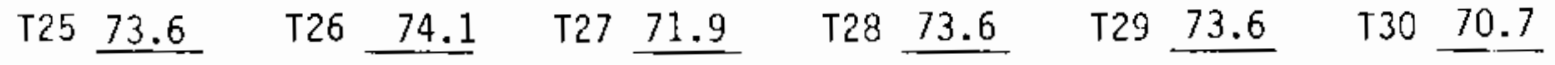

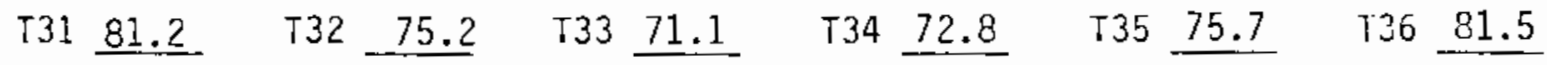

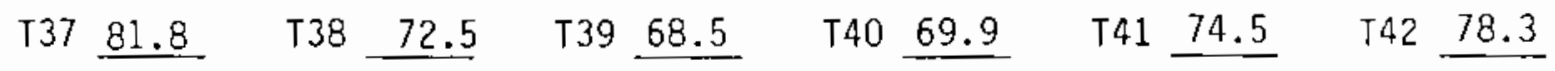

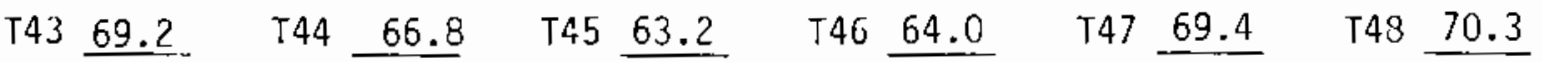

Boundary Temperatures $\left(^{\circ} \mathrm{C}\right)$

Front Walt (FW) $59.4 \quad$ Front Cooling Jacket (FCJ) 55.7

Back Walt (BW) _ $58.9 \quad$ Back Cooling Jacket (BCJ) 56.3

Electrode Wail, Right (ELR) $\quad 55.0$ Top Cooling Jacket (TCJ)__ 9.4

Electrode Wa 11 , Left (EWL) $56.2 \quad$ Electrode Cooling Jacket (ECJ) 49.9

$Y^{\star}=0.58$

* Current $<0.15 \mathrm{~A}$

(a) First number denotes power meter value, second number (in parenthesis) is RMS voltage times RMS current. 
TABLE A.5

TEMPERATURE PROFILE TABULATION

BIPP Physical Model

Run BRUN-T3B

Power Supply Measurements

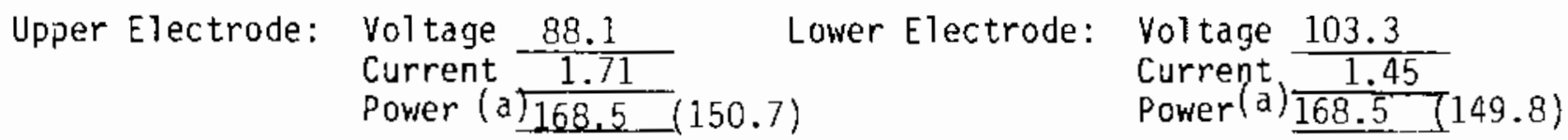

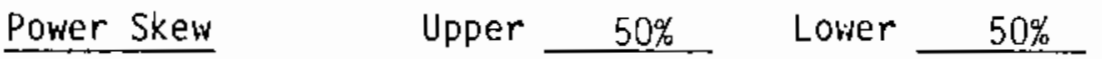

Tenperatures $\left({ }^{\circ} \mathrm{C}\right)$

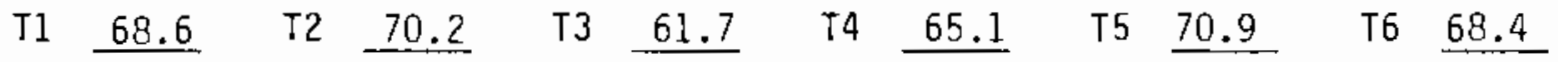

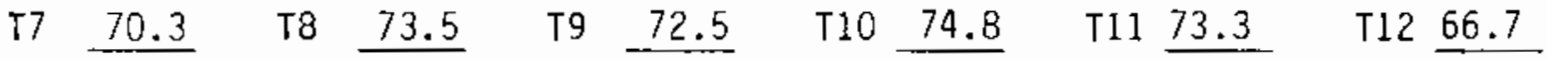

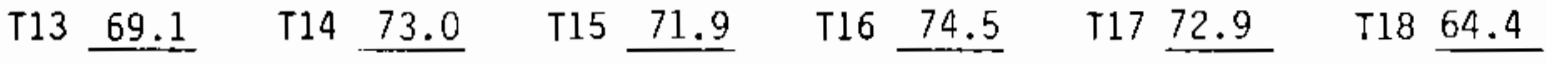

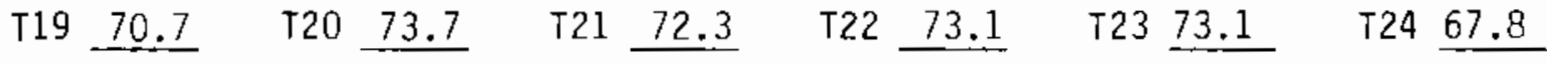

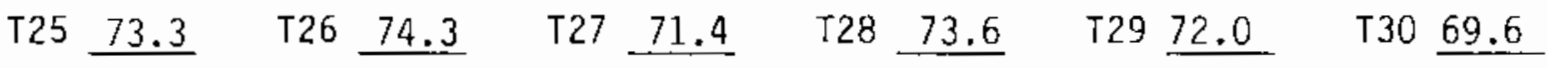

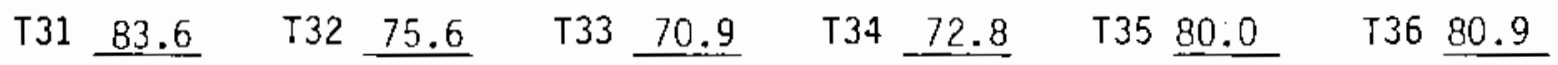

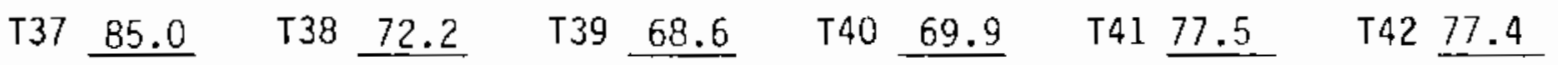

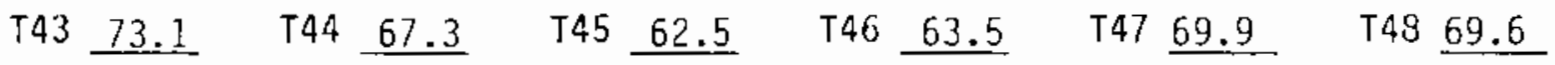

Boundary Temperatures $\left({ }^{\circ} \mathrm{C}\right)$

Front Wall (FW) 59.5

Front Cooling Jacket (FCJ) 55.7

Back Wall (BW) 58.9

Back Cooling Jacket (BCJ)

Electrode Wall, Right (EWR) 54.8

Top Cooling Jacket (TCJ) 9.7

Electrode Wall, Left (EWL) 56.1

Electrode Cooling Jacket (ECJ) 49.5

$Y^{\star}=0.42$

* Current $<0.15 \mathrm{~A}$

(a) First number denotes power meter value, second number (in parenthesis) is RMS voltage times RMS current. 


\section{TABLE A.6}

TEMPERATURE PROFILE TABULATION

BIPP Physical Model

Run BRUN-T4A

Power Supply Measurenents

Upper Electrode:
Lower Electrode: Voltage 74.3

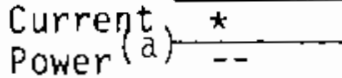

Power Skew

Upper $100 \%$

Lower $0 \%$

Temperatures $\left({ }^{\circ} \mathrm{C}\right)$

\begin{tabular}{|c|c|c|c|c|c|c|c|}
\hline I1 74.0 & $\mathrm{~T} 2 \quad 74.5$ & T3 69.5 & T4 & 71.6 & T5 & 74.5 & T6 72.4 \\
\hline 74.4 & 76.0 & T9 75.3 & T10 & 77.5 & $\mathrm{~T} 11$ & 75.8 & T12 71.9 \\
\hline 374.0 & T14 75.2 & $T 1574.8$ & $T 16$ & 76.4 & T17 & 74.9 & T18 $\underline{70.7}$ \\
\hline $9 \quad 75.3$ & $\mathrm{~T} 20 \quad 74.9$ & $\mathrm{~T} 2173.3$ & $\mathrm{~T} 22$ & 75.3 & $T 23$ & 74.9 & T24 75.5 \\
\hline $5 \quad 80.2$ & T26 73.3 & $\mathrm{~T} 2769.1$ & $T 28$ & 70.6 & T29 & 73.0 & T30 79.3 \\
\hline 111.7 & $T 32 \quad 67.0$ & $T 3364.2$ & T34 & 65,4 & $\mathrm{~T} 35$ & 66.3 & T36 69.1 \\
\hline 7 ב- & T38 & $739 \div$ & $T 40$ & - & T41 & $\ldots$ & $T 42^{-}$ \\
\hline - & $T 44=$ & $\mathrm{T} 45^{-}$ & T46 & & $T 47$ & 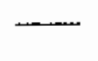 & T48 \\
\hline
\end{tabular}

Boundary Temperatures $\left({ }^{\circ} \mathrm{C}\right)$

Front Wall (FW) 59.3

Back Wall (BW) 58.7

Electrode Wall, Right (EWR) 58.5

Electrode Wall, Left (EWL) 58.8
Front Cooling Jacket (FCJ) 55.0

Back Cöoling Jacket (BCJ) 55.4

Top Cooling Jacket (TCJ) _ 9.3

Electrode Cooling Jacket (ECJ) 51.7

$y *=0.58$

* Current $<0.15 \mathrm{~A}$

(a) First number denotes power meter value, second number (in parenthesis) is RMS voltage times RMS current. 
TABLE A.7

TEMPERATURE PROFILE TABULATION

BIPP Physical Model

Run BRUN-T5A

Power Supply Measurements

Upper Electrode: Voltage 60.6

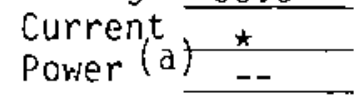

Power Skew

Upper
Lower Electrode: Voltage 114.9

Current $\frac{114.26}{2.26}$

Power (a) $\lcm{292.9}$ (259.7)

Temperatures $\left({ }^{\circ} \mathrm{C}\right)$

T1

T1 69.6

$17 \quad 70.4$

T13 68.7

T19 70.8

T25 114.1

T31 95.0

T37 -

T43
T2 71.

T8 73.1

T14 73.1

T20 76.5

T26 82.1

T32 78.1

T38

$$
\text { T44 }
$$

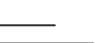

$0 \%$

Lower $\quad 100 \%$

Boundary Temeratures $\left({ }^{\circ} \mathrm{C}\right)$

Front wall (FW) 61.8

Back wall (BW) 60.0

Electrode Wall, Right (EWR) 58.2

Electrode Wall, Left (EWL) 58.3
Front Cooling Jacket (FCJ) $\underline{58.2}$

Back Cooling Jacket (BCJ) 58.5

Top Cooling Jacket (TCJ) 9.0

Electrode Cooling Jacket (ECJ) 52.2

$Y^{\star}=0.58$

* Current $<0.15 \mathrm{~A}$

(a) First number denotes power meter value, second number (in parenthesis) is RMS voltage times RMS current. 
TABLE A.8

TEMPERATURE PROFILE TABULATION

BIPP Physical Model

Run BRUN-T6A

Power Supply Heasurements

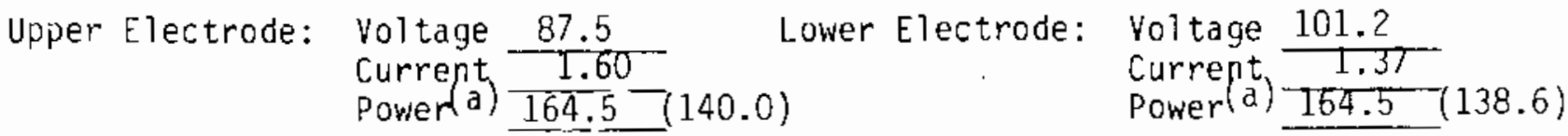

Power Skew Upper 50\% Lower $\quad$ L $50 \%$

Temperatures $\left.1^{\circ} \mathrm{C}\right)$

T1 $\underline{70.5}$ T2 $\underline{71.9} \quad$ T3 $\underline{64.9} \quad$ T4 $\underline{69.4} \quad$ T5 $\underline{71.0} \quad$ T6 $\underline{69.1}$

T7 22.1 T8 $\underline{74.7} \quad$ T9 $\underline{73.9} \quad$ T10 $\underline{75.0} \quad$ T11 $\underline{74.2}$ T12 $\underline{69.5}$

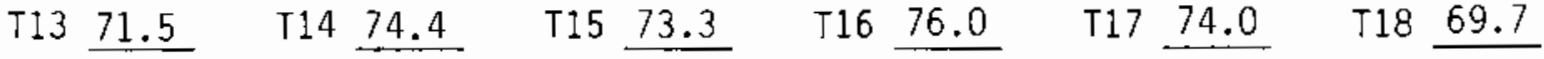

$\begin{array}{llllllll}\text { T19 } & 72.2 & \text { T20 } \underline{74.8} & \text { T21 } & 72.8 & \text { T22 } \underline{74.7} & \text { T23 } \underline{74.2} & \text { T24 } \underline{70.0}\end{array}$

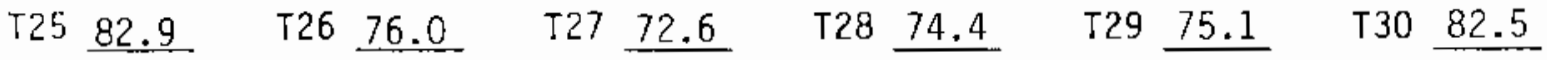

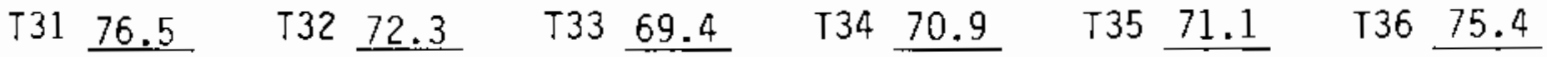

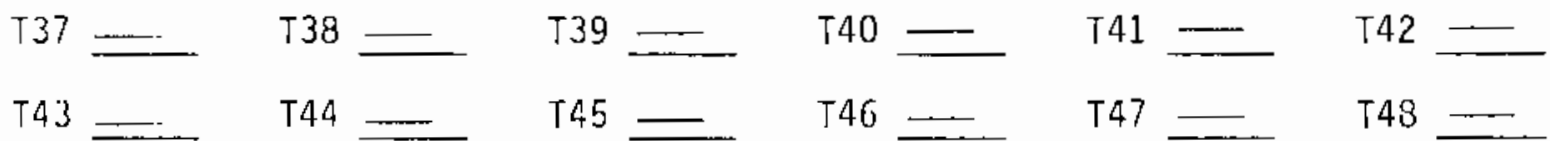

Boundary Temperatures $\left(1^{\circ} \mathrm{C}\right)$

\begin{tabular}{lll} 
Front Wall (FW) $\frac{60.7}{60.0}$ & Front Cooling Jacket (FCJ) $\frac{56.9}{57.3}$ \\
\hline Back Wall (BW) & Back Cooling Jacket (BCJ)
\end{tabular}

Electrode Wall, Right (EWR) 58.4 Top Cooling Jacket (TCJ) 16.7

Electrode Wall, Left (EWL) $\quad 57.6 \quad$ Electrode Cooling Jacket (ECJ) 51.8

$Y \star=0.58$

* Current $<0.15 \mathrm{~A}$

(a) First number denotes power meter value, second number (in parenthesis) is RMS voltage times RMS current. 
TABLE A.9

TEMPERATURE PROFILE TABULATION

BIPP Physical Model

Run BRUN-T7A

Power Supply Measurements

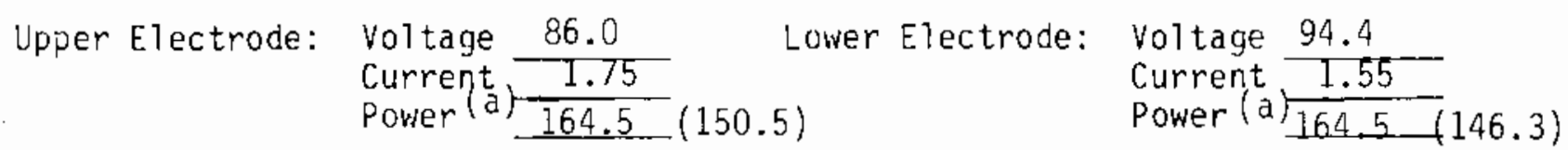

Power Skew $\quad$ Upper $50 \%$ Lower $50 \%$

Temperatures $\left({ }^{\circ} \mathrm{C}\right)$

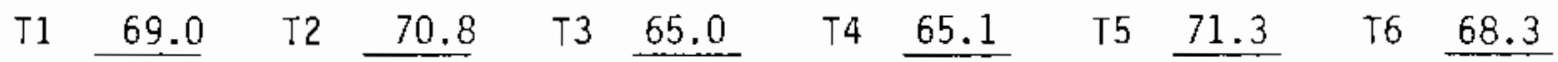

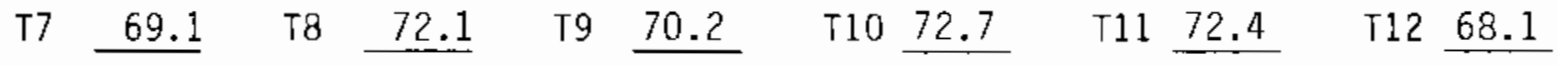

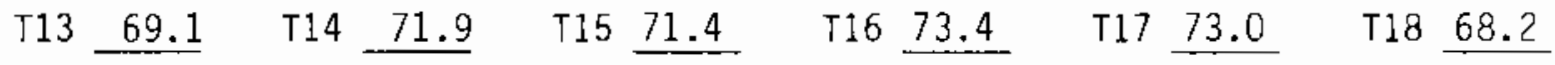

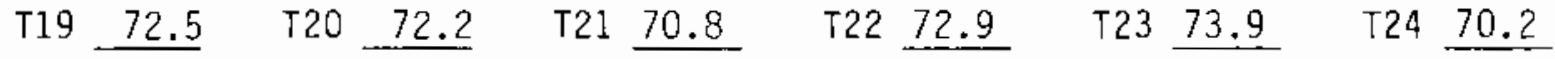

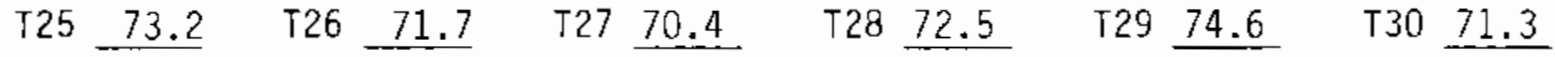

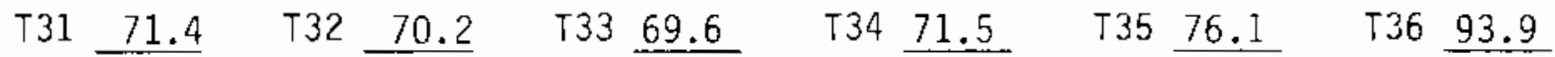

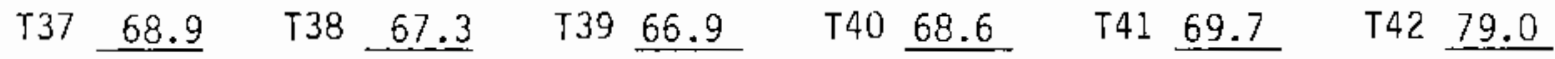

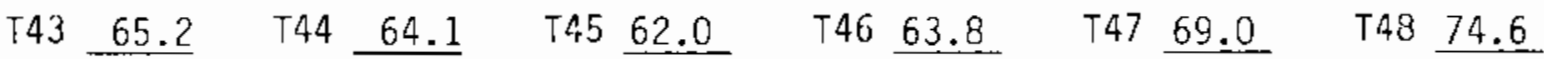

Boundary Temperatures $\left({ }^{\circ} \mathrm{C}\right)$

Front Wall (FW) $58.7 \quad$ Front Cooling Jacket (FCJ) 55.3

Back Wall (BW) $58.0 \quad$ Back Cooling Jacket (BCJ) 55.5

Electrode Wall, Right (EWR) 56.2 Top Cooling Jacket (TCJ) _ 9.5

Electrode Wall, Left (EWL) $56.0 \quad$ Electrode Cooling Jacket (ECJ) 49.8

$\gamma *=0.58$

* Current $<0.15 \mathrm{~A}$

(a) First number denotes power meter value, second number (in parenthesis) is RMS voltage times RMS current. 


\section{TABLE A.10}

TEMPERATURE PROFILE TABULATION

BIPP Physical Model

Run BRUN-T7B

Power Supply Measurements

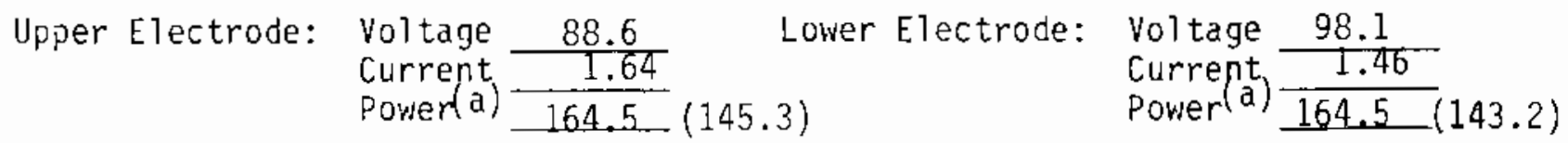

Power Skew Upper 50\% Lower $50 \%$

Temperatures $\left({ }^{\circ} \mathrm{C}\right)$

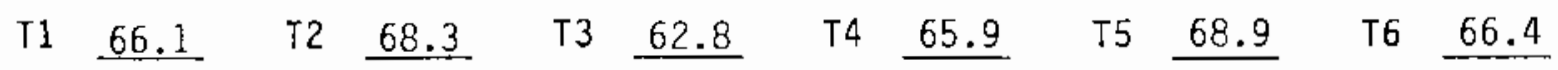

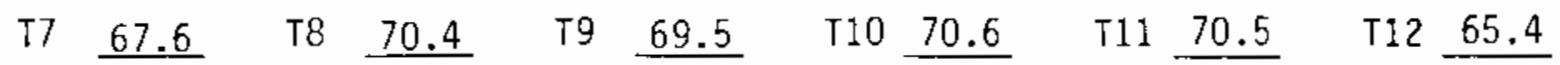

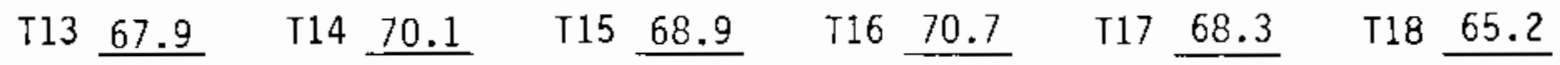

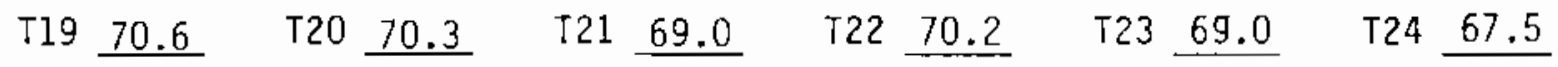

T25 $72.2 \quad T 26 \quad \underline{71.0} \quad T 27 \underline{68.4} \quad$ T28 $\underline{70.0} \quad$ T29 $\underline{67.6} \quad$ T30 $\underline{67.9}$

T31 $78.4 \quad$ T32 ⒉1 $\quad$ T33 $\underline{67.5} \quad$ T34 $\underline{69.0} \quad$ T35 $\underline{60.2} \quad$ T36 $\underline{66.3}$

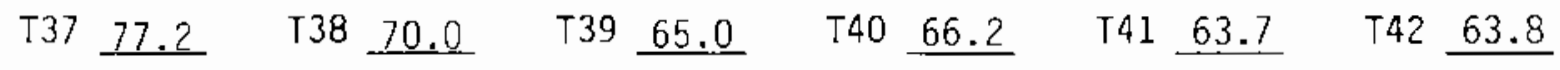

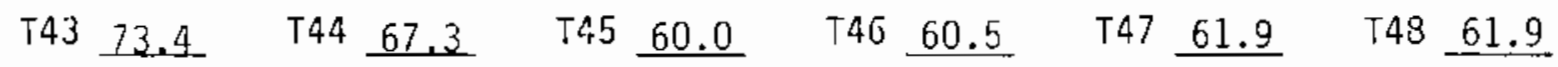

Boundary Temperatures $\left({ }^{\circ} \mathrm{C}\right)$

Front Wall (FW) 56.9 Front Cooling Jacket (FCJ) 53.9

Back Wall (BW) $\quad 56.3 \quad$ Back Cooling Jacket (BCJ) _. 54.1

Electrode Wal1, Right (EWR) ___ 55.1 Top Cooling Jacket (TCJ) _ 9.1

Electrode Wa11, Left (EWL) _.55.6 Electrode Cooling Jacket (ECJ) 49.8

$Y^{\star}=0.58$

$\star$ Current $<0.15 \mathrm{~A}$

(a) First number denotes power meter value, second number (in parenthesis) is RMS voltage times RMS current. 
TABLE A. 11

TEMPERATURE PROFILE TABULATION

BIPP Physical Mode?

Run BRUN-T8A

Power Supply Measurements

Upper Electrode: Voltage $\frac{93.4}{2.33}$ Lower Electrode: Voltage 83.3

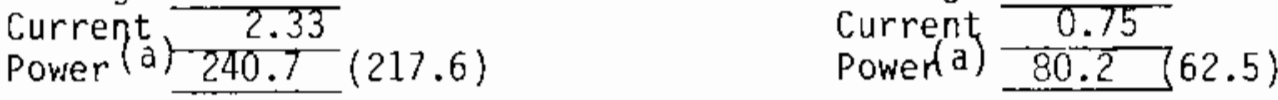

Power Skew Upper $75 \%$ Lower $25 \%$

Temperatures $\left({ }^{\circ} \mathrm{C}\right)$

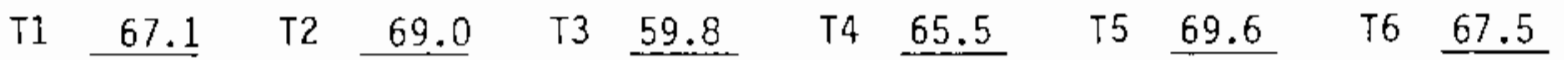

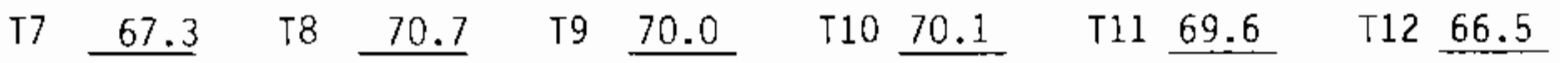

T13_67.3 T14 70.2 T15 $\underline{69.0} \quad T 16 \underline{71.3} \quad T 17 \underline{71.5} \quad$ T18 66.2

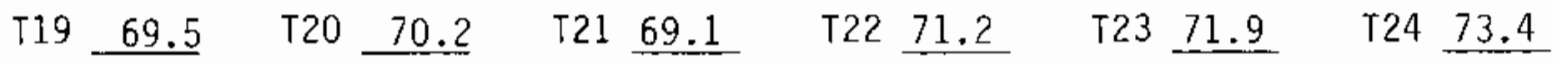

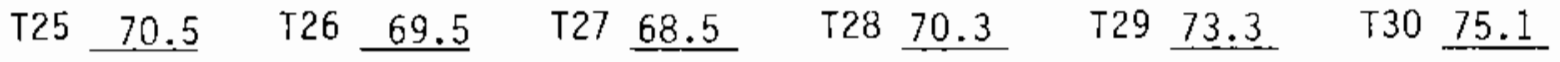

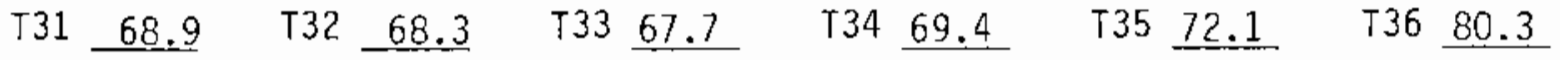

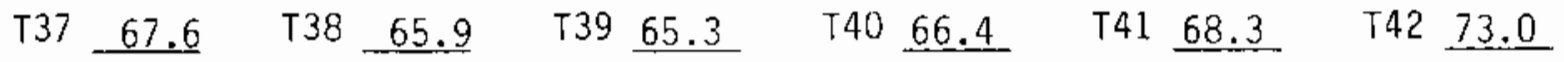

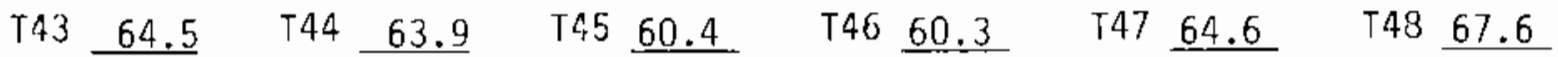

Boundary Temperatures $\left({ }^{\circ} \mathrm{C}\right)$

Front Wall (FW)

Back Wa13 (BW) 58.8

Electrode Wall, Right (EWR) $56.5 \quad$ Top Cooling Jacket (TCJ)

Electrode Wall, Left (EWL) 56.1 Electrode Cooling Jacket (ECJ) 50.5

$Y *=0.58$

* Current $<0.15 \mathrm{~A}$

(a) First number denotes power meter value, second number (in parenthesis) is RMS voltage times RMS current. 
TABLE A.12

TEMPERATURE PROFILE TABULATION

BIPP Physical Model

Run BRUN-T9A

Power Supply Measurements

Upper Electrode: Voltage 81.2 Lower Electrode: Voltage 93.8 Current $\frac{81.8}{1.84} \quad$ Current 1.53

Power(a) $168.5(149.4) \quad$ Power $\underline{168.5(143.5)}$

Power Skew Upper $50 \%$ Lower $50 \%$

Temperatures $\left({ }^{\circ} \mathrm{C}\right)$

$\begin{array}{llllllllllll}T 1 & \underline{70} .1 & \mathrm{~T} 2 & \underline{70.9} & \mathrm{~T} 3 & \underline{62.7} & \mathrm{~T} 4 & \mathbf{6 7 . 3} & \mathrm{6} 5 & \underline{70.5} & \text { T6 } & \underline{70.0}\end{array}$

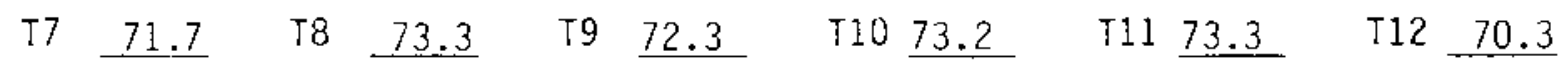

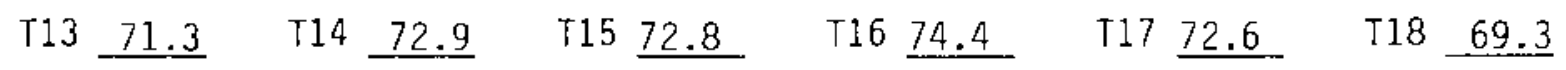

$\begin{array}{llllllll}\text { T19 } & \text { 74.2 } & \text { T20 } & \text { 73.2. } & \text { T21 } 72.2 & \text { T22 } \underline{74.3} & \text { T23 } \underline{73.1} & \text { T24 } 71.2\end{array}$

$\begin{array}{llllllll}T 25 & 75.5 & T 26 \quad \text { 73.6 } & T 27 \underline{71.6} & \text { T28 } & \underline{73.7} & \text { T29 } \underline{74.0} & \text { T30 } \underline{72.8}\end{array}$

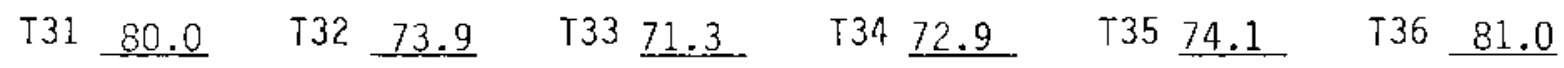

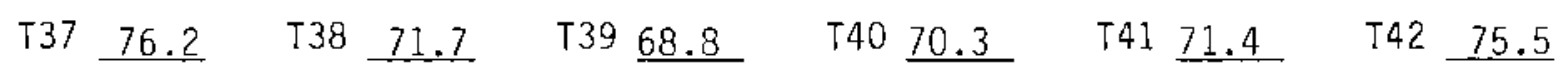

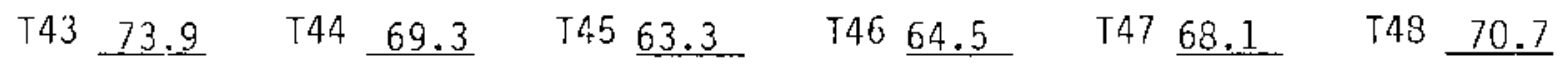

Boundary Temperatures $\left({ }^{\circ} \mathrm{C}\right)$

Front Wi1 (FW) 60.6

Front Cooling Jacket (FCJ)

Back Wall (BW) 60.3 Back Cooling Jacket (BCJ) 58.0

Electrode Wall, Right (EWR) _.56.8__ Top Cooling Jacket (TCJ) _.. 9.3

Electrode Wall, Left (EWL) 57.2 Electrode Cooling Jacket (ECJ) 50.6 $Y^{\star}=0.58$

* Current $<0.15 \mathrm{~A}$

(a) First number denotes power meter value, second number (in parenthesis) is RMS voltage times RMS current. 
APPENDIX 8

TABULATION OF MEASURED ELECTRIC FIELD DATA 
APPENDIX B

TABULATION DF MEASURED ELECTRIC FIELD DATA

Electric potential data reported in Section 5.3 of this report are tabulated in this appendix. Included are results for tests BRUN-1 to BRUN-9 inclusive. Test run identification throughout the report is given as BRUN-1 for example. In the tabulations, $-E 1$ refers to BRUN-1 where electric potential data were measured. An $A$ or $B$ is appended (e.g., -E1A) where multiple data sets were recorded for the same run. Probe positions are identified as E16, for example, and correspond to position listed in Figures 3.4 and 3.5 . 
TABLE B.1

$$
\begin{aligned}
& \text { POTENTIAL PROFILE TABULATION } \\
& \text { BIPP Physical Model } \\
& \text { Run BRUN-EIB }
\end{aligned}
$$

Power Supply Measurements

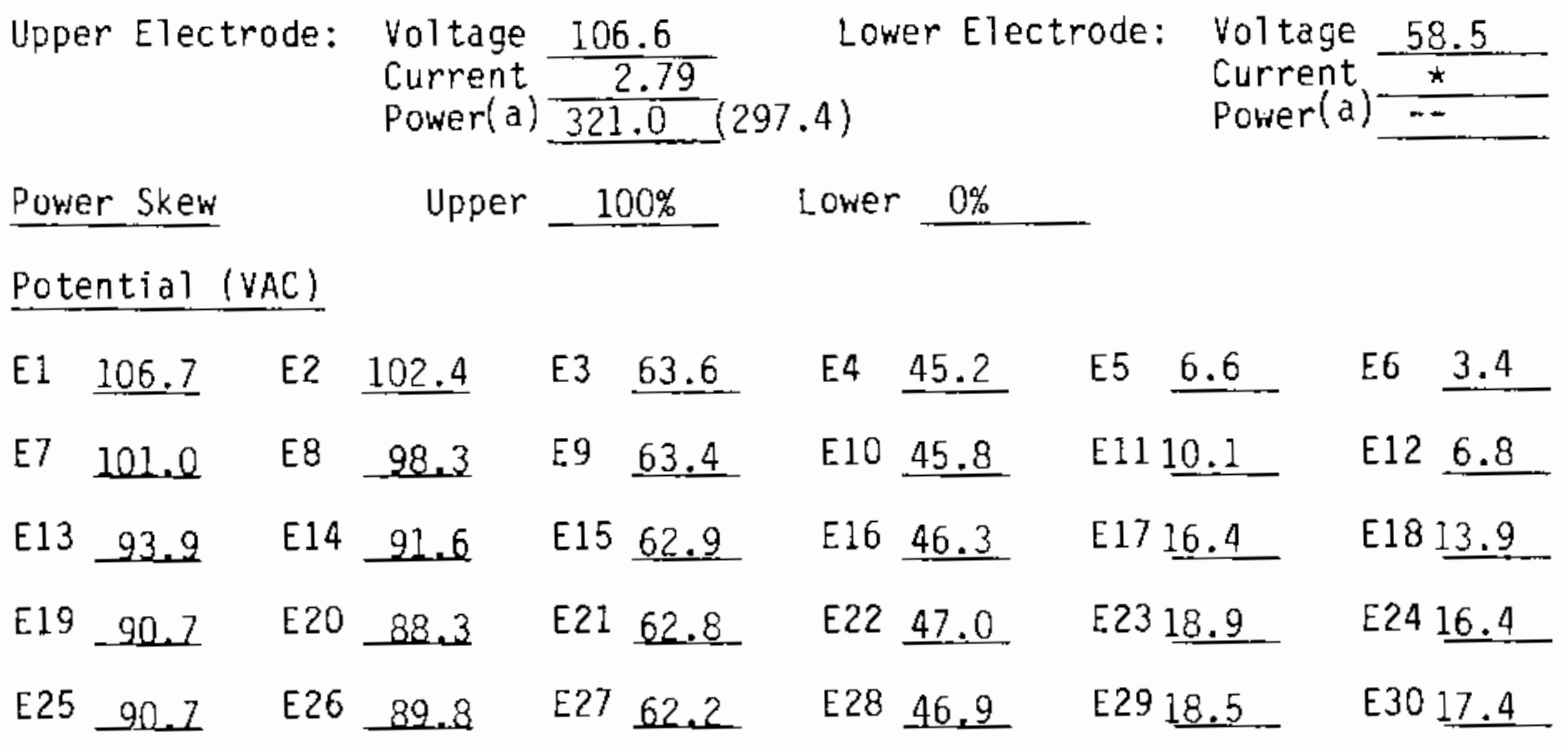

Boundary Temperatures $\left.1^{\circ} \mathrm{C}\right)$

Front Wall (FW) 58.9

Back wall (BW) $\quad 58.5$

Electrode Wal\}, Right (EWR) $\quad 56.5$

Electrode Wall, Left (EWL) _. 58.8.

Ground Upper negative electrode

$Y^{\star}=0.42$

* Current $<0.15 \mathrm{~A}$
Front Cooling Jacket (FCJ) _ 54.8 Back Cooling Jacket (BCJ) $\quad 55.8$ Top Cooling Jacket (TCJ) _. 2.6 Electrode Cooling Jacket (ECJ) 51.9

(a) First number denotes power meter value, second number (in parenthesis) is RMS voltage times RMS current. 


\section{TABLE B.2}

POTENTIAL PROFILE TABULATION

BIPP Physical Model

Run BRUN-E2B

Power Supply Measurements

Upper Electrode: Voltage 39.5

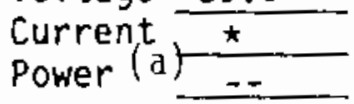

Power Skew

Potential (VAC)
E2 61.9

E3 47.2

E9 47.3

E7 63.0

E8 63.3

E14 66.7

$E 15 \quad 47.5$

E19 72.2

E20 $\underline{73.3}$

E21 47.5

E27 47.4
Lower Electrode: Voltage $\frac{84.3}{\text { Current }}-\frac{1.34}{1.34}$

Power(a) 128.0 113.0)
E4 $\quad 36.8$

E5 21.9

E6 22.2

E10 $\underline{36.5}$

E11 21.8

$E 16 \quad 36.2$

E17 18.0

E22 36.1

E23 $\underline{13.7}$

E28 36.1

E29 12.8
$\mathrm{E} 1221.4$

E18 18.9

E24 17.0

$530 \underline{6.6}$

Boundary Tenperatures $\left({ }^{\circ} \mathrm{C}\right)$

Front Wall (FW) 60.4

Back Wall (BW) 58.4

Electrode Wall, Right (EWR) 55.3

Electrode Wa11, Left (EWL) _ 56.1
Front Cooling Jacket (FCJ) 57.7 Back Cooling Jacket (BCJ) 56.5 Top Cooling Jacket (TCJ) 9.3 Electrode Cooling lacket (ECJ) 51.7

Ground: Lower negative electrode

$y \star=0.42$

* Current $<0.15 \mathrm{~A}$

(a) First number denotes power meter value, second number (in parenthesis) is RMS voltage times RMS current. 
TABLE B.3

POTENTIAL PROFILE TABULATION

BIPP Physical Model

Run $\quad$ BRUN-E3B

Power Supply Measurements

Upper Electrode: Voltage $\quad 89.6 \quad$ Lower Electrode: Voltage 104.4

$\begin{array}{ll}\text { Current } \frac{1.73}{168.5}(155.0) & \text { Current } \\ \text { Power } & \text { Power } \frac{1.45}{168.5}\end{array}$

Power Skew $\quad$ Upper $50 \%$ Lower $50 \%$

Potential (VAC)

E1 $\underline{94.9} \quad$ E2 $\underline{92.6} \quad$ E3 $\underline{60.9} \quad$ E4 $\underline{43.9} \quad$ E5 $17.2 \quad$ E6 16 .

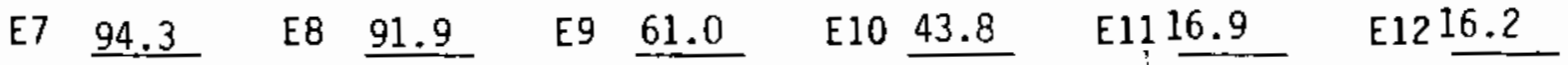

E13 92.6 E14 $\underline{90.3} \quad$ E15 $61.1 \quad$ E16 44.4 E17 $15.3 \quad$ E18 14.6

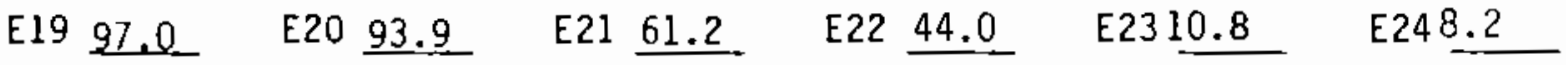

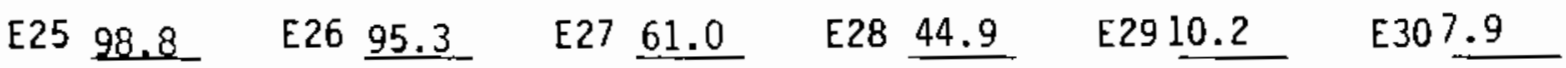

Boundary Tenperatures $\left({ }^{\circ} \mathrm{C}\right)$

Front Wall (FW) 59.7

Front Cooling Jacket (FCJ) 55.8

Back Wall (BW) 58.9

Back Cooling Jacket (BCJ) 56.3

Electrode Wall, Right (EWR) 55.1 Top Cooling Jacket (TCJ) 9.6

Electrode Wal1, Left (EWL) $56.3 \quad$ Electrode Cooling Jacket (ECJ) 49.9

Ground Lower negative electrode.

$Y^{*}=0.42$

* Current $<0.15 \mathrm{~A}$

(a) First number denotes power meter value, second number

(in parenthesis) is RMS voltage times RMS current. 


\section{TABLE B. 4}
POTENTIAL PROFILE TABULATION
BIPP Physical Model
Run BRUN-E4B

Power Supply Measurements

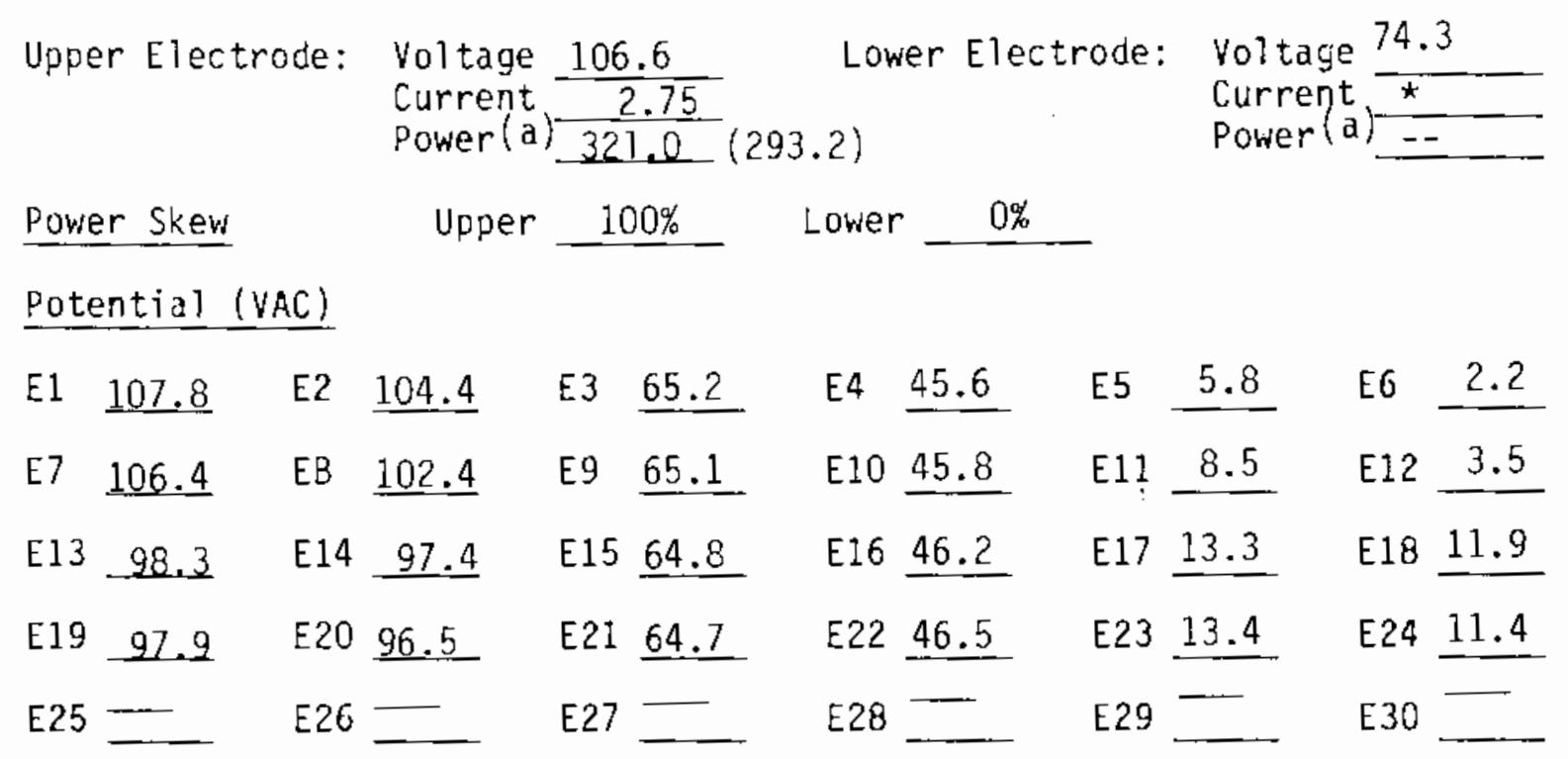

Boundary Temperatures $\left({ }^{\circ} \mathrm{C}\right)$

Front wail (FW) 59.5

Back Wall (BW) 58.3

Electrode Wall, Right (EWR) $58.7 \quad$ Top Cooling Jacket (TCJ) 9.8

Electrode wall, Left (EWL) $59.1 \quad$ Electrode Cooiling Jacket (ECJ) 52.1

Ground Upper negative electrode

$Y *=0.42$

* Current $<0.15 \mathrm{~A}$

(a) First number denotes power meter value, second number (in parenthesis) is RMS voltage times RMS current. 
TABLE B.5

POTENTIAL PROFILE TABULATION

BIPP Physical Mode1

Run BRUN-E5B

Power Suppiy Measurements

Upper Electrode: Voltage

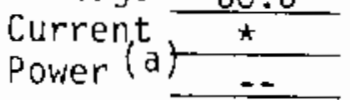

Power Skew

Upper
Lower Electrode: Voltage 115.5

Current $\frac{11.26}{2.26}$

Power (a) $\overline{292.9+(26] .0)}$

Potential (VAC)

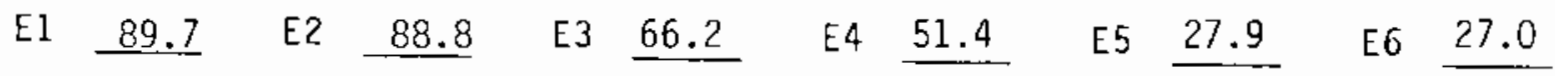

E7 $\quad \underline{90.9} \quad$ E8 $\underline{90.9} \quad$ E9 $\underline{60.4} \quad$ E10 $\underline{51.4} \quad$ E11 $24.9 \quad$ E12 25.2

E13 106.3 E14 $\underline{101.7} \quad$ E15 $\underline{66.5} \quad$ E16 $\underline{51.4} \quad$ E17 $16.4 \quad$ E18 12.4

E19 $10 \underline{107.1} \quad E 20 \underline{102.9} \quad$ E21 $67.0 \quad$ E22 $\underline{52.2} \quad$ E23 $\underline{15.4} \quad$ E24 11.1

$E 25=E 26 \div \quad E 27=E 28 \div \quad E 30-\quad \square$

Boundary Temperatures $\left({ }^{\circ} \mathrm{C}\right)$

Front Wall (FW) 61.5

Front Cooling Jacket (FCJ) 58.0

Back Wall (BH) $\quad 60.6$

Back Cooling Jacket (BCJ) _ 58.1

Electrode. Wal1, Right (EWR) $\quad 58.6$

Top Cooling Jacket (TCJ)

Electrode Wall, Left (EWL) $\quad 58.4 \quad$ Electrode Cooling Jacket (ECJ) 52.5

Ground Lower negative electrode

$y^{\star}=0.42$

* Current $<0.15 \mathrm{~A}$

(a) First number denotes power meter value, second number (in parenthesis) is RMS voltage times RMS current. 
TABLE B.6

POTENTIAL PROFILE TABULATION

BIPP Physical Model

Run BRUN-E6B

Power Supply Measurements

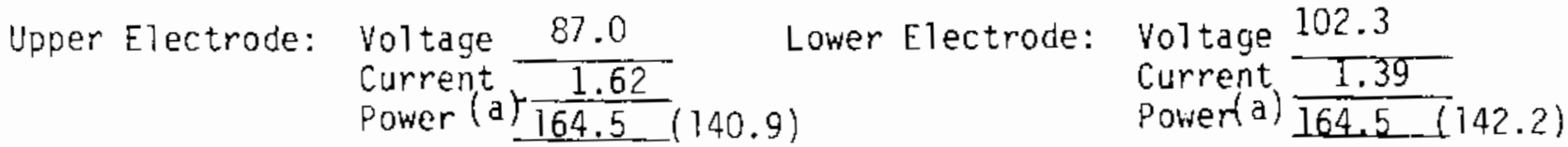

Power Skew Upper $50 \%$ Lower $50 \%$

Potentia) (VAC)

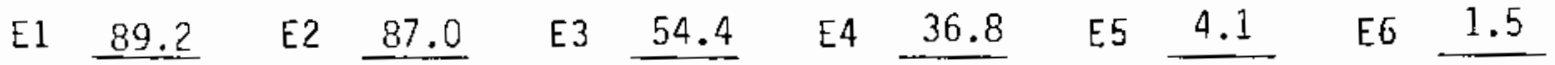

E7 89.3 E8 $\underline{87.1}$ E9 $\underline{54.5} \quad$ E10 $\quad 37.0 \quad$ E11 $4.6 \quad$ E

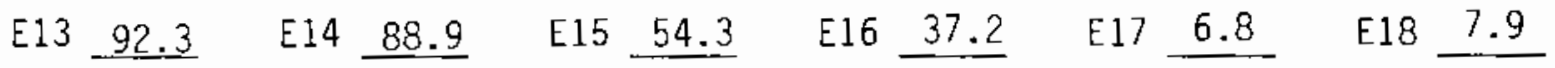

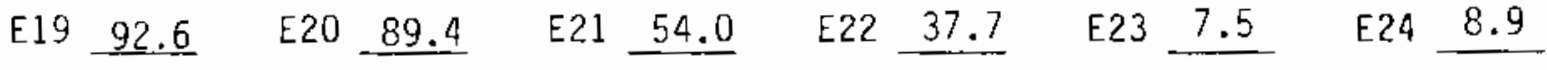

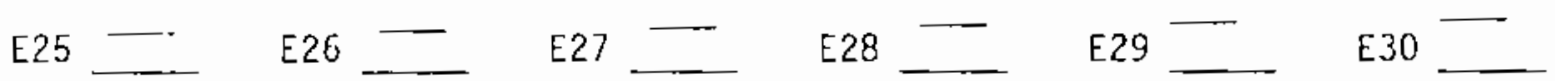

Boundary Tenperatures $\left({ }^{\circ} \mathrm{C}\right)$

Front wall (FW)

Front Cooling Jacket (FCJ) 56.9

Back wa11 (BW) $\quad 60.1$

Back Cooling Jacket (BCJ) 57.3

Electrode Wall, Right (EWR) 58.4

Top Cooling Jacket (TCJ)

Electrode Wa11, Left (EWL) 57.9

Electrode Cooling Jacket (ECJ) 51.8

Ground Upper negative electrode

$Y^{*}=0.42$

$\star$ Current $<0.15 \mathrm{~A}$

(a) First number denotes power meter vaiue, second number (in parenthesis) is RMS voltage times RMS current. 
TABLE B.7

POTENTIAL PROFILE TABULATION

BIPP Physical Model

Run BRUN-E7A

Power Supply Measurements

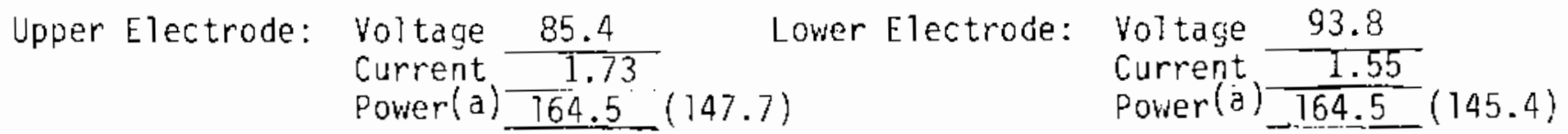

Power Skew $\quad$ Upper _ 50\% Lower _ $50 \%$

Potential (VAC)

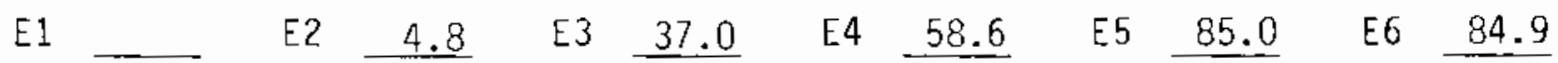

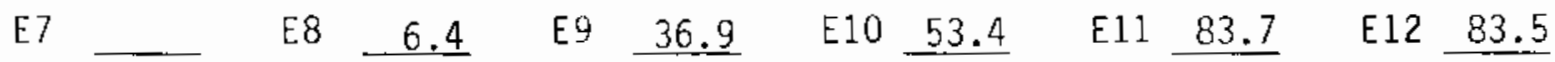

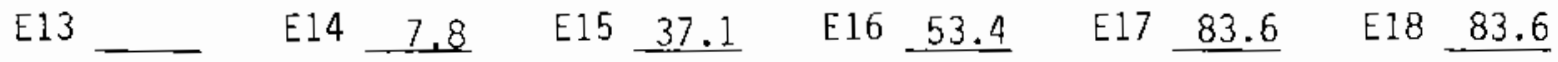

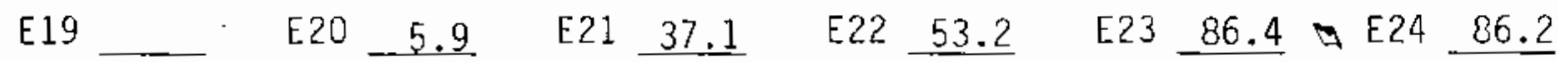

$E 25 \ldots E 27 \quad 37.5 \quad E 28 \quad 53.3 \quad E 29 \ldots E 30 \ldots$

Boundary Temperatures $\left({ }^{\circ} \mathrm{C}\right)$

Front wall (FW) 58.6

Front Cooling Jacket (FCJ) 55.1

Back Wail (BW) $\quad 58.1$

Back Cooling Jacket (BCJ) 55.6

Electrode wall, Right (EWR) 56.6

Top Cooling Jacket (TCJ)

Electrode Wal1, Left (EWL) $\quad 56.5 \quad$ Electrode Cooling Jacket (ECJ) 50.3

Ground: Upper negative electrode

$Y^{*}=0.42$

* Current $<0.15 \mathrm{~A}$

(a) First number denotes power meter value, second number (in parenthesis) is RMS voltage times RMS current. 
TABLE B.8

POTENTIAL PROFILE TABULATION

BIPP Physica? Model

Run BRUN-E7B

Power Supp1y Measurements

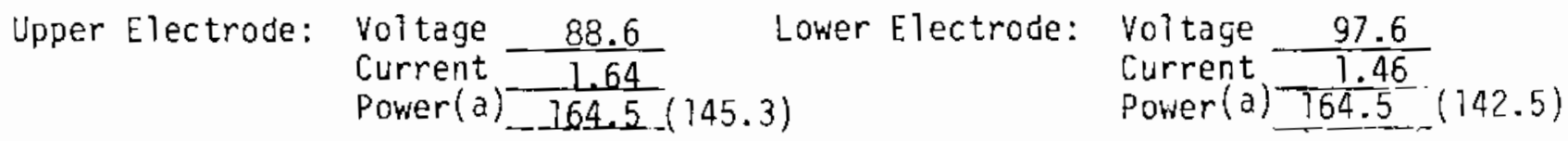

Power Skew $\quad$ Upper _ 50\% Lower _ 50\%

Potential (VAC)

E1 90.8 E2 88.3 E3 $\underline{\underline{56.1}}$ E4 $\underline{\underline{39.1}}$ E5 5.0 E6 1.7

E7 89.3 E8 86.8 E9 56.0 E10 $\underline{39.3} \quad$ E11 $\underline{6.5} \quad$ E12 4.4

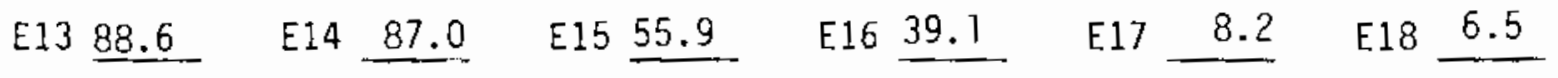

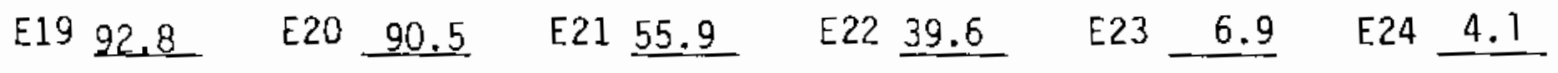

E25 $93.4 \quad E 26 \quad 97.1 \quad E 27$ 56.2 $\quad$ E28 39.7 $\quad E 29 \quad 6.9 \quad E 30 \quad 4.1$

Boundary Temperatures $\left({ }^{\circ} \mathrm{C}\right)$

Front Wall (FW) 56.7

Back Wall (BW) $\quad 56.2$

Electrode Wa11, Right (EWR) 55.0

Electrode Wal1, Left (EWL) 55.6

Front Cooling Jacket (FCJ) 53.7

Back Cooling Jacket (BCJ) 53.9

Top Cooling Jacket (TCJ) _ 9.4

Electrode Cooling Jacket (ECJ) 49.7

Ground: Upper negative electrode

$Y^{\star}=0.42$

* Current $<0.15 \mathrm{~A}$

(a) First number denotes power meter value, second number (in parenthesis) is RMS voltage times RMS current. 
TABLE B. 9

$$
\begin{aligned}
& \text { POTENTIAL PROFILE TABULATION } \\
& \text { BIPP Physical Model } \\
& \text { RUn BRUN-EBA }
\end{aligned}
$$

Power Supply Measurements

$$
\begin{aligned}
& \text { Upper Electrode: Voltage } \frac{93.4}{2.37} \text { Lower Electrode: Voltage } 83.3
\end{aligned}
$$

\begin{tabular}{|c|c|c|c|c|c|c|c|c|c|}
\hline E2 & 4.8 & E3 & 37.5 & E4 & 54.8 & E5 & 92.0 & $E 6$ & 95.7 \\
\hline E8 & 5.7 & E9 & 37.4 & E.10 & 54.4 & E11 & 88.3 & E12 & 91.6 \\
\hline E 14 & 8.3 & E15 & 37.3 & E16 & 53.8 & E17 & 85.0 & E18 & 86.6 \\
\hline E20 & 5.8 & E21 & 37.3 & $E 22$ & 53.3 & E23 & 84.6 & E24 & 87.5 \\
\hline$E 26$ & 7.0 & $\mathrm{E} 27$ & 37.4 & E28 & & E29 & & E30 & \\
\hline
\end{tabular}

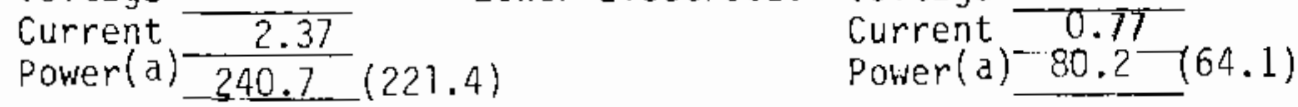

Power Skew Upper $75 \%$ Lower $25 \%$

Potential (VAC)

Boundary Temperatures $\left({ }^{\circ} \mathrm{C}\right)$

Front Wail (FW) 58.8

Back Wall (BW) $\quad 58.0$

Electrode Wall, Right (EWR) 55.9

Electrode Wal1, Left (EVL) $\quad 55.3$ Ground Top Electrode

$Y \star=0.42$

* Current $<0.15 \mathrm{~A}$

(a) First number denotes power meter value, second number (in parenthesis) is RMS voltage times RMS current.

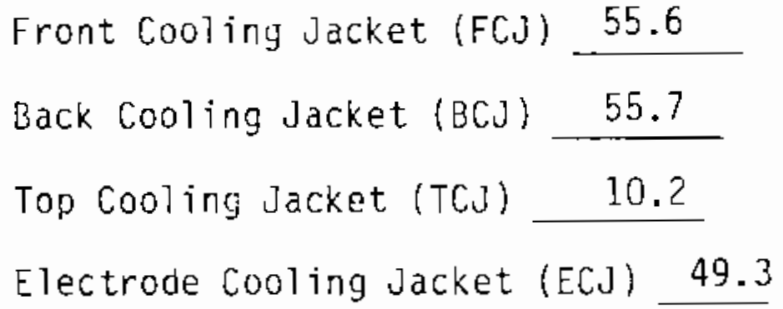




\title{
TABLE B. 10
}

\author{
POTENTIAL PROFILE TABULATION \\ BIPP Physical Model \\ Run BRUN-EgA
}

Power Supply Measurements
Upper Electrode: Voltage
Current $\frac{-81.7}{1.82}$
Power (a) $768.5-148.7$ )
Lower Electrode: Voltage $-\frac{93.3}{155}$
Power( a) $168.5(144.6)$
Power Skew Upper 50\% Lower $50 \%$
Potential (VAC)

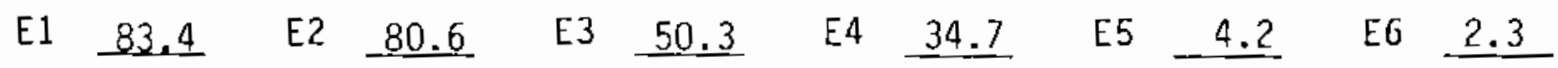

E7 82.3 E8 $\underline{79.4}$ E9 $50.0 \quad$ E10 $34.8 \quad$ E11

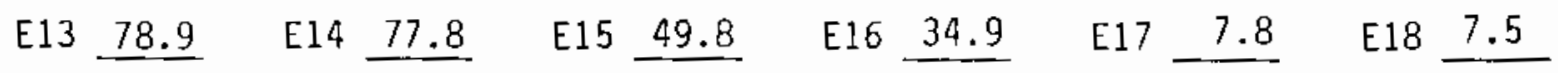

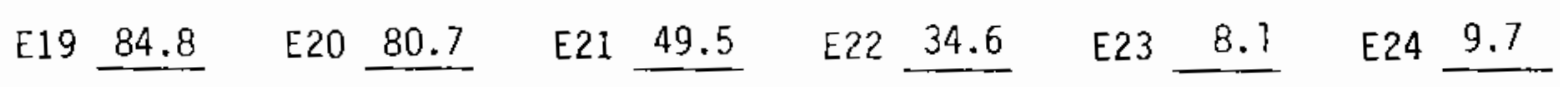

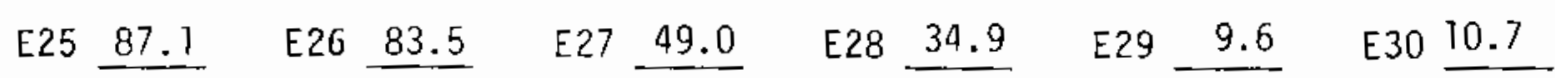

Boundary Temperatures $\left({ }^{\circ} \mathrm{C}\right)$

Front Wall (FW) 60.6

Back Wall (BW) 60.3

Front Cooling Jacket (FCJ) 57.7

Electrode Wall, Right (EWR) 56.8

Back Cooling Jacket (BCJ) 58.1

Electrode Walt, Left (EWL) 57.1

Top Cooling jacket (TCJ)

9.5

Ground: Upper negative electrode

$Y^{*}=0.42$

* Current $<0.15 \mathrm{~A}$

(a) First number denotes power meter value, second number (in parenthesis) is RMS voltage times RMS current. 


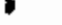


APPENDIX C

MONELING FLUID MF-0 PROPERTIES 


\section{APPENDIX C \\ MODELING FLUID MF-0 PROPERTIES}

Modeling fluid properties of fluid MF-0, used in test BRUN-1 to BRUN-9 inclusive are presented this appendix. Figures $C .1$ to $C .4$ present data graphically and Table C.1 presents regression fitted expressions to the data. 


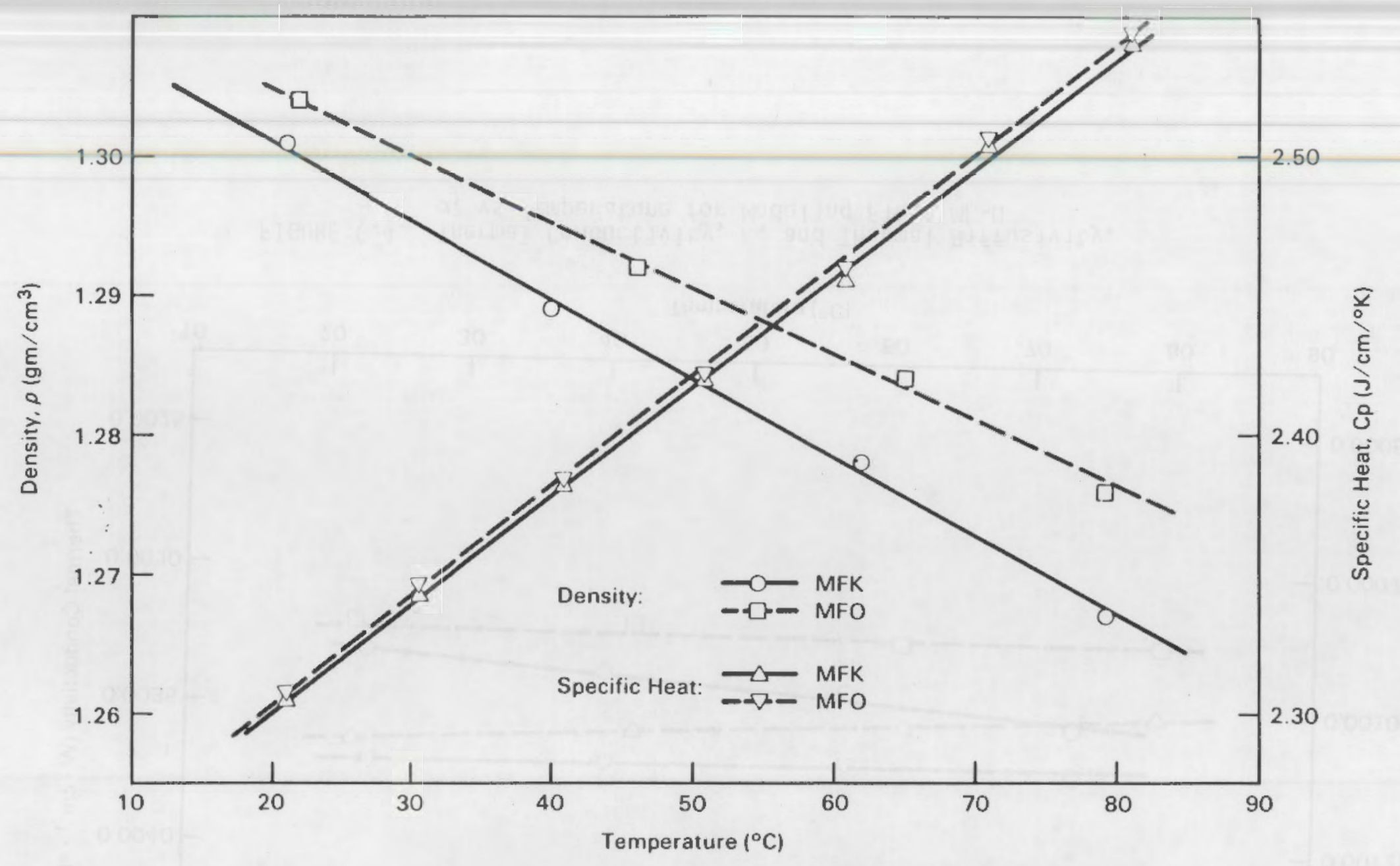

FIGURE C.3. Specific, $C_{p}$ and Density, $\rho$, vs Temperature for Modeling
Fluid MF-0 


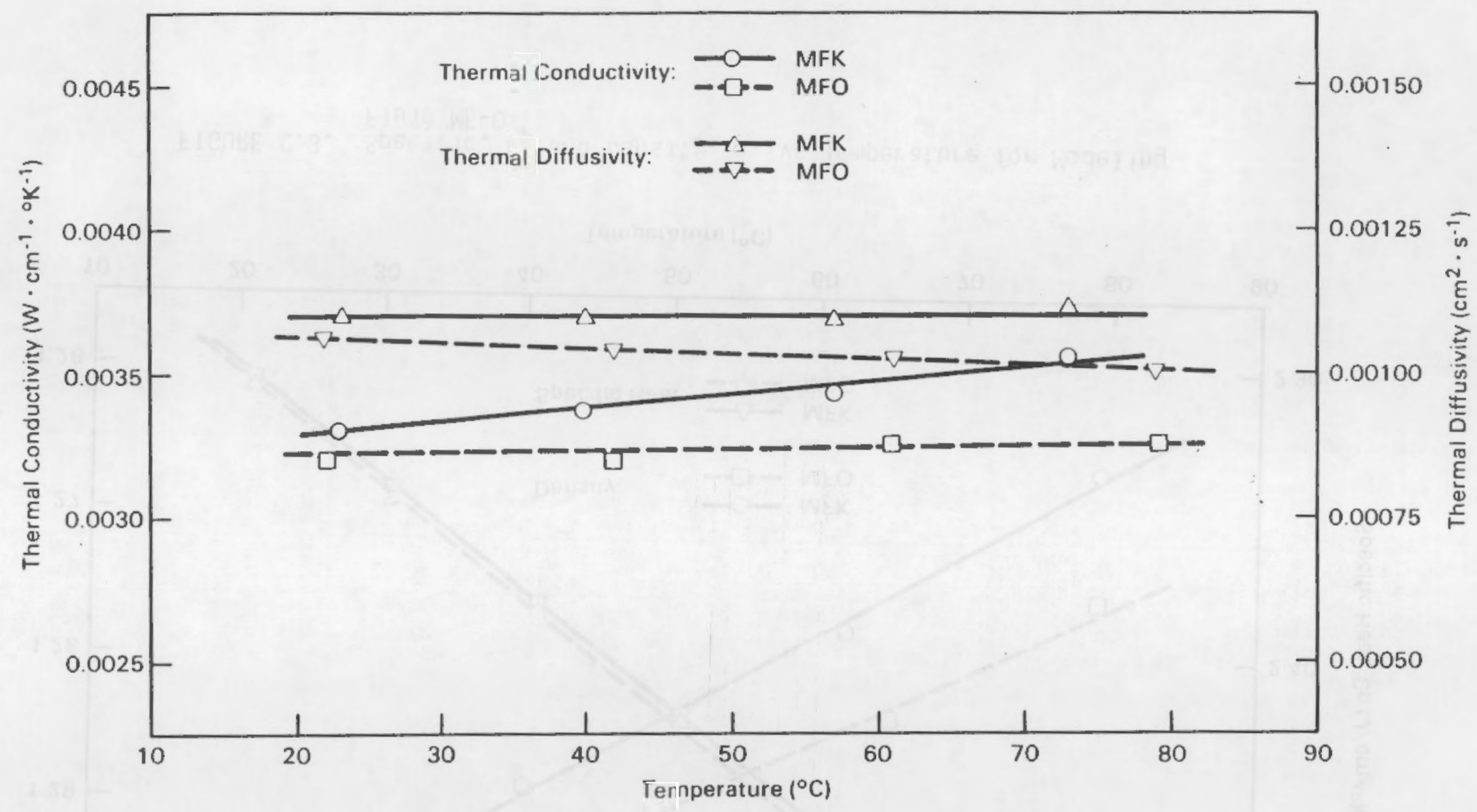

FIGURE C.4. Thermal Conductivity, K, and Thermal Diffusivity, $\alpha$, vs Temperature for Modeling Fluid MF-0 


\section{TABLE C.1}

\section{MODEL FLUID PROPERTIES}

Model Fluid MF-O

$$
\begin{aligned}
& \rho=-4.818 \times 10^{-4} \mathrm{~T}+1.315\left(\mathrm{~g} / \mathrm{cm}^{3}\right) \\
& C_{p}=3.943 \times 10^{-3} \mathrm{~T}+2.224 \quad(\mathrm{~J} / \mathrm{g} . \mathrm{K}) \\
& \mu=5.11 \times 10^{8} T^{-3.365} \quad \text { (centipofse) } \\
& K=8.97 \times 10^{-7} \mathrm{~T}+3.18 \times 10^{-3}(\mathrm{~W} / \mathrm{cm} . \mathrm{K}) \\
& X=5.636 \times 10^{-10} \mathrm{~T}^{3.634}(\Omega-\mathrm{cm})^{-1} \\
& \text { where: } T=\text { Modeling Fluid Temperature }\left({ }^{\circ} \mathrm{C}\right) \\
& \rho=\text { Density } \\
& C_{p}=\text { Specific heat } \\
& \mu=\text { Dynamic Viscosity } \\
& K=\text { Thermal conductivity } \\
& X=\text { Electrical conductivity }
\end{aligned}
$$




\section{DISTR IBUTION}

No. of

Copies

OFFSITE

30 DOE Technical Information Center

4 DOE Office of Civilian

Radioactive Waste Management

Forrestal Building

Washington, DC 20585

ATTN: D. H. Alexander, RW-24

C. R. Cooley, RW-43

J. J. Fiore, RW-2?

B. C. Rusche, RW-1

2 Doe Office of Defense Waste \& GTN Byproducts Management

Washington, DC 20545

ATTN: D. B. LeClaire, DP-12

R. D. Walton, ur., DP-123

7 DOE Office of Terminal Waste Disposal \& Remedial Action GTN

Washington, DC 20545

ATTN: J. E. Baublitz, NE-24

J. A. Coleman, NE-25

D. J. MCGOff, NE- 23

J. A. Turi, NE-25

W. R. voigt, NE-20

H. F. Walter, NE-25

J. B. Zorn, NE-?5

M. J. Bell

Division of Nuclear Materials

Safety \& Safeguards

Mail Station 881-SS

Nuclear Regulatory Commission

Washington, DC 20555

A.T. Clark

Division of Fuel Material Safety

Nuclear Regulatory Commission

Washington, DC 20555
No. of

Copies

W. J. Dircks

Office of the Executive Director for Operations

Mail Station 62009

Nuclear Regulatory Commission

Washington, DC 20555

2 Environmental Protection Agency Office of Radiation Programs 401 M Street, S.W. Washington, DC 20460

ATTN: D. Egan

$$
\text { G. L. Sjoblom }
$$

1 DOE Albuquerque Operations Office

P.0. Box 5400

Albuquerque, NM 87185

ATTN: J. MCGough

W. H. Hannum

DOE West Valley Operations office

P.0. Box 191

West Valley, NY 14171

2 DOE Idaho Operations Office

550 Second Street

Idaho Falls, ID 83401

ATTN: J. D. Hamric

J. B. Whitsett

L. Lanni

DOE San Francisco Operations

1333 Broadway

San Francisco, CA 94612

W. E. Pasko

DOE Oak Ridge Operations Office P.0. Rox $E$

Dak Ridge, TN 37830 
No. of

Copies

G. K. Dertel

DOE Savannah River Operations Office

P.0. Box A

Aiken, SC 29801

2 Argonne National Laboratory

9700 South Cass Avenue

Argonne, IL 60439

ATTN: C. S. Abrams/J. H. Kittel

M. J. Steindler/

L. E. Trevorrow

B. Rawles

Battelle Memorial Institute

Project Management Division

505 King Avenue

Columbus, $\mathrm{OH} \quad 43201$

F. Holzer

Lawrence Livermore National

Laboratory

University of California

P.0. Box 808

Livermore, CA 94550

D. T. Oakley, MS 671

Los Alamos Scientific Laboratory

P.0. Box 1663

Los Alamos, NM 87544

T. H. Row

0ak Ridge National Laboratory

P.0. Box $X$

Oak Ridge, TN 37830

3 Oak Ridge National Laboratory

P.0. Box $Y$

Oak Ridge, TN 37830

ATTN: W. D. Burch

Technical Library

Sandia Laboratories

P.0. Box 5800

Albuquerque, NM 87185
No. of

Copies

B. R. Wheeler

Westinghouse Idaho Nuclear

Co., Inc.

P.0. Box 4000

Idaho Falls, ID 83401

7 E. I. du Pont de Nemours Company

Savannah River Laboratory

Aiken, SC 29801

ATTN: M. D. Boersma

E. J. Hennelly

L. L. Kilpatrick/

L. M. Lee

S. Mirshak

R. M. Wallace

D. C. Witt

J. F. Ortaldo

E. A. Jennrich

EG\&G Idaho

P.0. Box 1625

Idaho Falls, In 83415

K. V. Gilbert/P. F. Hagen

Rockwell International

Rocky Flats Plant

P.0. Box 464

Golden, C0 80401

G. W. Meyers

Atomics International Division

Rockwell International

8900 DeSoto Avenue

Canoga Park, CA 91304

T. H. Pigford

Department of Nuclear Engineering

University of California

Berkeley, CA 94720

R. Williams

Electric Power Research Institute 341? Hillview Avenue

P.0. Box 1041?

Palo Alto, CA 94304 
No. of

Copies

5 West Valley Nuclear Services Company

P.0. Box 191

West Valley, NY 14171

ATTN: C. C. Chapman

J. L. Knabenschuh

3. F. Krauss

J. M. Pope

S. M. Barnes

W. A. Freeby/J. L. Jardine

Bechtel National, Inc.

P.0. Box 3965

San Francisco, CA 94119

Librarian

Westinghouse Electric

Corporation

Technical Library

P.0. Box 40039

Albuquerque, NM 87196

R. G. Post

College of Engineering

University of Arizona

Tucson, AZ 85721

DNSITE

4 DOE Richland Operations office

E. A. Bracken

J. J. Broderick

M. W. Shupe

J. D. White

7 Rockwell Hanford Operations

R. N. Gurley

i. M. Henderson

R. D. Prosser

K. R. Shah

R. J. Thompson

D. D. Wodrich

File Copy
No. of

Copies

UNC United Nuclear Industries

T. E. Dabrowski/w. J. Kyriazis

Westinghouse Hanford Company

R. E. Lerch

48 Pacific Northwest Laboratory

W. J. Apley/W. C. Cl iff

W. I. Rjorklund

H. T. Blair

W. F. Ronner

R. A. Brouns (2)

d. L. Buelt

H. C. Burkholder

3. R. Carrell

T. D. Chikalla

R. D. Dierks

D. W. Faletti

L. L. Eyler (10)

J. H. Jarrett

M. S. Hanson

W. W. Laity

D. E. Larson

W. L. Kuhn

D. E. Knowlton

J. M. Latkovich

R. C. Liikala

J. L. McElroy

G. L. MeVay

d. E. Minor

R. K. Nakaoka

J. M. Perez

R. A. Scott

D. H. Siemens

R. 1. Skarda (5)

D. S. Trent

d. H. Westsik

Technical information (5)

Publishing Coordination (2)

Distr-3 
.

\section{;}

